\title{
Chemicals from Alkynes with Palladium Catalysts
}

\author{
Rafael Chinchilla* and Carmen Nájera* \\ Departamento de Química Orgánica, Facultad de Ciencias, \\ and Instituto de Síntesis Orgánica (ISO), \\ Universidad de Alicante, Apartado 99, 03080 Alicante, Spain
}

\section{Contents}

1. Introduction

2. Chemicals by Palladium-Catalyzed Intermolecular Additions to Alkynes

2.1. Carbocycles

2.2. Heterocycles

2.3. Vinyl Arenes

2.4. Acrylic Acids, Esters and Amides

2.5. Ketones

2.6. Allyl and Vinyl Ethers

2.7. Imines, Enamines and Allylamines

2.8. Vinyl Sulfides and Selenides

2.9. Vinyl Phosphines, Phosphine Oxides, Phosphinates and Phosphonates

3. Chemicals by Palladium-Catalyzed Intramolecular Additions to Alkynes

3.1. Carbocycles

3.2 Heterocycles

4. Chemicals by Palladium-Catalyzed Oxidation of Alkynes

4.1. 1,2-Diketones

4.2. Esters

4.3. Furans

5. Olefins by Palladium-Catalyzed Reduction of Alkynes

6. Chemicals by Palladium-Catalyzed C-C Coupling Reactions of Alkynes

6.1. Alkynylated Arenes

6.2. Alkynylated Heterocycles

6.3. 1,3-Enynes

6.4. 1,3-Diynes

6.5. Ynones

6.6. Ynoates and Ynamides

7. Conclusions

8. Acknowledgments

9. References

* To whom correspondence should be addressed. Phone: +34 965903548. Fax: +34 965903549. Email: chinchilla@ua.es; cnajera@ua.es. URL: www.ua.es/dqorg 


\section{Introduction}

The carbon-carbon triple bond of alkynes is one of the basic functional groups, its reactions belonging to the foundations of organic chemistry. In the past decades, acetylene chemistry has experienced a renaissance due to, not only its occurrence in molecules in the frontiers of organic chemistry such as biochemistry or material sciences, but also as building blocks or versatile intermediates for the synthesis of a vast array of chemicals. ${ }^{1}$ This boost to the alkyne chemistry has been fueled mainly by the development of new synthetic methodologies based on transition metal catalysis, a field where palladium always occupies a leading position.

This review presents an overview of the use of alkynes as starting materials for the preparation of compounds, using procedures carried out under palladium catalysis. Many different reactions leading to many different chemicals could be included in such a review, and trying to cover all possibilities and particularities in a fully comprehensive way would be an overwhelming task. Thus, this review will present coverage of the main palladium-catalyzed reactions of alkynes leading to different chemical compounds, ordered by reaction type and chemical class. The 'alkynes' involved as starting materials in this review will only be those containing $\mathrm{H}$ or C-substituted carbon-carbon triple bonds. Therefore, palladium-catalyzed couplings involving alkynyl metals or other non-strictly considered alkyne-hydrocarbons, such as 1-haloalkynes, will be excluded. A summary of the transformations considered in this review is shown in Table 1. Only 'direct' reactions of alkynes will be shown, the preliminary transformation of the acetylene into an intermediate followed by a palladium-promoted conversion being not considered, as well as multi-step processes such as hydro/carbometalation-coupling sequences. When previous reviews of a particular palladiumcatalyzed topic exist, significant or relevant methodologies, as well as the most recent examples will be presented. 
Table 1. Summary of the palladium-catalyzed transformations of alkynes presented in this review.

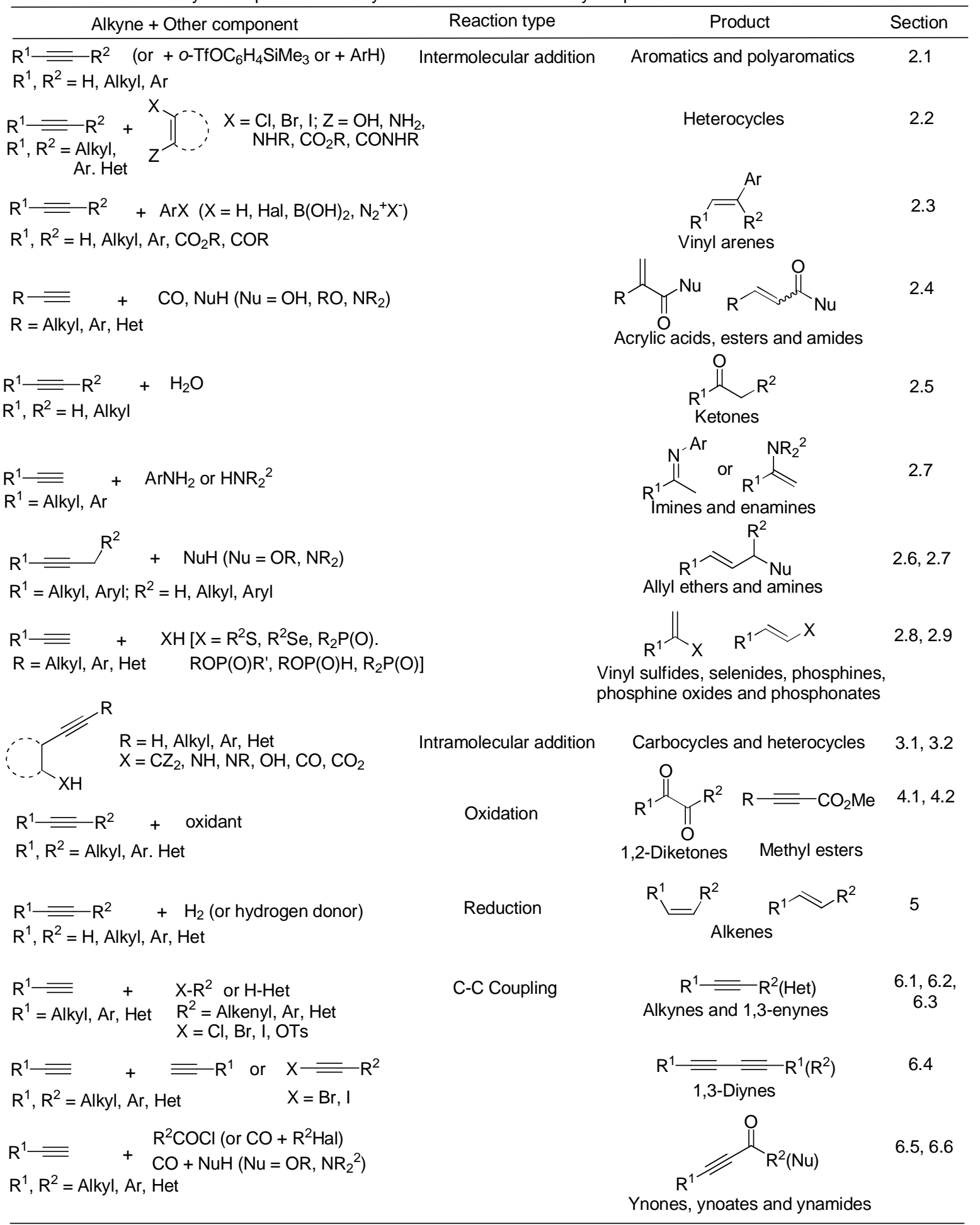


2. Chemicals by Palladium-Catalyzed Intermolecular Additions to Alkynes

The formal intermolecular addition reaction involving only the carbon atoms of an alkyne system is an approach which can lead directly to the synthesis of carbocyclic systems, a process which can be achieved under palladium-catalysis. In addition, the palladium-catalyzed intermolecular annulation of alkynes with halogenated heteroatombearing systems is also a formal addition to alkynes which leads to heterocycles. Other intermolecular additions to alkynes can be achieved under palladium-catalysis, as hydroarylation, hydrocarbonylation or the addition of heteroatomic nucleophiles to alkynes, a practical way of preparing a large variety of alkene-bearing chemicals, once the adequate regio- and stereocontrol are achieved. This section will present examples of carbocycles and heterocycles obtained by all these approaches, as well as a survey of chemicals obtained by palladium-catalyzed intermolecular addition of $\mathrm{C}, \mathrm{N}, \mathrm{O}, \mathrm{S}, \mathrm{Se}$ and $\mathrm{P}$ nucleophiles to alkynes.

\subsection{Carbocycles}

The transition metal-catalyzed conversion of internal and terminal alkynes to substituted benzene derivatives by a cyclotrimerization process is an old procedure which has also been achieved using palladium species as catalysts. ${ }^{2}$ The process has been traditionally considered to occur via coordination of two alkyne moieties to the metal, coupling reaction giving a metallacyclopentadiene, and further insertion or addition of an alkyne to the metallacycle giving a six-carbon metalacycle which forms the benzene ring after reductive elimination. ${ }^{2}$ Thus $\mathrm{PdCl}_{2}{ }^{3}$ and $\mathrm{PdCl}_{2}(\mathrm{PhCN})_{2}{ }^{4}$ catalyze the cyclotrimerization of alkynes to benzene derivatives, the yields generally depending on the alkyne substituents, as regioisomers are normally obtained in the case of unsymmetrical acetylenes. However, it has been shown that the addition of $\mathrm{CuCl}_{2}(200$ mol\%) to the reaction mixture, not only increases the yield of the process, as discovered in the case of the $\mathrm{PdCl}_{2}$-catalyzed cyclotrimerization of oct-4-yne to give 1,2,3,4,5,6hexapropylbenzene, ${ }^{5}$ but also induces regiospecificity in the process. Thus, unsymmetrical alkynes, such as oct-1-yne, where cyclotrimerized regiospecifically to benzene derivatives such as 1 under $\mathrm{PdCl}_{2}$ catalysis $(6 \mathrm{~mol} \%)$ in the presence of $\mathrm{CuCl}_{2}$ 
and a mixture of $n$-butanol/benzene as solvent at $40{ }^{\circ} \mathrm{C}$ (Scheme 1), ${ }^{6}$ diphenylacetylene affording no reaction. In addition, the presence of carbon dioxide was found to favor this $\mathrm{PdCl}_{2}$-catalyzed/ $\mathrm{CuCl}_{2}$-assisted process when performed in water. ${ }^{7}$ Moreover, the reaction has also been carried out in supercritical carbon dioxide. ${ }^{8}$

\section{Scheme 1}

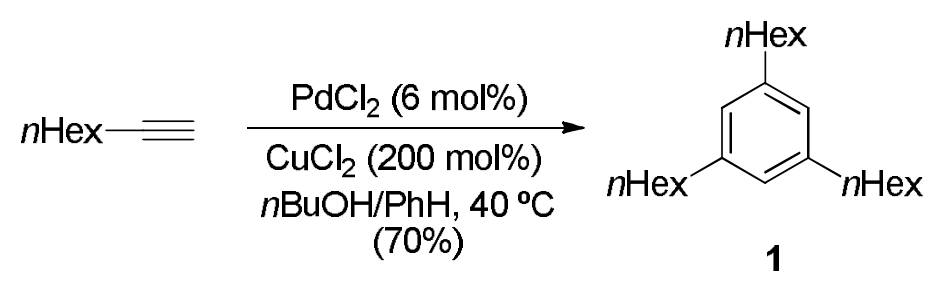

The palladium-catalyzed cyclotrimerization was also applied to strained cycloalkynes. ${ }^{9}$ For instance, $\mathrm{Pd}\left(\mathrm{PPh}_{3}\right)_{4}(10 \mathrm{~mol} \%)$ catalyzed the cyclotrimerization of cyclohexyne (3), generated in situ by a fluoride-induced $\beta$-elimination in trimethylsilylated triflate 2, to dodecahydrotriphenylene 4 in 64\% yield (Scheme 2), but subjecting cyclopentyne to the same conditions failed to afford isolable amounts of the cyclotrimer. $^{10}$

\section{Scheme 2}

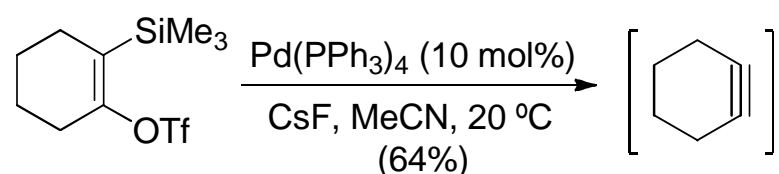

2

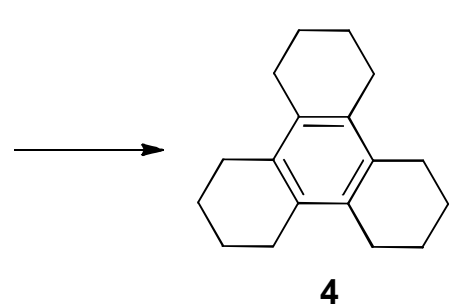

3

This cyclotrimerization reaction can also be performed using non-soluble palladium reagents as catalysts. Thus, the transformation of acetylene into benzene ${ }^{11}$ has been catalyzed by alumina-supported palladium ${ }^{12}$ and $\operatorname{Pd}(111)$ single crystals. ${ }^{13}$ In addition, the trimerization of alkynes has also been achieved using $10 \% \mathrm{Pd} / \mathrm{C}$ as catalyst in the presence of trimethylsilyl chloride, which is suggested to form highly dispersed 
palladium nanoparticles (PdNPs), in refluxing THF. ${ }^{14}$ Under these conditions, symmetrical alkynes such as diphenylacetylene gave quantitatively the corresponding hexasubstituted benzene 5 (Scheme 3), whereas unsymmetrical alkynes gave mixtures of regioisomers.

\section{Scheme 3}

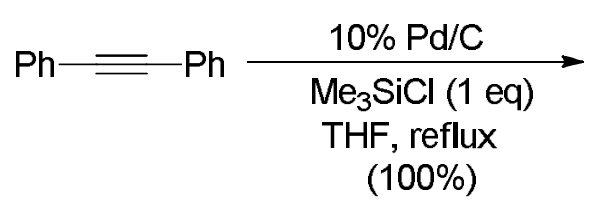<smiles></smiles>

Alkynes have been co-trimerized with arynes under palladium catalysis to give different arenes. ${ }^{15}$ For example, co-cyclization of electron-deficient alkynes and arynes afforded phenanthrene derivatives when catalyzed by $\mathrm{Pd}\left(\mathrm{PPh}_{3}\right)_{4}$, whereas naphthalene derivatives were obtained under $\operatorname{Pd}_{2}(\mathrm{dba})_{3}$ catalysis $\left(\mathrm{dba}=\right.$ dibenzylideneacetone) ${ }^{16}$ In addition, the co-trimerization of internal alkynes with benzyne, obtained in situ similarly than in the former case by fluoride-mediated triflic acid elimination in the corresponding arene 6, has been carried out using the combination $\mathrm{Pd}(\mathrm{OAc})_{2}(5 \mathrm{~mol} \%)$ and $\mathrm{P}(o \text {-tolyl })_{3}(5 \mathrm{~mol} \%)$ as catalyst, in acetonitrile as solvent at $60^{\circ} \mathrm{C}$, as exemplified in the formation phenanthrene 7 from phenylmethylacetylene (Scheme 4). ${ }^{17}$

\section{Scheme 4}<smiles>COc1ccccc1OC</smiles>

6

$$
\begin{aligned}
& \mathrm{Pd}(\mathrm{OAc})_{2}(5 \mathrm{~mol} \%) \\
& \frac{\mathrm{P}(\text { o-tolyl })_{3}(5 \mathrm{~mol} \%)}{\mathrm{CsF}(2 \mathrm{eq})}
\end{aligned}
$$

$(67 \%)$<smiles>Cc1c(-c2ccccc2)c2ccccc2c2ccccc12</smiles> 
Benzynes have been generated as above and react with internal alkynes in the presence of an aryl iodide to give substituted phenanthrenes under $\operatorname{Pd}_{2}(\mathrm{dba})_{3}$ catalysis $(5$ mol\%). An example of this methodology is the 3-components reaction of the generated benzyne from 6 with diphenylacetylene and ethyl 4-iodobenzoate to give phenanthrene 8, the process being carried out in the presence of equimolecular amounts of TlOAc in a mixture of acetonitrile/toluene as solvent at $90{ }^{\circ} \mathrm{C}$ (Scheme 5). ${ }^{18}$ In addition, a recent example of the use of arynes in these co-trimerization processes generates benzyne from benzoic acid in the presence of $\mathrm{Pd}(\mathrm{OAc})_{2}$ and $\mathrm{Cu}(\mathrm{OAc})_{2}$, which co-cyclizes with diphenylacetylene to give the corresponding phenanthrene if an excess of benzoic acid is added, or 1,2,3,4-tetraphenylnaphthalene if diphenylacetylene is present in excess. ${ }^{19}$

\section{Scheme 5}

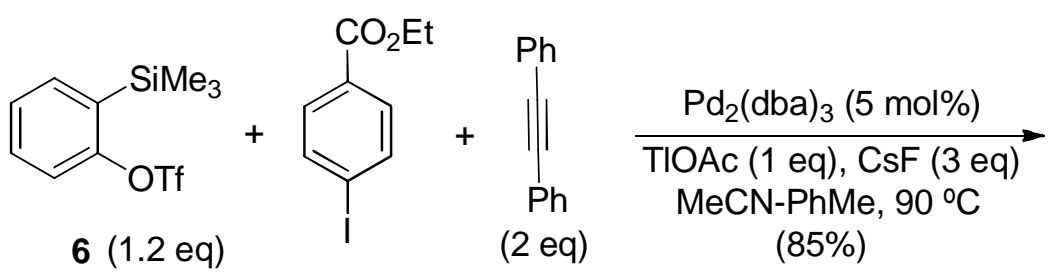<smiles>CCOC(=O)c1ccc2c(-c3ccccc3)c(-c3ccccc3)c3ccccc3c2c1</smiles>

Palladium-catalyzed oxidative carbocyclization processes are interesting routes for the preparation of highly substituted arenes. ${ }^{20}$ For example, highly substituted naphthalenes have been obtained by treatment of arenes, such as $p$-xylene, with diarylated alkynes, such as diphenylacetylene, using $\mathrm{Pd}(\mathrm{OAc})_{2}$ as catalyst and $\mathrm{AgOAc}$ as oxidant in acetonitrile/p-xylene as solvent at $110^{\circ} \mathrm{C}$, to afford naphthalene 9 (Scheme 6). ${ }^{21} \mathrm{~N}$-Arylated acetamides have also been used as arene counterparts in this reaction leading to naphthalenes, using $\mathrm{K}_{2} \mathrm{~S}_{2} \mathrm{O}_{8}$ as oxidant in the presence of $p$-toluenesulfonic acid in toluene as solvent at $80{ }^{\circ} \mathrm{C} .{ }^{22}$ In addition, 2-phenylbenzoic acids have been annulated with disubstituted alkynes in a decarboxylative approach catalyzed by $\mathrm{Pd}(\mathrm{OAc})_{2}(10 \mathrm{~mol} \%),{ }^{23}$ using acridine as ligand $(50 \mathrm{~mol} \%)$ and silver carbonate as oxidant, in DMF at $140{ }^{\circ} \mathrm{C}$, as exemplified in Scheme 6 with the annulation of acid $\mathbf{1 0}$ and diphenylacetylene leading to phenanthrene $\mathbf{1 1 .}$ 
Scheme 6
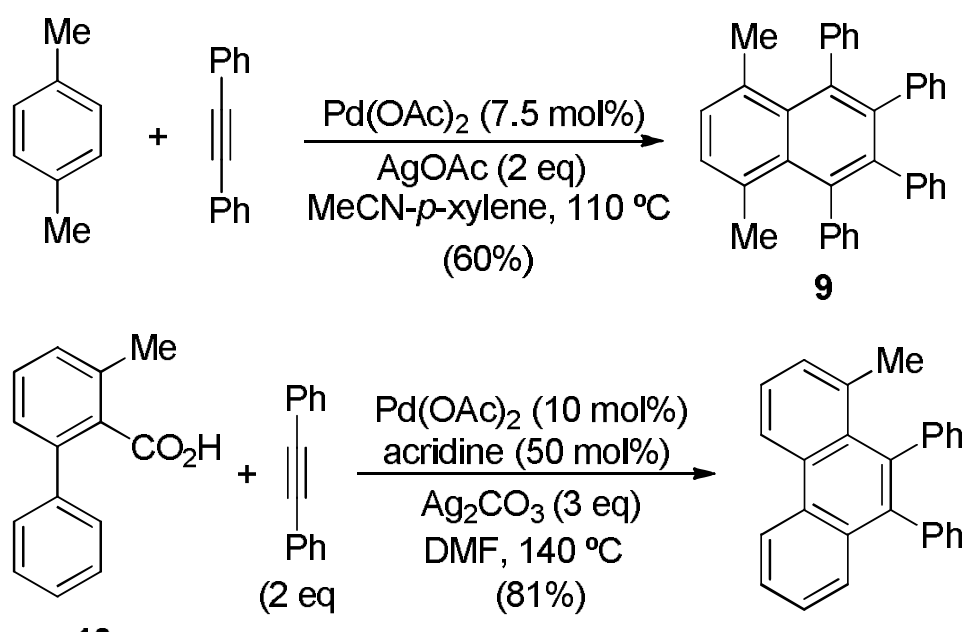

10<smiles>Cc1cccc2c1c(-c1ccccc1)c(-c1ccccc1)c1ccccc12</smiles>

11

Highly substituted indenes have been obtained by palladium-catalyzed carboannulation of internal alkynes using appropriately functionalized aryl halides, ${ }^{24}$ the operating mechanism being considered similar to the one suggested for the formation of heterocycles (see Section 2.2). Thus, iodinated arenes bearing highly acidic hydrogens such as $\mathbf{1 2}$ reacted with internal alkynes such as $\mathbf{1 3}$ under $\mathrm{Pd}(\mathrm{OAc})_{2}$ catalysis $(5 \mathrm{~mol} \%)$, in the presence of $n \mathrm{Bu}_{4} \mathrm{NCl}$ and $\mathrm{KOAc}$, to give indenes such as $\mathbf{1 4}$ with high regioselectivity (Scheme 7), which is probably due to the steric hindrance present in the developing $\mathrm{C}-\mathrm{C}$ bond. In addition, enantiomerically enriched indenols have been obtained by a $\mathrm{Pd}(\mathrm{OTf})_{2} 2 \mathrm{H}_{2} \mathrm{O}(3 \mathrm{~mol} \%)$-promoted tandem [3+2] annulation of 2acylarylboronic acids with internal electron-deficient alkynes employing the chiral biarylphosphine 15 as ligand $(3.3 \mathrm{~mol} \%){ }^{25}$ An example of this asymmetric transformation is shown in the preparation of optically active indenol $\mathbf{1 8}$ from formylated boronic acid 16 and propynoate 17 (Scheme 7). 


\section{Scheme 7}
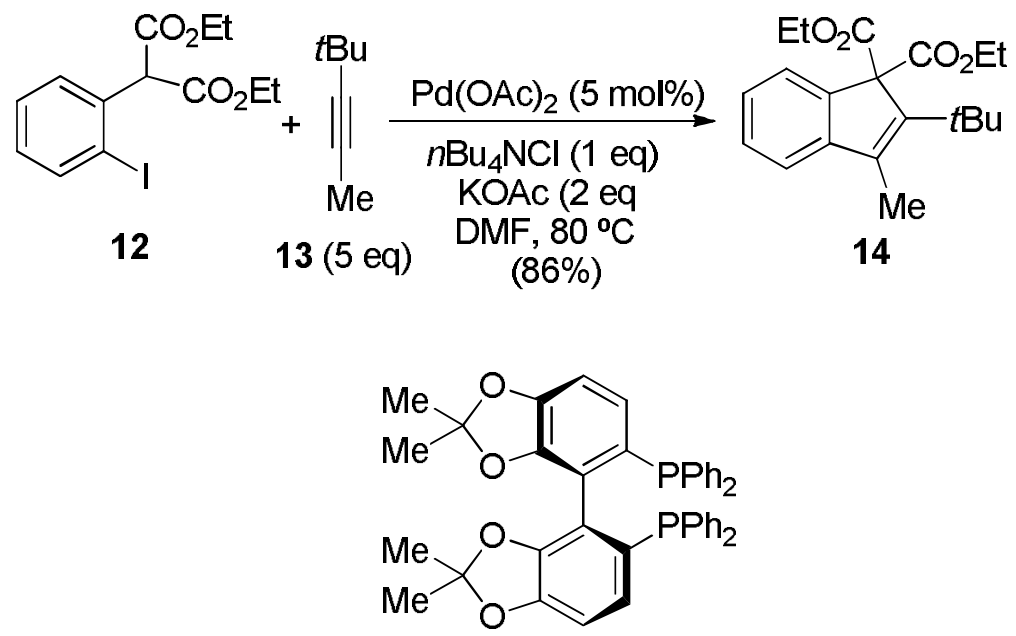

15

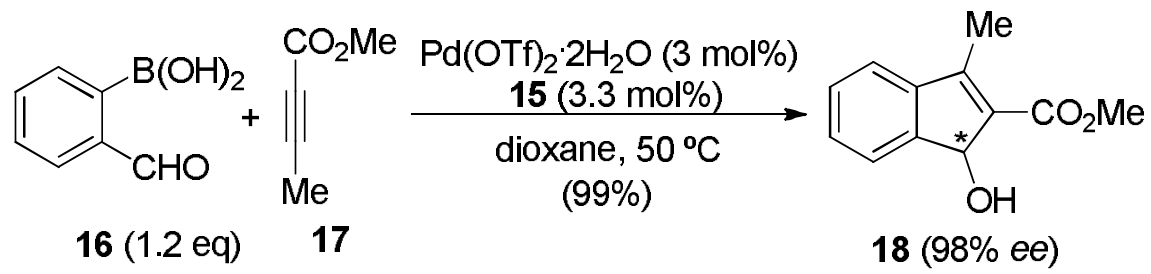

2,3-Disubstituted indenones can be obtained directly by palladium-catalyzed reaction of internal alkynes and $o$-halobenzaldehydes, a synthetic procedure that can be carried out using $\mathrm{Pd}(\mathrm{OAc})_{2}$ as catalyst $(5 \mathrm{~mol} \%) .{ }^{26}$ More recently, palladacycles have also been used successfully as catalysts for this transformation, ${ }^{27}$ as exemplified in the reaction of 2-bromobenzaldehyde and diphenylacetylene to give indenone 20 (Scheme 8), a process catalyzed by cyclopalladated ferrocenylimine $19(1 \mathrm{~mol} \%)$ in the presence of potassium carbonate as base and a mixture of tetra- $n$-butylammonium bromide $(\mathrm{TBAB}) /$ benzoic acid as additive, in DMF at $110^{\circ} \mathrm{C} .^{28}$ 
Scheme 8

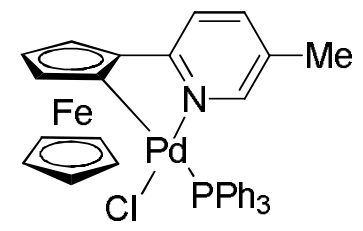

19

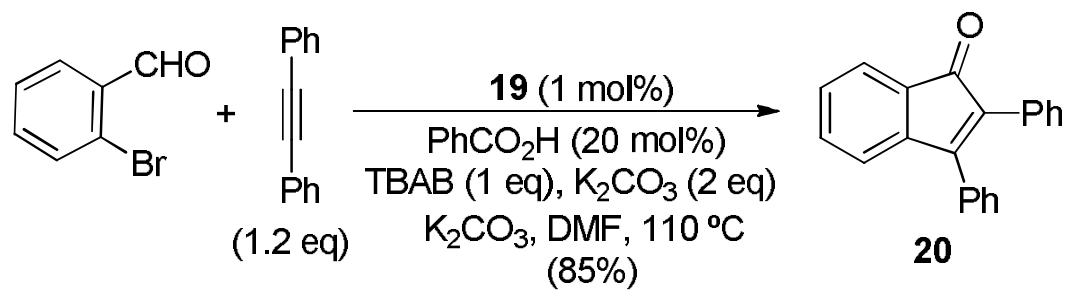

Monoannelated pentalenes have been prepared by a cascade carbopalladation reaction between alkynes and gem-dibromoolefins. ${ }^{29}$ The reaction is catalyzed by $\mathrm{PdCl}_{2}\left(\mathrm{PPh}_{3}\right)_{2}(5 \mathrm{~mol} \%)$ in the presence of zinc dust in toluene as solvent at $100{ }^{\circ} \mathrm{C}$ and allow the direct preparation of pentalenes in moderate yield, as exemplified in Scheme 9 with the synthesis of pentalene $\mathbf{2 2}$ from dibrominated olefin $\mathbf{2 1}$ and diphenylacetylene.

\section{Scheme 9}<smiles>BrC(Br)=Cc1ccccc1C#Cc1ccccc1</smiles>

21

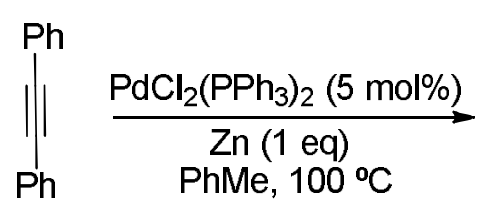

$(42 \%)$<smiles></smiles>

22

\subsection{Heterocycles}

The palladium-catalyzed intermolecular annulation of alkynes is particularly effective for the synthesis of a variety of heterocycles. ${ }^{30}$ The reaction usually takes place starting from an aryl or vinyl halide bearing a neighboring nucleophile $\mathbf{2 3}$ which is oxidatively palladated to $\mathbf{2 4}$. After subsequent cis carbopalladation of the alkyne leading to $\mathbf{2 5}$, the internal nucleophile may affect intramolecular displacement of the palladium towards heterocycle $\mathbf{2 7}$, probably by prior formation of a palladacycle $\mathbf{2 6}$ and reductive elimination (Scheme 10). ${ }^{30 \mathrm{~b}}$ 


\section{Scheme 10}
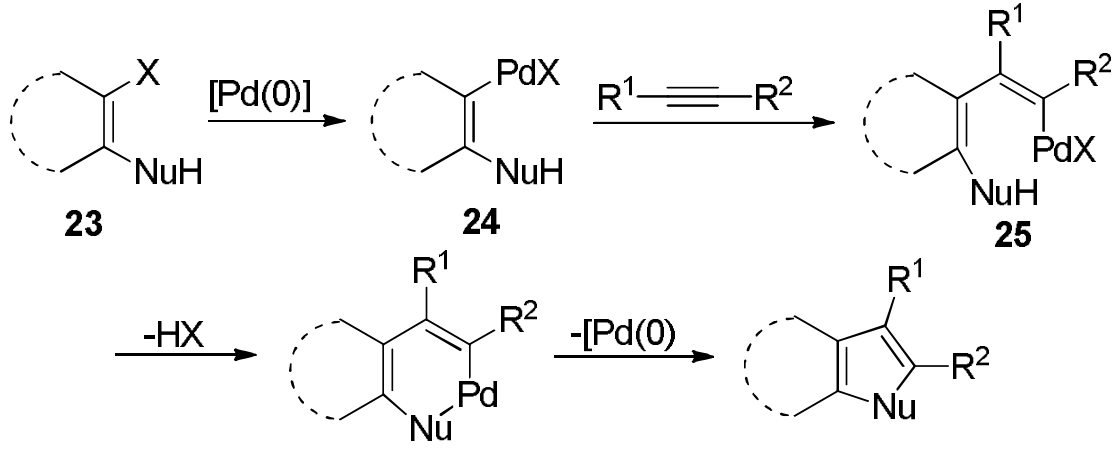

26

27

An example of application of this heterocyclic synthesis is the preparation of highly substituted pyrroles, such as $\mathbf{2 9}$, by reaction between stabilized iodoenamines, such as $\mathbf{2 8}$, with internal alkynes, the reaction being catalyzed by $\mathrm{Pd}(\mathrm{OAc})_{2}(5 \mathrm{~mol} \%)$ in the presence of $\mathrm{LiCl}$ as additive and potassium carbonate as base in $\mathrm{DMF}$ at $65{ }^{\circ} \mathrm{C}$ (Scheme 11). ${ }^{31}$

\section{Scheme 11}

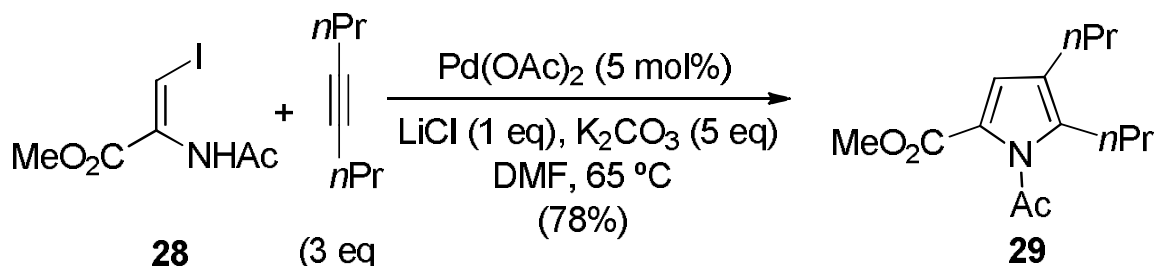

The indole skeleton is one of the most important in the world of heterocycles due to their presence in a huge number of interesting biologically active systems, and their synthesis via palladium-catalyzed reactions has been particularly intense. ${ }^{30 \mathrm{~b}, 30 \mathrm{~d}, 32}$ Among the developed methodologies, the intermolecular palladium-catalyzed reaction of $o$-iodoaniline derivatives with internal alkynes (Larock's intermolecular indole synthesis) was shown as a powerful procedure for the preparation of 2,3-disubstituted indoles from alkynes. ${ }^{33}$ Thus, in the presence of a catalytic amount of $\mathrm{Pd}(\mathrm{OAc})_{2}(5$ mol\%), a source of chloride anions $\left(n \mathrm{Bu}_{4} \mathrm{NCl}\right.$ or $\left.\mathrm{LiCl}\right)$ and a base such as potassium carbonate or acetate in DMF at $100{ }^{\circ} \mathrm{C}, o$-iodoaniline derivatives add formally to internal alkynes to give 2,3-disubstituted indoles, as exemplified in Scheme 12, with the preparation of indole 31 from iodoaniline $\mathbf{3 0}$ and 4,4-dimethylpent-2-yne. ${ }^{33 \mathrm{~b}}$ As observed, the more sterically hindered group on the alkyne results normally attached at 
position $\mathrm{C}-2$ of the indole. This process has also been carried out using oxime-derived palladacycles using only $1 \mathrm{~mol} \%$ of the catalyst, potassium carbonate as base in the presence of $\mathrm{TBAB}$ in $\mathrm{DMF}$ at $130{ }^{\circ} \mathrm{C} .{ }^{27 \mathrm{a}}$ In spite of these strongly ionic conditions, which suggest the presence of charged palladium species, most mechanistic approaches for this reaction are based on neutral conditions. In addition, heterogeneous versions of this Larock annulation have been reported. ${ }^{34}$ Thus, palladium ( 2 mol\%) has been supported on $\mathrm{NaY}$ zeolite, which has allowed suppressing the presence of a chloride source and recycle the catalyst up to four times, ${ }^{34 a}$ and on mesoporous silica SBA$15 .{ }^{34 \mathrm{~b}}$ In addition, the use of $\mathrm{Pd} / \mathrm{C}$ as catalyst $(2 \mathrm{~mol} \%$ ) has allowed the preparation of indoles starting from less reactive $o$-bromoanilines, the reaction taking place in the presence of sodium carbonate as base, in DMF as solvent at $140{ }^{\circ} \mathrm{C}$, as shown in Scheme 12 with the preparation of indole $\mathbf{3 3}$ from $o$-bromoaniline $\mathbf{3 2}$ and diphenylacetylene. $^{34 \mathrm{c}}$ Moreover, other related systems such as 2,3-disubstituted 5azaindoles have been recently obtained using this heteroannulation reaction between 4acetamido-3-iodopyrydines and internal alkynes under $\mathrm{PdCl}_{2}\left(\mathrm{PPh}_{3}\right)_{2}$ catalysis (5 $\operatorname{mol} \%) .{ }^{35}$

\section{Scheme 12}
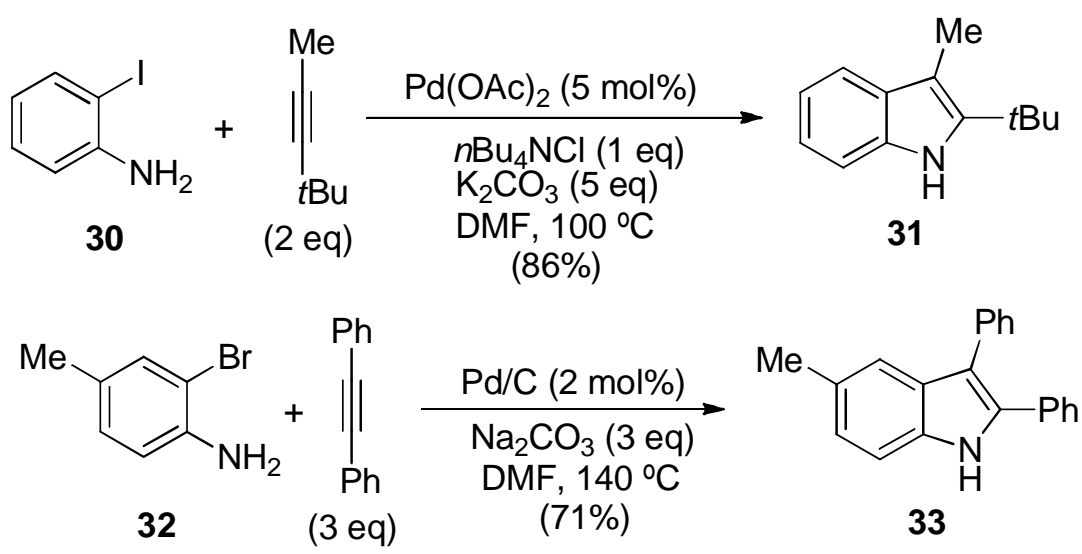

Different procedures which enable the use of less reactive halogenated aniline derivatives or other halogenated systems as precursors in the former Larock indole synthesis have been developed. ${ }^{32, \mathrm{f}}$ Thus, $o$-bromo- or even $o$-chloroanilines, such as $\mathbf{3 5}$, have been used in the intramolecular formal addition to internal alkynes, such as 36, leading to indoles, such as 37 (91:9 regioisomer ratio), in a process catalyzed by a combination of $\mathrm{Pd}(\mathrm{OAc})_{2}$ and the ferrocene-derived ligand 34 in the presence of potassium carbonate in NMP as solvent at 110 or $130{ }^{\circ} \mathrm{C}$ (Scheme 13). ${ }^{36}$ In addition, an 
example of other halogenated systems employed for this indole synthesis is the use of $o$ iodobenzoic acid, which has also been used as precursor in this type of reaction, following a one-pot Curtius rearrangement/palladium-catalyzed indolization with internal alkynes. ${ }^{37}$ This methodology involves the reaction of $o$-iodobenzoic acid with sodium azide in the presence of benzyl chloroformate and sodium tert-butoxide, followed by reaction with the internal alkyne, such as oct-4-yne, under $\operatorname{Pd}(\mathrm{OAc})_{2}$ catalysis (5 mol\%), to give disubstituted indole 38 (Scheme 13). Moreover, indoles can also be obtained by the intermolecular reaction of simple non-halogenated anilines with electron-deficient alkynes by means of $\mathrm{Pd}(\mathrm{OAc})_{2}$-catalyzed $\mathrm{C}-\mathrm{H}$ activation using molecular oxygen as oxidant. ${ }^{38}$

\section{Scheme 13}

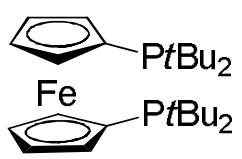

34
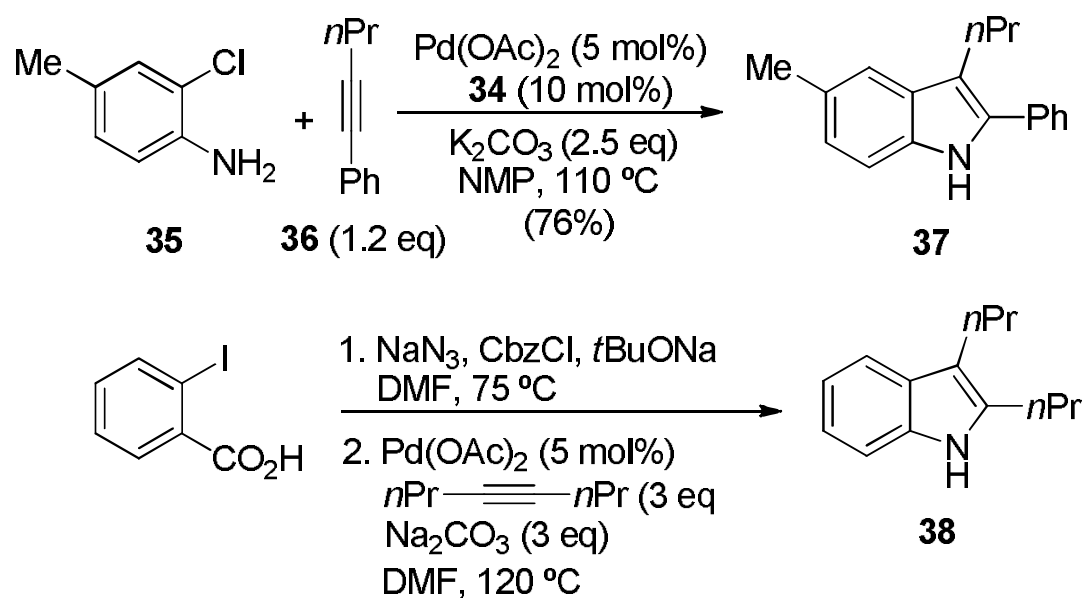

$(84 \%)$

Other more complex heterocycles have been obtained recently following this annulation scheme. Thus, pyrrole[1,2-a]quinolines have been obtained by palladiumcatalyzed cyclization of iodopyranoquinolines and internal alkynes, ${ }^{39}$ and cyclopentacarbazolones have been prepared from the annulation of 2-bromo-3formylcarbazoles and internal alkynes under $\mathrm{Pd}(\mathrm{OAc})_{2}$ catalysis. $^{40}$ In addition, 3,4substituted cinnolines such as $\mathbf{4 0}$ have been obtained by annulation of 2iodophenyltriazene 39 with diphenylacetylene, the reaction being catalyzed by a 
combination of $\mathrm{PdCl}_{2}(7.5 \mathrm{~mol} \%)$ and $\mathrm{P}(o \text {-tolyl })_{3}(15 \mathrm{~mol} \%)$ in the presence of tri- $n$ butylamine as base in DMF at $90{ }^{\circ} \mathrm{C}$ (Scheme 14). ${ }^{41}$

\section{Scheme 14}

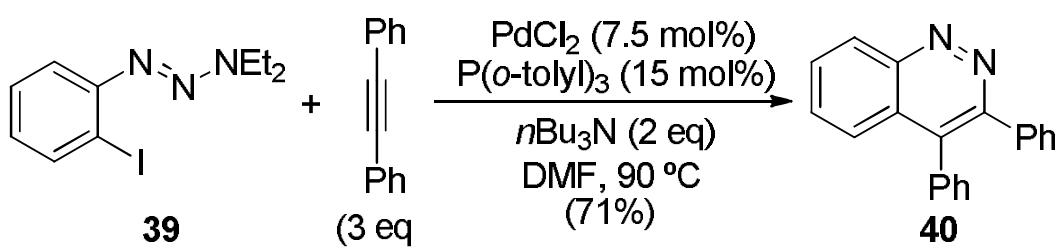

Oxygenated heterocycles can also be obtained using this intermolecular palladium-catalyzed coupling annulation strategy. For instance, the palladium-catalyzed heteroannulation of internal alkynes such as (3,3-dimethylbut-1-yn-1-yl)benzene by hydroxy-containing vinylic halides such as iodocyclohexenol $\mathbf{4 1}$ give rise to furan $\mathbf{4 2}$ after double bond isomerization, the process being carried out using a catalytic amount of $\mathrm{Pd}(\mathrm{OAc})_{2}(5 \mathrm{~mol} \%)$ in the presence of lithium chloride and sodium carbonate, in DMF at $100{ }^{\circ} \mathrm{C}$ (Scheme 15). ${ }^{42}$ This strategy, when performed using $o$-halogenated phenols and internal alkynes affords 2,3-disubstituted benzofurans, ${ }^{43}$ as in the case of the above mentioned synthesis of indoles, although the process is more difficult and usually higher temperatures are required. Under these reaction conditions, 3,4disubstituted isocoumarins and polysubstituted $\alpha$-pyrones can be prepared regioselectively in good yields by treating halogen- or triflate-containing aromatic and $\alpha, \beta$-unsaturated esters, respectively, with internal alkynes in the presence of a palladium catalyst, ${ }^{44}$ as illustrated in Scheme 15 with the preparation of isocoumarin $\mathbf{4 4}$ by the reaction of $o$-iodinated benzoate 45 with 4,4-dimethylpent-2-yne. In addition, $1 H$ isochromenes such as $\mathbf{4 6}$ can be prepared from $\boldsymbol{o}$-iodobenzylic alcohols such as $\mathbf{4 5}$ and an internal alkyne, using the same reaction conditions (Scheme 15). ${ }^{43 a}$ 


\section{Scheme 15}

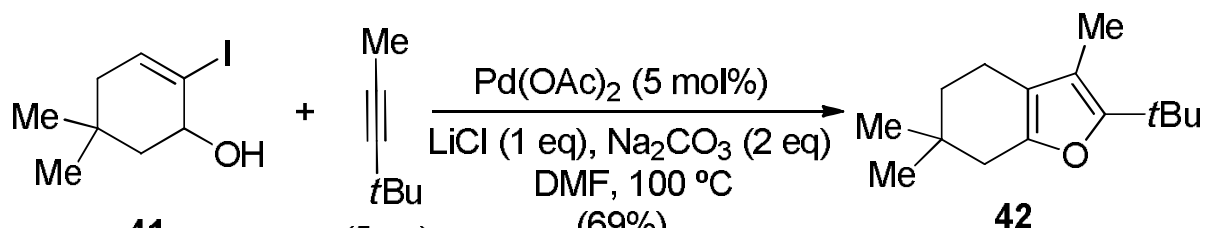

41

(5 eq)

$(69 \%)$

42
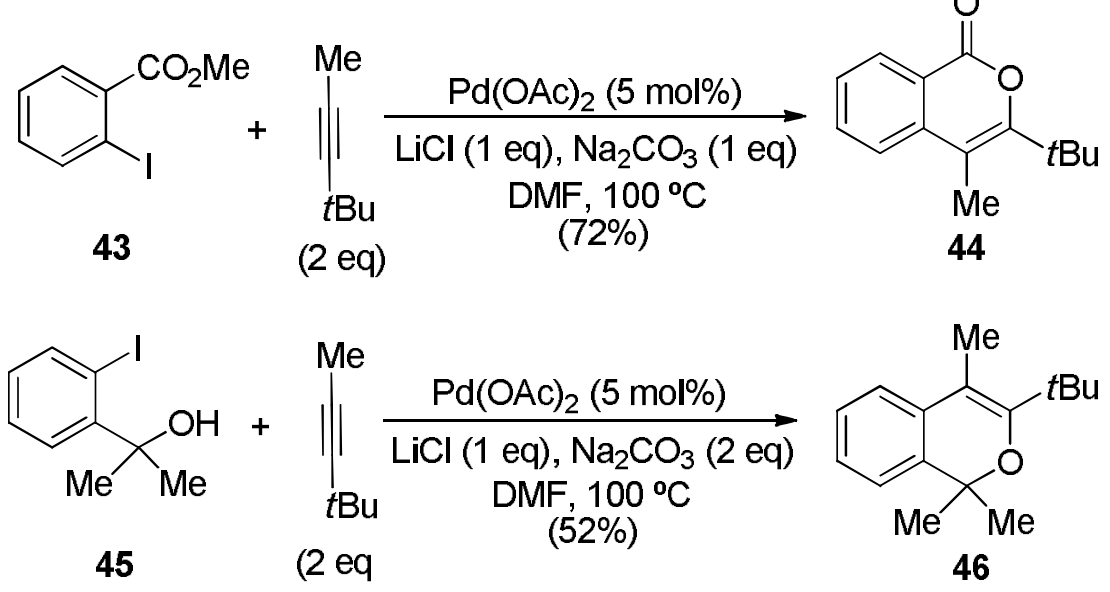

Isoquinolinones can be prepared from $\mathrm{N}$-methoxy- or $\mathrm{N}$-isopropoxybenzamides and internal alkynes via a ligand-free palladium-catalyzed $\mathrm{C}-\mathrm{H}$ and $\mathrm{N}-\mathrm{H}$ activation. ${ }^{45}$ The procedure is performed using $\mathrm{Pd}(\mathrm{OAc})_{2}$ as catalyst $(10 \mathrm{~mol} \%)$ in the presence of dihydrated sodium iodide as additive, in DMF at $120{ }^{\circ} \mathrm{C}$, as illustrated in Scheme 16 with the synthesis of isoquinolinone 48 by reaction of benzamide 47 and diphenylacetylene. In addition, carbolines have been obtained by palladium-catalyzed iminoannulation of internal alkynes, using oxygen as the oxidant, as in the case of the synthesis of carboline $\mathbf{5 0}$ from the annulation of the tert-butylimine of $\mathrm{N}$-substituted indole-2-carboxaldehyde 49 and dec-5-yne, promoted by $\mathrm{Pd}(\mathrm{OAc})_{2}(10 \mathrm{~mol} \%)$ in the presence of sodium bicarbonate as base and TBAB in DMF at $80^{\circ} \mathrm{C}$, in the presence of molecular sieves (MS) and under an atmospheric pressure of oxygen (Scheme 16). ${ }^{46}$ Similarly, $\beta$ - and $\gamma$-carbolinones have been obtained by palladium-catalyzed direct dehydrogenative annulation of indolecarboxamides with internal alkynes using air as oxidant, ${ }^{47}$ and benzazepines have been obtained by palladium-catalyzed oxidative cyclization of isatins and alkynes. ${ }^{48}$ 


\section{Scheme 16}<smiles>CONC(=O)c1ccccc1</smiles>

47

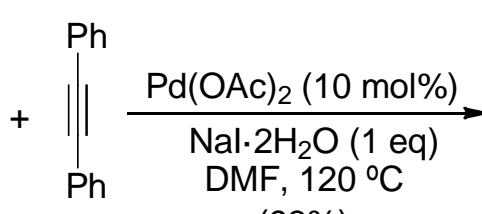

$(93 \%)$<smiles>COn1c(-c2ccccc2)c(-c2ccccc2)c2ccccc2c1=O</smiles>

48

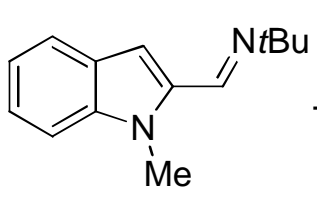

49

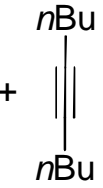

(2 eq)

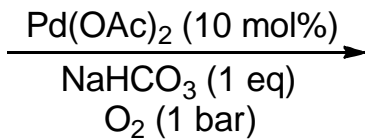

$4 \AA ̊ M S, D M F, 80 \stackrel{\circ}{C}$ (69\%)<smiles>CCCCc1ncc2c(c1CCCC)c1ccccc1n2C(C)C</smiles>

50

\subsection{Vinyl Arenes}

The direct hydroarylation of alkynes catalyzed by a transition metal such as palladium can formally be regarded as a reaction in which both aryl and hydrogen moieties add across a triple bond, providing a direct approach to the preparation of derivatives of styrene, stilbene, chalcone, cinnamic acid and related olefinic derivatives. ${ }^{49}$ The procedure is, in principle, simpler than those based on Heck reactions or cross-coupling methods, which require the use of haloarenes or other arene electrophiles. The reaction is considered to occur through activation of the triple bond by coordination with a cationic palladium, thus undergoing an electrophilic substitution with an electron-rich arene to form the arylvinylmetal complex 51, which is subsequently protonated to form the aryl-alkene 52 (Scheme 17). Another possible mechanism would arise when the palladium complex activates a $\mathrm{C}-\mathrm{H}$ (or $\mathrm{C}-\mathrm{X}$ ) bond of the arene by oxidative addition, forming an arylvinylmetal 53, which affords the arylalkene 54 after reductive elimination. The regioselectivity in the palladium-catalyzed intermolecular reactions of alkynes with arenes is dictated by the substitution pattern of the alkyne, and the addition proceeds in most cases in a electrophilic manner following a Markovnikov rule. ${ }^{50}$ 
Scheme 17

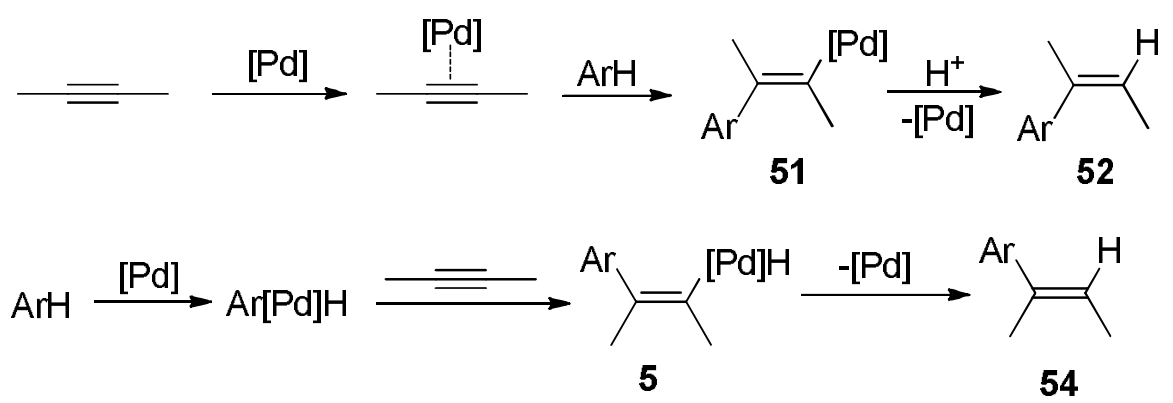

An example of the pioneering hydroarylation reaction employing $\mathrm{Pd}(\mathrm{OAc})_{2}(1$ mol\%) as catalyst under strong acidic conditions (TFA), is shown in Scheme 18 with the formation of vinylated alkene $\mathbf{5 6}$ from arene $\mathbf{5 5}$ and ethyl propiolate, ${ }^{51}$ the mechanism proceeding through the palladium-activated alkyne pathway. ${ }^{52}$ Good results have also been obtained in this reaction when preparing $(Z)$-cinnamic ester derivatives by coupling of arenes to propiolic acid esters, using palladium(II)- $N$-heterocyclic carbene (NHC) complexes as catalysts. ${ }^{53}$ A recent example of this hydroarylation is shown in Scheme 18, where the dinuclear palladium(II)-NHC complex $\mathbf{5 7}$ is used as catalyst $(0.5 \mathrm{~mol} \%)$ in the presence of TFA for the hydroarylation of ethyl propiolate with pentamethylbenzene giving the $(Z)$-product 58, the reaction being carried out in 1,2-dichloroethane as solvent at $80{ }^{\circ} \mathrm{C} .{ }^{53 \mathrm{~b}}$ A closely related palladium(II)-NHC complex bearing trifluoroacetates instead or bromides has been used as catalyst $(0.1 \mathrm{~mol} \%)$ for performing this reaction in the ionic liquid $\left[n \mathrm{BuMe}_{3} \mathrm{~N}\right]\left[\mathrm{NTf}_{2}\right]$ in the presence of TFA as acid and co-solvent. Although the final yields were moderate to low, recovery of the palladium species in the ionic liquid was possible. ${ }^{53 \mathrm{c}}$ In addition, heterocycles such as pyrroles and indoles have also been used for this hydroarylation reaction of alkynes. ${ }^{54}$ 


\section{Scheme 18}

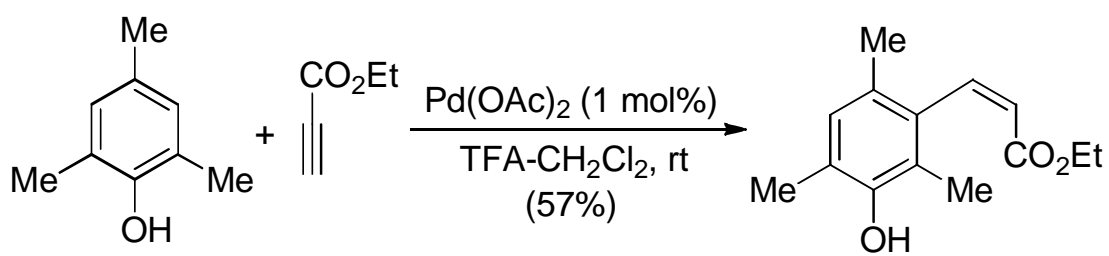

55 (2 eq)

56

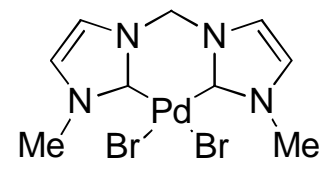

57<smiles>C#CC(=O)OCC</smiles>

Dinuclear palladium complexes have shown to catalyze the syn-hydroarylation of alkynes with arenes. ${ }^{55}$ Thus, the reaction between hex-3-yne and benzene in the presence of $\mathrm{Pd}_{2} p \operatorname{Tol}_{2}(\mu-\mathrm{OH})(\mu$-dpfam $) \quad\{$ dpfam $=N, N$ ''-bis[2-(diphenylphosphanyl)phenyl]formamidinate $\quad(\mathbf{5 9}, 2 \mathrm{~mol} \%)$ and $\mathrm{B}(n \mathrm{Bu})_{3}(30 \mathrm{~mol} \%)$ at $100{ }^{\circ} \mathrm{C}$ afforded quantitatively (E)-3-phenylhex-3-ene (60) (Scheme 19), the reaction proceeding through arene activation.

\section{Scheme 19}

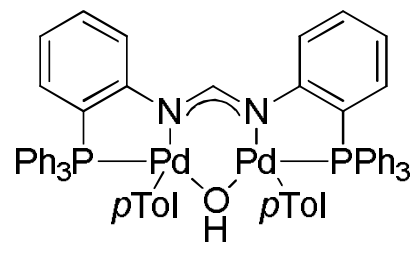

59

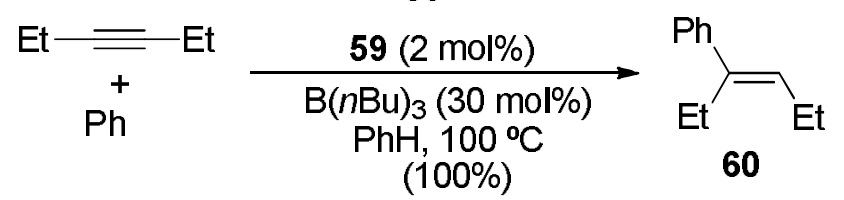

The palladium-catalyzed hydroarylation of alkynes carried out using aryl iodides and triflates is a known procedure which allows the formation of vinyl arenes with cisselectivity through activation of the arene. ${ }^{56}$ The reaction is performed using 
$\mathrm{Pd}(\mathrm{OAc})_{2} / \mathrm{PPh}_{3}$ as catalyst in the presence of an ammonium formate salt and shows a certain lack of regioselectivity, unless a bulky end is present on one side of the carboncarbon triple bond. This methodology could be converted into a phosphine ligand-free process using $\mathrm{Pd}(\mathrm{OAc})_{2}$ as the catalyst in the presence of potassium formate in DMF as solvent at $40{ }^{\circ} \mathrm{C}$, for the hydroarylation of 3,3-dialkoxy-1-aryl-1-propynes with aryl iodides. $^{57}$ More recently, this ligandless methodology has been used for the hydroarylation of propargylic alcohols at room temperature in ionic liquids. ${ }^{58}$ Under these reaction conditions, aryl iodides are used in the hydroarylation of propargyl alcohols, such as 61, using $\mathrm{Pd}(\mathrm{OAc})_{2}(5 \mathrm{~mol} \%)$ in the presence of triethylammonium formate in the ionic liquid [bmim] $\left[\mathrm{BF}_{4}\right]$ (bmim: 1-butyl-3-methylimidazolium) at $40{ }^{\circ} \mathrm{C}$, to afford regioselectively the corresponding arylated allyl alcohols 62 and 63 in good yield (Scheme 20). The mechanism of this phosphine-free hydroarylation reaction of alkynes has been investigated theoretically, explaining the unusual anti-Michael selectivity when $\alpha, \beta$-acetylenic carbonyl substrates are used. ${ }^{59}$

\section{Scheme 20}

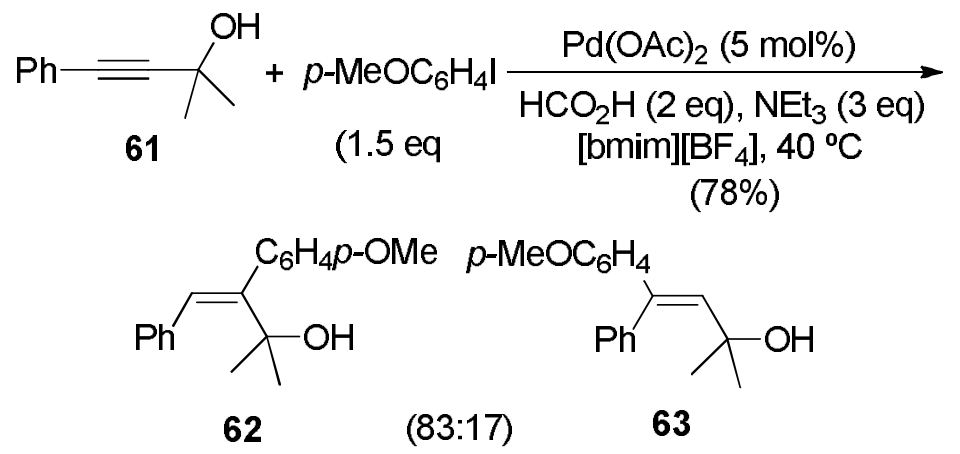

Arylboronic acids ${ }^{60}$ and also sodium tetraphenylborate ${ }^{61}$ have been used in palladium-catalyzed hydroarylation reactions of alkynes, affording trisubstituted alkenes in a syn-addition fashion. Thus, if a heteroatom-bearing directing group is present, as in the case of propargylic amines, the arylation takes place closer to that group, ${ }^{60 \mathrm{~d}}$ whereas typical terminal alkynes favor branched-type olefins, ${ }^{60 a}$ internal unsymmetrical ones afford regioisomeric mixtures favoring the less hindered position, ${ }^{60 \mathrm{~b}}$ and propiolates favor Michael-type olefins. ${ }^{60 a-c}$ Some examples of these reactions can be seen in Scheme 21, where diphenylacetylene is hydroarylated using phenylboronic acid, in a process catalyzed by the combination $\mathrm{PdCl}_{2} \quad(5 \mathrm{~mol} \%) / \mathrm{Pr}_{2} \mathrm{NPPh}_{2}(5 \mathrm{~mol} \%)$, in the presence of potassium carbonate as base, in THF as solvent at $65{ }^{\circ} \mathrm{C}$, to yield 
triphenylethylene (64). ${ }^{60}$ An example of the use of sodium tetraphenylborate as hydrophenylating agent is the transformation of hept-1-yne in a process carried out using $\mathrm{PdCl}_{2}\left(\mathrm{PPh}_{3}\right)_{2}(3 \mathrm{~mol} \%)$ in aqueous acetic acid at room temperature, yielding geminal- and $(E)$-olefins $\mathbf{6 5}$ and $\mathbf{6 6}$, the former being the major regioisomer (Scheme 21). ${ }^{61}$ In addition, arylboronic acids have also being used for the preparation of tetrasubstituted olefins via palladium-catalyzed double arylation of internal alkynes, as shown in the preparation of tetrasubstituted olefin $\mathbf{6 7}$ from addition of two equivalents of phenylboronic acid to ethylphenylacetylene (Scheme 21). ${ }^{62}$ The reaction involves the syn addition of two equivalents of an arylboronic acid to opposite ends on the triple bond, and is carried out using $\mathrm{Pd}(\mathrm{OAc})_{2}(5 \mathrm{~mol} \%)$ in $\mathrm{DMSO}$ as solvent in the presence of molecular sieves and using molecular oxygen as oxidant.

\section{Scheme 21}
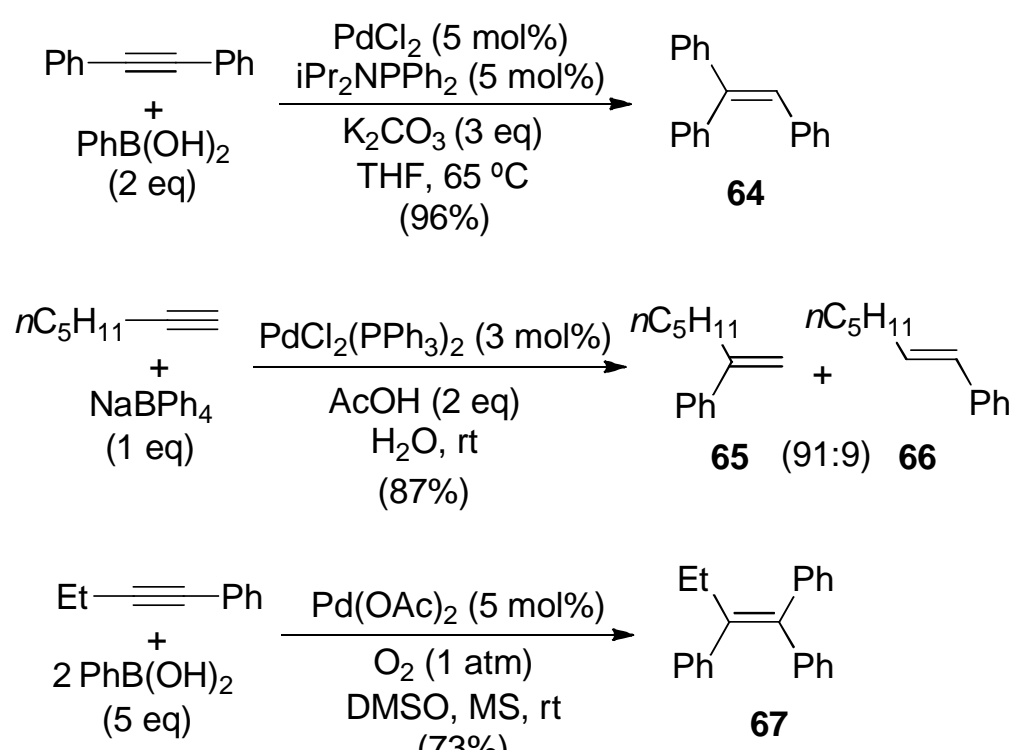

Arenediazonium tetrafluoroborates have also been used as aryl sources for the palladium-catalyzed hydroarylation of internal alkynes. ${ }^{63}$ The methodology employs $\mathrm{Pd}(\mathrm{OAc})_{2}(2 \mathrm{~mol} \%)$ as catalyst in the presence of triphenylsilane in THF at room temperature, as illustrated in Scheme 22 for the hydroarylation of diphenylacetylene with arenediazonium tetrafluoroborate 68 to give olefin 69. Unsymmetrical alkynes gave very low regioselectivities, whereas the reaction with ethyl phenylpropiolate afforded regio- and diastereoselectively ethyl $(Z)$-2-arylcinnamates $(E / Z>99: 1)$. 


\section{Scheme 22}<smiles></smiles>

$68(4 \mathrm{eq})$

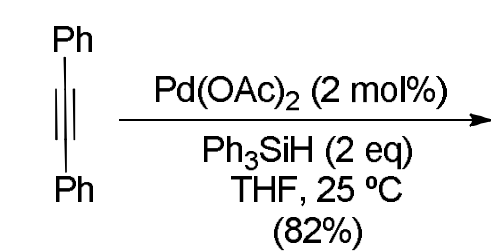

$(82 \%)$

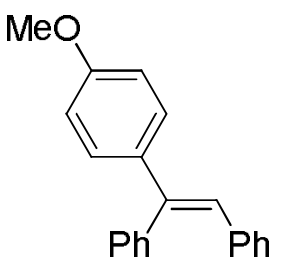

69

\subsection{Acrylic Acids, Esters and Amides}

The three-component reaction which converts unsaturated hydrocarbons, carbon monoxide and a nucleophilic heteroatom-bearing donor, such as water, alcohols and amines, into saturated or unsaturated acids or its corresponding derivatives, using group VIII transition metal catalysts is generally known as the Reppe carbonylation, palladium being one of the most frequent metals employed. ${ }^{64}$ Thus, the palladium-catalyzed carbonylation of terminal alkynes with water, alcohols or amines normally produces mixtures of linear and branched $\alpha, \beta$-unsaturated acids, esters or amides, respectively (Scheme 23), with a ratio largely depending on the catalytic system, the reaction conditions, the substrate used and the nucleophile. ${ }^{64 b, 65}$

\section{Scheme 2}

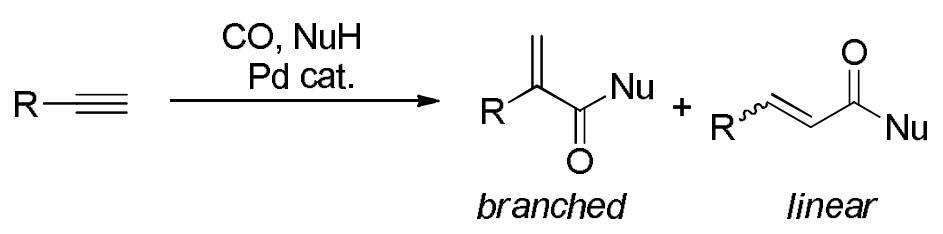

Among these palladium-catalyzed Reppe reactions with alkynes, the reaction using carbon monoxide and water leading to carboxylic acids (hydrocarboxylation) has been much less frequent than the reaction with alcohols (hydroesterification or hydroalkoxycarbonylation) and amines (aminocarbonylation). ${ }^{64 \mathrm{~b}, 65}$ Hydrocarboxylation reactions are usually slower than, for instance, methoxycarbonylation reactions, resulting in some catalytic deactivation. ${ }^{64 a}$ Particularly, the hydrocarboxylation of the most simple alkyne, acetylene, leading to acrylic acid, is very rare, ${ }^{64 b, 65}$ although there are recent studies about the hydrocarboxylation of acetylene using a catalytic system containing $\mathrm{Pd}(\mathrm{OAc})_{2}$, phosphines such as diphenyl(2-pyridyl)phosphine (2- $\left.\mathrm{PyPPh}_{2}\right)$ and 
acids such as trifluoromethanesulfonic acid ( $\mathrm{TfOH})$ under $\mathrm{CO}$ pressure (7-50 bar) and temperatures of $40 / 50{ }^{\circ} \mathrm{C} .{ }^{66}$ Under these conditions, $88 \%$ conversion of acetylene and 99\% selectivity towards acrylic acid was achieved, factors such as amount of water and initial partial pressure of $\mathrm{CO}$ having great influence on the catalytic activity.

Preference for the linear unsaturated acid has been observed in the hydrocarboxylation of phenylacetylene when using as catalytic combination a mixture of $\mathrm{Pd}(\mathrm{MeCN})_{2} \mathrm{Cl}_{2}(10 \mathrm{~mol} \%)$ and diphosphine $70(50 \mathrm{~mol} \%)$, in the presence of methanesulfonic acid (MsOH) under a $\mathrm{CO}$ pressure of 70 bar and at $80^{\circ} \mathrm{C}$ (Scheme 24). Under these reaction conditions, (E)-cinnamic acid (72) was obtained as the major product, whereas the branched 2-phenylacrylic acid (73) was obtained in only a $4 \%$ yield, small amounts of saturated 3-phenylpropanoic and 2-phenylsuccinic acids from hydrogenation and secondary hydrocarboxylation, respectively, being also detected. ${ }^{67}$ On the contrary, the branched 2-phenylacrylic acid (73) was exclusively observed when using as catalyst a combination of $\mathrm{Pd}(\mathrm{OAc})_{2}(1 \mathrm{~mol} \%)$ and sulfonated Binap diphosphine $71(4 \mathrm{~mol} \%)$ in the presence of $\mathrm{Al}(\mathrm{OTf})_{3}(2 \mathrm{~mol} \%)$ under a $\mathrm{CO}$ pressure of 35 bar and at $82{ }^{\circ} \mathrm{C}$, using as solvent $\mathrm{MeOH} / \mathrm{H}_{2} \mathrm{O}(1: 2)$, neat $\mathrm{H}_{2} \mathrm{O}$ or $\mathrm{H}_{2} \mathrm{O} / \mathrm{DME}(1: 1)$ (Scheme 24). ${ }^{68}$

\section{Scheme 24}<smiles>CCCCCCCCc1ccccc1CPCCC</smiles>

70<smiles></smiles>

71

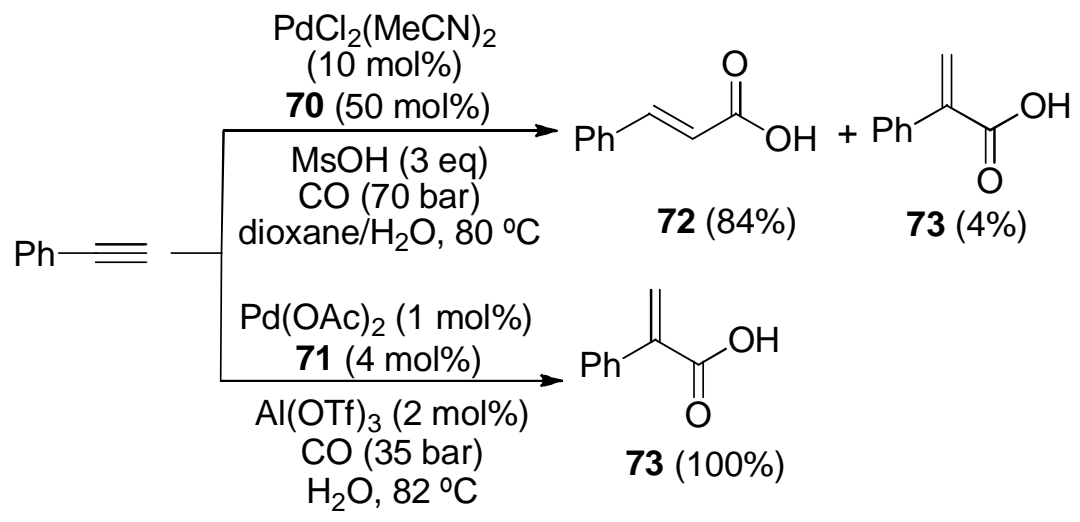


The most efficient palladium catalyst for the methoxycarbonylation of alkynes was developed in the 1990 s by combining $\mathrm{Pd}(\mathrm{OAc})_{2}$ and the already mentioned ligand 2- $\mathrm{PyPPh}_{2}$, together with methanesulfonic acid, a mixture that achieved the methoxycarbonylation of propyne with extremely high efficiency. ${ }^{69}$ Thus, 40.000 TON and $99.95 \%$ selectivity towards methyl methacrylate (MMA) was obtained at 60 bar CO and $45-60{ }^{\circ} \mathrm{C}$. The success of this $2-\mathrm{PyPPh}_{2}$ ligand inspired its use in other carbonylation reactions of alkynes (as above mentioned), for instance in a recent methoxycarbonylation of acetylene leading to methyl acrylate. ${ }^{70}$ In addition, other heterocycle-containing phosphines were prepared for related uses, ${ }^{64 b, 65}$ as 2,6-bis(biphenylphosphino)pyridine, which was employed by the Shell company, combined to $\mathrm{Pd}(\mathrm{OAc})_{2}$, in a commercial synthesis of methyl methacrylate by a highly branchedselective methoxycarbonylation of propyne. ${ }^{64 a, 71}$

The methoxycarbonylation of alkynes usually displays certain preference for the branched regioselectivity, ${ }^{64 b, 65}$ as is exemplified in Scheme 25, which shows the highly selective and quantitative preparation of methyl 2-phenylacrylate (74) (methyl atropate) from phenylacetylene (99:1 branched/linear) when using as a catalytic system a mixture of $\mathrm{Pd}(\mathrm{OAc})_{2}(0.1 \mathrm{~mol} \%) / \mathrm{Binap}(0.4 \mathrm{~mol} \%)$ and $\mathrm{Al}(\mathrm{OTf})_{3}(0.2 \mathrm{~mol} \%)$, in methanol as solvent and under a $\mathrm{CO}$ pressure of 35 bar and at $80{ }^{\circ} \mathrm{C}$ reaction temperature. ${ }^{68}$ However, the mentioned crucial influence of the catalytic system in the regioselectivity of these Reppe reactions can clearly be seen in Scheme 25, where the linear methoxycarbonylation product of phenylacetylene, methyl $(E)$-cinnamate (75), is obtained (99:1 branched/linear regioselectivity) using a mixture of $\operatorname{Pd}_{2}(\mathrm{dba})_{3}(0.25$ $\mathrm{mol} \%) / 70(3 \mathrm{~mol} \%)$ as catalyst and the presence of $\mathrm{MsOH}$ (3 mol\%), working under $\mathrm{CO}$ pressure (30 bar) in methanol as solvent at $80{ }^{\circ} \mathrm{C} .{ }^{67}$ The uncommon regiochemistry of this last reaction is explained by a hydride mechanism involving sterically-induced addition of a created palladium hydride onto the alkyne leading to a linear vinyl palladium species, followed by $\mathrm{CO}$ insertion and methanolysis. 
Scheme 25

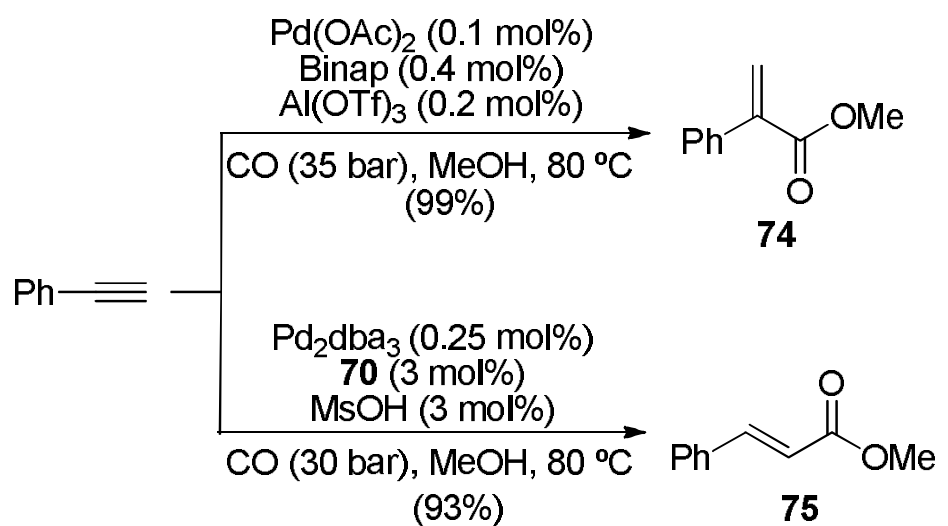

This mentioned influence of the reaction conditions in the regioselectivity of these carbonylation processes has been explored in extension, as in the model methoxycarbonylation of phenylacetylene using $\mathrm{Pd}(\mathrm{OAc})_{2}$ as palladium source, dppb as ligand $[\mathrm{dppb}=$ bis(diphenylphosphino)butane $]$ and $p$-toluenesulfonic as acid additive, in the presence of methanol under $\mathrm{CO}$ pressure $(6.9$ bar $)$ in acetonitrile at $110{ }^{\circ} \mathrm{C} .{ }^{72}$ These conditions afforded the linear methyl $(E)$-cinnamate (75) as the main compound. However, a change in the palladium source from $\mathrm{Pd}(\mathrm{OAc})_{2}$ to $\mathrm{PdCl}_{2}\left(\mathrm{PPh}_{3}\right)_{2}$ changed the selectivity from the linear acrylate $\mathbf{7 5}$ to the branched ester $\mathbf{7 4}$, whereas a change in the ligand from dppb to 1,1'- bis(diphenylphosphino)ferrocene (dppf) has the same effect. In addition, exchanging acetonitrile by DMF or DMSO also led to the branched ester as the major regioisomer.

Methyl $\beta$-methoxyacrylates such as $\mathbf{7 7}$ have been obtained by reaction of terminal alkynes, such as dec-1-yne, with $\mathrm{CO}(1 \mathrm{bar})$ in methanol at $10^{\circ} \mathrm{C}$, the process being catalyzed by combining palladium(II) trifluoroacetate $\left[\mathrm{Pd}\left(\mathrm{CF}_{3} \mathrm{COO}\right)_{2}\right](5 \mathrm{~mol} \%)$ and the bis-oxazoline ligand $(S)-\mathrm{PhBox}(76)(7.5 \mathrm{~mol} \%)$ in the presence of $p$ benzoquinone (Scheme 26). ${ }^{73}$ 
Scheme 26<smiles>COC(=O)C=C(OC)OC</smiles>

Internal alkynes have been less common substrates than terminal ones for these types of carbonylation reactions, as regioselectivity is a frequent problem. ${ }^{64 \mathrm{~b}, 65}$ However, when symmetrical alkynes are employed, carbonylation reactions can be synthetically useful, as shown in Scheme 27, where the reaction conditions employed in the preparation of methyl $(E)$-cinnamate are used for the methoxycarbonylation of oct4-yne, leading to the $\alpha, \beta$-unsaturated methyl ester $78 .{ }^{67}$ In addition, depending of the substrate, even unsymmetrical alkynes can be regioselectively hydroesterified, as can be seen in Scheme 27. Thus, ethyl phenylpropiolate is hydrophenoxycarbonylated to diester 79 using as catalyst a mixture of $\operatorname{Pd}(\mathrm{OAc})_{2} \quad(5 \mathrm{~mol} \%)$ and 1,3bis(diphenylphosphino)propane (dppp, $5 \mathrm{~mol} \%$ ) in the presence of zinc $(75 \mathrm{~mol} \%)$ as additive and phenol, under an atmosphere of $\mathrm{CO}(1 \mathrm{bar})$ in toluene as solvent at 100 ${ }^{\circ} \mathrm{C} .{ }^{74}$

\section{Scheme 27}
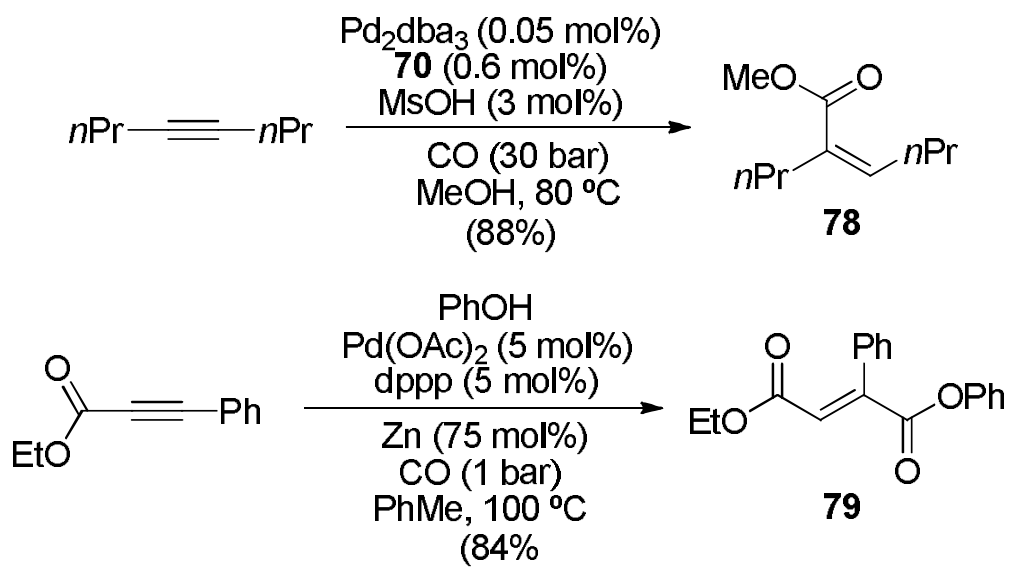
The use of $\mathrm{CO}$ in these hydroesterification reactions can be avoided using other carbonyl sources, such as formate or oxalate esters. ${ }^{64 b, 65}$ For instance, aryl formates have been used as a $\mathrm{CO}$ source in the hydroesterification of internal alkynes, such as $\mathbf{8 1}$, using $\mathrm{Pd}(\mathrm{OAc})_{2}(5 \mathrm{~mol} \%)$ as palladium source, Xantphos $(\mathbf{8 0})$ as ligand (10 mol\%), in mesitylene as solvent at $100{ }^{\circ} \mathrm{C}$, to give the corresponding unsaturated phenyl ester 82 with total $(E)$-stereoselectivity (Scheme 28). ${ }^{75}$ This methodology has also been applied to terminal alkynes, affording almost exclusively the corresponding branched regioisomers.

\section{Scheme 28}<smiles>CC1(C)c2cccc(P)c2Oc2c(P)cccc21</smiles>

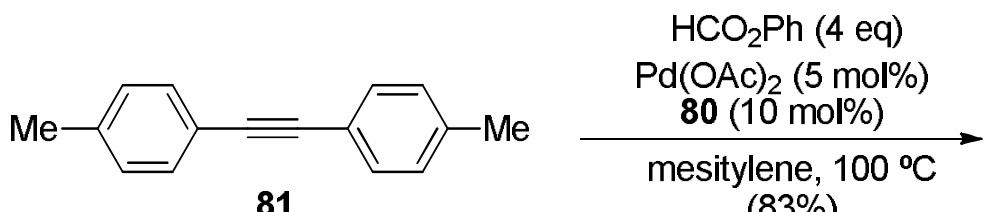

81

$(83 \%)$

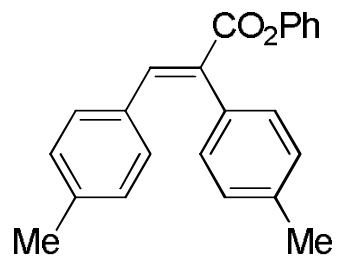

82

The synthesis of $\alpha, \beta$-unsaturated amides from alkynes has been performed similarly to the alkoxycarbonylation process, but using primary or secondary amines instead of water, alcohols or phenols. ${ }^{64 b, 65}$ For example, the aminocarbonylation of phenylacetylene has been achieved in the presence of diisobutylamine, using $\operatorname{Pd}(\mathrm{OAc})_{2}$ as palladium source $(2 \mathrm{~mol} \%), \mathrm{dppb}$ as ligand $(8 \mathrm{~mol} \%)$ and $p$-toluenesulfonic acid ( $p$ $\mathrm{TsOH})$ as additive $(30 \mathrm{~mol} \%)$, in the presence of methanol under $\mathrm{CO}$ pressure (6.9 bar) in acetonitrile at $110^{\circ} \mathrm{C}$. Under these conditions, the corresponding branched amide $\mathbf{8 3}$ was almost exclusively obtained, a negligible amount of the linear cinamide 84 being observed (Scheme 29). ${ }^{72}$ It is remarkable that under exactly the same reaction conditions, but in the presence of methanol, the corresponding linear methyl cinamate was the main product (12:88 branched/linear ratio), as above commented. ${ }^{72}$ This 
indicated that not only the palladium source, ligand, additive or solvent exert an influence in the regioselectivity of these carbonylation reactions, but also that the nucleophile exerts a strong control. All these data reveal a complex mechanism still not fully understood, as well as different catalytic cycles governing alkoxycarbonylation and aminocarbonylation processes. ${ }^{76}$

\section{Scheme 29}

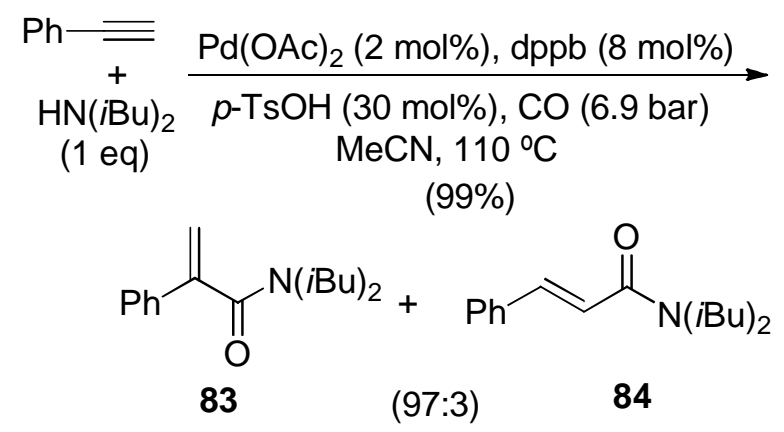

The use of $\mathrm{CO}$ has also been avoided in the case of the aminocarbonylation reaction, for instance, by using formamides. Thus, the reaction of formamides with internal alkynes in the presence of a $\mathrm{PdCl}_{2}(\mathrm{PhCN})_{2}(2.5 \mathrm{~mol} \%)$, Xantphos (80) (2.5 mol\%) and benzoyl chloride $(20 \mathrm{~mol} \%)$ as an in situ $\mathrm{HCl}$-forming additive, in mesitylene at $140{ }^{\circ} \mathrm{C}$, afforded $(E)-\alpha, \beta$-unsaturated amides regio- and steroselectively, as shown in Scheme 30. Thus, the aminocarboxylation of 1,2-di(thiophen-2-yl)ethyne 852 ) with $N, N$-dimethylformamide afforded the unsaturated amide 86 in a $99: 1 \mathrm{E} / \mathrm{Z}$ diastereoselectivity. ${ }^{77}$ These conditions were also used for the aminocarbonylation of terminal alkynes, affording the corresponding branched amides as the major products in regioselectivities higher than $81 / 19$ branched/linear ratio. ${ }^{77}$ Control experiments revealed that in this catalytic reaction, formamide reacts directly with the alkyne, not by decomposition of the formamide to $\mathrm{CO}$ and the amine and subsequent conventional aminocarbonylation. 


\section{Scheme 30}
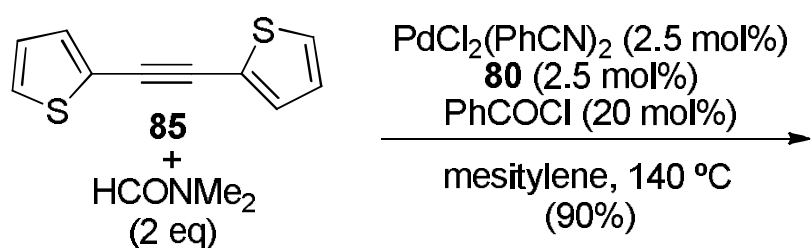<smiles>CN(C)C(=O)/C(=C/c1cccs1)c1cccs1</smiles>

86

The transition metal-catalyzed addition of carboxylic acid to alkynes (hydrooxycarbonylation) is a process suitable for the preparation of vinyl carboxylates, some of them of paramount industrial importance as is the case of vinyl acetate, and also used heavily in intramolecular reactions. ${ }^{30 a}$ However, the examples of palladium-catalyzed intermolecular addition of carboxylic acids to alkynes is restricted to few old examples. $^{30 \mathrm{a}}$ The most recent study is the use of dinuclear palladium complexes such as 59 (2 mol\%), which have shown suitable to induce stereoselectively the hydrocarboxylation of alkynes such as hex-3-yne using carboxylic acids, such as benzoic acid, in the presence of Lewis acids, such as $\mathrm{B}(n \mathrm{Bu})_{3}(30 \mathrm{~mol} \%)$, as additives at $100{ }^{\circ} \mathrm{C}$ (Scheme 31). ${ }^{78}$ The resulting vinyl benzoate 87 is obtained as the $(Z)$-isomer, this stereoselectivity being generally the major one in this process.

\section{Scheme 31}

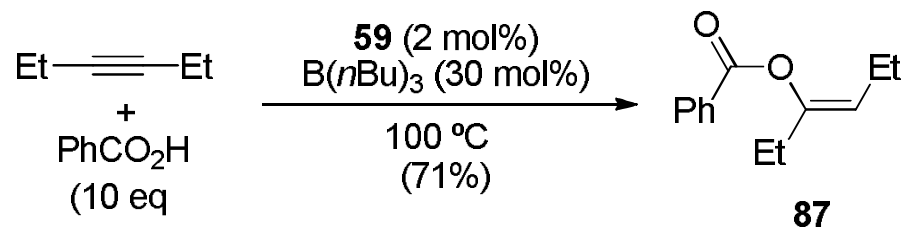




\subsection{Ketones}

The addition of heteroatom-hydrogen bonds (including N-H, O-H, S-H, Se-H, and $\mathrm{P}-\mathrm{H}$ ) across the carbon-carbon triple bond catalyzed by transition-metal species is an important process from a synthetic point of view as it leads to a diverse array of different functionalities and, in principle, can be performed with $100 \%$ atom economy a requirement of 'green chemistry'. 30a,50

Among these processes, the palladium-catalyzed addition of water to alkynes (hydration) can be an easy way of generating ketones from alkynes, ${ }^{79}$ although anchimeric assistance (neighboring group participation) has been sometimes necessary. Thus, $\mathrm{PdCl}_{2}(\mathrm{MeCN})_{2}$ in aqueous acetonitrile under microwave irradiation was used in the hydration of ketone $\mathbf{8 8}$ as it leads to 1,4-diketone 89 (Scheme 32). ${ }^{80}$ Modified conditions have been the use of a phase-transfer agent in a two-phase system in the case of the hydration of a hydroxylated alkyne ${ }^{81}$ or the use of a Nafion/palladium(II) resin in aqueous ethanol for the hydration of 2-methylbut-3-yn-2-ol to 3-hydroxy-3methylbutan-2-one. ${ }^{82}$ However, there are isolated examples where carbonyl or hydroxyrelated anchimeric assistance have not been necessary in particular cases, as the Markovnikov hydration of ethynylferrocene (91) to acetylferrocene (92) catalyzed by camphor hydrazone-derived palladium(II) complex 90 (10-25\%) in aqueous methanol at room temperature (Scheme 32), although related alkynes such as 1-ferrocenylprop-1yne or simple terminal acetylenes such as oct-1-yne of several ethynylbenzenes were not affected or polymerized. ${ }^{83}$ 


\section{Scheme 32}<smiles>C#CCC1CCCC1=O</smiles>

88
$\underset{\mathrm{MeOH} / \mathrm{H}_{2} \mathrm{O}, \mathrm{MW}, 25 \stackrel{\mathrm{PdC}}{\mathrm{C}}}{\longrightarrow}$ $(81 \%)$<smiles>CN(C)N=C1C2(C)CCC1(C)C(=N[Pb](Cl)(Cl)N(C)C)C2=O</smiles>

90

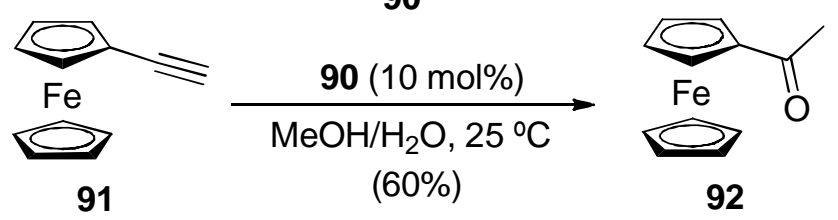

\subsection{Allyl and Vinyl Ethers}

The intermolecular addition of alcohols to alkynes (hydroalkoxylation), which leads to alkenylated ethers, is a more difficult process to accomplish than its intramolecular version, therefore few and not very recent reports can be found. ${ }^{30 a, 50}$ An example of a simple and good-yielding hydroalkoxylation of a simple internal alkyne such as 1-phenyl-1-propyne with alcohols, such as benzyl alcohol, yielding the cinnamyl ether 93 is shown in Scheme $33 .{ }^{84}$ The reaction takes place with $(E)$ streoselectivity through the corresponding allene intermediate and was performed using $\mathrm{Pd}\left(\mathrm{PPh}_{3}\right)_{4}(10 \mathrm{~mol} \%)$ as catalyst and benzoic acid as additive $(10 \mathrm{~mol} \%)$ in dioxane as solvent at $100{ }^{\circ} \mathrm{C}$. When the hydroalkoxylation process is intended to achieve vinylated ethers, activated alkynes such as propiolic acid esters were used as starting materials. Thus, a polynuclear transition-metal-sulfur complex, ${ }^{85}$ such as the single-cubane-type cluster $\left[\mathrm{PdMo}_{3}\left(\mu_{3}-\mathrm{S}\right)_{4}(\operatorname{tacn})_{3} \mathrm{Cl}\right]\left[\mathrm{BF}_{4}\right]_{3}(\operatorname{tacn}=1,4,7$-triazacyclononane $)$, was used as catalyst $(1 \mathrm{~mol} \%)$ in the hydroalkoxylation of different propiolic acid esters following a trans-addition. This is the case of the hydromethoxylation of methyl but-2-ynoate to give the corresponding $\beta$-methoxylated unsaturated ester $\mathbf{9 4}$, the reaction being carried out in methanol at $40{ }^{\circ} \mathrm{C}$ and monoarylated acetylenes remaining unreactive (Scheme 33). ${ }^{86}$ When related bimetallic cluster $\left[(\mathrm{Cp} * \mathrm{Ir})_{2}\left(\mu_{3}-\mathrm{S}\right)_{2} \mathrm{PdCl}_{2}\right]\left(\mathrm{Cp}^{*}=\eta^{5}-\mathrm{C}_{5} \mathrm{Me}_{5}\right)$ were used for the hydroalkoxylation of a series of nonactivated arylacetylenes, the 
regioselectively formed Markovnikov-type vinyl ethers were in situ transformed into diacetals after a second hydroalkoxylation reaction. ${ }^{87}$ In addition, diynes have been hydroaryloxylated in an 'anti-Wacker'-type process catalyzed by $\operatorname{Pd}\left(\mathrm{PPh}_{3}\right)_{4}(5 \mathrm{~mol} \%)$ in the presence of triphenylphosphine oxide $(10 \mathrm{~mol} \%)$ in toluene at room temperature, as shown in Scheme 30, where hexa-2,4-diyne in transformed into the phenoxylated enyne 95. ${ }^{88}$

Scheme 33

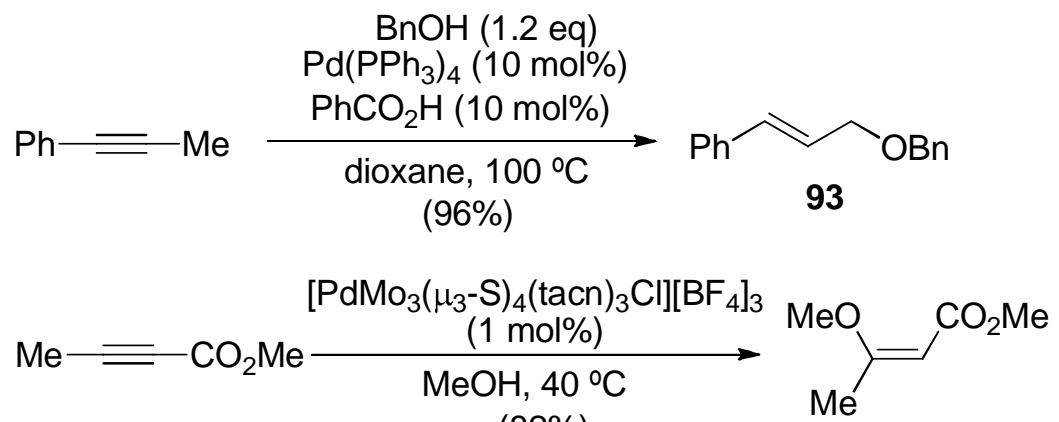

$(82 \%)$

94

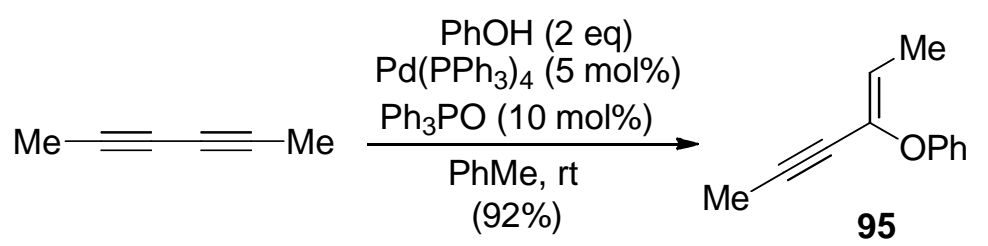

\subsection{Enamines, Imines and Allylamines}

The palladium-catalyzed addition of amines to alkynes (hydroamination) leads to an enamine which, according to the nature of the amine, can remain or evolve as an imine (or can be hydrolized to a ketone). This methodology has experienced a considerable research and success in the case of the intramolecular version, as many nitrogen-containing heterocyclic systems, as indoles, can be obtained in this way (see Section 3.2), its intermolecular counterpart being however much less explored. ${ }^{30,50,89}$ Recent uses of palladium complexes for the intermolecular preparation of these nitrogenated systems can be seen in Scheme 34 in the synthesis of acetophenone imines, such as 98, by reaction of aromatic amines, such as 2,6-dimethylaniline, with phenylacetylene. This reaction is catalyzed by the CSC-pincer palladium complex 96 (1 mol\%) in the presence of triflic acid ( $5 \mathrm{~mol} \%)$ as additive in toluene as solvent at 100 
${ }^{\circ} \mathrm{C} .{ }^{90}$ Acetophenone imines have also been prepared by using as catalyst a palladium(II) 4-iminophosphine complex 97 , working in $\mathrm{THF}$ at $70^{\circ} \mathrm{C}$, the use of cyclic secondary amines, such as morpholine, under these reaction conditions allowing the preparation of the corresponding enamine 99 (Scheme 34). ${ }^{91}$

\section{Scheme 34}<smiles>CCC(Br)(Br)c1nccn1Cc1nccn1Cc1nccn1Cc1ccccc1</smiles>

96

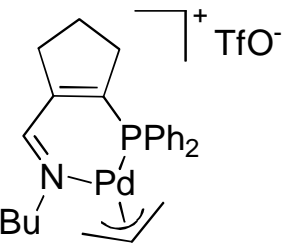

97

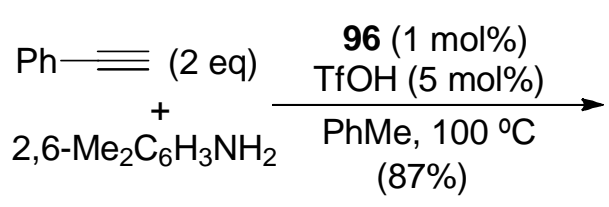

$(87 \%)$

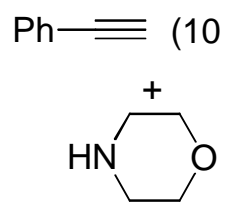

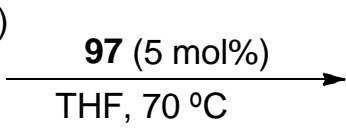

$(62 \%)$<smiles>C/C(=N\c1c(C)cccc1C)c1ccccc1</smiles>

98<smiles>C=C(c1ccccc1)N1CCOCC1</smiles>

99

Allylic amines have been prepared from internal phenyl acetylenes and secondary amines following a hydroamination protocol consisting of using simple $\mathrm{Pd}\left(\mathrm{PPh}_{3}\right)_{4}$ as catalyst $(5 \mathrm{~mol} \%)$ in the presence of a substoichiometric amount of benzoic acid $(10 \mathrm{~mol} \%)$ in dioxane as solvent at $100{ }^{\circ} \mathrm{C} .{ }^{92}$ According to this procedure, allylamines such as $\mathbf{1 0 0}$ were prepared by reaction of dibenzylamine with prop-1-yn-1ylbenzene with total stereoselectivity, the process taking place through the allene intermediate (Scheme 35).

\section{Scheme 35}

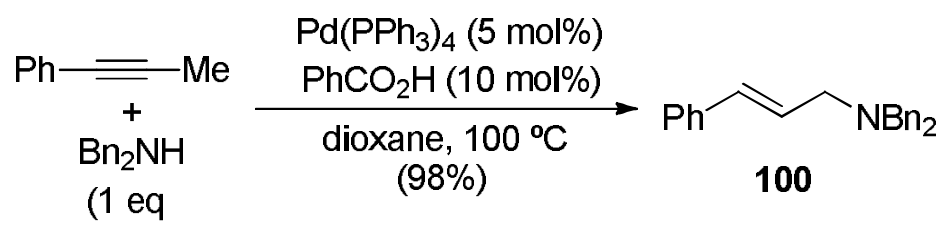




\subsection{Vinyl Sulfides and Selenides}

The transition-metal-catalyzed addition of thiols or selenols to alkynes (hydrothiolation or hydroselenation) was a process that did not received much attention, probably due to the prejudice that these types of compounds can act as a catalyst poison. However, in the last ten years, considerable research has been carried out in this $\operatorname{area}^{30 a, 93}$ due to the interest of vinyl sulfides and selenides in synthesis and in material sciences.

The intermolecular palladium-catalyzed addition of thiols and selenols has been usually carried out on terminal alkynes, achieving mainly the corresponding branched Markovnikov-type vinyl chalcogenides, contrary to the regiochemistry resulting from the classical radical addition reaction. ${ }^{30 a, 93}$ A typical example of palladium catalyzed addition of thiols to alkynes is the pioneering use of simple $\mathrm{Pd}(\mathrm{OAc})_{2}$ as catalyst. Thus, terminal alkynes such as oct-1-yne reacted with naphthalene-2-thiol using this palladium salt as catalyst $(2 \mathrm{~mol} \%)$ in THF at $40{ }^{\circ} \mathrm{C}$ to give the branched vinyl sulfide 101 (Scheme 36), internal alkynes giving mixtures of regio- and (E/Z)-stereoisomers. ${ }^{94}$ The use of other palladium(II) catalysts such as $\mathrm{PdCl}_{2}\left(\mathrm{PPh}_{3}\right)_{2}$ required higher temperatures leading to certain isomerization, whereas $\mathrm{Pd}\left(\mathrm{PPh}_{3}\right)_{4}$ showed lower reactivity. When using two equivalents of thiols and $\mathrm{Pd}(\mathrm{OAc})_{2}$ as catalysts in water as solvent, a second hydrothiolation of the branched vinyl sulfide took place leading to ketone thioacetals. ${ }^{95}$ A more recent hydrothiolation of alkynes has been carried out using shape-controlled PdNPs of the type $\left[\mathrm{Pd}(\mathrm{SR})_{2}\right]_{\mathrm{n}}$, generated by dissolving the $\mathrm{Pd}(\mathrm{OAc})_{2}(5 \mathrm{~mol} \%)$ in the alkyne and adding the thiol. This methodology afforded high yields and regioselectivity in the hydrothiolation of terminal alkynes, ${ }^{96}$ as shown in Scheme 36 for the formation of vinyl sulfide $\mathbf{1 0 2}$ from 2-methylbut-3-yn-2-ol and phenylmethanethiol. In addition, heterogeneous palladium 'nanosalts' have shown high efficiency and regioselectivity in these hydrothiolation (and hydroselenation) of terminal alkynes. ${ }^{97}$ 
Scheme 36

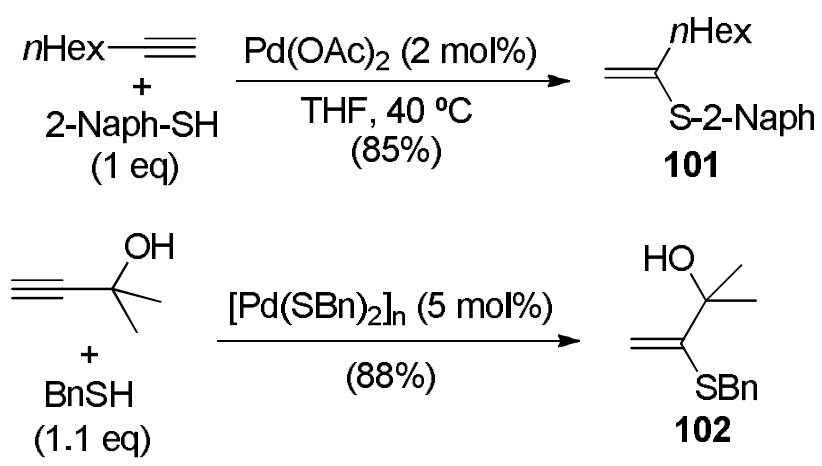

The uncommon preferential anti-Markovnikov-type addition of thiols to terminal alkynes has been achieved recently using as catalyst a dichlorobis(aminophosphine) complex of palladium. ${ }^{98}$ Thus, $\mathrm{PdCl}_{2}\left(\mathrm{PCy}_{2} \mathrm{NC}_{5} \mathrm{H}_{10}\right)_{2}$, in the presence of sodium hydroxide in NMP/THF as solvent $120^{\circ} \mathrm{C}$, has been employed as a very reactive catalyst $(0.05 \mathrm{~mol} \%)$ in the hydrothiolation of terminal aromatic alkynes with aromatic thiols. This procedure achieved total regioselectivity of the anti-Markovnikov-type linear vinyl sulfide in high yields and with high (Z)-diastereoselectivity, as in the case of the preparation of vinyl sulfide $\mathbf{1 0 3}$ from the hydrothiolation of phenylacetylene with benzenethiol (Scheme 37). Terminal aliphatic alkynes afforded however the Markovnikov-type branched vinyl sulfide as the major product, although with not so high regioselectivity than before, whereas internal alkynes gave $Z / E$ mixtures of isomers.

\section{Scheme 37}

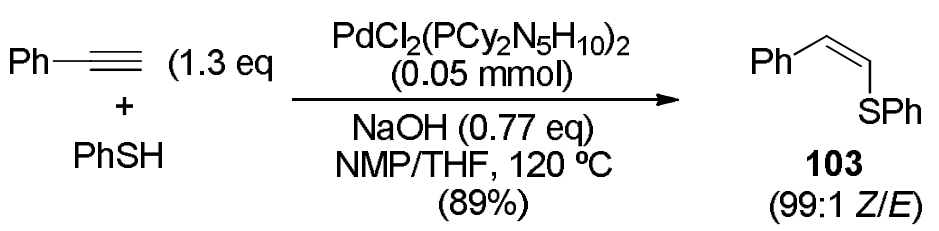

The use of $\mathrm{Pd}(\mathrm{OAc})_{2}(2 \mathrm{~mol} \%)$ showed to catalyze the hydroselenation of terminal alkynes with benzeneselenol in benzene as solvent at $80{ }^{\circ} \mathrm{C}$, leading to branched vinyl selenides. ${ }^{99}$ However, small amounts of byproducts from double hydroselenation and isomerization are formed under these conditions, the selectivity to 
the final terminal alkene being achieved totally by using pyridine as solvent as exemplified in Scheme 38 with the preparation of $\mathbf{1 0 4}$ from 5-methylhex-1-yne. ${ }^{100}$

\section{Scheme 38}

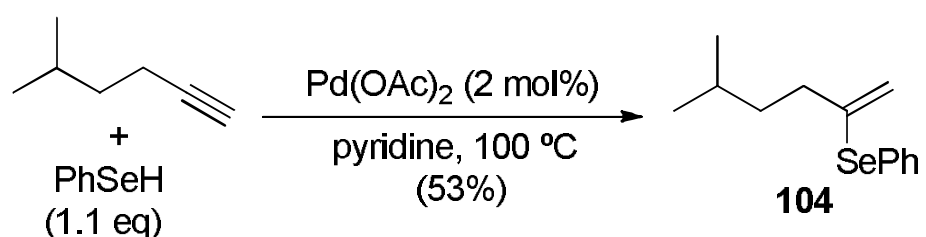

The palladium-catalyzed addition of diaryl or dialkyl-1,2-disulfides and 1,2diselenides to terminal alkynes, affords the corresponding vinyl 1,2-disulfides or 1,2diselenides mainly with $(Z)$-stereoselectivity. ${ }^{93}$ This was demonstrated in the pioneering work that showed that $\mathrm{Ph}_{2} \mathrm{~S}_{2}$ and $\mathrm{Ar}_{2} \mathrm{Se}_{2}$ add to terminal alkynes under $\operatorname{Pd}\left(\mathrm{PPh}_{3}\right)_{4}$ catalyzed conditions giving the $Z$-isomer, except in the case of phenylacetylene which afforded significant amounts of the $E$-isomer. ${ }^{101}$ Since then, other palladium species and reaction conditions have been attempted to improve yields and steroselectivities for this process. $^{93}$ As an example of using a recyclable supported catalyst, (Z)-1,2bis(arylsulfanyl)-substituted alkenes such as $\mathbf{1 0 6}$ have been synthesized by the stereoselective addition of diaryl disulfides to terminal alkynes catalyzed by a mobil crystalline material MCM-41-supported bidentate phosphine palladium(0) complex 105, as is the case of the addition of diphenyldisulfide to hex-1-yne (Scheme 39). ${ }^{102}$ The catalyst was reused up to five times keeping its activity.

\section{Scheme 39}

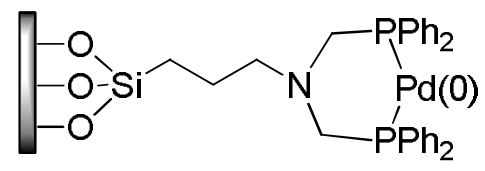

105

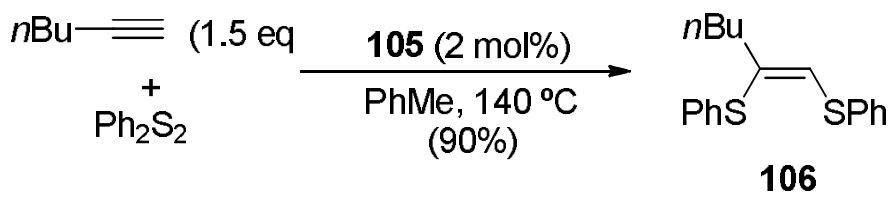


The ionic liquid $[\mathrm{bmim}]\left[\mathrm{BF}_{4}\right]$ has been used as solvent for the highly regioselective addition of $\mathrm{Ar}_{2} \mathrm{Z}_{2}\left(\mathrm{Z}=\mathrm{S}\right.$, Se) to terminal alkynes catalyzed by $\mathrm{Pd}\left(\mathrm{PPh}_{3}\right)_{4}$ ( $2 \mathrm{~mol} \%$ ), as shown in the case of the preparation of (Z)-1,2-disulfide and 1,2-diselenide 107 from phenylacetylene, no traces of the $E$-isomer being observed (Scheme 40). ${ }^{103}$ The ionic liquid containing the catalyst was recycled two times in the case of the addition of $\mathrm{Ph}_{2} \mathrm{Se}_{2}$ to hex-1-yne, showing identical yield of the final 1,2-diselenide. Moreover, examples can be found about the cyanochalcogenation of terminal alkynes with $\mathrm{PhZCN}(\mathrm{Z}=\mathrm{S}, \mathrm{Se})$ catalyzed by $\mathrm{Pd}\left(\mathrm{PPh}_{3}\right)_{4}(10 \mathrm{~mol} \%)$, the corresponding (Z)olefins bearing the cyano group at the terminal position. ${ }^{104}$

\section{Scheme 40}

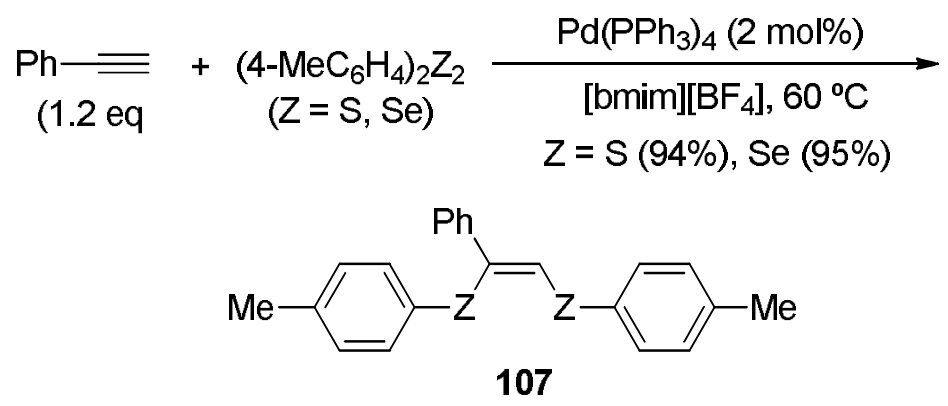

More exotic examples of addition of sulfur-bearing species to alkynes can also be found, as exemplified in the reaction of iminosulfides such as $\mathbf{1 0 8}$ to oct-1-yne to give the iminothiolation product 109 with good $E / Z$ stereoselectivity (18:82) (Scheme 41). ${ }^{105}$ The process is catalyzed by the combination $\mathrm{Pd}(\mathrm{dba})_{2}(5 \mathrm{~mol} \%) / \mathrm{PPh}_{3}(10 \mathrm{~mol} \%)$, using 1,2-dichloroethane as solvent at $80^{\circ} \mathrm{C}$. Another example would be the synthesis of 2,3-dihydrothiopyran-4-one derivatives by the $\mathrm{PdCl}_{2}(1 \mathrm{~mol} \%) / \mathrm{CuI}(10 \mathrm{~mol} \%)$ catalyzed reaction between $\alpha, \beta$-unsaturated thioesters and propargyl alcohols in the presence of bases, the addition to the triple bond taking place after both carbon-sulfur bonds cleavage. ${ }^{106}$ 
Scheme 41

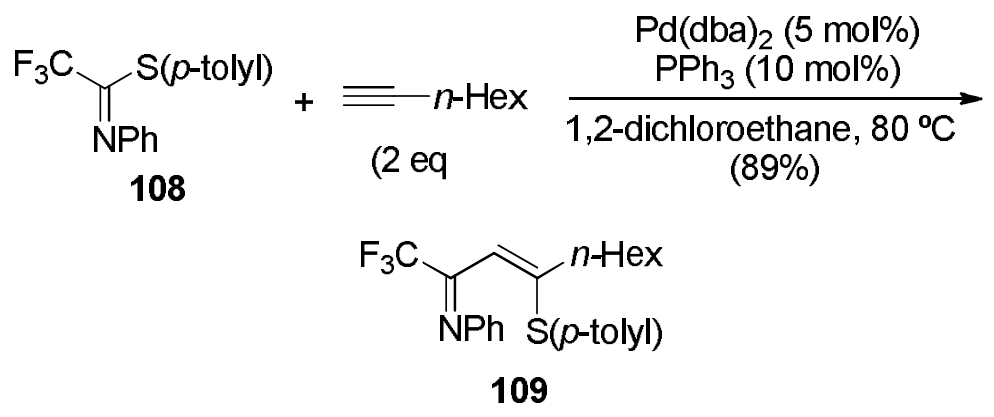

\subsection{Vinyl Phosphines, Phosphine Oxides, Phosphinates and Phosphonates}

The formation of C-P bonds by the transition-metal-catalyzed addition of P-H species to alkynes is a methodology that has received strong interest in the last years due to the increasing importance of phosphorus-related chemicals in the synthesis of compounds with biological activity. ${ }^{30 a, 107}$ Among these transformations, the intermolecular palladium-catalyzed addition of species containing $\mathrm{P}(\mathrm{III})-\mathrm{H}$ or $\mathrm{P}(\mathrm{V})-\mathrm{H}$ bonds to alkynes has been carried out mainly on terminal acetylenes, leading to a preference for the branched/linear final product depending on the nature of the palladium species, the nature and geometrical arrangement of the phosphorus group being also crucial. ${ }^{108}$

Alkenylated phosphines have been very scarcely prepared following this hydrophosphination methodology. Thus, the palladium-catalyzed $\left[\mathrm{Pd}\left(\mathrm{PPh}_{3}\right)_{4}, \mathrm{Pd}_{2}(\mathrm{dba})_{3}\right.$, $\left.\mathrm{Pd}(\mathrm{OAc})_{2}\right]$ addition of diphenylphosphine to terminal alkynes allowed the preparation of mixtures of the linear alkenylphosphine accompanied of the branched product, the proportions strongly depending on the reaction conditions. ${ }^{109}$ In addition, particularly remarkable is the regioselective addition of triphenylphosphine to terminal alkynes catalyzed by $\mathrm{Pd}\left(\mathrm{PPh}_{3}\right)_{4}(0.1 \mathrm{~mol} \%)$ in the presence of methanesulfonic acid in refluxing THF affording Markovnikov-type vinyl phosphonium salts such as 110, obtained after reaction with but-3-yn-1-ylbenzene and anion exchange (Scheme 42). Under these conditions, functionalities such as alcohols, nitriles or esters remained unaltered, the use of other phosphines giving no reaction. ${ }^{110}$ 


\section{Scheme 42}

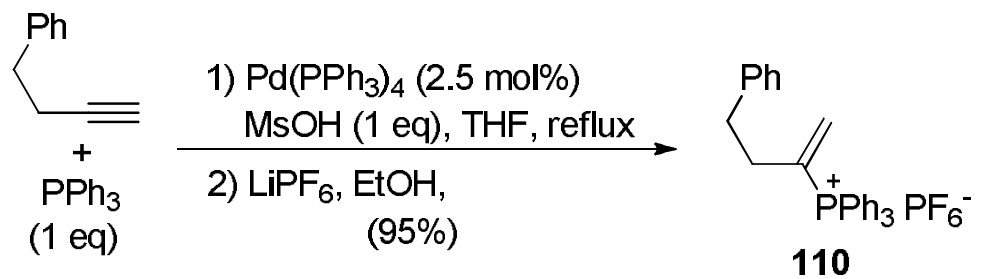

Vinylated phosphine oxides have been obtained by palladium-catalyzed addition of dialkylated or diarylated phosphine oxides to alkynes. Thus, a very effective hydrophosphinylation of terminal alkynes following this methodology has been achieved by using diphenylphosphine oxide and $\mathrm{Pd}\left(\mathrm{PPh}_{3}\right)_{4}$ as catalyst $(5 \mathrm{~mol} \%)$ in benzene at $35^{\circ} \mathrm{C}$. Under these conditions, terminal alkynes (except 1-ethynylcyclohex1-ene) afforded regio- and diastereoselectively the anti-Markovnikov-type linear alkenylphosphine oxide with $(E)$-stereochemistry, as in the case of the reaction of oct-1yne, affording the phosphine oxide 111 (Scheme 43). ${ }^{111}$ The regioselectivity of this reaction has been reversed totally by using as catalyst the complex cis$\left[\mathrm{Me}_{2} \mathrm{Pd}(\mathrm{PPhMe})_{2}\right](4 \mathrm{~mol} \%)$ in the presence of trace amounts of diphenylphosphinic acid (5 mol\%), which afforded the corresponding Markovnikov-type branched alkenylphosphine oxide 112 (94\% regioselectivity) (Scheme 43). ${ }^{112}$ The authors justify the formation of this branched regioisomer by formation of a new reactive $\mathrm{Ph}_{2} \mathrm{P}(\mathrm{O})$ $\mathrm{Pd}\left(\mathrm{L}_{2}\right)-\mathrm{OP}(\mathrm{O}) \mathrm{Ph}_{2}$ complex, insertion of the $\mathrm{Pd}-\mathrm{P}(\mathrm{O}) \mathrm{Ph}_{2}$ bond into the carbon-carbon triple bond (phosphinylpalladation) with formation of an alkynylpalladium species, and subsequent protonolysis with $\mathrm{Ph}_{2} \mathrm{P}(\mathrm{O}) \mathrm{H}$.

\section{Scheme 43}

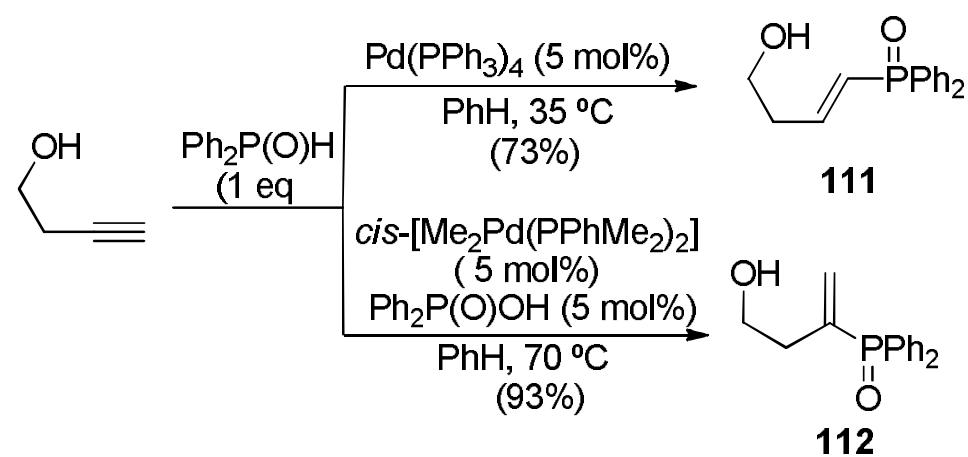


A recent example of the synthesis of $\mathrm{C}_{2}$-symmetric vinylphosphine oxides with regioselectivity towards the branched vinylphosphine oxide is shown in Scheme 40, where terminal alkynes such as phenylacetylene reacted with $(2 R, 5 R)-2,5-$ diphenylphospholane 1-oxide (113) in the presence of $\mathrm{Pd}\left(\mathrm{PPh}_{3}\right)_{4}(5 \mathrm{~mol} \%)$ in toluene as solvent at $80{ }^{\circ} \mathrm{C}$, to give enantiomerically pure branched-type vinylphosphine oxide 114 (Scheme 44). ${ }^{113}$ In addition, examples can be found of Markovnikov-type addition of diphenylphosphine oxide to terminal alkynes catalyzed by $\mathrm{Pd}(\mathrm{OAc})_{2}(5 \mathrm{~mol} \%)$ and $1,2-$ bis(diphenylphosphino)ethane (dppe, $8 \mathrm{~mol} \%$ ) in propionitrile as solvent at $100{ }^{\circ} \mathrm{C},{ }^{114}$ as well as the use of a diphosphine-hydrosilane binary systems that allows the regioselective synthesis of branched vinylphosphine oxides from terminal alkynes under $\mathrm{Pd}\left(\mathrm{PPh}_{3}\right)_{4}$ catalysis $(5 \mathrm{~mol} \%) .{ }^{115}$ Moreover, tetraphenyldiphosphine has been used in the hydrophosphinylation reaction of terminal alkynes catalyzed by $\mathrm{Pd}(\mathrm{OAc})_{2}(5 \mathrm{~mol} \%)$, leading to branched vinylated phosphine oxides after air-oxidation during work-up, ${ }^{116}$ and diphenylphosphine oxide has been used in a double addition to oct-1-yne using a $\mathrm{Zr}$ (or Hf)-Pd heterobinuclear system as catalyst, the preliminary branched and linear vinylated phosphine oxides being intermediates. ${ }^{117}$

\section{Scheme 44}

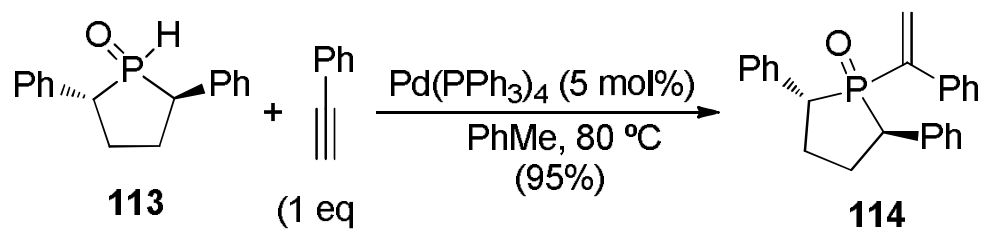

Enantiomerically pure Markovnikov-type vinylphosphinates, such as 116, have been regioselectively prepared (>95\% selectivity) by the hydrophosphinylation reaction of terminal alkynes, such as oct-1-yne, with (-)-menthyl $H$-phosphinate 115 catalyzed by the former combination cis-[ $\left.\mathrm{Me}_{2} \mathrm{Pd}\left(\mathrm{PPhMe}_{2}\right)_{2}\right](3 \mathrm{~mol} \%)-\mathrm{Ph}_{2} \mathrm{P}(\mathrm{O}) \mathrm{OH}(5 \mathrm{~mol} \%)$ (Scheme 45). ${ }^{118}$ Under these conditions, trimethylsilylacetylene afforded the linear $(E)$ isomer, probably for steric interactions, whereas an internal alkyne such as diphenylacetylene afforded the corresponding chiral phosphinate product of the synaddition. 


\section{Scheme 45}

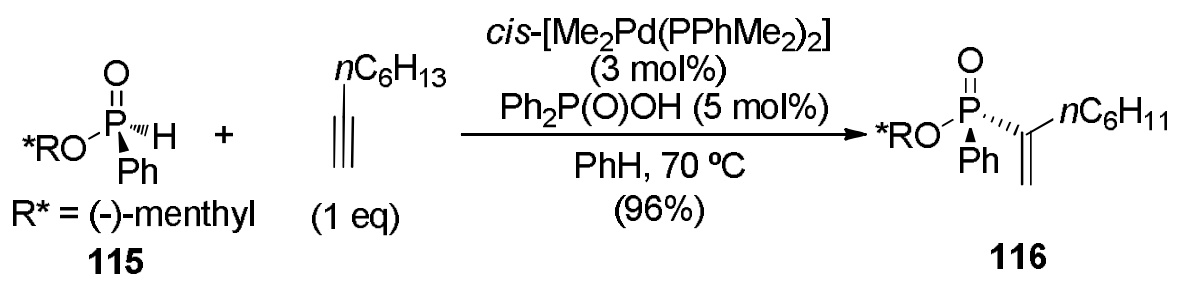

Ethyl phenylphosphinate has been used in the regioselective hydrophosphinylation of terminal alkynes catalyzed by the combination $\mathrm{Pd}(\mathrm{OAc})_{2}(5$ mol\%)/dppe $(7.5 \mathrm{~mol} \%)$ in toluene at $100{ }^{\circ} \mathrm{C}$, the branched Markovnikov-type branched vinylphosphinates obtained with regioselectivities generally higher than $94 \% .{ }^{119}$ In addition, hypophosphorous compounds $\mathrm{ROP}(\mathrm{O}) \mathrm{H}_{2}$ have been shown to add to terminal alkynes with a regioselectivity strongly dependent to the ligand in the catalytic palladium species. ${ }^{120}$ Thus, the use of $\mathrm{PdCl}_{2}\left(\mathrm{PPh}_{3}\right)_{2}{ }^{121}$ or $\mathrm{Pd}_{2}(\mathrm{dba})_{3} / \mathrm{dppf}^{122}$ favors the branched isomer, whereas the presence of the Xantphos ligand (80) favors the linear one with $(E)$-stereoselectivity. ${ }^{121,122}$ This is the case of the hydrophosphinylation of 3,3dimethylbut-1-yne with $n \mathrm{BuOP}(\mathrm{O}) \mathrm{H}_{2}$, which gave a reversal of the regioselectivity by changing the ligand, from branched phosphinate 117 (2.6/1 branched/linear ratio) to the linear one 118 (1/6.7 branched/linear ratio) (Scheme 46). ${ }^{122}$ These results have been justified by the different bite angle of the ligand in the palladium catalyst, as well as by stereoelectronic effects.

\section{Scheme 46}

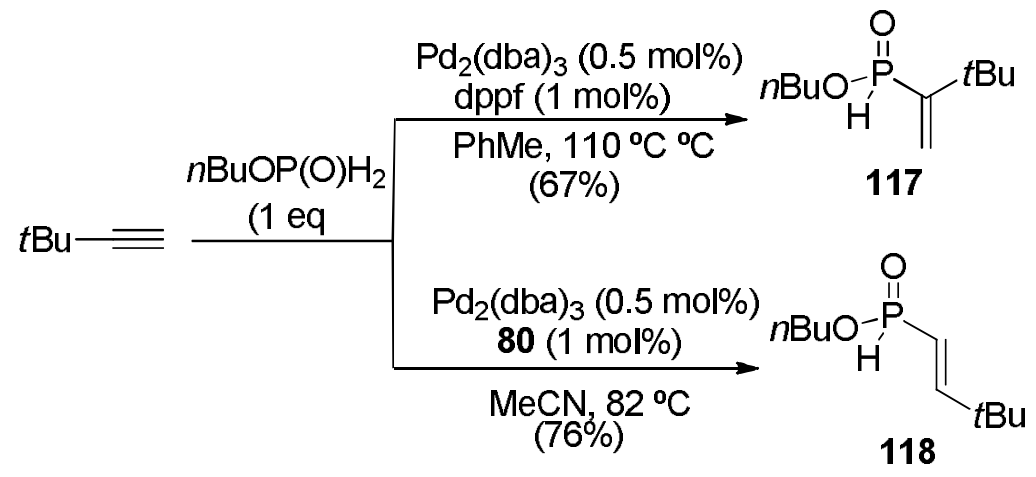

Alkenylphosphonates have been obtained by using the above mentioned palladium complex cis-[ $\left.\mathrm{Me}_{2} \mathrm{Pd}\left(\mathrm{PPhMe}_{2}\right)_{2}\right]$ as catalyst $(3 \mathrm{~mol} \%)$ in the addition of dimethylphosphonate to terminal alkynes (hydrophosphonylation) leading 
regioselectively to the branched vinylphosphonates. ${ }^{123}$ This procedure was improved by using commercial $\mathrm{Pd}_{2}(\mathrm{dba})_{3}$ as catalyst in the presence of triphenylphosphine, ${ }^{124}$ as exemplified in Scheme 47, where terminal alkynes, such as hept-1-yne, reacted with dialkylphosphonates, such as diisopropylphosphonate, under $\mathrm{Pd}_{2}(\mathrm{dba})_{3}(3 \mathrm{~mol} \%) / \mathrm{PPh}_{3}$ (12 mol\%) catalysis in the presence of TFA $(10 \mathrm{~mol} \%)$ in THF at $50{ }^{\circ} \mathrm{C}$, to give the corresponding vinylphosphonate 119. ${ }^{124 \mathrm{~b}}$ Following this procedure, an internal alkyne, such as hex-3-yne, gave the corresponding hydrophosphonylated compound with synaddition, whereas trimethylsilylacetylene gave the linear $(E)$-phosphonate. ${ }^{124 \mathrm{~b}}$ In addition, the combination $\operatorname{Pd}_{2}(\mathrm{dba})_{3} / \mathrm{Xantphos}(\mathbf{8 0})$ (2 mol\%) has been used as catalyst for the hydrophosphonylation of an internal alkyne such as oct-4-yne with hypophosphorous acid affording vinylated phosphonic acid 120 (Scheme 47). ${ }^{125}$ The process is a two-step procedure consisting of an initial hydrophosphinylation followed by oxidation by air.

\section{Scheme 47}

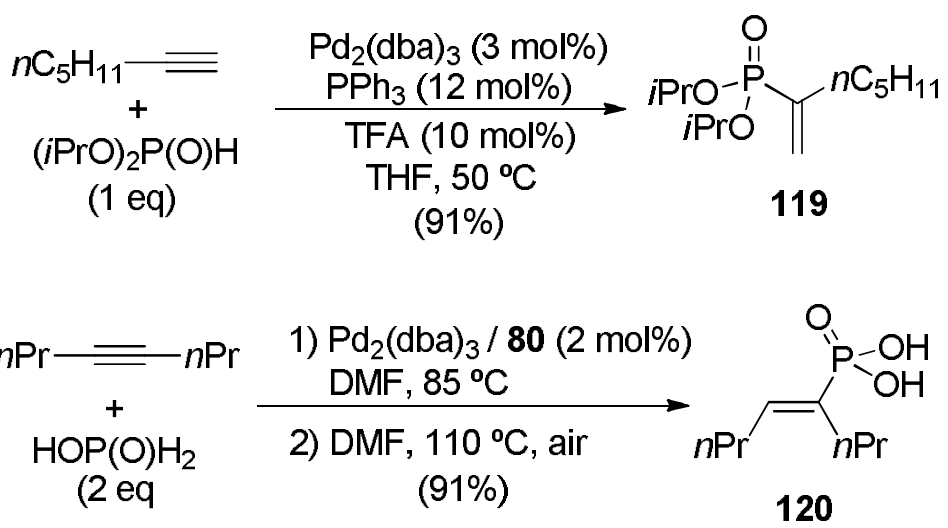

\section{Chemicals by Palladium-Catalyzed Intramolecular Additions to}

\section{Alkynes}

The intramolecular reaction of carbon and heteroatom nucleophiles to alkynes catalyzed by palladium species is a practical way of obtaining carbo- and hetero-cycles, respectively. Thus, if an alkyne contains an internal nucleophile, the coordination of the organopalladium species to the carbon-carbon triple bond, followed by cyclization produce a cyclic vinylpalladium adduct. Both endo and exo cyclization adducts can be obtained depending on the number of carbon atoms between the triple bond and the nucleophilic center. Reductive elimination produces the heterocyclic or carbocyclic 
product regenerating the catalyst. This approach is particularly important in the case of the palladium-catalyzed internal cycloaddition of heteroatoms to acetylenic systems, a huge array of heterocyclic systems being prepared in this way. In this section, examples of these internal cyclizations leading to carbo- and heterocycles will be shown.

\subsection{Carbocycles}

The intramolecular addition of enolates to alkynes under transition metal catalysis is a powerful tool to construct five-membered carbocyclic compounds bearing an olefinic moiety. ${ }^{126}$ The cyclization usually proceeds in a 5-exo-dig mode to provide methylenecyclopentanes starting from $\varepsilon, \zeta$-alkynyl carbonyl compounds, as exemplified in seminal works where compounds such as malonate-derived alkyne $\mathbf{1 2 1}$ are deprotonated with a substoichiometric amount of potassium tert-butoxide in the presence of a crown ether, and subsequently cyclized in the presence of a catalytic amount of $\mathrm{Pd}(\mathrm{dppe})_{2}(5 \mathrm{~mol} \%)$ in $\mathrm{THF}$ at $20{ }^{\circ} \mathrm{C}$ to give cyclopentane 122 (Scheme 48). ${ }^{127}$

\section{Scheme 48}

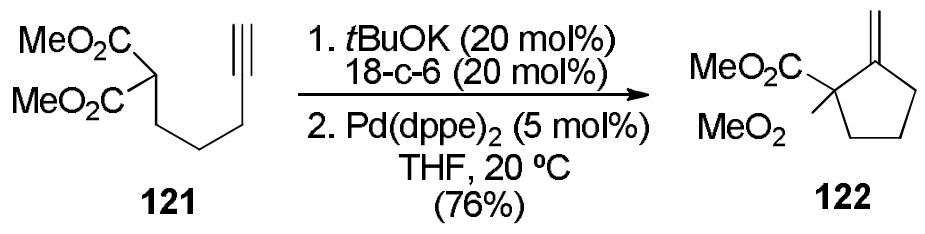

More recently, the use as catalyst of a combination of $\operatorname{Pd}_{2}(\mathrm{dba})_{3}(1.25 \mathrm{~mol} \%)$ and the ligand XPhos (123) (2.5 mol\%) in the presence of sodium hexamethyldisilazide and an organic halide, has allowed the 5-endo-dig cyclization of homopropargylsubstituted dicarbonyl compounds leading to 1,2-disubstituted cyclopentenes, as in the case of the preparation of cyclic system 125 from alkyne $\mathbf{1 2 4}$ and phenyl chloride (Scheme 49). ${ }^{128}$ In addition, this type of 5-endo-dig carboannulation is observed in arylative cyclizations leading to indenes, with structurally limited substrates activated by the conjugation of the aromatic ring. ${ }^{129}$ An example of this last process is represented in Scheme 49, where 2-[2-(2-phenylethynyl)phenyl]malonate (126) is cyclized in the 
presence of an aryl or vinyl halide such as phenyl iodide under $\operatorname{Pd}\left(\mathrm{PPh}_{3}\right)_{4}$ catalysis (5 $\mathrm{mol} \%$ ) and potassium carbonate as base in DMF at $100{ }^{\circ} \mathrm{C}$, affording indene $\mathbf{1 2 7} .{ }^{130}$

\section{Scheme 49}<smiles>CC(C)c1cc(C(C)C)c(-c2ccccc2C(C)C)c(C(C)C)c1</smiles>

123

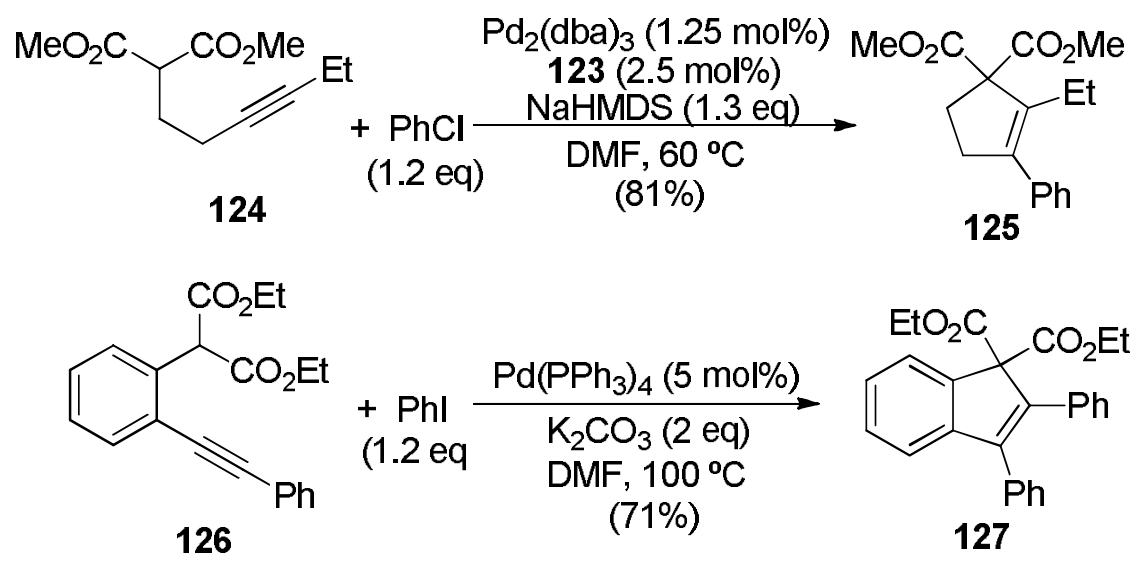

The intramolecular palladium(II)-catalyzed asymmetric cycloisomerization of enynes can be used for the synthesis of biaryls, which can be enantioselectively obtained when chiral ligands are employed. Thus, the use of $(R)$-Binap (6 mol\%) as ligand combined to $\mathrm{Pd}(\mathrm{MeCN})_{4}\left(\mathrm{BF}_{4}\right)_{2} \quad(5 \mathrm{~mol} \%)$ as palladium source in dichloroethane as solvent at $60{ }^{\circ} \mathrm{C}$ gave axially chiral biaryls with up to $99 \% e e$, the reactivity and enantioselectivity depending on the nature and position of substituent of the arene ring. ${ }^{131}$ Particularly, the enynes with an aryl group substituted by an $o$-methoxy group at alkyne terminus gave chiral biaryls with good enantioselectivity, as exemplified in the preparation of enantiomerically pure biaryl 129 from the cyclization of 128 (Scheme $50)$. 


\section{Scheme 50}<smiles>COc1cccc(C)c1C#Cc1ccccc1C1=CCCC1</smiles>

128
$\mathrm{Pd}(\mathrm{MeCN})_{4}\left(\mathrm{BF}_{4}\right)_{2}(5 \mathrm{~mol} \%)$ (R)-Binap (6 mol\%) $\mathrm{ClCH}_{2} \mathrm{CH}_{2} \mathrm{Cl}, 60^{\circ} \mathrm{C}$ (65\%)<smiles>COc1cccc(C)c1-c1cc2ccccc2c2c1CCC2</smiles>

$129(99 \%$ ee)

\subsection{Heterocycles}

The palladium-catalyzed cyclization of alkynes bearing a heteronucleophile has proven extraordinarily useful for the synthesis of a wide variety of heterocycles, ${ }^{30,32 c, d, 32 \mathrm{f}, 89 \mathrm{c}, 129}$ the process proceeding by coordination of the palladium species to the $\mathrm{C}-\mathrm{C}$ triple bond, followed by cyclization and reductive elimination. Both endo and exo cyclization products can be obtained depending on the number of carbon atoms between the triple bond and the nucleophilic center. Classic examples of this heterocyclic-leading process are the synthesis of five- and six-membered nitrogencontaining heterocycles by internal hydroamination, ${ }^{30 \mathrm{a}, 89 \mathrm{c}, 132}$ as in the intramolecular exo-dig aminopalladation of alkynylamines which gave intermediary alkenylpalladium compounds that hydrolyzed and isomerized to thermodynamically stable cyclic imines. ${ }^{133}$ Thus, treatment of 3-alkynylamines with a catalytic amount of $\mathrm{PdCl}_{2}(\mathrm{MeCN})_{2}$ (5 mol\%) gave exclusively 1-pyrrolines in good yields, whereas 5alkynylamines afforded 2,3,4,5-tetrahydropyridines, as shown in Scheme 51 with the preparation of tetrahydropyridine $\mathbf{1 3 1}$ from alkynylamine 130, after isomerization of the exo double bond. ${ }^{133 a}$ When 1-amino-3-alkyn-2-ols were cyclized under $\mathrm{PdCl}_{2}$ or $\mathrm{Pd}(\mathrm{OAc})_{2}$ catalysis $(5 \mathrm{~mol} \%)$ in refluxing $\mathrm{DMF}$, pyrroles were obtained upon cyclization and dehydration. ${ }^{134}$ This procedure can be made more versatile considering that it is possible to trap the intermediate alkenylpalladium species resulting from the intramolecular hydroamination with organic halides, in a tandem intramolecular aminopalladation/ cross-coupling reaction. This is the case of the stereodefined synthesis of 2-(alkylidene) piperidine 133, which was synthesized by treatment of acetylenic tosylated amine 132 with $n \mathrm{BuLi}$, followed by addition of a catalytic amount of $\mathrm{Pd}(\mathrm{OAc})_{2}(5 \mathrm{~mol} \%)$ and triphenylphosphine (10 mol\%) in THF and, finally, phenyl iodide (Scheme 51). ${ }^{135}$ 


\section{Scheme 51}
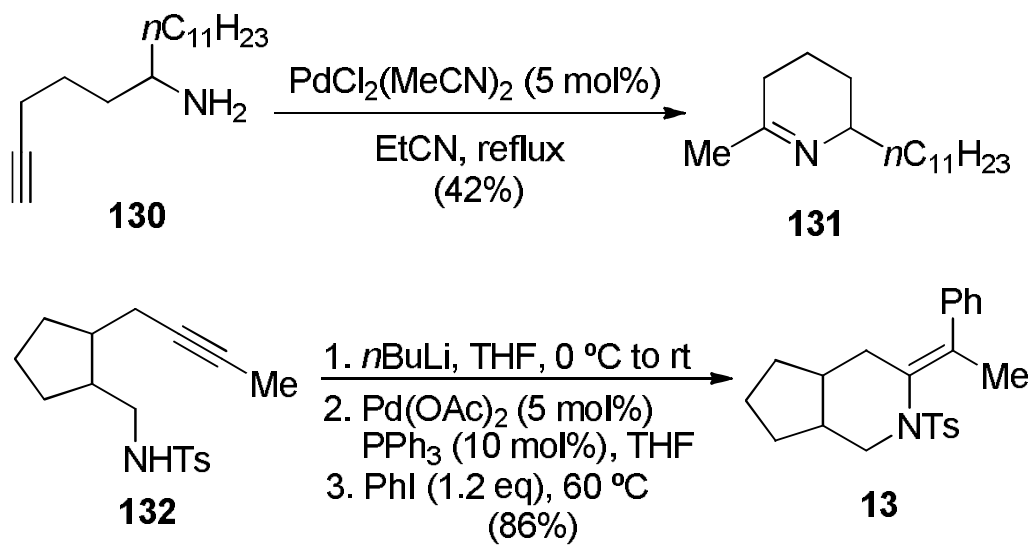

This intramolecular cyclization reaction to an alkyne has been one of the most frequently employed palladium-catalyzed methodologies for the synthesis of the already mentioned important indole system (see Section 3.2). ${ }^{30 \mathrm{~b}, 30 \mathrm{~d}, 32 \mathrm{c}-\mathrm{f}, 129}$ Thus, the palladiumcatalyzed intramolecular cyclization of $o$-alkynylated anilines allows the synthesis of the indole ring, an example being the preparation of 2-phenylindole (135) from $o$ alkynylated aniline $\mathbf{1 3 4}$ after treatment in open air with a catalytic combination of $\mathrm{PdCl}_{2}$ (1 $\mathrm{mol} \%)$ and $\mathrm{FeCl}_{3}(2 \mathrm{~mol} \%)$, as reoxidant of the formed palladium(0) to palladium(II), in dichloroethane (DCE) as solvent at $80{ }^{\circ} \mathrm{C}$ (Scheme 52). ${ }^{136}$ The internal cyclization with unprotected anilines can also be achieved using solid-supported palladium catalysts. $^{137}$ However, the use of unprotected anilines for this reaction is not so common, as usually lower conversions and high catalyst loadings are required. ${ }^{138}$ More frequent has been the use of $\mathrm{N}$-protected systems as starting materials, for instance in the form of trifluoroacetanilides, as exemplified in the synthesis of 2-methylindole (137) from $o$-alkynylated trifluroacetanilide 136 (Scheme 52). This reaction was catalyzed by $\mathrm{Pd}\left(\mathrm{PPh}_{3}\right)_{4}(2 \mathrm{~mol} \%)$ in the presence of a formate as reducing agent and takes place through and allenyl/propargylpalladium complex. ${ }^{139}$ Interestingly, when two nitrogenated functionalities are conveniently situated to both sides of the alkyne system, a palladium-catalyzed double cyclization has been observed. ${ }^{140}$ 


\section{Scheme 52}<smiles>Nc1ccccc1C#CP</smiles>

134

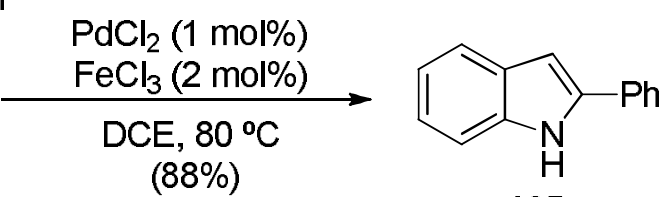

135

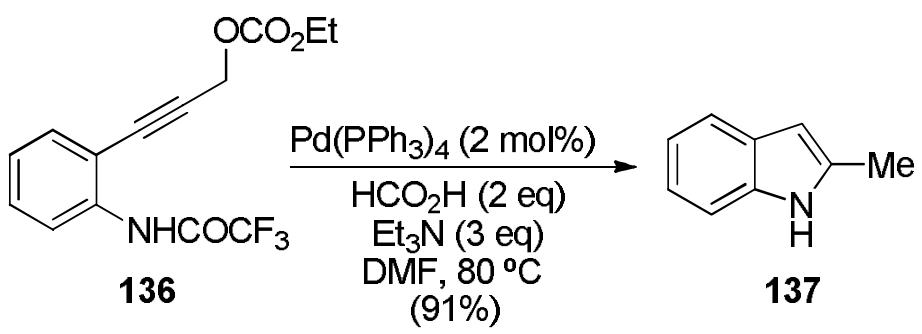

Furthermore, the indoles produced can be subsequently substituted at the 3position by trapping the intermediate cyclic alkenylpalladium complex, formed after the cyclization, with an organic electrophile. Examples of the use of this useful methodology with aryl/heteroaryl, ${ }^{141}$ alkyl, ${ }^{142}$ and alkynyl halides, ${ }^{143} \alpha$-iodoenones, ${ }^{144}$ aryl ${ }^{141 \mathrm{~d}}$ and vinyl triflates, ${ }^{141 \mathrm{a}, \mathrm{c}, \mathrm{e}}$ arenediazonium tetrafluoroborates, ${ }^{145}$ an allyl esters ${ }^{146}$ as electrophiles can be found. Arylboronic acids have also been employed, as in the case of the synthesis of 2,3-diphenylindole (139), which was obtained by cyclization of 2alkynyltrifluoroacetanilide 138 catalyzed by $\mathrm{Pd}(\mathrm{OAc})_{2}$ (5 mol\%)/dppp (5 mol\%) followed by an in situ cross-coupling with phenylboronic acid, the process being performed in the presence of potassium phosphate under an atmospheric pressure of oxygen, in methanol at $60{ }^{\circ} \mathrm{C}$ (Scheme 53). ${ }^{147}$ Recently, even allylic alcohols have been used for the incorporation of allyl moieties to the 3-position of 2-substituted indoles when using this 5-endo-dig cyclization. ${ }^{148}$

\section{Scheme 53}<smiles>O=C(Nc1ccccc1C#Cc1ccccc1)C(F)(F)F</smiles>

138

$$
\begin{array}{cc}
\mathrm{PhB}(\mathrm{OH})_{2} & \begin{array}{c}
\mathrm{Pd}(\mathrm{OAc})_{2}(5 \mathrm{~mol} \%) \\
\mathrm{dppp}(5 \mathrm{~mol} \%)
\end{array} \\
\begin{array}{c}
\mathrm{K}_{3} \mathrm{PO}_{4}(2 \mathrm{eq}) \\
\mathrm{MeOH}, 60 \text { 으 } \mathrm{C} \\
(65 \%)
\end{array}
\end{array}
$$<smiles>c1ccc(-c2[nH]c3ccccc3c2-c2ccccc2)cc1</smiles> 
The starting $o$-alkynylated aniline derivatives for these palladium-catalyzed indole syntheses are frequently prepared from terminal alkynes using the well-known palladium-catalyzed Sonogashira reaction (see Section 6.1). Therefore, it is suitable to in situ generate the $o$-alkynylated system from a terminal alkyne and an $o$-halogenated aniline derivative, and further perform the cyclization reaction. An example of the use of this indole synthesis is shown in Scheme 54, where $o$-iodinated trifluoroacetanilide 140 is converted into the intermediate alkynylated system 141 in the presence of phenylacetylene and a catalytic system formed by $\mathrm{Pd}(\mathrm{OAc})_{2}(5 \mathrm{~mol} \%)$ and triphenylphosphine (20 mol\%). This species cyclizes forming the alkenylpalladium 142, which gives 2,3-disubstituted indole 143 after reductive elimination. ${ }^{149}$ Recent examples of the preparation of more complex heterocycles using this strategy can be found, as in the case of the preparation of pyrrolo[3,2-c]quinoline derivatives by palladiumcatalyzed alkynylation/cyclization of 3-iodo-4(phenylamino)quinolines. ${ }^{150}$

\section{Scheme 54}
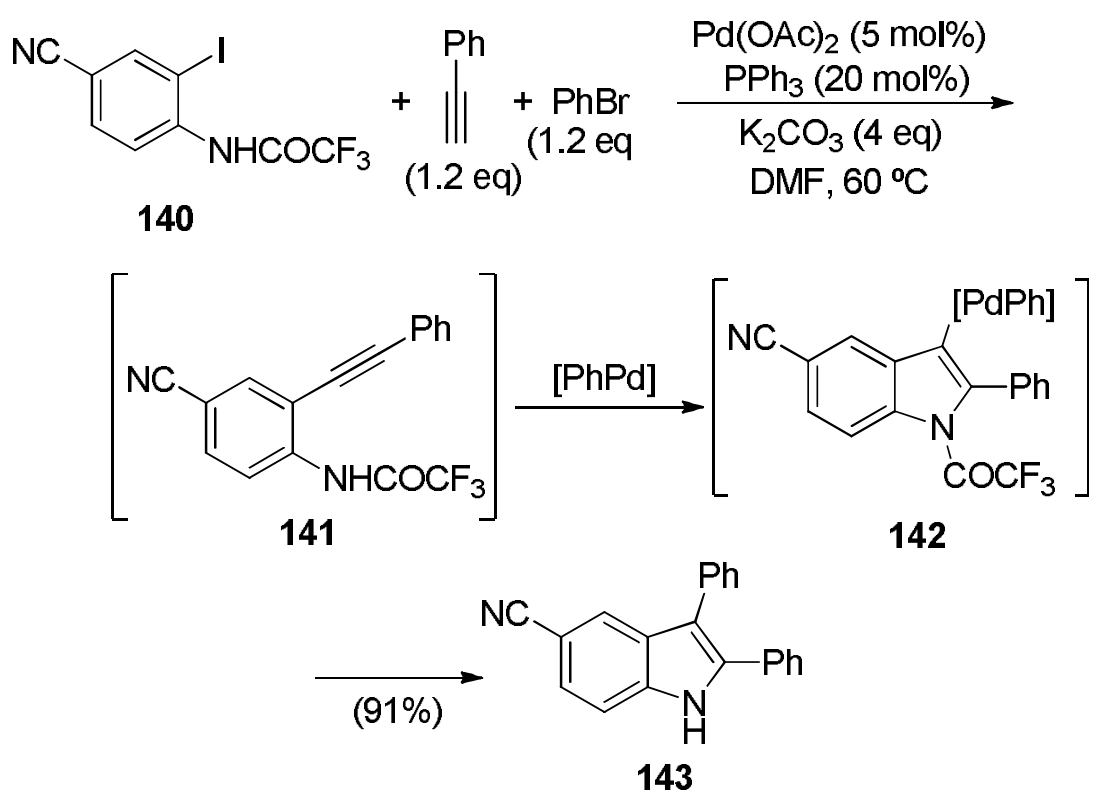

The intramolecular hydroalkoxylation reaction of alkynes with a close $\mathrm{OH}$ group has been more deeply studied than the intermolecular version (see Section 3.2). This reaction provides a straightforward methodology for the construction of oxygencontaining heterocycles. $^{30,129}$ Thus, a seminal work on this topic is the synthesis of bicyclic 2,3-dihydrofuran 145 by intramolecular hydroalkoxylation of alkynol 144, a process catalyzed by $\mathrm{PdCl}_{2}(5 \mathrm{~mol} \%)$ in refluxing acetonitrile (Scheme 55). ${ }^{132}$ However, 
3-, 4- and 5-alkyn-1-ols led to mixtures of the expected dihydrofurans and dihydropyrans and ketones resulting from the hydration of the triple bond. A similar procedure when applied to $\beta, \gamma$-acetylenic ketones or 2-methoxy-3-alkyn-1-ols afforded the corresponding furans in good yields. ${ }^{132}$ Other examples of the synthesis of furans are the palladium-catalyzed internal cyclization of (Z)-2-en-4-ynol, ${ }^{151}$ and the cyclization of 2-propargyl-1,3-dicarbonyl compounds such as $\mathbf{1 4 6}$ with vinyl and aryl triflates or halides, such as methyl $p$-iodobenzoate, under $\mathrm{Pd}\left(\mathrm{PPh}_{3}\right)_{4}$ catalysis $(5 \mathrm{~mol} \%)$ in the presence of potassium carbonate as base, which gave the 2,3,5-substituted furan 147 (Scheme 55). ${ }^{152}$

\section{Scheme 55}<smiles>CC(C)(C)CC#CCC1CCCC1O</smiles><smiles>C#CCC(C(C)=O)C(C)=O</smiles>
146<smiles>CC(=O)c1ccc(Cc2cc(C(C)=O)c(C)o2)cc1</smiles>

When $o$-alkynylated phenols are involved as starting materials, the corresponding benzofurans are obtained after a palladium-catalyzed intramolecular hydroalkoxylation. A recent example can be seen in Scheme 52, where 2-benzofuran (149) is obtained from $o$-alkynylated phenol 148 in a cyclization carried out in a flow reactor and catalyzed by PdNPs immobilized on mesoporous silica SBA-15, in the presence of iodobenzene dichloride as an oxidant, in toluene at room temperature (Scheme 56). ${ }^{153}$ In addition, an example of a further extension of this strategy to the synthesis of more complex systems is the preparation of tetrahydrodibenzofuran $\mathbf{1 5 1}$ by the usual intramolecular cyclization of alkynylated phenol 150 followed by an oxidative Heck reaction, this cascade process being catalyzed by $\mathrm{PdCl}_{2}(5 \mathrm{~mol} \%)$ in the presence 
of maleic anhydride as additive and potassium iodide in $\mathrm{DMF}$ at $100{ }^{\circ} \mathrm{C}$ in air (Scheme 56). ${ }^{154}$ Moreover, similarly than in the case of the synthesis of 2,3-disubstituted indoles, 2,3-disubstituted benzofurans can be prepared by cyclization of $o$-alkynylated phenols following by trapping the alkenylpalladium intermediate with unsaturated halides or triflates. ${ }^{155}$

\section{Scheme 56}<smiles>Oc1ccccc1C#CP</smiles>

148<smiles>CCOC(=O)/C=C/CCCC#Cc1ccccc1O</smiles>
150

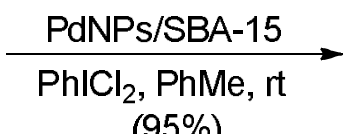
(95\%)

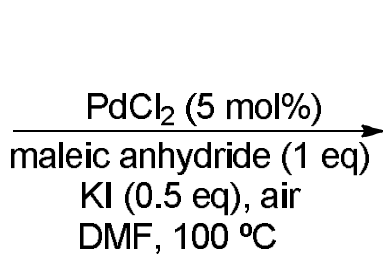

$(91 \%)$<smiles>c1ccc(-c2cc3ccccc3o2)cc1</smiles><smiles>CCOC(=O)/C=C1\CCCc2oc3ccccc3c21</smiles>

151

However, it has been more frequent to prepare these kind of benzocondensed systems from $o$-iodinated phenols and terminal alkynes by the above mentioned in situ palladium-catalyzed Sonogashira coupling (see Section 6.1) followed by intramolecular cyclization. ${ }^{155,156}$ An example is the preparation of benzofuran $\mathbf{1 5 4}$ by in situ formation of alkynylphenol intermediate 153 from iodophenol 152 and 2-methylbut-3-yn-2-ol under Sonogashira conditions, followed by intramolecular cyclization. The process is catalyzed by a combination of $\operatorname{Pd}(\mathrm{OAc})_{2}$ and a water-soluble phosphine such as $3,3^{\prime}, 3^{\prime \prime}-$ phosphinidynetris(benzenesulfonic acid (TPPTS), in the presence of triethylamine as base in aqueous acetonitrile as solvent at room temperature (Scheme 57). ${ }^{157}$ In addition, the use of a ligand and an amine can be avoided, using tetra- $n$-butyl acetate as base in acetonitrile as solvent under ultrasound irradiation. ${ }^{158}$ When this two-step Sonogashiracyclization methodology is performed starting from $o$-iodobenzoic acids, phthalide isobenzofuranones ${ }^{159}$ and 3 -substituted isocoumarins ${ }^{160}$ have been obtained. 


\section{Scheme 57}

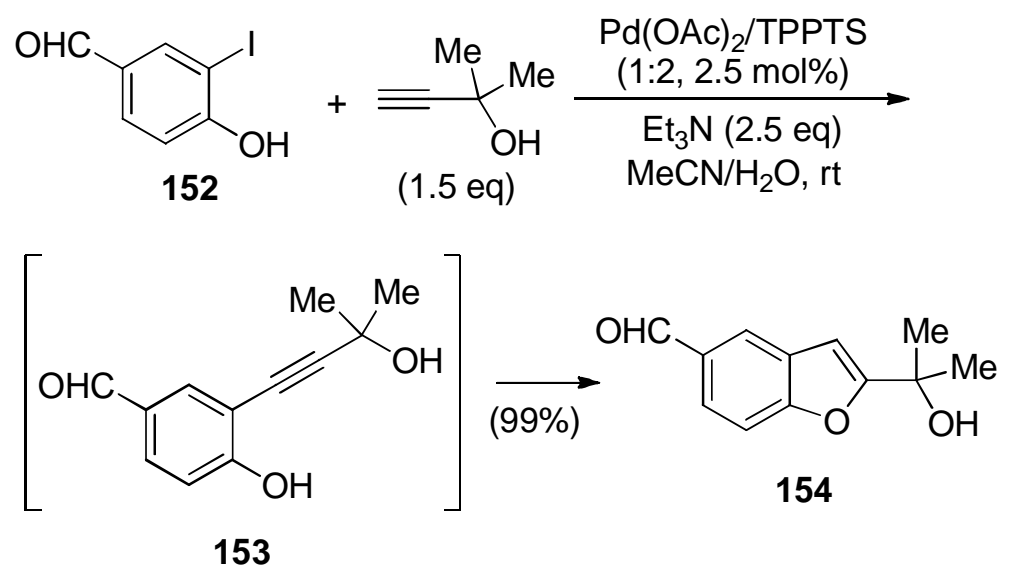

$1 H$-Isochromenes have been prepared from $o$-alkynylated benzaldehydes in a process catalyzed by $\mathrm{Pd}(\mathrm{OAc})_{2}(5 \mathrm{~mol} \%)$ in the presence of $p$-benzoquinone and an alcohol, in dioxane as solvent, as in the case of the synthesis of isochromene 156 from alkynylbenzaldehyde 155 (Scheme 58). ${ }^{161}$ This process has also been performed via the in situ Sonogashira/cyclization strategy, without isolation of the disubstituted alkyne intermediate, starting from 2-chloro-3-formylquinolines and leading to pyrano[4,3b]quinolines. ${ }^{162}$ In addition, indoles has been used as nucleophiles, instead of alcohols for this reaction. ${ }^{163}$ Moreover, 4-alkynoic acids can be transformed regio- and stereoselectively into $(E)$-butyrolactones by reaction with aryl or vinyl halides or triflates. ${ }^{164}$ The reaction is catalyzed by a combination of $\mathrm{Pd}(\mathrm{OAc})_{2}(5 \mathrm{~mol} \%)$ and triphenylphosphine $(5 \mathrm{~mol} \%)$ in the presence of tetra- $n$-butylammonium chloride (TBAC) and triethylamine in DMF at $60^{\circ} \mathrm{C}$, as shown in Scheme 58 with the preparation of butyrolactone 158 from pent-4-ynoic acid (157) and $p$-iodoanisole. Other more complex oxygenated systems, such as chromene quinoxalines have been recently prepared by alkynylation of phenol-containing 2-chlorinated quinoxalines with terminal alkynes under palladium-on-charcoal catalysis. ${ }^{165}$ 


\section{Scheme 58}<smiles>O=Cc1ccccc1C#CP</smiles>

155

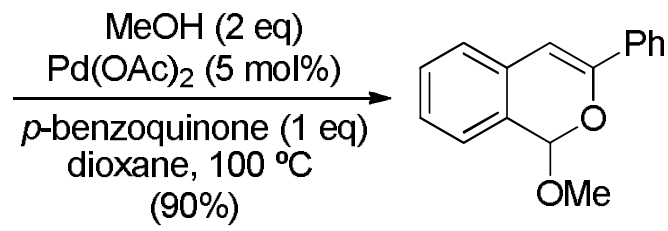

156

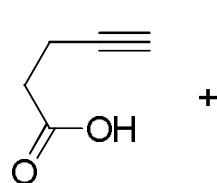

157<smiles>COc1ccc(I)cc1</smiles>

(0.67 eq)
$\mathrm{Pd}(\mathrm{OAc})_{2}(5 \mathrm{~mol} \%)$

$\mathrm{PPh}_{3}(5 \mathrm{~mol} \%)$

$n \mathrm{Bu}_{4} \mathrm{NCl}(1.5 \mathrm{eq})$

$\mathrm{Et}_{3} \mathrm{~N}(20 \mathrm{eq})$

DMF, $60^{\circ} \mathrm{C}$ (70\%)<smiles>COc1ccc(/C=C2\CCC(=O)O2)cc1</smiles>

158

\section{Chemicals by Palladium-Catalyzed Oxidation of Alkynes}

The carbon-carbon triple bond can be oxidized under palladium-catalyzed conditions, ${ }^{166}$ although this is a procedure much less explored than the corresponding oxidation of alkenes. The reactivity and selectivity of the reaction depends on the substitution of the triple bond, 1,2-diarylethynes being the most reactive. The main oxidation products are 1,2-diketones, esters or furans, depending on both the used procedure and the substrate. However, it is known that catalytic amounts of $\operatorname{Pd}\left(\mathrm{NO}_{3}\right)_{2}$ and $\mathrm{PdCl}_{2}$ in aqueous nitric acid can transform acetylene in oxalic acid and glyoxal, respectively, ${ }^{166 a}$ although these methodologies have not found practical uses. In this section, examples of palladium-catalyzed synthetic procedures leading to the above mentioned main type of chemicals are shown.

\subsection{1,2-Diketones}

The palladium-catalyzed oxidation of the carbon-carbon triple bond of internal alkynes, mainly diarylated acetylenes, leading to the corresponding 1,2-diketones has been carried out using DMSO as a solvent and an oxidant, in reactions catalyzed by 
$\mathrm{PdCl}_{2},{ }^{167} \mathrm{PdI}_{2}{ }^{168}$ or the combination $\mathrm{Pd}(\mathrm{OAc})_{2} / \mathrm{CuBr}_{2} .{ }^{169}$ Other procedures that combine DMSO and molecular oxygen as dual oxidants using $10 \% \mathrm{Pd} / \mathrm{C}(10 \mathrm{~mol} \%)$ as catalyst can be used, as shown in the typical formation of benzil (159) from diphenylacetylene (Scheme 59). ${ }^{170}$ It is necessary to note that all these DMSO-containing oxidation procedures produce unpleasant dimethylsulfide as oxidation residue. Therefore, other oxidants have also been used, as in the recent oxidation of diarylalkynes catalyzed by $10 \% \mathrm{Pd} / \mathrm{C}(10 \mathrm{~mol} \%)$, where pyridine $N$-oxide has been used as oxidant and solvent, the supported catalyst being recovered by filtration and reused up to five times. ${ }^{171}$

\section{Scheme 59}

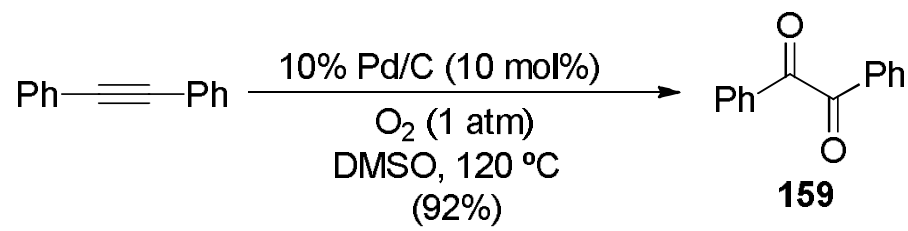

A Wacker-type oxidation of alkynes has been developed using as catalyst the combination $\mathrm{PdBr}_{2}(5 \mathrm{~mol} \%)-\mathrm{CuBr}_{2}(10 \mathrm{~mol} \%)$ using molecular oxygen as oxidant in aqueous dioxane as solvent. ${ }^{172}$ As usual, almost all the examples of alkynes reported following this procedure are diarylacetylenes, although there is an example using the dialkylated acetylene 160 which is also oxidized to 1,2-diketone 161 (Scheme 60). Moreover, the mixture $\mathrm{PdCl}_{2}(5 \mathrm{~mol} \%)-\mathrm{CuCl}_{2}(5 \mathrm{~mol} \%)$ has been used as catalytic mixture in the oxidation of diarylacetylenes and some alkylphenylacetylenes to the corresponding diketones, the reaction being performed in PEG-400 in the presence of water at room temperature. ${ }^{173}$

\section{Scheme 60}

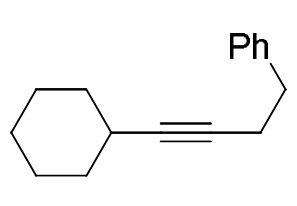

160

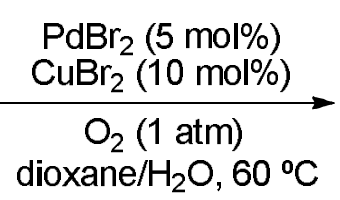

(41\%)<smiles>O=C(CCc1ccccc1)C(=O)C1CCCCC1</smiles>

16 


\subsection{Esters}

Esters can be formed by oxidative cleavage of alkynes under palladium catalysis in the presence of an alcohol. ${ }^{174}$ The reaction proceeds using $\mathrm{Pd}(\mathrm{OAc})_{2}(2 \mathrm{~mol} \%)$ as catalyst in the presence of $\mathrm{ZnCl}_{2} \cdot 2 \mathrm{H}_{2} \mathrm{O}(20 \mathrm{~mol} \%)$ under oxygen pressure (7.5 bar), using the alcohol as solvent at $100{ }^{\circ} \mathrm{C}$, as in the case of the oxidative cleavage of di- $p$ tolylacetylene (81) in methanol, which afforded the corresponding methyl ester $\mathbf{1 6 2}$ (Scheme 61). Unsymmetrical diaryl- and alkyl aryl acetylenes gave mixtures of both esters, whereas terminal alkynes gave only esters from the substituted side.

\section{Scheme 61}

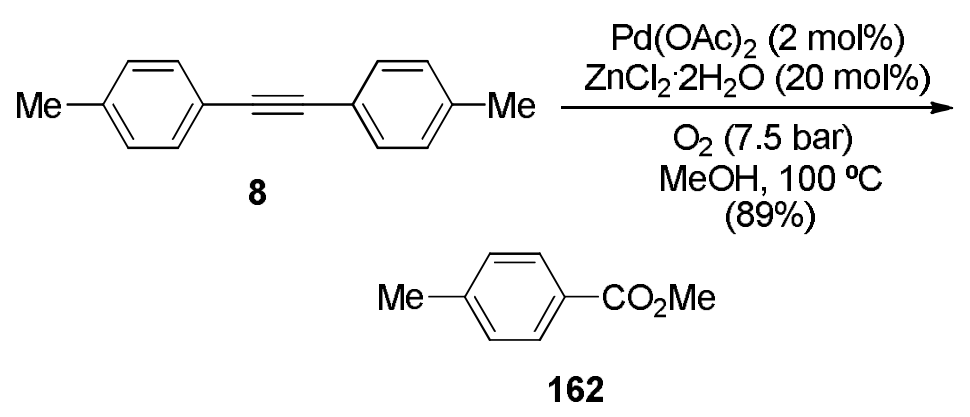

\subsection{Furans}

Related to the oxidative cleavage of alkynes to esters, ${ }^{174}$ it was discovered that under similar reaction conditions, but using zinc(II) triflate ( $3 \mathrm{~mol} \%$ ) as Lewis acid, diarylalkynes where transformed into tetrasubstituted furans. ${ }^{175}$ The process probably takes place through formation of the corresponding 1,2-diketone, which suffers Lewis acid-promoted cyclocondensation. An example of this reaction is shown in Scheme 62, with the formation of furan $\mathbf{1 6 3}$ by oxidation-cyclocondensation of di- $p$-tolylacetylene (81). In addition, tetrasubstituted furans from diarylalkynes have also been obtained in a reaction catalyzed by $\mathrm{PdCl}_{2}$ in DMA ( $N, N$-dimethylacetamide) $-\mathrm{H}_{2} \mathrm{O}$ as solvent under an oxygen atmosphere, ${ }^{176}$ as well as using $\operatorname{Pd}(\mathrm{OAc})_{2}$ as catalyst and a fluorous biphasic system of DMA and perfluorodecalin as solvent under oxygen. ${ }^{177}$ 
Scheme 62

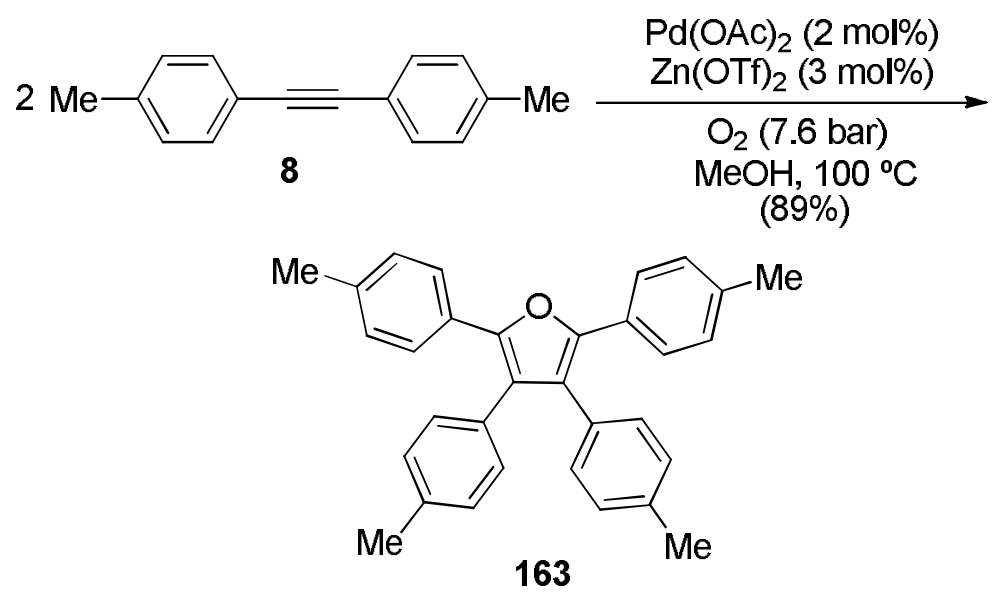

\section{Olefins by Palladium-Catalyzed Reduction of Alkynes}

The catalytic reduction by partial hydrogenation (semi-hydrogenation) of internal alkynes is an efficient method for the production of olefins, and palladium catalysts have been the most effective achieving this transformation. ${ }^{178}$ This reaction, particularized in the case of the semi-hydrogenation of acetylene to ethylene, is applied, for instance, into the industrial polymerization of ethylene to polyethylene in order to purify the feedstock from acetylene, which would otherwise poison the polymerization catalyst. ${ }^{179}$ Thus, research on new palladium species for the catalytic semihydrogenation of acetylene to ethylene is a subject of present industrial interest. ${ }^{180}$

The semi-hydrogenation of alkynes is problematic because the reaction is often accompanied by isomerization and/or over-reduction of the alkenes formed with the same catalysts. Commonly, palladium is not employed alone. Instead the reaction is promoted by a second metal, ${ }^{179 a}$ termed also as a co-catalysts or just as a promoter, which slightly modifies the activity, selectivity and stability of the catalyst. These promoters can be metals of group $11(\mathrm{Cu}, \mathrm{Ag}, \mathrm{Au})$, sp metals or semi-metals (Pd, Sn, $\mathrm{Bi}$, Ga among others), and group 1 metal ions (Na, K). ${ }^{181}$ In addition, a selectivity or process modifier is added, such as carbon monoxide, amines, nitriles, alkali and sulfur compounds, which are species able to coordinate the palladium modifying its reactivity. ${ }^{179 a, 182}$ Studies of the gas-phase hydrogenation of alkynes on solid palladium catalysts have shown strong modifications in the near-surface region of palladium, in which carbon (from fragmented feed molecules) occupies interstitial lattice sites forming a palladium carbide. Much less carbon is dissolved in palladium during 
unselective, total hydrogenation, and this process proceeds on hydrogen-saturated $\beta$ hydride, whereas selective hydrogenation is only possible after decoupling bulk properties from the surface events. ${ }^{183}$ Thus, the population of subsurface sites of palladium by either hydrogen or carbon, governs the hydrogenation events on the surface.

The Lindlar catalyst $\left[\mathrm{Pd} / \mathrm{CaCO}_{3}\right.$ and $\mathrm{Pb}(\mathrm{OAc})_{2}$, in conjunction with quinoline], is an old an effective system for the semi-hydrogenation of internal alkynes to the corresponding (Z)-alkenes, ${ }^{184}$ although it has disadvantages, such as the use of environmentally unfriendly $\mathrm{Pb}(\mathrm{OAc})_{2}$ during the catalyst preparation, and that generally it cannot be used for the semi-hydrogenation of terminal alkynes. Therefore, a variety of palladium-based catalyst systems, mainly heterogeneous, ${ }^{178 c, d}$ but also homogeneous, ${ }^{178 b}$ have been studied for this palladium-catalyzed semi-hydrogenation of acetylenes to olefins. Particularly, the development of catalytic systems based on specifically created supported PdNPs for this semi-hydrogenation reaction has been frequent in the last years, as the catalytic behavior of supported PdNPs vary considerably in terms of both the size of the particles and their interaction with the support. ${ }^{185}$ For instance, it has been shown that larger particles are more selective to semi-hydrogenation. ${ }^{186}$

Palladium(0) has been supported on different materials for achieving this reductive transformation. Thus, mono- and bi-metallic palladium and tungsten catalyst were supported over alumina and used in the partial hydrogenation of hept-1-yne (substrate/palladium: 1,100 molar ratio) under a hydrogen pressure of 1.5 bar in toluene at $30{ }^{\circ} \mathrm{C}$, bimetallic PdW species affording better results. ${ }^{187}$ In addition, palladium $(0)$ supported on $\mathrm{ZnO}$ and a palladium-zinc alloy, have been used as catalyst in the gasphase semi-hydrogenation of pent-1-yne, achieving suppression of the total hydrogenation to the corresponding alkane, contrary to when using palladium( $(0)$ on silica gel as catalyst. ${ }^{188}$ However, it has been shown that the addition of small amounts of DMSO to a $\mathrm{Pd} / \mathrm{SiO}_{2}$ catalyst suppresses this over-hydrogenation and isomerization of alkenes, probably due to preferential adsorption of DMSO compared to alkene products. This supported catalyst has been then applied to both internal alkynes and terminal alkynes, as shown in the semi-hydrogenation of $\mathbf{1 6 4}$ to give alkene $\mathbf{1 6 5}$ (Scheme 63). ${ }^{189}$ The catalyst was separable from the reaction mixture after the hydrogenation and reusable without loss of its high catalytic activity or selectivity. Moreover, palladium(0) has been deposited on the surface of $\mathrm{SiO}_{2}-\mathrm{Al}_{2} \mathrm{O}_{3}$ in an 'eggshell' distribution through 
the reduction of palladium salts by solution-phase carbon monoxide. ${ }^{190}$ This distribution, compared to a uniformly impregnated catalyst, had significant catalyst activity in the gas-phase partial hydrogenation of phenylacetylene, an important industrial process in polystyrene production to eliminate alkyne traces which poison the polymerization catalysts. This process has also been achieved in liquid-phase by using $1 \%$ palladium(0) supported on $\mathrm{TiO}_{2}$, achieving moderate to high selectivity towards styrene (86-90\%) at complete conversion, the process being carried out under an hydrogen pressure of 1-5 bar, in ethanol at room temperature. ${ }^{191}$

\section{Scheme 63}

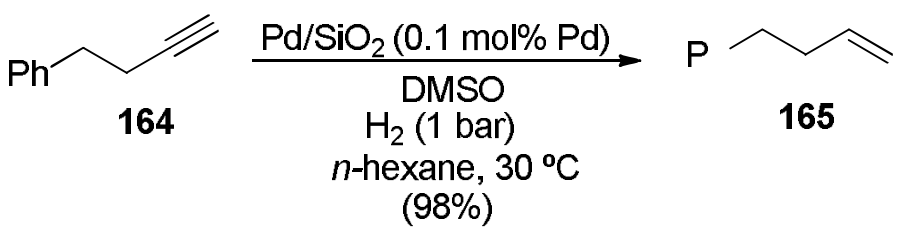

Graphite oxide has also been used as a supporting material for PdNPs of controlled crystallite size, and this material has been used as a catalyst (substrate/catalyst: 2,500-10,000 ratio) in the liquid-phase partial hydrogenation of internal alkynes (10 bar, $25^{\circ} \mathrm{C}$ ), affording selectivities for the cis-alkenes ranging from 83 to $98 \%$. Recently, palladium(0) supported on boron nitride ( $\mathrm{Pd} / \mathrm{BN})$ has been applied as catalyst in the presence of diethylenetriamine (DETA) to the semi-hydrogenation of terminal and internal alkynes to furnish the corresponding olefins, as exemplified in the very effective partial hydrogenation of estrone-derived alkyne 166 to compound 167 (Scheme 64). The reaction has been performed under an atmospheric pressure of hydrogen in methanol at room temperature and resulted in a very high cis-selectivity when internal alkynes were involved. ${ }^{192}$ 


\section{Scheme 64}
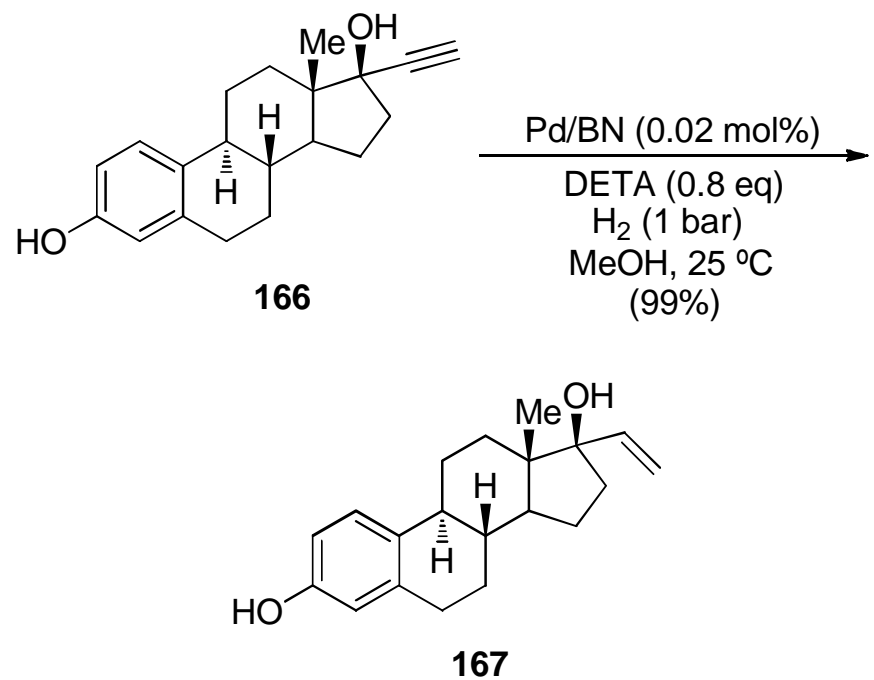

The BASF company recently developed a technology $\left(\text { NanoSelect }{ }^{\mathrm{TM}}\right)^{193}$ that allows the preparation of the now commercially available colloidal palladium $(0)$ on water-wet activated carbon (NanoSelect LF 100) or titanium silicate (NanoSelect LF 200), these materials acting as catalyst for the selective hydrogenation of alkynes to alkenes, its results being comparable to the Lindlar catalyst. In addition, palladium on carbon $(20 \% \mathrm{w} / \mathrm{w})$ has been employed as catalyst for the partial hydrogenation of internal and terminal alkynes using the Hantzsch ester (168) as hydrogen donor. ${ }^{194}$ The reaction was performed in refluxing ethanol as solvent, as shown in Scheme 65 in the stereoselective preparation of the (Z)-allylic alcohol 169 from 3-phenylprop-2-yn-1-ol, other functionalized systems such as phenylpropiolic acid and its methyl ester giving also good results, although terminal alkynes gave rise to rather low yields. Furthermore, PdNPs modified with subsurface carbon via blending a glucose precursor, have been used as catalyst in the liquid-phase hydrogenation of 3-hexyn-1-ol under hydrogen (3 bar) in isopropanol at $30{ }^{\circ} \mathrm{C}$, achieving $92 \%$ selectivity towards the corresponding alkene in a $10.8 \mathrm{Z} / \mathrm{E}$ ratio. ${ }^{195}$ Interestingly, the use of commercial $5 \% \mathrm{Pd} / \mathrm{C}$ as catalyst under these conditions gave no selectivity at all towards the alkene. 


\section{Scheme 65}<smiles>COC(=O)C1=C(C)NC(C(C)=O)=C(C)C1</smiles>

168

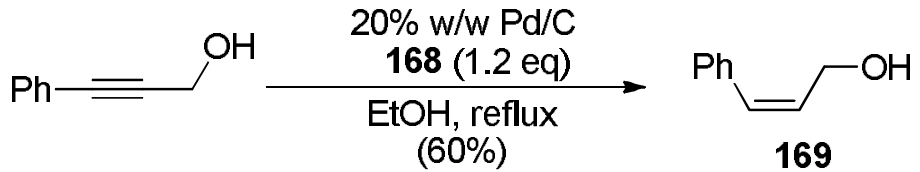

PdNPs have been supported on other carbonaceous materials apart from activated carbon, such as carbon black and multiwall carbon nanotubes, and have been used as recyclable catalysts for the gas-phase semi-hydrogenation of phenylacetylene, those supported on carbon nanotubes giving the highest selectivity (ca. 96\%), their activity remained intact after five reuse cycles. ${ }^{196}$ Carbon nanofibers (CNF) have also been employed as support for PdNPs, acting as catalyst in the liquid phase semihydrogenation of 1-pentyl-3-ol, ${ }^{197}$ whereas when doped with nitrogen (Pd-N-CNF, $1 \%$ $\mathrm{Pd}$, substrate/catalyst: 2,000) allowed the selective cis-hydrogenation of internal alkynes, working at atmospheric pressure of hydrogen in ethyl acetate as solvent at room temperature, as in the hydrogenation of ethyl phenylpropiolate to the corresponding (Z)-alkene 170 (Scheme 66). ${ }^{198}$ Moreover, palladium loaded in detonation nanodiamond has been explored as catalyst in the semi-hydrogenation of diphenylacetylene under molecular hydrogen (20 bar) in methanol at $50{ }^{\circ} \mathrm{C}$, although its selectivity cis-stilbene to 1,2-diphenylethane was low. ${ }^{199}$

\section{Scheme 66}

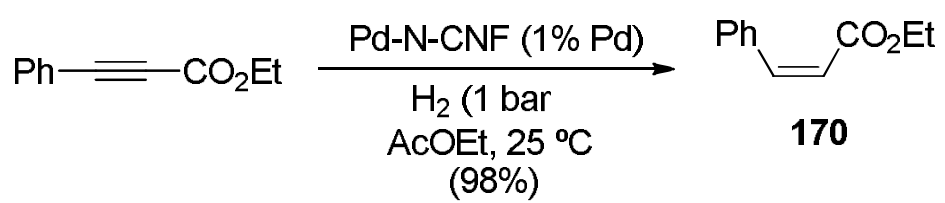

Polymers have also been used for supporting PdNPs formed by impregnation of the polymer with palladium(II) salts and further reduction. For example, hypercrosslinked polystyrene-containing PdNPs has been used as catalysts in the selective hydrogenation of terminal acetylene alcohols ( 1 bar $\mathrm{H}_{2}$ pressure, toluene, $25^{\circ} \mathrm{C}$ ), these nanocomposites 
showing high selectivity (up to $98.5 \%$ at $100 \%$ conversion) towards the corresponding terminal olefins. ${ }^{200}$ However, more abundant examples where the polymer contains nitrogenated groups can be found, as nitrogen atoms can act as modifiers of the activity of the palladium species. Thus, PdNPs have been supported on polyaniline and employed as catalyst $(1 \mathrm{~mol} \%)$ in the hydrogenation of diphenylacetylene and ethyl phenylpropiolate, the reaction being performed under hydrogen atmosphere (1 bar) in methanol at room temperature. ${ }^{201}$ In the former case, Z-stilbene was the main product (12\% of 1,2-diphenylmethane byproduct is obtained), commercial $10 \% \mathrm{Pd} / \mathrm{C}$ affording just 1,2-diphenylethane from total hydrogenation, whereas much less selectivity was observed in the last case. In addition, PdNPs supported on polyethyleneimine (10\% wt Pd-PEI) have resulted very effective and (Z)-selective as catalyst in the partial hydrogenation of internal and terminal alkynes, working under an atmospheric pressure of hydrogen in a 1:1 mixtures of methanol/dioxane or methanol/ethyl acetate as solvents at room temperature, ${ }^{202}$ as in the case of the semi-hydrogenation of propargylated diol 171 to the corresponding dihydroxylated (Z)-alkene 172 (Scheme 67). ${ }^{202 a}$ Moreover, gel-type co-polymeric resins obtained by polymerization of glycidyl methacrylate, styrene and ethylene glycol dimethacrylate, and functionalized with amine groups have been used as supports for PdNPs, acting this material as catalyst with low palladium content (0.5- $1 \mathrm{wt} \% \mathrm{Pd})$ for the partial hydrogenation of alkynes such as 2-butyne-1,4diol or phenylacetylene, the catalyst being recycled up to four times keeping its reactivity. ${ }^{203}$ Finally, examples of nitrogenated dendron-stabilized PdNPs for the semihydrogenation of internal alkynes ${ }^{204}$, as well as PdNPS stabilized on DNA from salmon or calf for the partial hydrogenation of 3-butyne-2-ol ${ }^{205}$ can be found.

\section{Scheme 67}
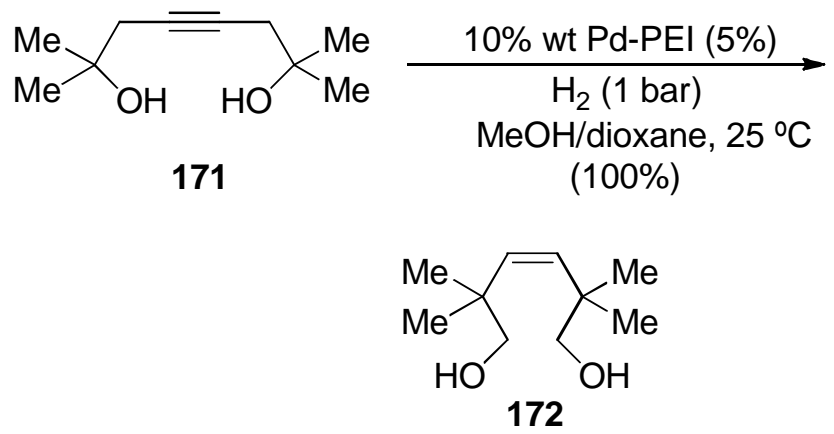
The use of homogeneous conditions in the palladium-catalyzed syn-semihydrogenation of alkynes leading to alkynes is less frequent, ${ }^{178 b}$ although examples of the use of bisphosphine-containing complexes of palladium employed in alkyne semihydrogenation reactions can be found. ${ }^{206}$ An uncommon $(E)$-selectivity for the corresponding olefin in the partial reduction of internal alkynes by transfer hydrogenation has been achieved with $\mathrm{PdCl}_{2}(\mathrm{dppf})(1.5 \mathrm{~mol} \%)$ as catalyst and $\mathrm{CuSO}_{4}$ as modifier, using $\mathrm{HSiEt}_{3}$ as hydrogen donor in refluxing aqueous toluene. Under these conditions, the corresponding $(E)$-alkenes were the main products, as in the case of the reduction of diphenylacetylene, leading to trans-stilbene (173) (Scheme 68). ${ }^{207}$ Interestingly, in the absence of the $\mathrm{CuSO}_{4}$ modifier, the cis-product was mainly obtained, suggesting that $\mathrm{CuSO}_{4}$ induces isomerization of the nascent cis-isomer. In addition, it has been shown in a transfer semihydrogenation of alkynes catalyzed by $\operatorname{Pd}_{2}(\mathrm{dba})_{3}(1 \mathrm{~mol} \%) / \mathrm{dppb}(2-4 \mathrm{~mol} \%)$ that, by changing the hydrogen donor from formic acid to $25 \%$ aqueous formic acid in dioxane at $80{ }^{\circ} \mathrm{C}$, the stereoselectivity of the process can be switched from $Z$ to $E$, again through an in situ $Z / E$ isomerization. ${ }^{208}$ Although both transfer hydrogenation methods mostly provide excellent $E$-selectivities and yields, their dependence on a $Z / E$ isomerism largely restricts the substrate scope to internal, conjugated alkynes, nonconjugated internal alkynes giving rather poor stereoselectivity.

\section{Scheme 68}

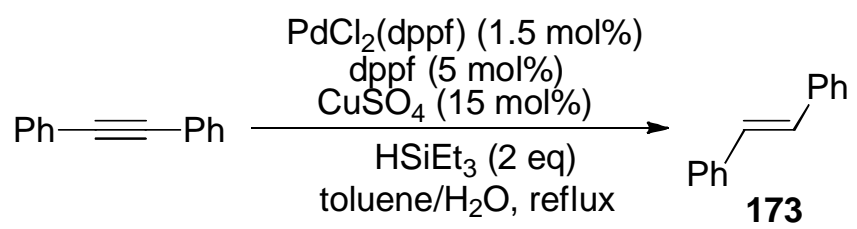

$(99 \%)$

Examples of the use of palladium-NHC complexes as catalysts in the semihydrogenation of alkynes can also be found. Thus, the NHC-complex 174 has been used as catalyst $(0.25 \mathrm{~mol} \%)$ in the reduction of diphenylacetylene to cis-stilbene and also in the partial hydrogenation of fluorenol-derived terminal alkyne 175 to olefin 176 (Scheme 69), the reaction being carried out under at atmospheric pressure of hydrogen in $\mathrm{MeOH}$ at room temperature. ${ }^{209}$ Other examples of the use of zero-valent palladiumNHC complexes as catalysts for the transfer semi-hydrogenation of terminal ${ }^{210}$ and internal ${ }^{210,211}$ alkynes, using $\mathrm{HCO}_{2} \mathrm{H}$ as hydrogen source have been reported. Recently, even ammonia-borane has been used as hydrogen donor for the cis-semihydrogenation 
of a couple of symmetric internal alkynes, using a very low loading (0.05-0.25 mol\%) of a zero-valent palladium-NHC complex as catalyst. ${ }^{212}$

\section{Scheme 69}<smiles>C#CC1(O)c2ccccc2-c2ccccc21</smiles>

175<smiles>CC(C)c1cccc(C(C)C)c1N1CCN(c2c(C(C)C)cccc2C(F)(F)F)C1=[PH](C(F)(F)F)C(F)(F)F</smiles>

174

$174(0.25 \mathrm{~mol} \%)$

$\mathrm{H}_{2}$ (1 bar)

$\mathrm{MeOH}, 25^{\circ} \mathrm{C}$

$(95 \%)$<smiles>C=CC1(O)c2ccccc2-c2ccccc21</smiles>

176

Excellent results have been achieved in the stereoselective partial hydrogenation of internal alkynes using the simple ligand-free $\mathrm{Pd}(\mathrm{OAc})_{2}$ as catalyst $(2 \mathrm{~mol} \%)$ and $\mathrm{DMF} / \mathrm{KOH}$ as hydrogen source at $145^{\circ} \mathrm{C}$, a methodology applied to the synthesis of analogues of cis-combretastatin A-4, such as (Z)-alkene 178 from the reduction of diarylacetylene 177 (Scheme 70). ${ }^{213}$

\section{Scheme 70}

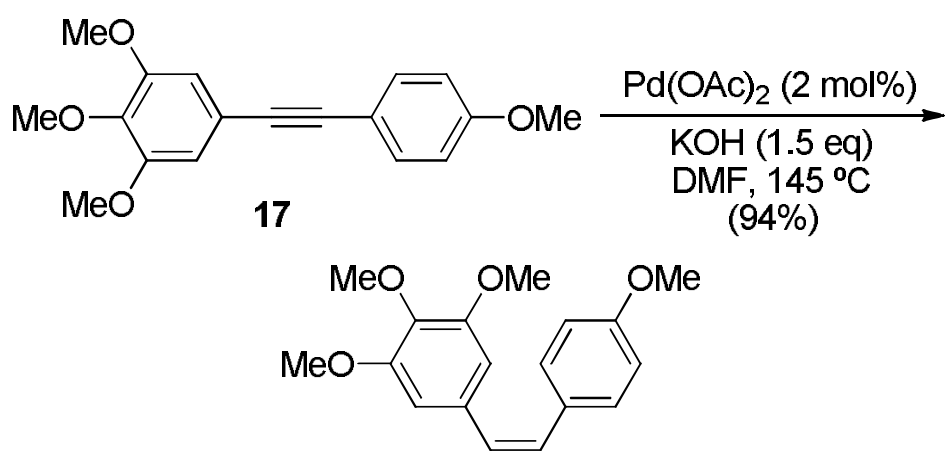

178

Solubilized PdNPs, created from $\mathrm{Pd}(\mathrm{OAc})_{2}$ and potassium tert-butoxide in $\mathrm{DMF}$ at room temperature, and stabilized by the presence of tetra- $n$-butylammonium borohydride, have been employed in the semi-hydrogenation of terminal and internal alkynes such as oct-4-yne, with a substrate/Pd ratio as high as 200,000:1 under a 
hydrogen atmosphere ( 8 bar) in THF at $30{ }^{\circ} \mathrm{C}$, to give $(Z)$-oct-4-ene (179) in $>99 \%$ content and complete conversion (Scheme 71), the absence of tetra- $n$-butylammonium borohydride leading to partial over-reduction of the alkene. ${ }^{214}$ In addition, differently shaped palladium nanocrystals with controlled size have been assayed in selective alkyne semi-hydrogenations, such as nanohexagons and nanospheres ${ }^{215}$ or nanocubes ${ }^{216}$ for the hydrogenation of 2-methyl-3-butyn-2-ol to the corresponding alkene, the nanocrystals shape becoming in important factor in the selectivity of the process.

\section{Scheme 71}

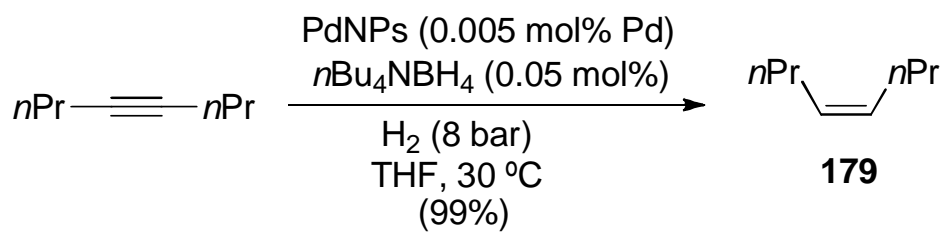

The reaction of $\mathrm{PdCl}_{2}$ dispersed in $\mathrm{TBAB}$ with tri- $n$-butylamine at $120^{\circ} \mathrm{C}$ led to stable isolable PdNPs which have been dispersed in an ionic liquid or in methanol or used in solventless conditions for the cis-selective hydrogenation of 2-hexyne ( 2 bar of hydrogen and $20^{\circ} \mathrm{C}$ ), the use of $[\mathrm{bmim}]\left[\mathrm{BF}_{4}\right]$ as ionic liquid allowing the recycle of the catalyst up to four times keeping the reaction rate. ${ }^{217}$ In addition, mono-dispersed PdNPs have been prepared in ionic liquids and employed in the semi-hydrogenation of internal and terminal alkynes, the system being suitable for recycling affording similar results after four runs. Hydrogen pressure influenced strongly the selectivity towards alkanes or alkenes using this last methodology, and 1 bar hydrogen pressure yielded (Z)-alkenes, whereas a 4 bar hydrogen pressure afforded alkanes. ${ }^{218}$

cis-Deuterated alkenes can be prepared by using the Lindlar catalyst for partial reductive deuteration of 1,2-disubstituted alkynes in the presence of an atmosphere of $\mathrm{D}_{2}$. However, $\mathrm{D}_{2}$ gas is expensive and not easily obtainable because of the usually complicated acquisition process as a consequence of its combustible nature and import restrictions, being considered as a strategic material. Thus, cis-deuterated alkenes have been obtained from internal alkynes, such as diphenylacetylene, using $\mathrm{D}_{2}$ gas generated by the electrolysis of $\mathrm{D}_{2} \mathrm{O}$ in a special flow reactor using the Lindlar catalyst. ${ }^{219}$ Terminal alkynes cannot be transformed into the corresponding $c i s-\mathrm{D}_{2}$-alkenes using the Lindlar catalyst due to over-reduction, and recently they have been obtained by reaction of $\mathrm{D}_{2}$ gas, generated by stirring $\mathrm{Pd} / \mathrm{C}$ in $\mathrm{D}_{2} \mathrm{O}$ at room temperature, with terminal alkynes 
using a $0.3 \%$ palladium supported on boron nitride (Pd-BN, $0.10 \mathrm{~mol} \%$ ) as catalyst in the presence of molecular sieves and 2,6-lutidine as base in pyridine as solvent at room temperature. ${ }^{220}$ This methodology is exemplified in Scheme 72 with the reduction of terminal alkyne $\mathbf{1 8 0}$ to the cis-deuterated alkene 181. In addition, trans-deuteration has been observed by using a combination of hexamethyldisilane and deuterium oxide as a deuterium transfer reagent in the presence of a catalytic amount of $\left[\mathrm{PdCl}\left(\eta^{3}-\mathrm{C}_{3} \mathrm{H}_{5}\right)_{2}\right]_{2}(5$ $\mathrm{mol} \%)$ and $\mathrm{PPh}_{3}(10 \mathrm{~mol} \%)$ in $N, N$-dimethylacetamide at $80{ }^{\circ} \mathrm{C}$, the process taking place through the corresponding $(\mathrm{Z})$-isomer intermediate. ${ }^{221}$

\section{Scheme 72}

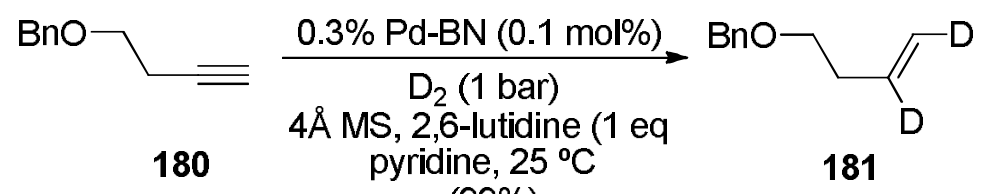

$(99 \%)$

\section{Chemicals by Palladium-Catalyzed C-C Coupling Reactions of}

\section{Alkynes}

Palladium-catalyzed methodologies are probably the most effective for the formation of $\mathrm{C}(\mathrm{sp})-\mathrm{C}\left(\mathrm{sp}^{2}\right)$ and $\mathrm{C}(\mathrm{sp})-\mathrm{C}(\mathrm{sp})$ bonds starting from terminal alkynes and leading to an important array of conjugated systems. Thus, the palladium-catalyzed transformation of terminal alkynes into alkynylated arenes and heteroarenes, 1,3-enynes and 1,3-diynes, as well as carbonyl-containing conjugated ynones and ynamides will be presented in this section. Only examples of the use of 'real' alkynes as starting materials in palladium-catalyzed transformations will be commented, the use of previously prepared alkynylated species (such as alkynyl metals) being excluded.

\subsection{Alkynylated Arenes}

Alkynyl arenes are chemicals of high interest, for instance as intermediates in the synthesis of carbo- and heterocycles (see Section 3) or becoming part of highly conjugated systems in advanced acetylene-based materials for electrooptical 
applications ${ }^{222}$ or nanoscale architectures. ${ }^{223}$ Although there are limited examples of the direct palladium-catalyzed alkynylation of arene $\mathrm{C}-\mathrm{H}$ bonds under oxidative conditions through chelation-assisted strategies, ${ }^{224}$ the palladium-catalyzed Sonogashira crosscoupling reaction between a terminal alkyne and an aryl halide or triflate is the main and principal way of obtaining this kind of compounds. Although there are recent ligand-free procedures involving continuous flow conditions with tubular reactors of catalytic metal inner surfaces, ${ }^{225}$ the process is typically performed using a phosphinecontaining palladium complex as catalyst in the presence of a catalytic amount of a copper(I) salt and an excess of an amine (or inorganic base) under homogeneous conditions. $^{226}$ The presence of the copper co-catalyst (the traditional and properly named Sonogashira reaction), although beneficial in terms of increasing the reactivity of the system, adds additional environmental problems, complicates purification of the formed alkynes and makes necessary to avoid the presence of oxygen in order to block the undesirable formation of 1,3-diynes from alkyne homocoupling through a coppermediated Hay/Glaser reaction. ${ }^{227}$ Therefore, coupling procedures avoiding the use of copper have been developed by making the catalytic system more reactive, achieving the so-called 'copper-free' Sonogashira reaction. ${ }^{226}$ This reaction name, although very common, is a bit unfair, as Cassar ${ }^{228}$ and $\mathrm{Heck}^{229}$ pioneered this palladium-catalyzed alkynylation reaction in the absence of copper.

As in other palladium-catalyzed cross-coupling reactions, the palladium species experiences more or less easy oxidative addition to the carbon-halogen(triflate) bond depending on the type of halogen atom (or triflate) present, ${ }^{230}$ the general reactivity order of the $\mathrm{sp}^{2}$ species being aryl iodide $>$ aryl triflate $\geq$ aryl bromide $>>$ aryl chloride. Therefore, the Sonogashira reaction with terminal alkynes usually is easier when the more unstable aryl iodides are used, whereas the use of the more stable aryl chlorides, if not strongly activated (electron-poor), still represent a challenge. ${ }^{226}$ In this section, we will present some recent examples of the use of terminal alkynes for the preparation of alkynylated arene systems by means of the palladium-catalyzed Sonogashira crosscoupling reaction, including homogeneous and heterogeneous catalytic systems as well as copper-cocatalyzed and copper-free procedures.

The most used palladium catalysts for this reaction have been $\mathrm{Pd}\left(\mathrm{PPh}_{3}\right)_{4}$ [sometimes formed in situ by mixing a palladium(II) salt and triphenylphosphine] and the more stable and soluble $\mathrm{PdCl}_{2}\left(\mathrm{PPh}_{3}\right)_{2}$. These two complexes continue to be nowadays by far the most frequently employed catalysts when a copper-cocatalyzed 
Sonogashira cross-coupling reaction is going to be used in a practical application. Example of a practical use of this typical copper-cocatalyzed Sonogashira alkynylation reaction using aryl iodides as coupling partners is the preparation of phenylene ethynylene polymers or oligomers, which are key compounds for the fabrication of electronic and optoelectronic devices. ${ }^{222}$ Another recent example is the synthesis of a series of di-tert-butyl-substituted phenylene ethynylene dimer, trimer, tetramer, and pentamer, compounds with high interests as organic wires, in a stepwise process. ${ }^{231}$ Thus, reaction of di-tert-butylated iodobenzene 182 with trimethylsilylacetylene (TMSA) (an acetylene equivalent) under the traditional Sonogashira conditions catalyzed by $\mathrm{PdCl}_{2}\left(\mathrm{PPh}_{3}\right)_{2} \quad(0.4 \mathrm{~mol} \%) / \mathrm{CuI} \quad(0.4 \mathrm{~mol} \%)$ in the presence of triethylamine/THF as solvent at room temperature afforded the alkynylated compound 183, after desilylation with tetra- $n$-butylammonium fluoride (TBAF) (Scheme 73). Subsequent Sonogashira reaction with 1,4-diiodobenzene gave iodinated alkyne 184, which was alkynylated again with TMSA to yield dimer 185. Obviously, this last compound can be desilylated and coupled again with 1,4-diiodobenzene and so on to give phenylene ethynylene oligomers. However, the amount of the observed homocoupling products is increased when increasing the substituent group size on the terminal alkyne.

\section{Scheme 73}
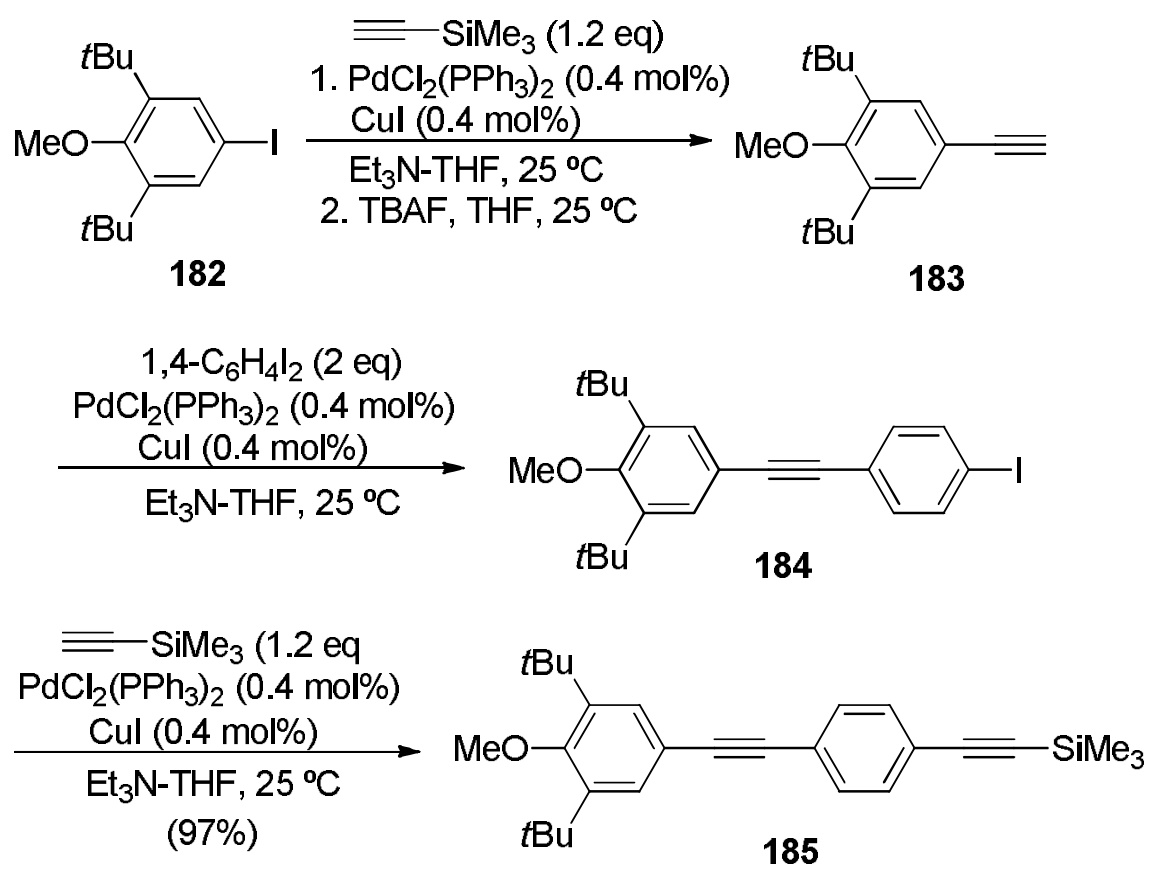
Another recent example of the classical copper-cocatalyzed Sonogashira coupling of a terminal alkynes and an aryl iodide, now devoted to the preparation of compounds of biological interest is the synthesis of diaryl alkyne 188, an intermediate of lysosomal cysteine protease inhibitor Cathepsin S (Scheme 74). ${ }^{232}$ This compound has been prepared by coupling terminal alkyne 187 and aryl iodide 186 using the same reaction conditions than in the previous example, the higher reactivity of the C-I bond compared to that of $\mathrm{C}-\mathrm{Cl}$ bond being demonstrated.

\section{Scheme 74}<smiles>CC(C)(C)OC(=O)N1CCc2c(c(-c3ccc(Cl)c(I)c3)nn2CCCN2CCOCC2)C1</smiles>

186<smiles>C#Cc1ccc(CN(Cc2ccc(Cl)cc2)C(=O)C(F)(F)F)cc1</smiles>

187

$(69 \%)$

$\mathrm{PdCl}_{2}\left(\mathrm{PPh}_{3}\right)_{4}(5 \mathrm{~mol} \%)$

Cul (5 mol\%)

$\mathrm{Et}_{3} \mathrm{~N}, \mathrm{THF}, 25^{\circ} \mathrm{C}$<smiles>CC(C)(C)OC(=O)N(Cc1ccc(Cl)cc1)Cc1ccc(C#Cc2cc(-c3nn(CCCN4CCOCC4)c4c3CN(C(=O)OC(C)(C)C)CC4)ccc2Cl)cc1</smiles>

188

Examples of the use of aryl bromides for the palladium-catalyzed coupling with terminal alkynes leading to interesting compounds are common, as in the recent synthesis of donor-acceptor tetrakis(ethynyl)pyrenes, obtained from the corresponding tetrabrominated pyrenes and terminal alkynes using the classical copper-cocatalyzed Sonogashira conditions. ${ }^{233}$ However, copper-free procedures are nowadays more deeply explored. Thus, aryl bromides have been coupled with terminal alkynes using as catalyst $\left[\mathrm{Pd}\left(\mathrm{C}_{3} \mathrm{H}_{5}\right) \mathrm{Cl}\right]_{2}(0.05 \mathrm{~mol} \%)$ combined to the tetraphosphine $189(0.1 \mathrm{~mol} \%)$, using potassium phosphate as base in dioxane as solvent at $105{ }^{\circ} \mathrm{C}$, as shown in the reaction of aryl bromide 190 and phenylacetylene to give disubstituted alkyne 191 (Scheme 75). ${ }^{234}$ Other copper-free coupling of aryl bromides and terminal alkynes have 
also been recently achieved using chlorophosphine, ${ }^{235}$ biphenyl-containing bis(diphenylphosphine) $)^{236}$ or functionalized ionic liquid-containing phosphine-ligated ligands. ${ }^{237}$ In addition, aryl bromides have been coupled recently with terminal alkynes under continuous flow conditions. ${ }^{238}$

\section{Scheme 75}
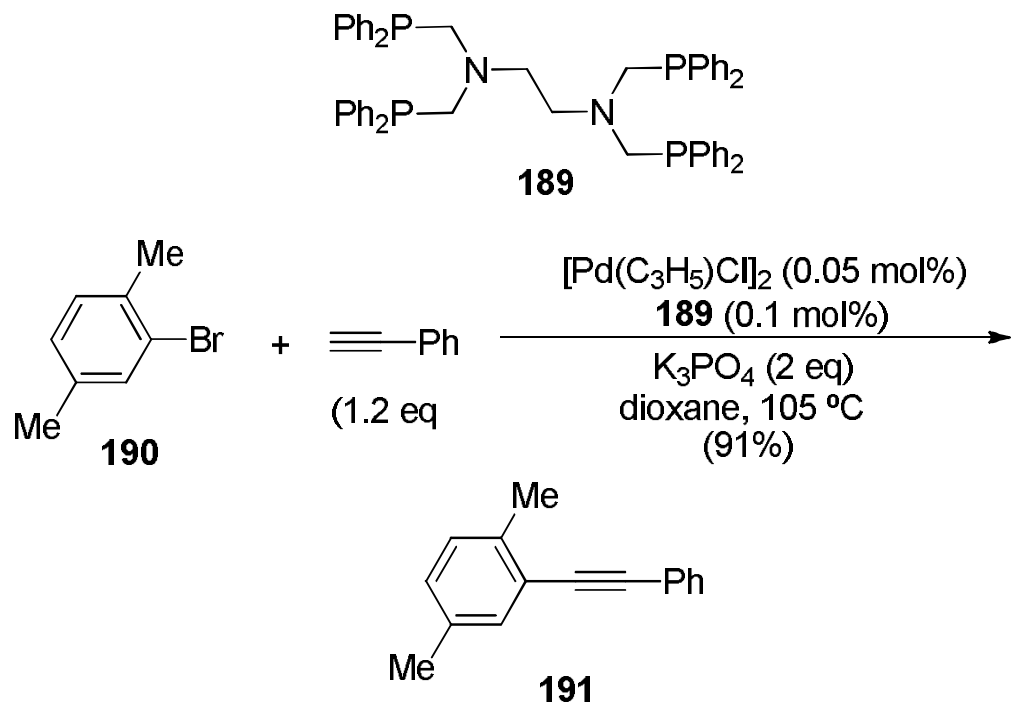

Supporting the phosphine ligands on different polymers or inorganic supports allows the preparation of recoverable palladium catalysts which can be reused further, something important in large scale synthesis. ${ }^{226 b, c}$ Recent examples of phosphinecontaining supported palladium catalysts devoted to the preparation of alkynylated arenes are the magnetic nanoparticle-supported palladium complex 192, which has been used as catalyst ( $1 \mathrm{~mol} \% \mathrm{Pd}$ ) for the copper-free Sonogashira coupling of terminal alkynes and aryl iodides or aryl bromides using potassium carbonate as base in DMF at $100{ }^{\circ} \mathrm{C}$, as in the coupling of $p$-iodotoluene with hex-1-yne to give alkyne 193 (Scheme 76). ${ }^{239}$ The catalyst was recovered by using a magnet and reused up to eight times with almost no loss of activity. Further examples of the use as catalysts of palladium(II) coordinated to diphenylphosphine-functionalized mesoporous silica, ${ }^{240}$ silica nonospheres, ${ }^{241}$ or to metal-organic frameworks ${ }^{242}$ can be found, although only employed in the coupling of phenylacetylene and iodobenzene. In addition, commercial polyurea-encapsulated palladium-triphenylphosphine Pd-EnCat ${ }^{\mathrm{TM}}$ TPP30 has been used as recyclable catalyst $(3.5 \mathrm{~mol} \% \mathrm{Pd})$ for the coupling of terminal acetylenes and aryl bromides. ${ }^{243}$ The reaction was performed in the presence of DBU as base in acetonitrile 
at $120^{\circ} \mathrm{C}$ under microware irradiation, the supported catalyst being recycled up to six times with only a slight decrease in the reactivity.

\section{Scheme 76}
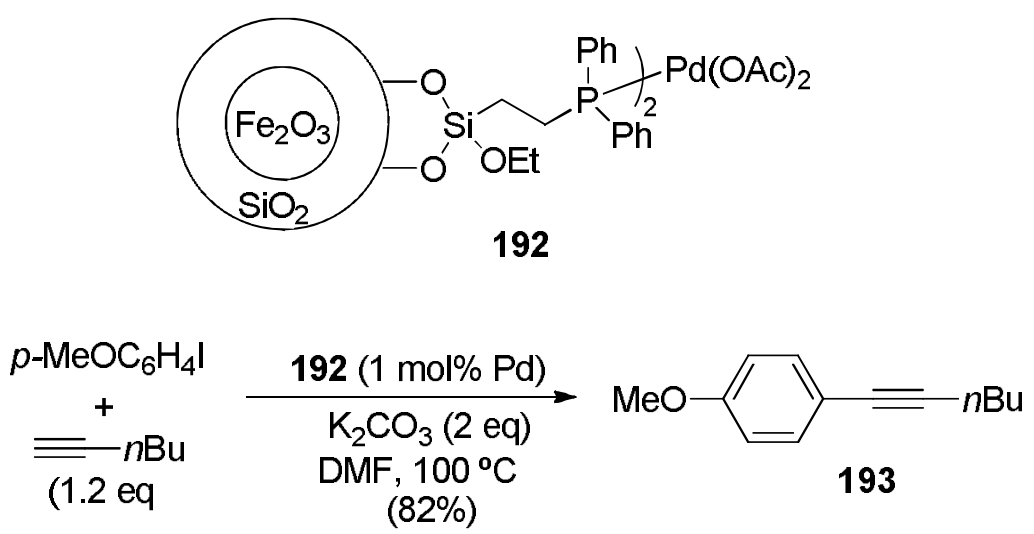

Although phosphine ligands are the most frequently employed in the Sonogashira alkynylation reaction of arene halides, many other non-phosphonated complexes has been employed, although most often only for the coupling of terminal alkynes with aryl iodides and bromides. ${ }^{226}$ A recent example is the use a nitrogenated ligand such as hydrazone 194 , which when combined $(0.5 \mathrm{~mol} \%)$ to $\operatorname{Pd}(\mathrm{acac})_{2}(\mathrm{acac}=$ acetylacetonate) at a very low loading $(0.001 \mathrm{~mol} \%)$ in the presence of $\mathrm{CuI}(0.5 \mathrm{~mol} \%)$ allowed the cross-coupling of terminal alkynes and aryl bromides, as in the case of the synthesis of alkyne 196 from the alkynylation of $p$-bromotoluene with terminal alkyne 195 (Scheme 77). ${ }^{244}$ 


\section{Scheme 77}<smiles>C(=NN1CCCCC1)NN1CCCCC1</smiles>

194
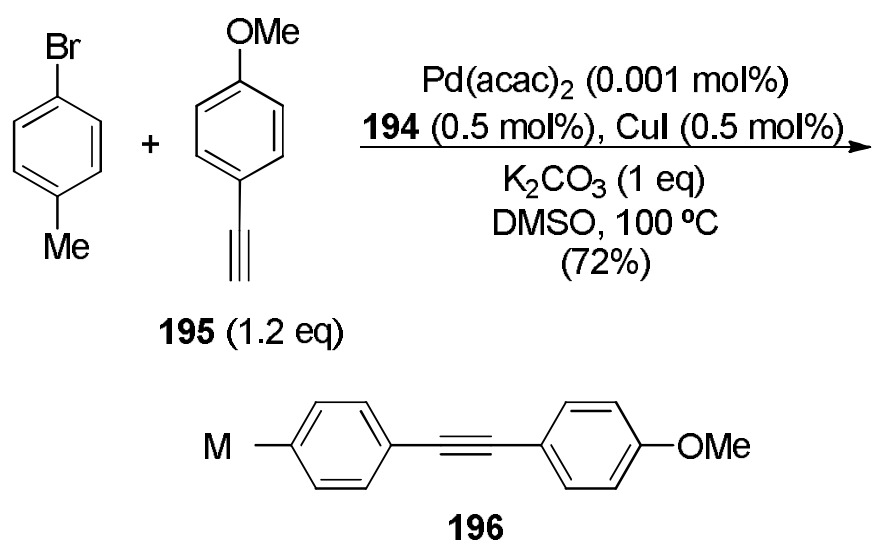

Non-phosphanated palladium complexes have also been immobilized on different materials in order to achieve recoverable and reusable systems. Recent examples include the use of polystyrene-anchored palladium(II)-salophen complex 197 as catalyst $(0.5 \mathrm{~mol} \% \mathrm{Pd})$ for the coupling of aryl iodides and activated aryl bromides with phenylacetylene in water, as shown in Scheme 78 with the coupling of $p$ bromobenzaldehyde and phenylacetylene to give alkyne 198, the catalyst being recovered by filtration and reused up to 5 times with a $10 \%$ loss of activity. ${ }^{245}$ Water has also being used as solvent when a polystyrene-supported terpyridine palladium complex has been used as catalyst ( $5 \mathrm{~mol} \% \mathrm{Pd}$ ) in the coupling of phenylacetylene and aryl iodides. ${ }^{246}$ In addition, polystyrene has also been used to anchor a palladium(II) phenylditiocarbazate complex which has been used as catalyst $(0.01 \mathrm{~mol} \% \mathrm{Pd})$ in the coupling of aryl iodides and bromides with terminal acetylenes, reuse up to five times being possible. ${ }^{247}$ Moreover, a palladium(II)-salophen complex has been immobilized on diatomite and has been found suitable to catalyze $(0.003 \mathrm{mmol} \%)$ the copper-free Sonogashira coupling or terminal alkynes and aryl iodides and bromides in triethylamine at room temperature, reusing up to three runs being possible. ${ }^{248}$ Furthermore, examples of the use of superparamagnetic nanoparticles-supported palladium(II) complexes with Schiff-base bidentate ligands, ${ }^{249}$ metallodendritic palladium catalysts containing 2-pyridyl-1,2,3-triazole moieties as ligands, ${ }^{250}$ mesoporous organosilica palladium(II) complexes containing a phloroglucinol-diimine 
moiety as ligand, ${ }^{251}$ as well as carbon nanotubes with thiol-containing ligands for palladium $^{252}$ can be found, although synthetically limited to the use of aryl iodides.

\section{Scheme 78}

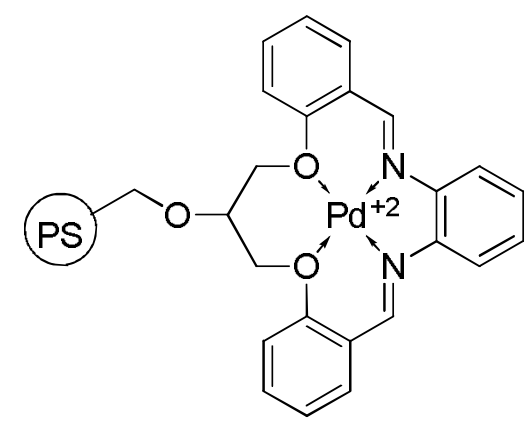

197

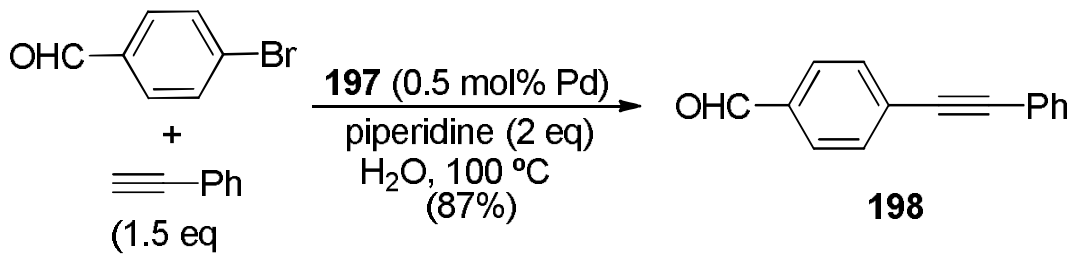

NHC-palladium complexes are gaining popularity as catalysts in Sonogashira alkynylation reactions due to their enhanced catalytic activity, thus allowing copper-free couplings. $^{226 \mathrm{~b}, \mathrm{c}}$ A recent example of their use as catalysts in the formation of alkynylated arenes is the chiral complex 199, which has been employed (1 mol\%) in the copper-free alkynylation of aryl bromides in the presence of potassium carbonate as base in DMSO as solvent at $100{ }^{\circ} \mathrm{C}$, as shown in the preparation of alkynylated arene 200 from phenyl bromide and hex-1-yne (Scheme 79). ${ }^{253}$ Other abnormally bonded NHC-palladium complexes have been used as catalysts in the copper-free Sonogashira alkynylation of aryl halides, ${ }^{254}$ whereas thiol-functionalized NHC-palladium complexes have also been used as catalysts, although the presence of copper(I) iodide resulted necessary. ${ }^{255}$ 
Scheme 79

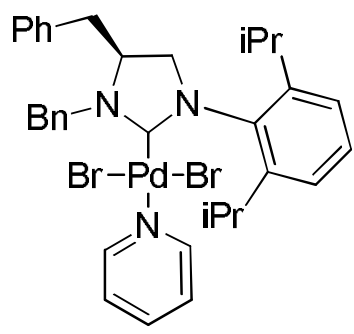

199

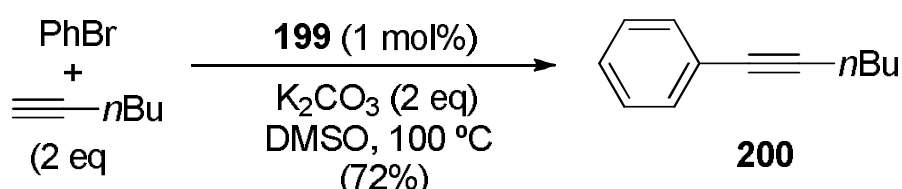

Palladacycles are palladium compounds that usually show high catalytic activity and high stability, being precursors of active PdNPs ${ }^{256}$ which can act as catalysts in the copper-free Sonogashira reaction. ${ }^{26 \mathrm{~b}}$ Recent examples of their use in the copper-free Sonogashira alkynylation aryl halides are the cyclopalladated ferrocenylpyridazine palladium complex 201, which has been used as catalyst (0.1-2 mol\%) in the reaction of terminal alkynes with aryl bromides, using cesium acetate as base, in $N, N$ dimethylacetamide (DMA) as solvent at $120{ }^{\circ} \mathrm{C} .{ }^{257}$ An example of the use of this methodology is the preparation of alkyne $\mathbf{2 0 3}$ from the reaction of $o$-bromotoluene and phenylacetylene (Scheme 60). Aryl bromides afforded high yields, although aryl chlorides gave rise to moderate yields only when bearing electron-withdrawing groups. In addition, aqueous solvents at $40{ }^{\circ} \mathrm{C}$ have been employed in the alkynylation of aryl iodides using as catalyst $(0.25 \mathrm{~mol} \%)$ the palladacycle $202 .{ }^{258}$ Other recent examples involve the use of an ortho-palladated complex of homoveratrylamine using aryl iodides and bromides ${ }^{259}$ or recyclable palladacycle systems using ionic liquids as solvents, although working only with aryl iodides as coupling partners. ${ }^{260}$ In addition, recent examples of coupling of aryl iodides and bromides with terminal alkynes using polystyrene-anchored Schiff-based palladacycles as catalysts can be found. ${ }^{261}$ Moreover, aryl iodides $^{262}$ and bromides $^{262 a}$ have also been coupled to terminal acetylenes using palladium-containing pincer complexes as catalysts. 


\section{Scheme 80}

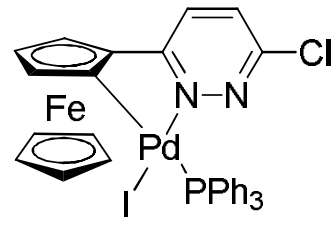

201

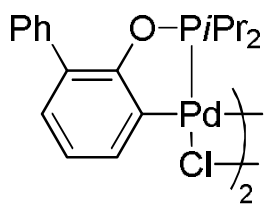

202

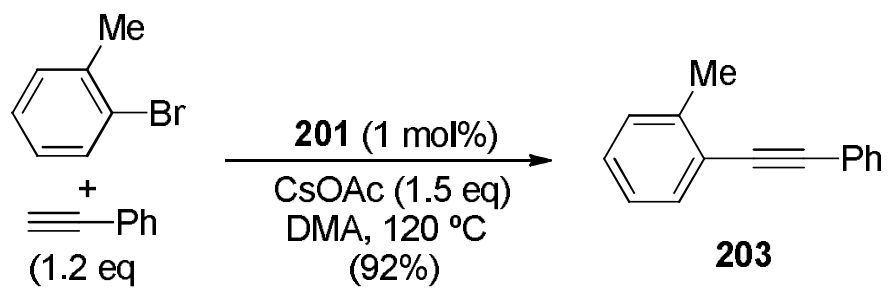

Palladium salts, deprived of any ligand, can be used as catalysts in the Sonogashira coupling of terminal alkynes and aryl halides, mainly iodides and bromides. For instance, terminal alkynes, such as $\mathbf{2 0 5}$, have been cross-coupled with aryl iodides, such as 204, affording the corresponding alkyne 206, in a reaction catalyzed by $\operatorname{Pd}(\mathrm{OAc})_{2}(2 \mathrm{~mol} \%)$ in the presence of a tetra- $n$-butylammonium acetate (TBAA) as a probable nanoparticle stabilizer, the process being performed in DMF as solvent at room temperature (Scheme 81). ${ }^{263}$ Another recent example is the use of formate-based room temperature ionic liquids as solvents at $100{ }^{\circ} \mathrm{C}$ for the coupling of phenylacetylene and aryl iodides and bromides, low loadings of $\mathrm{PdCl}_{2}$ being used as catalyst $(0.02 \mathrm{~mol} \%) .{ }^{264}$ In addition, two commercially available recyclable polyureaencapsulated Pd-EnCat ${ }^{\mathrm{TM}}$, deprived of any phosphine ligand, have been used in copperfree Sonogashira couplings. Thus, Pd EnCat 30 (1 mol\%) have been employed as catalyst in the coupling of aryl iodides with terminal alkynes, piperidine being used as base in aqueous acetonitrile $(1: 1)$ at $40{ }^{\circ} \mathrm{C}$, the catalyst being recovered and reused up to three times with slight decrease in the final yield of the cross-coupled product. ${ }^{265}$ The less porous Pd-EnCat 40 has been reported to perform $(0.1-0.01 \mathrm{~mol} \% \mathrm{Pd})$ the coupling of aryl iodides and a few aryl bromides using pyrrolidine as solvent at $85^{\circ} \mathrm{C}$, microwave irradiation accelerating the process. ${ }^{266}$ 


\section{Scheme 81}

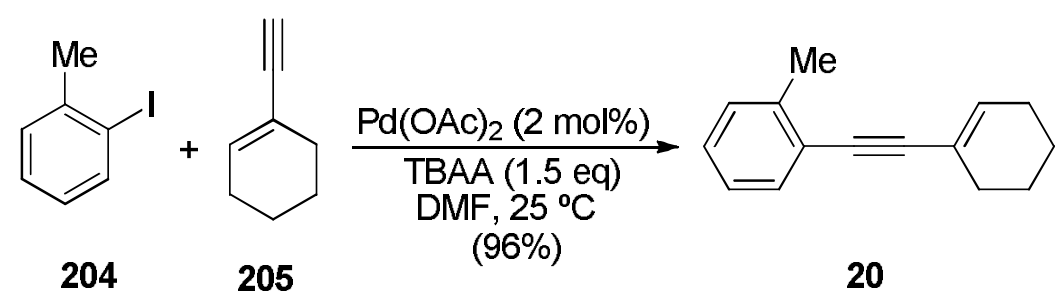

The use of PdNPs as catalysts in the Sonogashira cross-coupling reaction has found rising interest, ${ }^{226 b, c, 267}$ as evidence has shown that PdNPs can in fact be the real catalyst in many Sonogashira processes as a consequence of decomposition of the original palladium salt or complex. One of the reasons for the rapidly developing field of nanoparticle research is the distinctly differing physicochemical properties presented by metal nanoparticles compared to their bulk counterparts due to their large surface-tovolume ratio, providing many highly active metal uncoordinated sites. An example of their use in this alkynylation reaction as catalysts is the in situ generation of PdNPs by combining $\mathrm{PdCl}_{2}(0.5 \mathrm{~mol} \%)$ and sodium hydroxide, which are stabilized by oil-inwater microemulsions (ME) formed by the mixture Triton ${ }^{\circledR}$ X100/n-heptane $/ n$ butanol/water/PEG at $80{ }^{\circ} \mathrm{C} .{ }^{268}$ These conditions have allowed to couple aryl iodides, such as 207, with phenylacetylene yielding the corresponding alkyne 208 (Scheme 82). Other examples of this disubstituted alkyne synthesis catalyzed by PdNPs, ${ }^{269}$ even Pd$\mathrm{Cu}$ bimetallic and specifically fabricated tripodal-shaped nanoparticles, ${ }^{270}$ using water as solvent can be found. In addition, differently immobilized PdNPs have been employed as recyclable catalysts in Sonogashira couplings, ${ }^{226 \mathrm{~b}, \mathrm{c}}$ recent examples being PdNPs stabilized on linear polystyrene, ${ }^{271}$ poly(vinyl alcohol) nanofiber mats, ${ }^{272}$ polypyrrole globules, ${ }^{273}$ agarose, ${ }^{274}$ synthetic adsorbent resins, ${ }^{275}$ graphite $^{276}$ and graphene $^{277}$ oxides and silicate base materials ${ }^{278}$ as well as dendrimers. ${ }^{279}$ However, the use of PdNPs as catalyst is mostly limited to the coupling of terminal alkynes with reactive aryl iodides or activated aryl bromides. ${ }^{226 b, c}$ 


\section{Scheme 82}

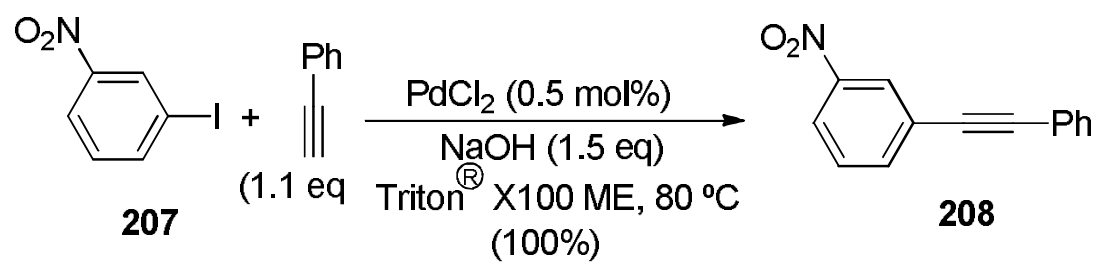

As mentioned, not only the desire of avoiding the presence of a copper(I) cocatalyst, but also the necessity of coupling terminal alkynes with the less reactive aryl chlorides has boosted the development of more reactive palladium-containing catalytic systems based, for instance, in the presence of bulky electron-rich phosphine ligands. For example, the $\operatorname{Ad}_{2} \mathrm{P}(n-\mathrm{Bu})(\mathrm{Ad}=$ adamantyl) (4 mol\%) ligand showed its usefulness years ago in the coupling of aryl chlorides with selected alkynes in the presence of $\mathrm{Na}_{2} \mathrm{PdCl}_{4}(2 \mathrm{~mol} \%)$ as palladium catalyst precursor and $\mathrm{CuI}(1.5 \mathrm{~mol} \%)$ as co-catalyst, electron-deficient aryl chlorides affording very high yields but electron-neutral and electron-rich chlorides giving lower yields. ${ }^{280}$ Under these conditions, the use of $t \mathrm{Bu}_{3} \mathrm{P}$ gave slightly better yields with electron-rich systems. This last ligand, combined to $\mathrm{PdCl}_{2}\left(\mathrm{PPh}_{3}\right)_{2}(2 \mathrm{~mol} \%)$ and DBU resulted also efficient in the copper-free coupling of aryl chlorides and terminal alkynes under microwave irradiation. ${ }^{281}$ In addition, another copper-free Sonogashira coupling protocol for the coupling of activated or not aryl chlorides and tosylates using Xphos (123) (3 mol\%) combined to $\mathrm{PdCl}_{2}\left(\mathrm{MeCN}_{2}(1\right.$ mol\%) was also developed, ${ }^{282}$ as well as a copper-free procedure for the use of aryl chlorides catalyzed by $\mathrm{PdCl}_{2}\left(\mathrm{PCy}_{3}\right)_{2}(3 \mathrm{~mol} \%)$ in the presence of cesium carbonate as base in DMSO at $100-150{ }^{\circ} \mathrm{C} .{ }^{283}$ Very recently, palladium(0) and (II) complexes with the $p-\mathrm{Me}_{2} \mathrm{NC}_{6} \mathrm{H}_{4} \mathrm{P}(t \mathrm{Bu})_{2}$ ligand have been shown as effective catalysts $(0.5-1.5 \mathrm{~mol} \%)$ for the copper-free coupling of aryl chlorides and terminal acetylenes, cesium carbonate being used as base and DMF as solvent at $90-110{ }^{\circ} \mathrm{C} .{ }^{284}$ An example employing $\operatorname{Pd}[p$ $\left.\mathrm{Me}_{2} \mathrm{NC}_{6} \mathrm{H}_{4} \mathrm{P}(t \mathrm{Bu})_{2}\right]_{2}(0.5 \mathrm{~mol} \%)$ as catalyst is shown in Scheme 83, with the coupling of a deactivated aryl chloride such as $p$-chloroanisole with dec-1-yne, yielding disubstituted acetylene 209. 
Scheme 83

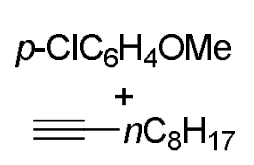

$(1.2 \mathrm{eq})$

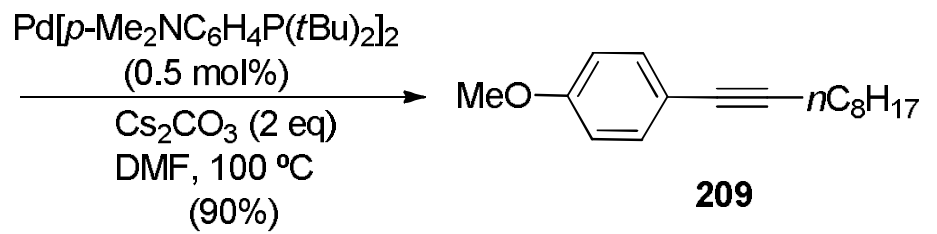

$(90 \%)$

Some phosphine-free catalytic systems have also been used for the successful coupling of terminal alkynes and aryl chlorides. ${ }^{226 c}$ For example, low loadings $(0.5$ mol\%) of the $\beta$-di-ketiminatophosphine palladium complex $\mathbf{2 1 0}$ have shown to catalyze efficiently the copper-free Sonogashira coupling of aryl chlorides with terminal alkynes, as illustrated in the coupling of the hindered chloride 211 with phenylacetylene to give disubstituted alkyne 212 (Scheme 84). ${ }^{285}$ The reaction is carried out in the presence of piperidine as base and TBAB in aqueous DMF at only $50{ }^{\circ} \mathrm{C}$.

\section{Scheme 84}<smiles>[R]C1=C(C)C=C(C)C([R])[R8]1(C)NCC</smiles>

$$
\mathrm{R}=2,6-\mathrm{Me}_{2} \mathrm{C}_{6} \mathrm{H}_{3}
$$

210

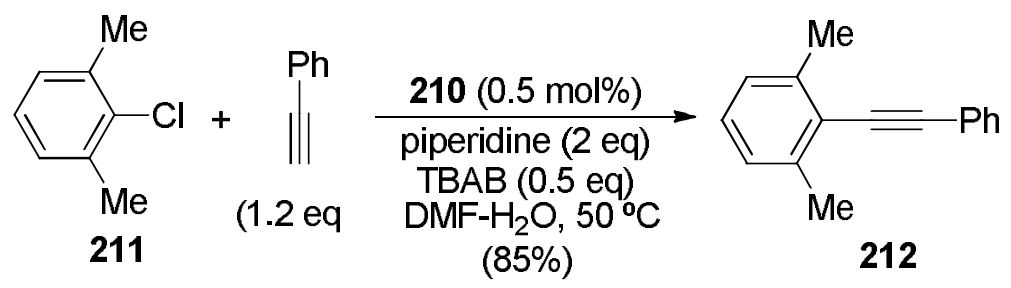

Recently, even highly electron-poor polyfluoroaryls have been employed in palladium-catalyzed Sonogashira-type couplings with terminal alkynes, although with moderate yields of the final alkyne. ${ }^{286}$ The procedure has been carried out using highly fluorinated nitrobenzene systems (pentafluoronitrobenzene and tetrafluoronitrobenzenes) and phenylacetylene or 2-methylbut-3-yn-2-ol as coupling partners, $\mathrm{Pd}\left(\mathrm{PPh}_{3}\right)_{4}(0.05 \mathrm{~mol} \%)$ as catalyst and $\mathrm{DMSO}$ as solvent at $120{ }^{\circ} \mathrm{C}$ under microwave irradiation. An example is shown in Scheme 85 with the coupling of tetrafluoronitrobenzene $\mathbf{2 1 3}$ and phenylacetylene to give disubstituted alkyne $\mathbf{2 1 4}$. 


\section{Scheme 85}

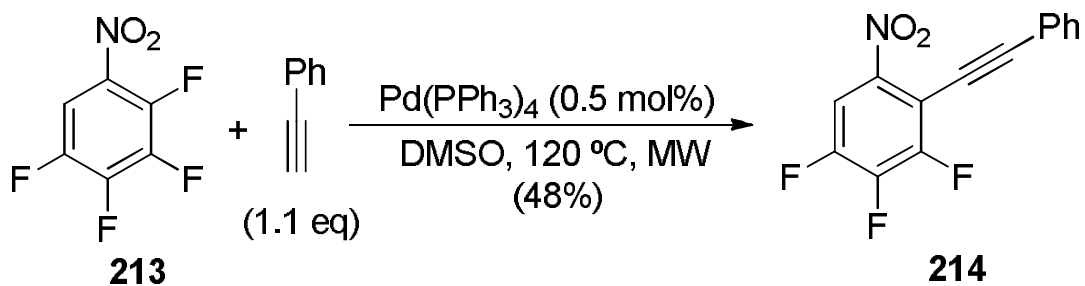

Aryl tosylates ${ }^{287}$ and mesylates ${ }^{287 b}$ are obtained easily from phenols and can be employed as the coupling partners of terminal alkynes in Sonogashira cross-coupling reactions leading to alkynyl arenes. An example is the cross-coupling of tosylate 216, which has been alkynylated with a terminal alkyne such as hept-1-yne using as catalytic system a combination of $\mathrm{Pd}(\mathrm{OAc})_{2}(2 \mathrm{~mol} \%)$ and the CM-Phos (215) ligand (6 mol\%) using potassium phosphate as base and tert-butanol as solvent at $100{ }^{\circ} \mathrm{C}$, to give internal alkyne 217 (Scheme 86). ${ }^{287 \mathrm{~b}}$

\section{Scheme 86}<smiles>Cn1c(-c2ccccc2C(C)(C)C)cc2ccccc21</smiles>

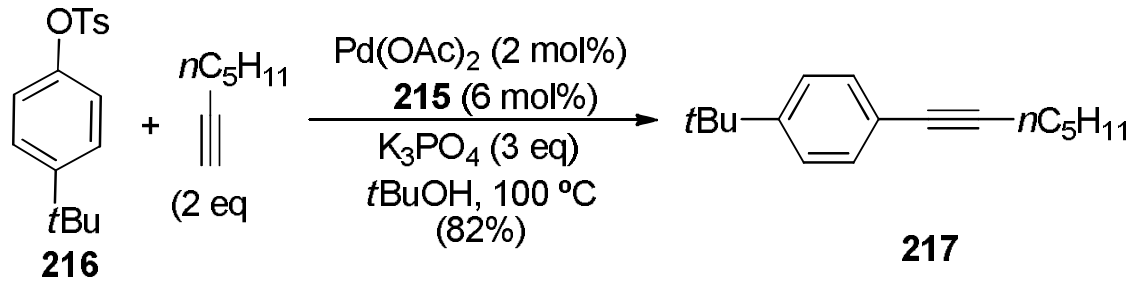

Similarly to aryl tosylates, aryl imidazol-1-ylsulfonates, also prepared from the corresponding phenols, can be coupled with terminal alkynes using a palladiumcatalyzed copper-free Sonogashira-like procedure, using $\mathrm{Pd}(\mathrm{OAc})(0.1 \mathrm{~mol} \%)$ as palladium source in the presence of Xphos as ligand (0.2 mol\%), potassium phosphate as base and DMSO as solvent at $65^{\circ} \mathrm{C} .{ }^{288}$ This copper-free coupling has also been performed very recently in neat water at $110^{\circ} \mathrm{C}$ assisted by microwave irradiation using the oxime palladacycle 218 as precatalyst (0.5 mol\%), Sphos (219) (2 mol\%) as ligand, hexadecyltrimethylammonium bromide $(\mathrm{CTAB})$ as additive and triethylamine as base, 
as in the case of the coupling of phenyl imidazylate $\mathbf{2 2 0}$ with phenylacetylene to give disubstituted alkyne 221 (Scheme 87). ${ }^{289}$

\section{Scheme 87}

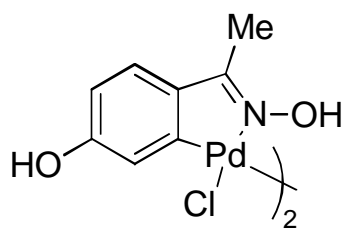

218<smiles>CCOc1ccccc1-c1c(OC)cccc1OC</smiles>

219<smiles>C#C[P+]c1ccccc1</smiles>

220

$(1.5 \mathrm{eq})$

$$
\begin{gathered}
218(0.5 \mathrm{~mol} \%) \\
219(2 \mathrm{~mol} \%) \\
\hline \mathrm{CTAB}(40 \mathrm{~mol} \%) \\
\mathrm{Et}_{3} \mathrm{~N}(2 \mathrm{eq}) \\
\mathrm{H}_{2} \mathrm{O}, 130 \circ \mathrm{C}, \mathrm{MW} \\
(92 \%)
\end{gathered}
$$<smiles>Cc1ccccc1C#Cc1ccccc1</smiles>

221

Arenediazonium salts (from the corresponding anilines) have also been used as coupling partners of terminal alkynes in palladium-catalyzed Sonogashira reactions in the presence of copper co-catalysis. ${ }^{290}$ This coupling can also be performed starting directly from anilines, using in situ generated arenediazonium salts by means of tertbutyl nitrite. This is a copper-free procedure based on the use of the mixture $\mathrm{Pd}(\mathrm{OAc})_{2}$ (2 mol\%)/tri-(2-furyl)phosphine (TFP) (4 mol\%) as catalytic combination in DMSO as solvent at $32{ }^{\circ} \mathrm{C}$, as in the case of the coupling of aniline with terminal acetylene 222 to give internal alkyne 223 (Scheme 88). ${ }^{291}$

\section{Scheme 88}

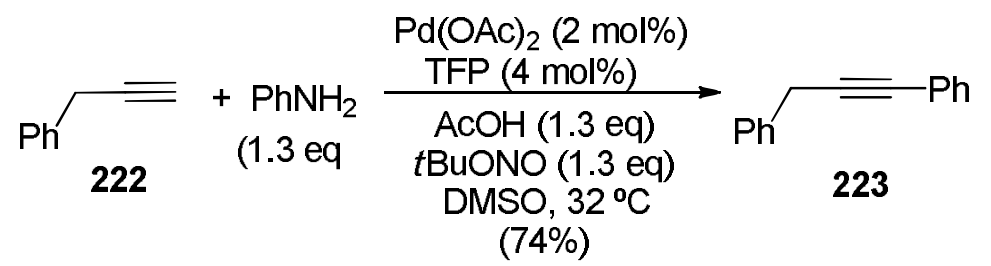

\subsection{Alkynylated Heterocycles}

The Sonogashira cross-coupling reaction between halogenated heterocyclic systems and terminal alkynes is the most evident strategy to follow when the preparation of 
alkynylated heteroarenes is intended. ${ }^{226 b}$ As in carbocyclic systems (see Section 6.1), the alkynylation of aromatic heterocyclic systems by means of a transition-metalcatalyzed reaction is governed by the higher or lower electrophilicity of the carbon atom at the heterocycle. In the oxidative addition step, $\operatorname{Pd}(0)$ acts as a nucleophile and will preferentially attack the most electron-deficient position. Thus, cross-coupling reactions for which the oxidative addition is rate determining, i.e. the Sonogashira cross-coupling, often show a high preference in favor of the most electrophilic position. ${ }^{292}$ In this section, some examples of the introduction of an alkyne moiety into heterocyclic systems, using the 'typical' copper-cocatalyzed Sonogashira reaction, as well as employing the 'copper-free' procedure, and also examples of the not very common direct oxidative coupling of terminal alkynes and heterocycles, will be shown.

The traditional Sonogashira reaction has been used for the alkynylation of fivemembered heterocycles such as maleimides. ${ }^{293}$ Thus, using $\mathrm{PdCl}_{2}\left(\mathrm{PPh}_{3}\right)_{2}$ as catalysts (5 $\mathrm{mol} \%)$ in the presence of $\mathrm{CuI}$ as cocatalyst $(10 \mathrm{~mol} \%)$ and diisopropylethylamine (DIPEA) as base, dibrominated maleimide $\mathbf{2 2 4}$ has been dialkynylated with terminal alkynes, such as pent-1-yne, to give dialkynylated maleimide $\mathbf{2 2 5}$, the reaction being performed in THF as solvent at room temperature (Scheme 89).

\section{Scheme 89}

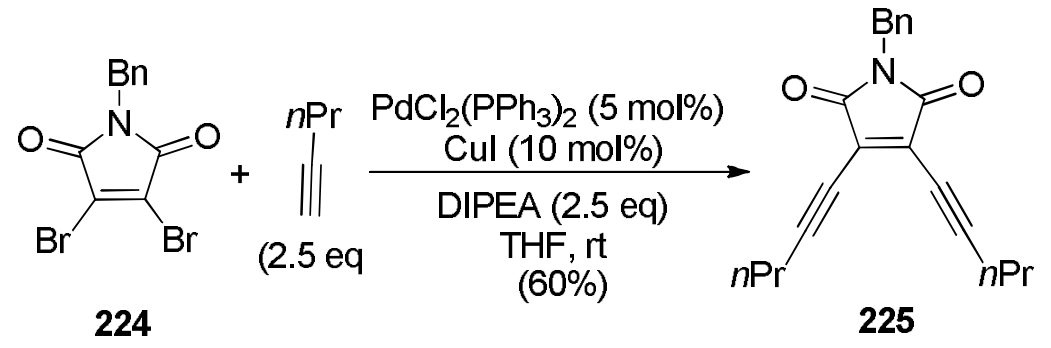

Terminal alkynes can alkynylate a pyrrole unit bearing an appropriate halide under Sonogashira conditions, even copper-free when reactive enough species are involved. An example is the selective alkynylation of 3,13-dibromo-5-methoxybacteriochlorin (226) for biomedical applications. ${ }^{294}$ Thus, 226 can be monoalkynylated with terminal alkyne 227 under copper-free Sonogashira conditions using $\mathrm{Pd}\left(\mathrm{PPh}_{3}\right)_{4}(10 \mathrm{~mol} \%)$ as catalyst and potassium carbonate as base in $\mathrm{DMF}$ at $80{ }^{\circ} \mathrm{C}$ as solvent, to give bacteriochlorin 228 (Scheme 90). Subsequent alkynylation with terminal alkynes, such as phenylacetylene, also under copper-free conditions using now $\mathrm{PdCl}_{2}\left(\mathrm{PPh}_{3}\right)_{2}(5 \mathrm{~mol} \%)$ 
as catalyst in $\mathrm{DMF} /$ triethylamine at $80{ }^{\circ} \mathrm{C}$ afforded dialkynylated nonsymmetrical bacteriochlorin 229.

\section{Scheme 90}

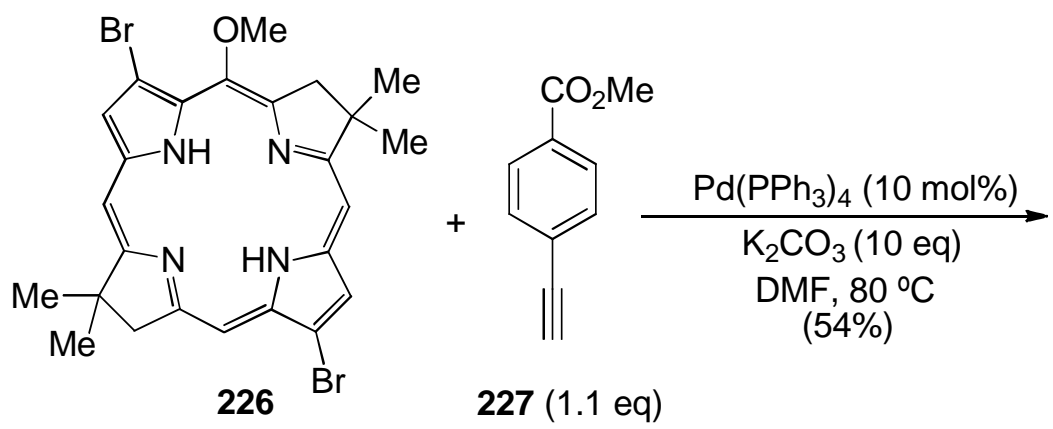

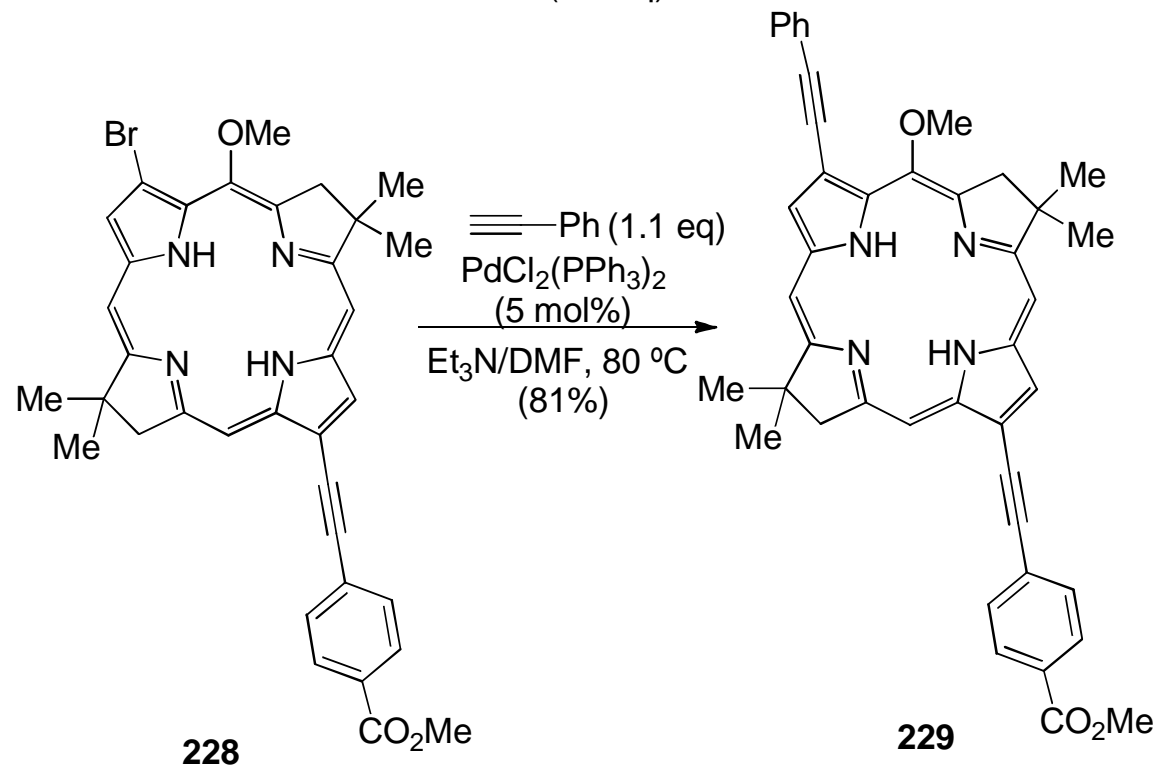

The alkynylation of the structurally important indole has been performed on systems bearing an halogen or even a triflate leaving group under the typical Sonogashira conditions, ${ }^{32 \mathrm{a}, \mathrm{e}}$ an example being the synthesis of a library of 3-alkynylated indoles, in solution and on a solid support, obtained from 3-iodinated indoles and terminal alkynes. ${ }^{295}$ The synthesis has been carried out using the combination $\mathrm{PdCl}_{2}\left(\mathrm{PPh}_{3}\right)_{2}(5 \mathrm{~mol} \%) / \mathrm{CuI}(10 \mathrm{~mol} \%)$ as catalyst, in diethylamine at $65{ }^{\circ} \mathrm{C}$, as in the case of the preparation of 3-alkynyl indole 231 from iodinated indole 230 and phenylacetylene (Scheme 91). In addition, alkynylated azaindoles can also be obtained, as exemplified in the preparation of compounds such as $\mathbf{2 3 4}$, obtained by coppercocatalyzed Sonogashira coupling of terminal alkynes, such as $\mathbf{2 3 3}$, to 2-iodinated azaindole 232 (Scheme 91). ${ }^{296}$ The palladium source in this transformation was $10 \%$ 
palladium on charcoal, a frequently employed palladium catalyst for the alkynylation of hetaryl halides. ${ }^{297}$ In this case, triethylamine was used as base and water at $80{ }^{\circ} \mathrm{C}$ as solvent, although the addition of triphenylphosphine was required. Other halogenated dinuclear five-six-membered nitrogenated heterocycles, such as imidazo[1,2a]pyridines, ${ }^{298}$ and imidazo[1,2-b]pyridazines ${ }^{299}$ have been alkynylated with terminal alkynes under copper-cocatalyzed Sonogashira conditions, using $\mathrm{PdCl}_{2}\left(\mathrm{PPh}_{3}\right)_{2}$ as palladium source.

\section{Scheme 91}<smiles>Cn1c(-c2ccccc2)c(I)c2ccccc21</smiles>

230
$\mathrm{Ph} \quad \mathrm{PdCl}_{2}\left(\mathrm{PPh}_{3}\right)_{2}(5 \mathrm{~mol} \%)$<smiles>C1#C[CH]CC#C1</smiles>

$(1.2 \mathrm{eq})$

$\mathrm{HNEt}_{2}, 65 \stackrel{\circ}{\circ} \mathrm{C}$

$(43 \%)$<smiles>Cn1c(-c2ccccc2)c(C#Cc2ccccc2)c2ccccc21</smiles>

231

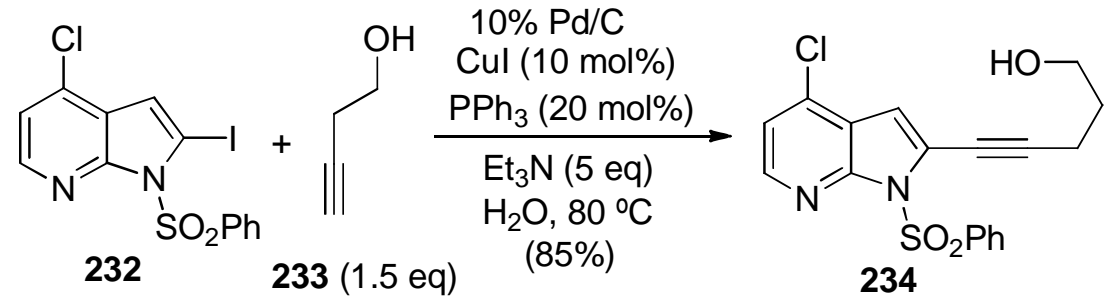

The pyrazole ring has also been alkynylated using the Sonogashira reaction conditions, as exemplified in Scheme 92 with the preparation of 3-alkynylated pyrazole4-carbaldehyde 236 from pyrazole 235, bearing a triflate as leaving group, and phenylacetylene. ${ }^{300}$ The process is catalyzed using large amounts of the catalytic combination $\mathrm{PdCl}_{2}\left(\mathrm{PPh}_{3}\right)(10 \mathrm{~mol} \%) / \mathrm{CuI}(10 \mathrm{~mol} \%)$, using triethylamine as base in DMF at $65{ }^{\circ} \mathrm{C}$. An example of alkynylation of an halogenated aryltriazole can also be seen in Scheme 92, where 5-brominated triazole $\mathbf{2 3 7}$ is alkynylated with terminal alkynes, such as 238, under usual Sonogashira reaction conditions and microwave irradiation, to give arylethynyltriazole acyclonucloside derivative 239, which has been found to inhibit hepatitis $\mathrm{C}$ virus replication. ${ }^{301}$ 


\section{Scheme 92}

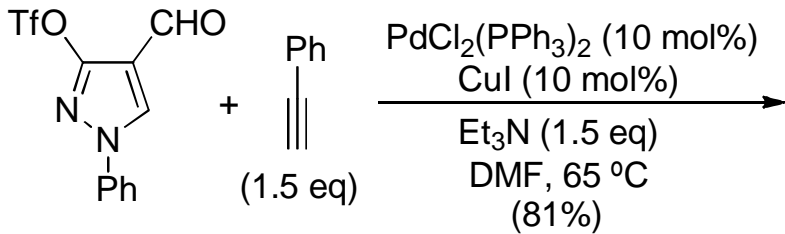

235<smiles>O=Cc1cn(-c2ccccc2)nc1C#Cc1ccccc1</smiles>

236<smiles>NC(=O)c1nc(Br)n(COCCO)n1</smiles><smiles>NC(=O)c1nc(C#Cc2ccc(F)cc2)n(COCCO)n1</smiles>

239

2-Halo-3-alkyl imidazo[4,5-b]pyridines have been recently found as appropriate substrates to experience a 2-alkynylation with terminal alkynes under copper- and amine-free Sonogashira conditions, using $\mathrm{PdCl}_{2}\left(\mathrm{PCy}_{3}\right)_{2}(10 \mathrm{~mol} \%)$ as catalyst in the presence of tetra- $n$-butylammonium acetate and NMP as solvent under microwave irradiation. ${ }^{302}$ Under these conditions, iodo-, bromo- and chloro-substituted systems such as $\mathbf{2 4 0}$ have been alkynylated with a terminal alkyne such phenylacetylene, to give imidazopyridine 241 (Scheme 93).

\section{Scheme 93}

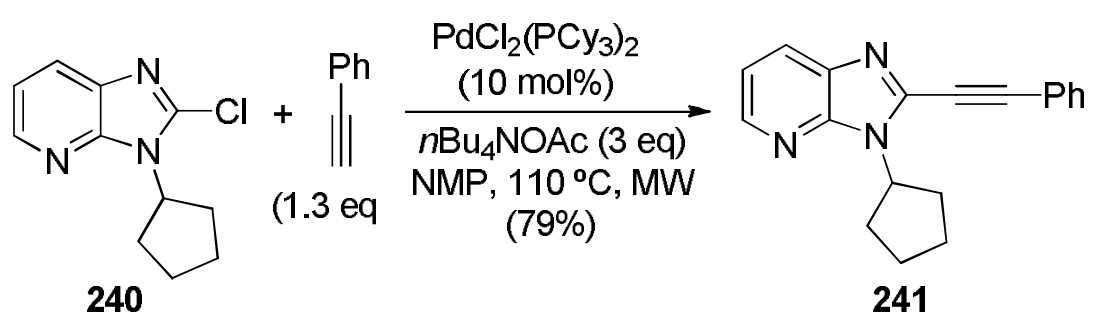

Halogenated pyridines can be alkynylated under the typical Sonogashira reaction conditions, the 2-position being the most reactive. For instance, 2-bromo-5- 
nitropyridine (242) has been 2-alkynylated with a terminal alkyne such as phenylacetylene, to give pyridine $\mathbf{2 4 3}$, in a process catalyzed by the combination $\mathrm{PdCl}_{2}\left(\mathrm{PPh}_{3}\right)_{2}(1 \mathrm{~mol} \%) / \mathrm{CuI}(1 \mathrm{~mol} \%)$, in the presence of potassium acetate as base using acetonitrile as solvent at a reaction temperature of $40{ }^{\circ} \mathrm{C}$ (Scheme 94). ${ }^{303}$ Similarly, phenylacetylene has been used for the alkynylation of 2bromonicotinaldehyde, using $\mathrm{Pd}(\mathrm{OAc})_{2}$ as palladium source, $\mathrm{CuI}$ as co-catalyst and triphenylphosphine as external ligand, in triethylamine. ${ }^{304}$ In addition, pyridines bearing a chloro and a bromo substituent have shown to be monoalkynylated always at the carbon bearing the bromo atom when using the typical copper-cocatalyzed Sonogashira conditions. ${ }^{305}$ Moreover, 2- and 3-bromopyridines have been alkynylated with terminal alkynes using as catalyst a nanosized MCM-41 anchored palladium bipyridyl complex in the presence of $\mathrm{CuI}$ as co-catalyst and triphenylphosphine, using triethylamine as base and solvent at $90{ }^{\circ} \mathrm{C}$, the anchored catalyst being suitable for reusing with a slight loss of activity after three runs. ${ }^{306}$

\section{Scheme 94}

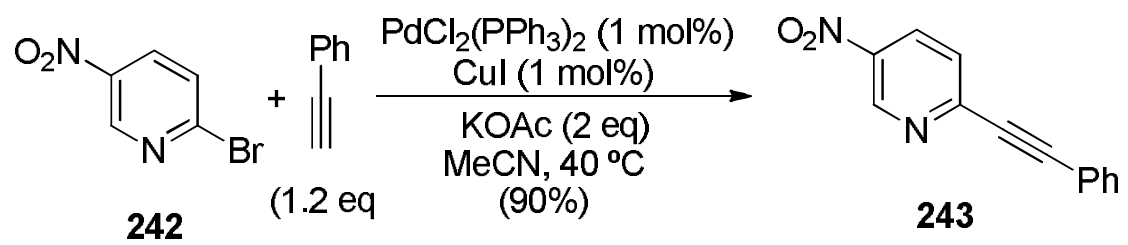

As mentioned, the addition of electron-rich phosphines as ligands improves the reactivity of the catalyst thus, allowing the use of less reactive substrates and sometimes copper-free conditions. An example is the difficult but high-yielding penta-alkynylation of pentachloropyridine (244) with phenylacetylene to give $\mathbf{2 4 5}$, using as catalyst a combination of $\mathrm{PdCl}_{2}(\mathrm{MeCN})_{2}(5 \mathrm{~mol} \%)$, Xphos (123) (10 mol\%) and $\mathrm{CuI}(3 \mathrm{~mol} \%)$, in a mixture of $\mathrm{iPr}_{2} \mathrm{NH}$ and dioxane at $100{ }^{\circ} \mathrm{C}$ as solvent (Scheme 95). ${ }^{307}$ Another example of the use of an electron-rich phosphine ligand, this time in a copper-free Sonogashira procedure is the alkynylation of 2-, and 3-chloropyridines and electron-rich 2-amino-5bromopyridines with terminal alkynes in high yields in aqueous isopropanol at $90{ }^{\circ} \mathrm{C}$, using as catalyst a combination of $\mathrm{Na}_{2} \mathrm{PdCl}_{4}(1 \mathrm{~mol} \%)$ and the electron-rich watersoluble protonated phosphine 246 (2 mol\%). 2-Chloropyridine (247) has been alkynylated with oct-1-yne under these conditions to give the pyridine derivative $\mathbf{2 4 8}$ 
(Scheme 95). ${ }^{308}$ In addition, copper-free Sonogashira conditions using $\mathrm{PdCl}_{2}\left(\mathrm{PPh}_{3}\right)_{2}$ and $\mathrm{DABCO}$ as the base under microwave irradiation in acetonitrile or water as solvents, have been employed for the coupling reaction of terminal alkynes with a pyridinium $N$ heteroarylamidine such as $N$-(5-iodopyridin-2-yl)amidine. ${ }^{309}$

\section{Scheme 95}

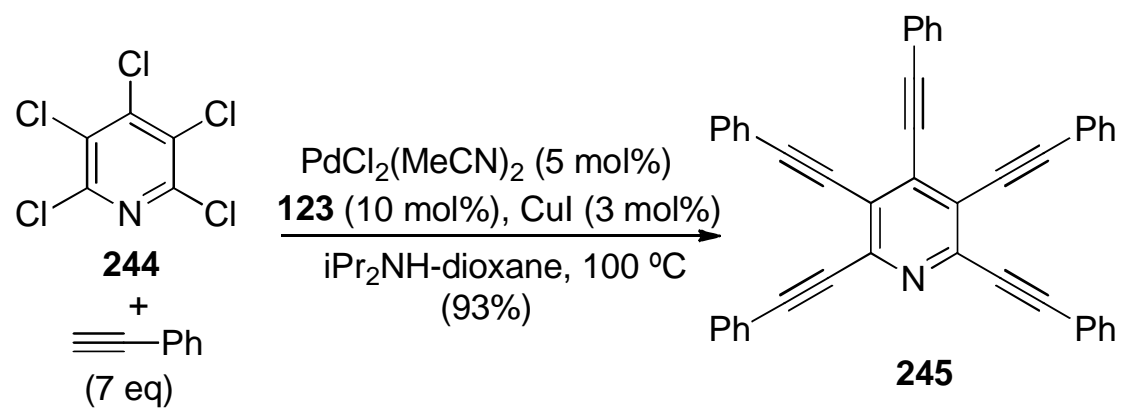<smiles>O=S(=O)(O)c1ccc(S(=O)(=O)O)cc1</smiles>

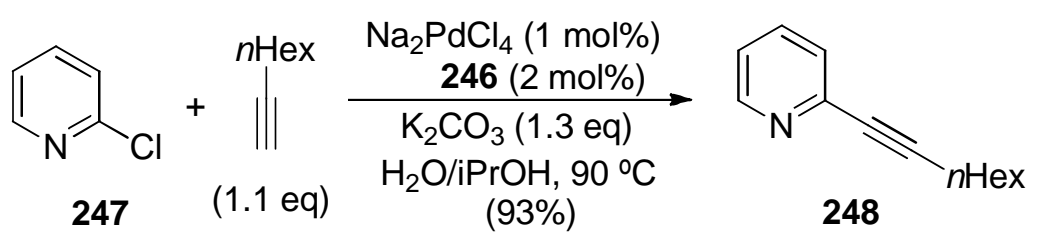

2-Alkynylquinolines have been prepared from 2-chloroquinolines and terminal alkynes using a copper co-catalyzed Sonogashira cross-coupling reaction promoted by $10 \%$ palladium-on-charcoal combined to triphenylphosphine and using water at $80{ }^{\circ} \mathrm{C}$ as solvent, as exemplified in the preparation of alkynylated quinoline $\mathbf{2 5 0}$ from 2chloroquinoline (249) and oct-1-yne, triethylamine being used as base (Scheme 96). ${ }^{310}$ Under these reaction conditions, the Sonogashira reaction of 2,4-dichloroquinoline afforded exclusively the 2-alkynylated product, as a result of the being the more activated position. ${ }^{310}$ When iodo or chloro substituents are present on the quinoline nucleus, the alkynylation takes place at the more reactive iodo-bearing position, as shown in the reaction of 4-chloro-3-iodoquinolines with terminal alkynes under the typical Sonogashira conditions. ${ }^{311}$ In addition, 2-, 3-, and 4-chlorinated [2,3-b]indoles can be alkynylated with terminal alkynes by means of the copper-cocatalyzed 
Sonogashira reaction. ${ }^{312}$ Moreover, 4-terminal alkynes have been used for the alkynylation of 1-chloroisoquinolines, but under copper-free Sonogashira conditions, using as catalyst a combination of $\mathrm{Pd}(\mathrm{OAc})_{2}(2.5 \mathrm{~mol} \%)$ and the electron-rich phosphine Ruphos (251), triethylamine as base and aqueous THF at $70{ }^{\circ} \mathrm{C}$ as solvent, as exemplified in the preparation of 1-alkynylated isoquinoline 253 from 1chloroisoquinoline 252 and cyclohexylacetylene (Scheme 96). ${ }^{313}$

\section{Scheme 96}
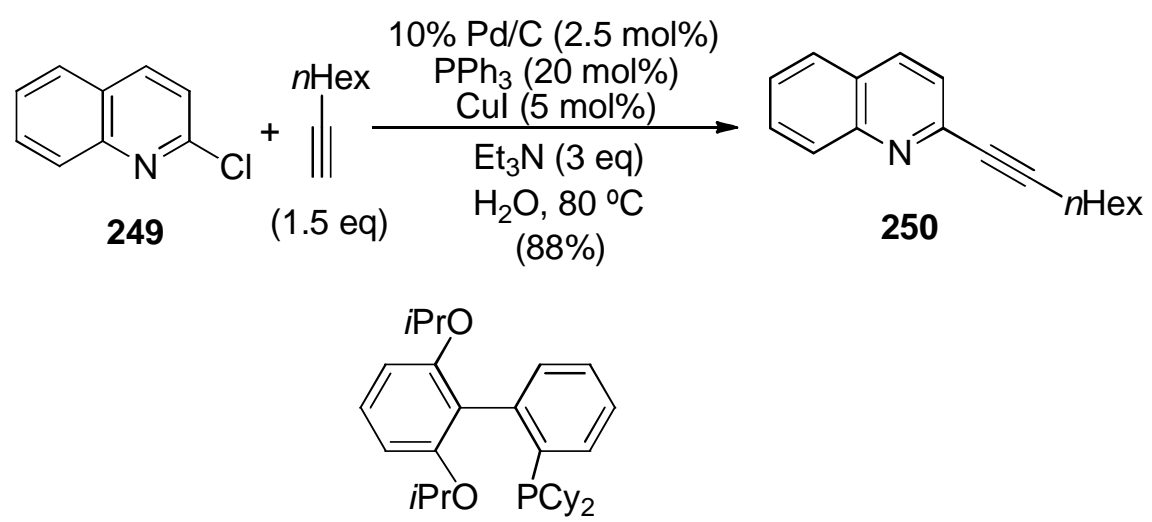

251

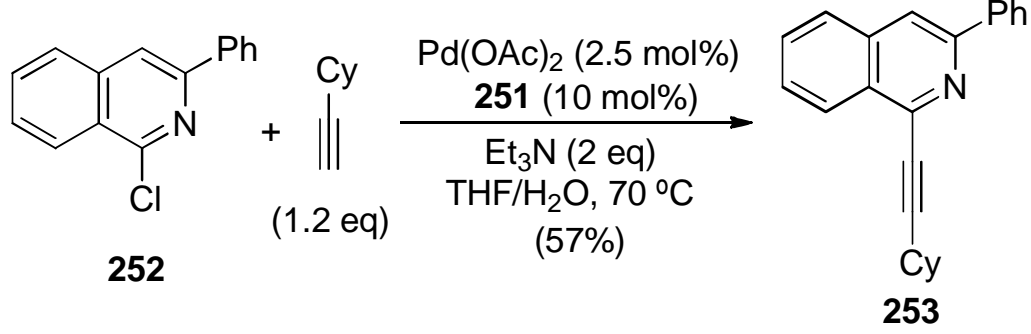

Pyrazines are activated substrates that, even bearing relatively unreacting carbonchlorine bonds, can be alkynylated reacting with terminal alkynes under the typical Sonogashira conditions. An example is the reaction of chlorinated pyrazine 254, which reacts with alkyne 255 under $\mathrm{Pd}\left(\mathrm{PPh}_{3}\right)_{4}$ catalysis and $\mathrm{CuI}$ co-catalysis, in the presence of sodium carbonate in $\mathrm{THF}$ at $80{ }^{\circ} \mathrm{C}$ as solvent, affording the corresponding alkynylated system 256 (Scheme 97), employed as precursor of aza-phthalocyanines dyes with well-defined spectral properties. ${ }^{314}$ Recent examples of alkynylation of chlorinated pyrazin-2-(1H)-ones ${ }^{315}$ or pyrido[2,3-d]pyridazines ${ }^{316}$ under this coppercocatalyzed conditions can also be found. 


\section{Scheme 97}

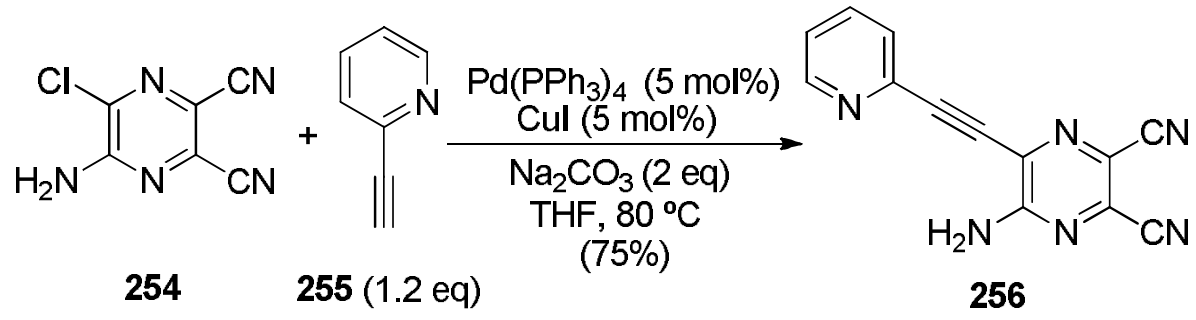

The alkynylation of the nucleobases of nucleosides allows the synthesis of nonnatural systems with interesting biological properties, and the Sonogashira reaction has been particularly useful for achieving this purpose. ${ }^{226 b, c}$ An interesting example of this palladium-catalyzed transformation is shown in Scheme 98, where unprotected 5iodouridine 258 reacts with terminal alkynes such as phenylacetylene under coppercocatalyzed Sonogashira conditions to give alkynylated system 259. ${ }^{317}$ This methodology, which has also been applied to the alkynylation of 8-bromopurines, is carried out using $\mathrm{Pd}(\mathrm{OAc})_{2}(10 \mathrm{~mol} \%)$ as palladium source, $\mathrm{CuI}$ as co-catalyst (10 mol\%) and TXPTS [trisodium tri(2,4-dimethyl-5-sulfonatophenyl)phosphine] (257) as water-soluble ligand, allowing to perform the reaction in aqueous acetonitrile at $65{ }^{\circ} \mathrm{C}$ as solvent. In addition, 5-iodo uracil-morpholino monomers have been recently 5alkynylated with different terminal alkynes using $\mathrm{Pd}\left(\mathrm{PPh}_{3}\right)_{4}(10 \mathrm{~mol} \%)$ as catalyst under copper-cocatalyzed reaction conditions. ${ }^{318}$

\section{Scheme 98}<smiles>CCCc1cc(S(=O)(=O)O[Na])c(C)cc1C</smiles>

257

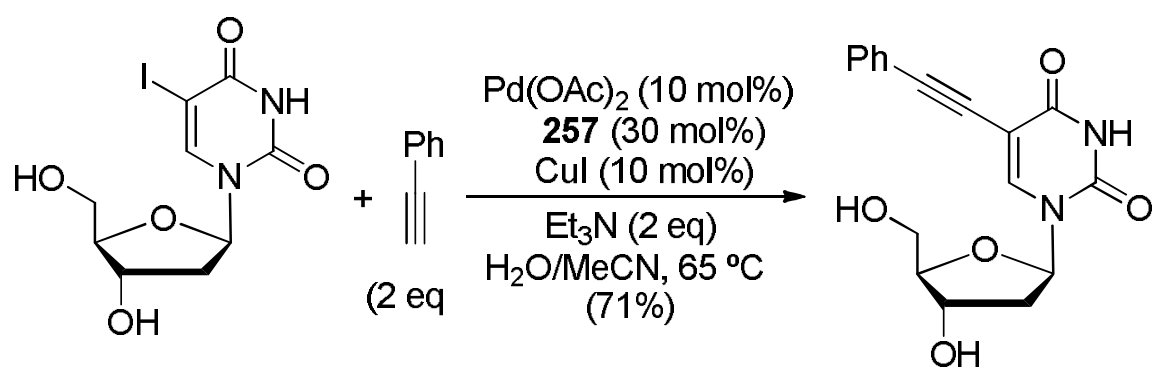


An example of the alkynylation of halogen-bearing oxygenated heterocycles using the 'typical' copper-cocatalyzed Sonogashira conditions is the reaction of methylsulfanyl-containing iodinated benzofuran 260, which was alkynylated with terminal alkynes, such as $p$-tolylacetylene, using $\mathrm{PdCl}_{2}\left(\mathrm{PPh}_{3}\right)_{2}(1 \mathrm{~mol} \%) / \mathrm{CuI}(2 \mathrm{~mol} \%)$ as catalytic mixture, in triethylamine at room temperature, yielding 3-alkynylated benzofuran 261 (Scheme 99). ${ }^{319}$ In addition, 4-(1-alkynyl)-2-(5H)-furanones have been obtained from $\beta$-tetronic acid bromide and terminal acetylenes under palladium/copper catalysis, ${ }^{320}$

\section{Scheme 99}<smiles>Cc1oc2ccccc2c1I</smiles>

260

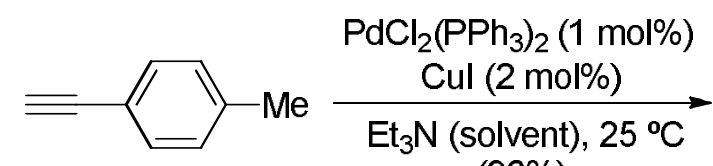

$(96 \%)$

$(2.5 \mathrm{eq}$

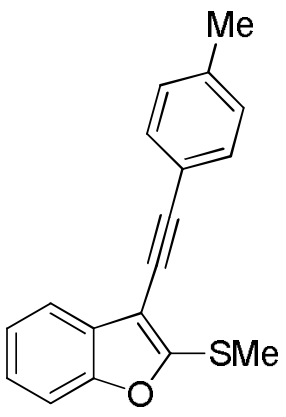

261

An application of the use of electron-rich phosphines as ligands for the copper-free Sonogashira coupling of difficult chlorinated substrates, when applied to sulfurcontaining heterocycles is, for instance, the alkynylation of 3-chlorothiophene (263) with terminal alkynes. This reaction is suitable to be performed in a copper-free fashion using the 'Buchwald-type' ligand 262 (3 mol\%) combined to $\mathrm{PdCl}_{2}\left(\mathrm{MeCN}_{2}(1 \mathrm{~mol} \%)\right.$ as palladium source, using sodium carbonate as base in toluene at $90^{\circ} \mathrm{C}$. An application of this methodology is shown in the preparation of alkynylated thiophene 264 using cyclopentylacetylene (Scheme 100). ${ }^{321}$ In addition, a copper-free Sonogashira procedure has also been used for the cross-coupling reaction of terminal alkynes with 3iodoselenophenes. ${ }^{322}$ In this case, $\mathrm{PdCl}_{2}\left(\mathrm{PPh}_{3}\right)_{2}$ was used as palladium catalyst, although in high loading (10 mol\%), and triethylamine as base in DMF at room temperature, an example being the synthesis of 3-alkynylselenophene 266 from iodoselenophene $\mathbf{2 6 5}$ 
and 3-ethoxyprop-1-yne (Scheme 100). However, alkynyldihydroselenophene derivatives have been obtained from 3-iododihydroselenophenes by alkynylation with terminal alkynes under $\mathrm{PdCl}_{2}\left(\mathrm{PPh}_{3}\right)_{2}(10 \mathrm{~mol} \%)$ catalysis in the presence of $\mathrm{CuI}(2 \mathrm{~mol}$ $\%) .{ }^{323}$

\section{Scheme 100}

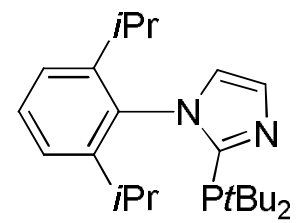

262

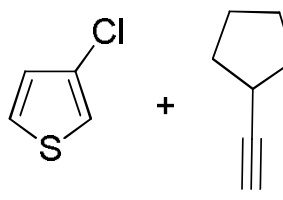

263 (2 eq)

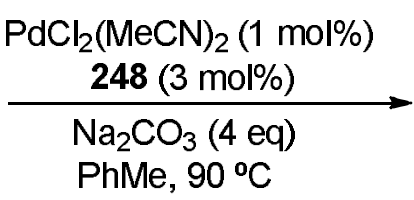

(73\%)

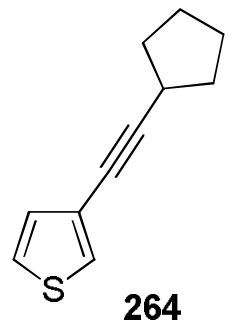

264

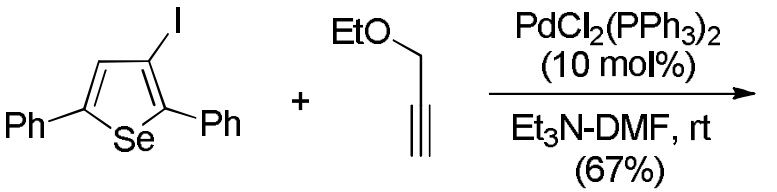

265

(3 eq)<smiles>CCOCC#Cc1cc(-c2ccccc2)[se]c1-c1ccccc1</smiles>

266

When the palladium-catalyzed alkynylation reaction is intended to be performed at a carbon bearing a hydroxy group, instead of a halogen, a solution is to transform the hydroxyl group in a better leaving one, such as a triflate. This has been carried out in situ in the case of 4-hydroxycoumarins, which have been 4-alkynylated with terminal alkynes under copper-free Sonogashira conditions $\left[\mathrm{PdCl}_{2}\left(\mathrm{PPh}_{3}\right)_{2} \quad(5 \mathrm{~mol} \%)\right.$, ethyldiisopropylamine, acetonitrile as solvent at $\left.60^{\circ} \mathrm{C}\right]$ when the reaction is performed in the presence of $p$-toluenesulfonyl chloride. ${ }^{324}$ The nonafluorobutanesulfonate (Nf) group (obtained from the corresponding hydroxyl group) has been used as a leaving group in the copper-cocatalyzed Sonogashira alkynylation of pyridines. ${ }^{325}$ An example of this transformation is the alkynylation of pyridine 267 with hex-1-yne to give compound 268, using $\mathrm{Pd}(\mathrm{OAc})_{2}$ as catalyst (5 mol\%), $\mathrm{CuI}$ as co-catalyst (5 mol\%) and adding triphenylphosphine (20 mol\%), diisopropylamine being used as base and solvent combined to $\mathrm{DMF}$ at $70{ }^{\circ} \mathrm{C}$ (Scheme 101). Moreover, tautomerizable heterocycles can 
be alkynylated with terminal alkynes via in situ $\mathrm{C}-\mathrm{OH}$ activation with the peptide coupling reagent bromotripyrrolidinophosphonium hexafluorophosphate (PyBrOP), followed by Sonogashira coupling using as catalyst a copper-free system formed by $\mathrm{PdCl}_{2}\left(\mathrm{MeCN}_{2}(5 \mathrm{~mol} \%)\right.$ and 2-(dicyclohexylphosphino)biphenyl (2- $\left.\mathrm{PhC}_{6} \mathrm{H}_{4} \mathrm{PCy}_{2}\right)$ (15 $\mathrm{mol} \%)^{326}$

\section{Scheme 101}

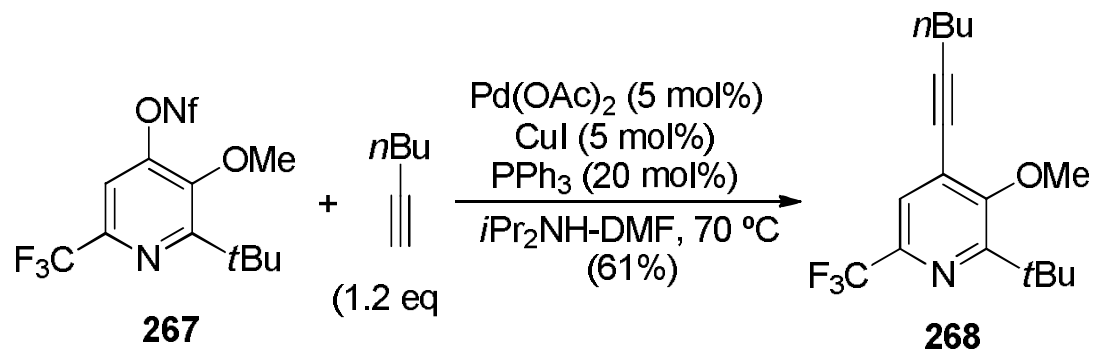

The direct oxidative alkynylation of some 5-membered heteroarenes with terminal alkynes has been achieved under palladium catalysis. Concerning atom economy, this process can be potentially superior to the Sonogashira coupling. Thus, $N$ alkylated 3-methylindoles have been alkynylated at C-2 with terminal alkynes in a process catalyzed by $\mathrm{K}_{2} \mathrm{PdCl}_{4}(10 \mathrm{~mol} \%)$ using cesium carbonate as base and oxygen (1 bar) and pivalic acid as oxidants, in DMSO as solvent at $80^{\circ} \mathrm{C} .{ }^{327}$ Another more simple oxidative 2-alkynylation of oxazoles and thiazoles has been performed using $\mathrm{Pd}\left(\mathrm{PPh}_{3}\right)_{4}$ as catalyst (5 mol\%) and lithium tert-butoxide as base, using air as oxidant in toluene at $100{ }^{\circ} \mathrm{C},{ }^{328}$ as is the case of the reaction of benzo[ $\left.d\right]$ oxazole 269 with alkyne 270 to give the alkynylated heterocycle 271 (Scheme 102). In addition, azole derivatives containing two different alkynyl groups have been prepared by direct oxidative alkynylation using as catalyst $\mathrm{Pd}(\mathrm{OAc})_{2}(2.5 \mathrm{~mol} \%)$ in the presence of silver carbonate and acetic acid, working in a mixture of DMF-DMSO as solvent at $120{ }^{\circ} \mathrm{C} .{ }^{329}$ Furthermore, another five-membered heterocycles, particularly thiophenes, have been alkynylated with terminal acetylenes using as catalyst $\mathrm{Pd}_{2}(\mathrm{dba})_{3}(0.2 \mathrm{~mol} \%)$ and $\mathrm{Ag}_{2} \mathrm{O}$ as oxidant, in the presence of pivalic acid $(\mathrm{PivOH})$, cesium carbonate and triethylamine, in 1,2dimethoxyethane as solvent at $90{ }^{\circ} \mathrm{C}$, leading to interesting 2-alkynylated systems. ${ }^{330} \mathrm{An}$ example this last methodology can be seen in Scheme 102, where 2-alkynylated thiophene 273 has been obtained from the direct oxidative coupling of 2-acylthiophene (272) and phenylacetylene. 


\section{Scheme 102}
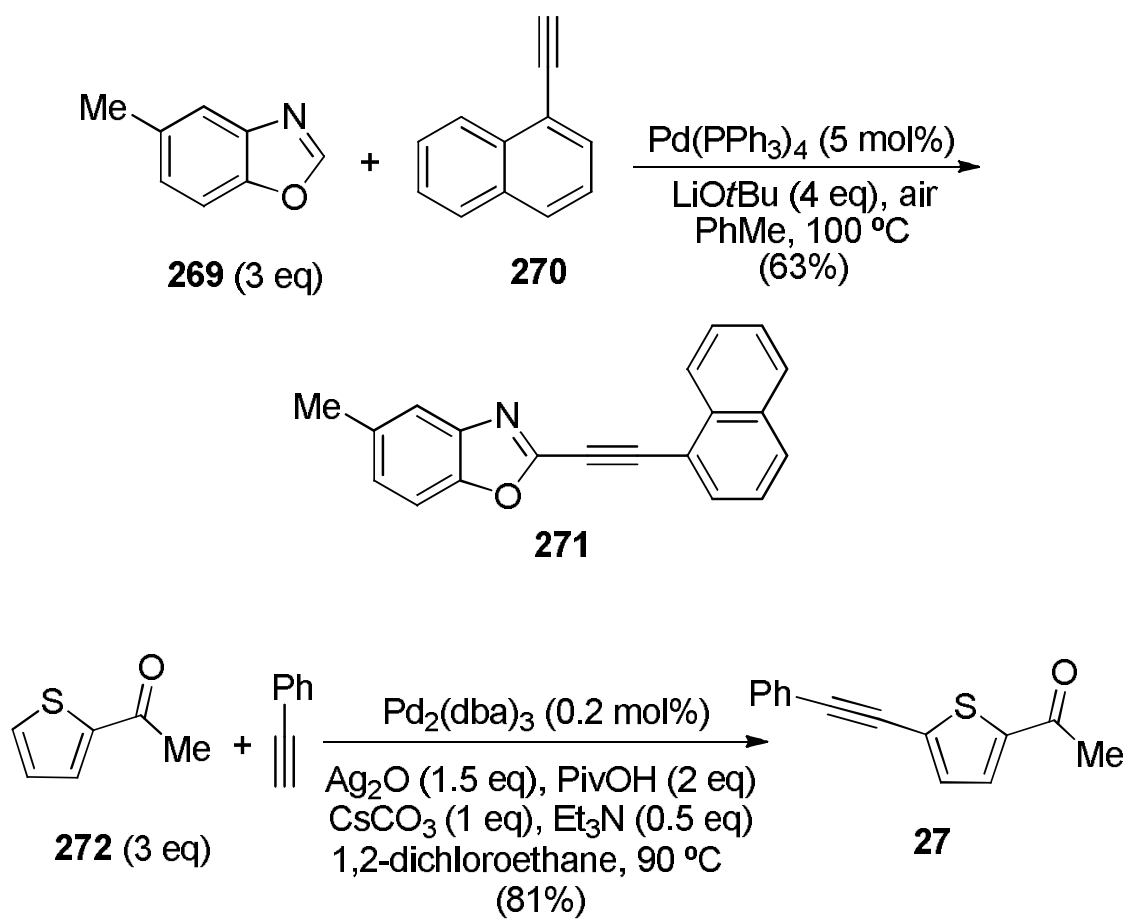

\subsection{1,3-Enynes}

The conjugated 1,3-enyne moiety is a structure of high interest due to its presence in many natural products and biologically active substrates as well as in new functional materials, and its preparation by the cross-coupling of terminal alkynes and vinylic systems is straightforward by using a configuration-retention stereospecific procedure such as the palladium-catalyzed Sonogashira methodology. ${ }^{226}$ In this section, mainly examples of recent synthesis of the 1,3-enyne system by using this coppercocatalyzed and copper-free alkynylation procedure with different catalytic systems will be shown. Other less used palladium-catalyzed synthesis of enynes, such as alkyne dimerization or direct coupling of alkynes and alkenes will also be shown.

The typical copper-cocatalyzed Sonogashira reaction has been employed for the preparation of conjugated enynes using as coupling partners the 'easy' vinyl iodides, as exemplified in Scheme 103, which shows the use of $\mathrm{PdCl}_{2}\left(\mathrm{PPh}_{3}\right)_{2}(5 \mathrm{~mol} \%)$ combined to $\mathrm{CuI}(5 \mathrm{~mol} \%)$ as catalytic combination for the coupling of hex-1-yne with cyclic vinyl iodide 274 affording enyne 275, the reaction being performed in triethylamine as solvent at room temperature. ${ }^{331}$ In addition, water has been used as solvent in the coupling of terminal alkynes with vinyl iodides under $\mathrm{Pd}\left(\mathrm{PPh}_{3}\right)_{4}(2 \mathrm{~mol} \%) / \mathrm{CuI}(4$ 
mol\%) catalysis using pyrrolidine as base. ${ }^{332}$ Other functionalized vinyl iodides have also being used for the coupling with terminal alkynes, leading to enynes under this classical Sonogashira reaction, such as $(E)$-2-iodovinyl sulfones ${ }^{333}$ and $(E)$-1-iodovinyl1-tributylstannanes. ${ }^{334}$

\section{Scheme 103}

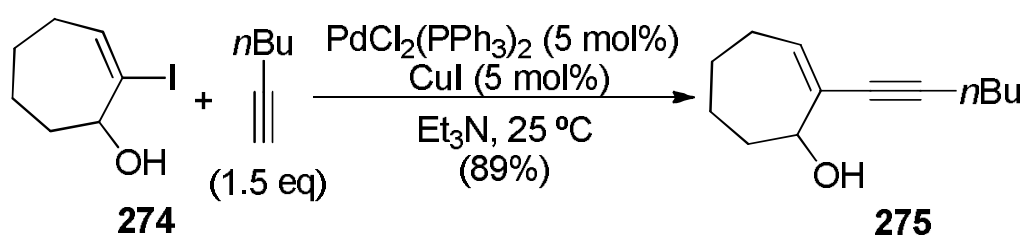

A recent example of the use of vinyl bromides as the coupling partners of terminal alkynes for the synthesis of 1,3-enynes via the copper-cocatalyzed Sonogashira reaction is the process promoted by palladacycle 276 ( 1 mol\%) combined to $\mathrm{CuBr}(20$ mol\%). ${ }^{335}$ Using this catalytic combination, $(E)$ - $\beta$-bromostyrene $(\mathbf{2 7 8})$ has been coupled to phenylacetylene to give enyne $\mathbf{2 7 9}$, cesium carbonate being used as base and DMSO as solvent at $40{ }^{\circ} \mathrm{C}$ (Scheme 104). This reaction has also been carried out under copperfree conditions using as catalyst the palladium(II) complex based on $N, N$ dimethylethanolamine 277 ( $1 \mathrm{~mol} \%$ ), cesium carbonate as base and DMF as solvent at room temperature. ${ }^{336}$

\section{Scheme 104}

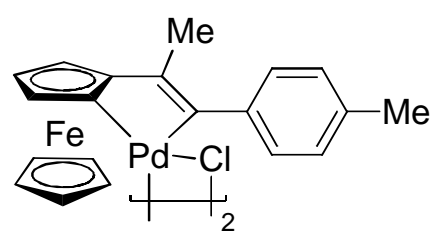

276<smiles>CN1CCO[PH]12OCCN2C</smiles>

277

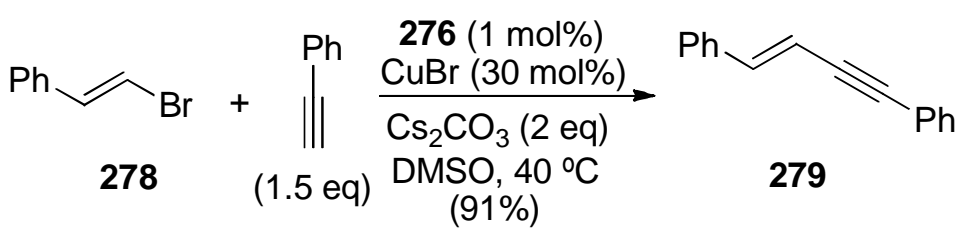

Vinyl chlorides, similarly to aryl chlorides (see Section 6.1), are less reactive towards the coupling with terminal alkynes by means of the Sonogashira reaction than 
their corresponding iodides or bromides, therefore their applicability for this crosscoupling process has been less frequent. For instance, when a chlorine and bromine atoms are on an alkene system, as in the case of $\mathbf{2 8 0}$, the Sonogashira reaction takes place on the C-Br bond, as shown in the synthesis of enyne $\mathbf{2 8 1}$ after reaction of $\mathbf{2 8 0}$ with phenylacetylene catalyzed by $\mathrm{PdCl}_{2}\left(\mathrm{PPh}_{3}\right)_{2}(5 \mathrm{~mol} \%)$ and $\mathrm{CuI}(15 \mathrm{~mol} \%)$ in the presence of triethylamine as base in toluene at $80{ }^{\circ} \mathrm{C}$ (Scheme 105). ${ }^{337}$ The more reactive $(Z)$-1,2-dichloroethylene has been used under the classical Sonogashira reaction conditions catalyzed by $\mathrm{PdCl}_{2}\left(\mathrm{PPh}_{3}\right)_{2}(5 \mathrm{~mol} \%) / \mathrm{CuI}(10 \mathrm{~mol} \%)$, giving rise to enynes and dienynes, as in the case of its reaction with monoarylated alkyne 282, using $n$ butylamine as base in ether as solvent at $20^{\circ} \mathrm{C}$. Chlorinated enyne $\mathbf{2 8 3}$, an intermediate in the synthesis of anticancer Combrestatin analogues, was obtained under these conditions (Scheme 105). ${ }^{338}$ In addition, (Z)-1,2-dichloroethylene has also been used for the coupling with amino acid-containing terminal alkynes, in reaction catalyzed by $\mathrm{PdCl}_{2}(\mathrm{PhCN})_{2}(0.05 \mathrm{~mol} \%)$ and $\mathrm{CuI}(0.05 \mathrm{~mol} \%) .{ }^{339}$ Moreover, activated $(E)-2-$ chlorovinyl sulfones have also been used for the coupling with terminal acetylenes. ${ }^{340}$

\section{Scheme 105}
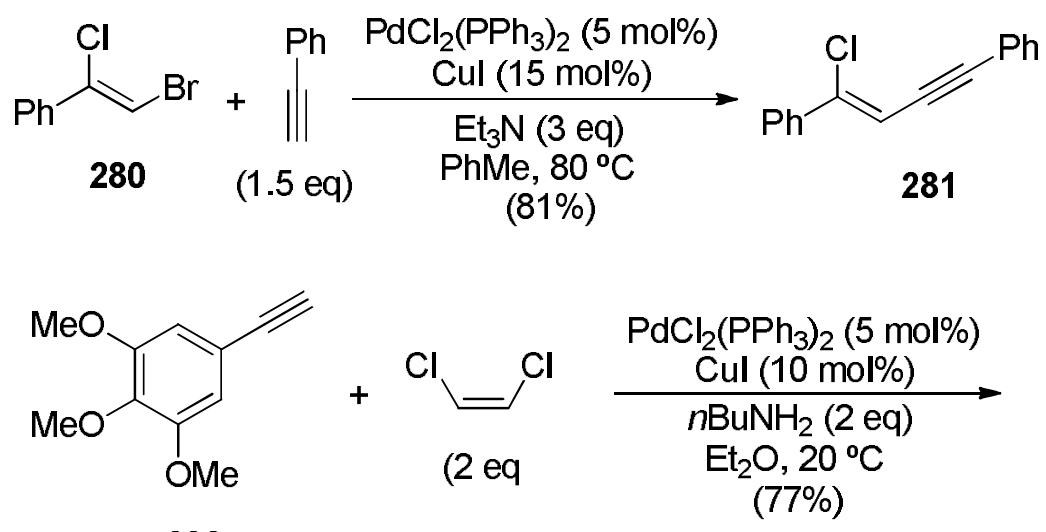

282<smiles>COc1cc(C#C/C=C\Cl)cc(OC)c1OC</smiles>

283

Vinyl triflates, prepared easily by trapping the corresponding enolate from ketones, can also be used for the palladium-catalyzed Sonogashira coupling with terminal alkynes, giving rise to conjugated enynes. A useful example of this 
methodology is the cross-coupling of 17-steroidal triflates, such as $\mathbf{2 8 4}$, and terminal alkynes, such as but-3-yn-1-ol, to give 17-alkynylsteroids such as $\mathbf{2 8 5}$ (Scheme 106). ${ }^{341}$ The process was catalyzed by the combination of $\mathrm{Pd}\left(\mathrm{PPh}_{3}\right)_{4}(5 \mathrm{~mol} \%) / \mathrm{CuI}(20 \mathrm{~mol} \%)$ in the presence of diisopropylethylamine and in DMF as solvent at room temperature, although it was observed that the use of silver acetate as cocatalyst instead of CuI gave rise to higher yields.

\section{Scheme 106}

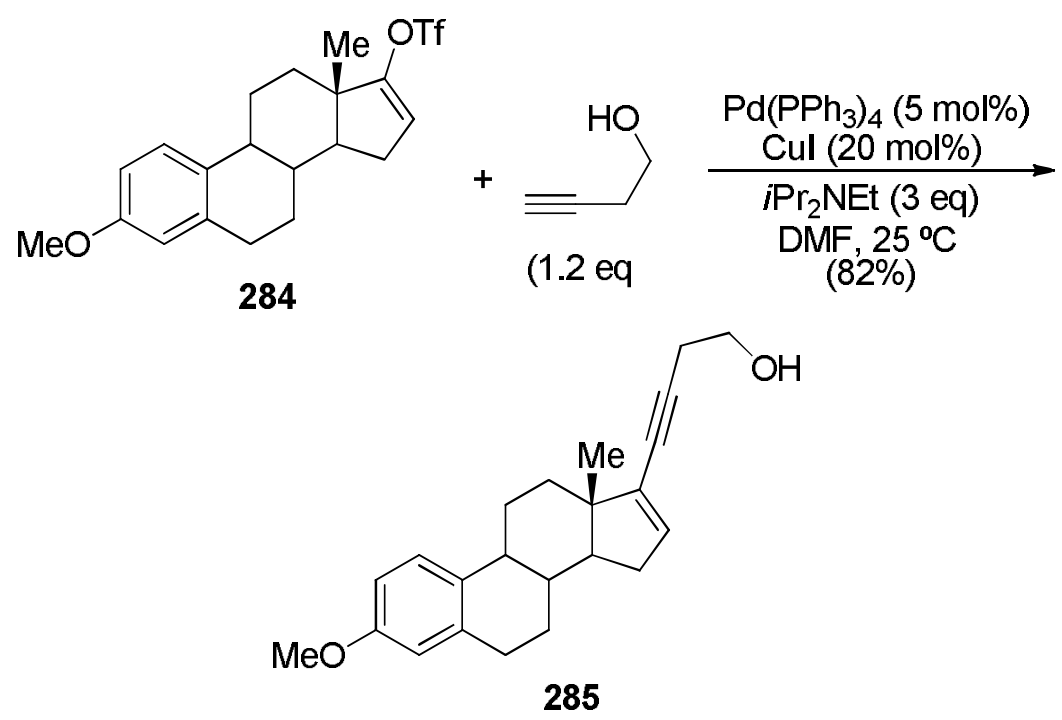

Apart from the Sonogashira cross-coupling reaction, other less-frequently employed methodologies for the synthesis of 1,3-enynes have been used. Thus, inactivated alkenes have been coupled with ethynyl bromides under $\mathrm{Pd}(\mathrm{OAc})_{2}$ catalysis (5 mol\%) in a 'reverse' Sonogashira reaction. ${ }^{342}$ However, the direct palladiumcatalyzed dimerization of alkynes is a more atom-economical approach towards conjugated enynes. The highly selective head-to-tail palladium-catalyzed dimerization of terminal alkynes was developed some time ago, using as catalytic system a combination of $\mathrm{Pd}(\mathrm{OAc})_{2}(2 \mathrm{~mol} \%)$ and the electron-rich and bulky ligand tris(2,6dimethoxyphenyl)phosphine (TDMPP) $(2 \mathrm{~mol} \%),{ }^{343}$ as in the case of the dimerization of oct-1-yne to yield enyne 286 (Scheme 107). ${ }^{343 a}$ However, when using a $\mathrm{Pd}(\mathrm{OAc})_{2}$ /imidazolium chloride catalytic system, mixtures of regio- and stereoisomeric enynes were obtained. ${ }^{344}$ 
Scheme 107

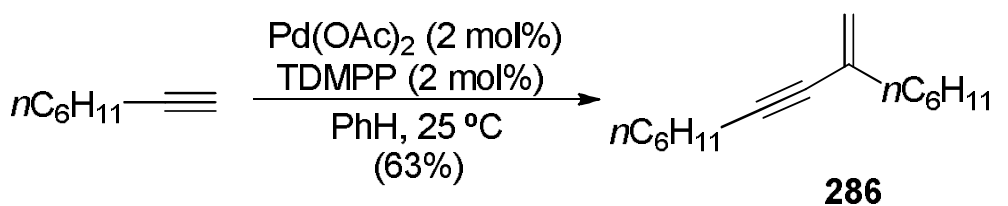

The head-to-head palladium-catalyzed dimerization of terminal alkynes has been achieved with high regio- and (E)-stereoselectivity, using as catalyst $\mathrm{Pd}_{2}(\mathrm{dba})_{3} \mathrm{CHCl}_{3} / \mathrm{TDMPP}$, although the method is limited to terminal aryl acetylenes bearing a requisite ortho- $\mathrm{H}$ atom, as agostic interactions are involved. ${ }^{345}$ More recently, a very selective head-to-head dimerization has been achieved using as catalyst the bis$N$-heterocyclic carbene palladium complex 287 ( $2 \mathrm{~mol} \%)$ in the presence of TDMPP (2 mol\%) in toluene at $60{ }^{\circ} \mathrm{C}$, as in the dimerization of 3-ethynylthiophene (288) to give enyne 289 (Scheme 108). ${ }^{346}$ In addition, (Z)-1,3-enynes have been obtained by dehydrogenative olefination of terminal arylalkynes with allylic ethers, as exemplified in the coupling of phenylacetylene and allyl methyl ether to yield compound 290 (Scheme 108), the process being catalyzed by $\mathrm{Pd}(\mathrm{OAc})_{2}(5 \mathrm{~mol} \%) / \mathrm{dppp}(6 \mathrm{~mol} \%)$ in acetic acid/acetonitrile as solvent at $80{ }^{\circ} \mathrm{C} . .^{347}$

\section{Scheme 108}<smiles>CC(C)c1cccc(C(C)C)c1N1C=CN2c3c(C(C)C)cccc3C(C(F)(F)F)C(C(F)(F)F)(C(F)(F)F)C12</smiles>

287
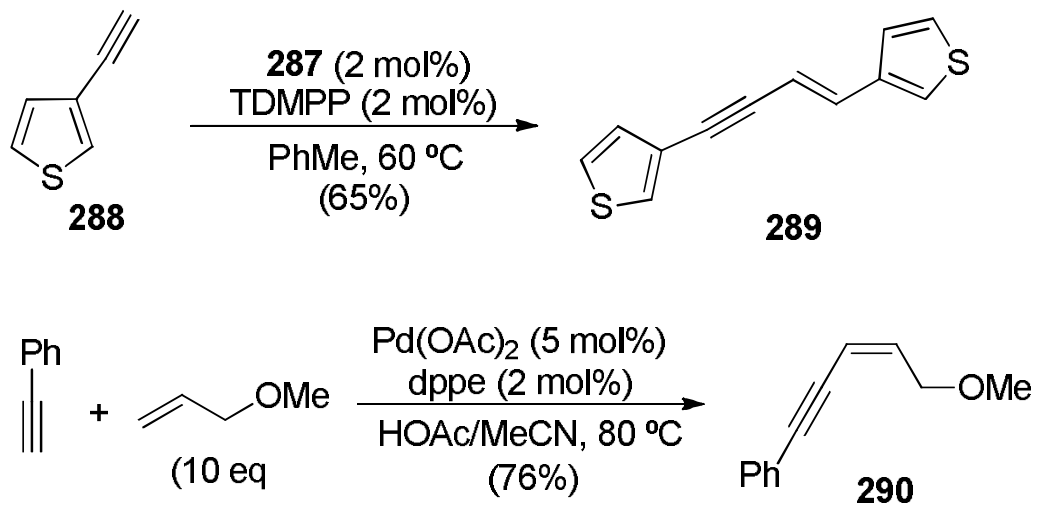
Conjugated enynones have been prepared by palladium-catalyzed oxidative coupling of terminal alkynes and conjugated carbonyl systems, such as vinyl ketones, acrylates or acroleine, a reaction catalyzed by $\mathrm{Pd}\left(\mathrm{OCOCF}_{3}\right)_{2}(2 \mathrm{~mol} \%)$ in the presence of potassium carbonate as base in DMF at room temperature under molecular oxygen (1 bar). ${ }^{348}$ A particular example of this methodology is the synthesis of enynone 291 by coupling of tert-butyl acrylate and 3,3-dimethylbut-1-yne (Scheme 109).

\section{Scheme 109}

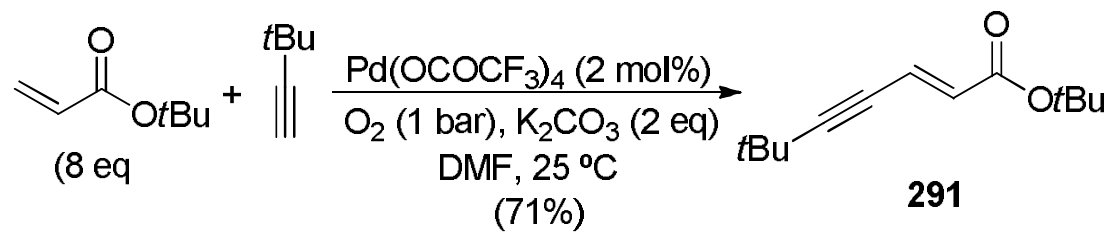

\subsection{1,3-Diynes}

1,3-Diynes occur widely in numerous biologically active natural products, ${ }^{227,349}$ and are important scaffolds in supramolecular chemistry, ${ }^{350}$ as well as playing an important role in the design of advanced materials such as conjugated polymers, liquid crystals, molecular wires or nonlinear optic materials. ${ }^{351}$ Therefore, different methodologies have been described for the preparation of 1,3-diynes using the simple and direct carboncarbon coupling or terminal alkynes, and those achieved by using palladium catalysis are one of the most attractive due to their usual efficiency and mildness. ${ }^{352}$

The mentioned (Section 6.1) Glaser-type ${ }^{353}$ formation of 1,3-diynes as byproducts in the palladium-copper catalyzed Sonogashira coupling of aryl halides with terminal alkynes when an oxidant such as air was present in the reaction medium, ${ }^{354}$ inspired the use of this methodology for the preparation of this type of conjugated diynes. ${ }^{352}$ The process was optimized for the coupling of arylacetylenes using $\mathrm{Pd}\left(\mathrm{PPh}_{3}\right)_{4}$ as catalyst (2 $\mathrm{mol} \%)$ and $\mathrm{CuI}(8 \mathrm{~mol} \%)$ as co-catalyst using chloroacetone as oxidant and in the presence of triethylamine as base, in benzene at room temperature. ${ }^{355}$ Under these conditions, aryl alkynes such as phenylacetylene, afforded the corresponding 1,3diynes, such as 292 (Scheme 110), aliphatic alkynes affording mixtures of the 1,3-diyne and trialkynylated olefin oligomers. 


\section{Scheme 110}

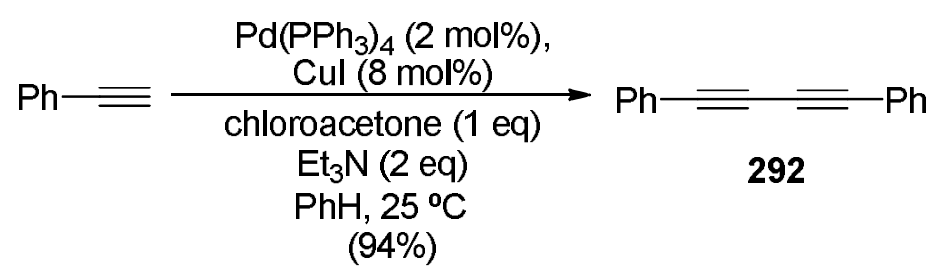

Other oxidants, combined with a catalytic mixture of a commercial palladium complex or salt and $\mathrm{CuI}$, have been employed to achieve the homocoupling or terminal alkynes, as is the case of 4-iodo-2-nitroresorcinol or DMSO [with $\mathrm{PdCl}_{2}\left(\mathrm{PPh}_{3}\right)_{2}$ ], ${ }^{356}$ iodine [with $\mathrm{PdCl}_{2}\left(\mathrm{PPh}_{3}\right)_{2}$ ], ${ }^{357}$ ethyl bromoacetate [with $\mathrm{PdCl}_{2}\left(\mathrm{PPh}_{3}\right)_{2}$ ], ${ }^{358}$ air [with $\mathrm{Pd}(\mathrm{OAc})_{2}$ ], ${ }^{359}$ triethylamine oxide [with $\mathrm{PdCl}_{2}$ ] ${ }^{360} p$-chloranyl [with $\left.\mathrm{Pd}\left(\mathrm{PPh}_{3}\right)_{4}\right],{ }^{361}$ (diacetoxyiodo)benzene [with $\mathrm{PdCl}_{2}$ ], ${ }^{362}$ (diacetoxyiodo)benzene and iodosylbenzene [with $\mathrm{PdCl}_{2}+\mathrm{PPh}_{3}$ ]. ${ }^{363}$ Silver(II) oxide has also been used recently as an oxidant combined to a rather low loading of $\mathrm{Pd}\left(\mathrm{PPh}_{3}\right)_{4}$ as catalyst $(1 \mathrm{~mol} \%)$ in the copper-free homocoupling of aryl and alkylacetylenes, the reaction being performed in THF as solvent at $60{ }^{\circ} \mathrm{C}$, as in the case of the homocoupling of cyclohexylacetylene to give 1,3 diyne 293 (Scheme 111). ${ }^{364}$ In addition, there are examples where no stoichiometric oxidant has been added to achieve the homocoupling using the combination $\mathrm{PdCl}_{2}\left(\mathrm{PPh}_{3}\right)_{2} \quad(3 \mathrm{~mol} \%) / \mathrm{CuI} \quad(3 \mathrm{~mol} \%)$ as catalyst, the addition of more triphenylphosphine ( $9 \mathrm{~mol} \%$ ) being sufficient. ${ }^{365}$ This is the case of the homocoupling of propargyl glycosides, although large amounts of $\mathrm{PdCl}_{2}\left(\mathrm{PPh}_{3}\right)_{2}(10 \mathrm{~mol} \%)$ and 1 equivalent of $\mathrm{CuI}$ have been necessary. ${ }^{366}$ Moreover, water-soluble phosphines have also been used combined to $\operatorname{Pd}(\mathrm{OAc})_{2}$ in a homogeneous acetonitrile-water system, with $^{367}$ and without ${ }^{157} \mathrm{Cu}(\mathrm{I})$ promotor, affording diynes with moderate yields, whereas $\operatorname{Pd}_{2}(\mathrm{dba})_{3}(5 \mathrm{~mol} \%)$ has been used for the homocoupling of terminal alkynes in the presence of allyl bromide and $\mathrm{TBAB}$, in $\mathrm{CH}_{2} \mathrm{Cl}_{2} / 50 \%$ aq $\mathrm{NaOH}$ under phase-transfer conditions. $^{368}$

\section{Scheme 111}

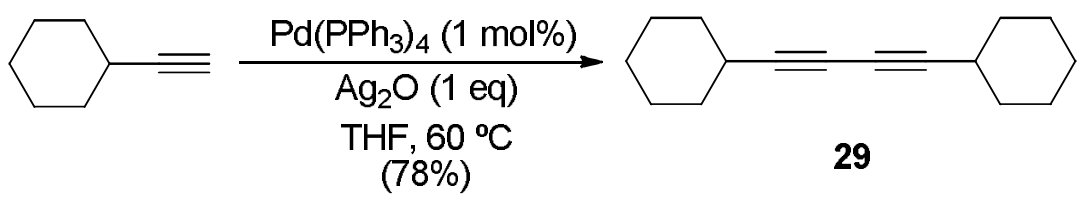


Palladium complexes bearing pyridine rings as ligands have been employed as catalyst in this homocoupling reaction, as shown in the case of complex 294 which has proved successful acting as catalyst at a very low loadings (0.05-0.5 mol\%) in the homocoupling of phenylacetylene. ${ }^{369}$ The reaction was carried out in the presence of $\mathrm{CuI}$ as co-catalyst (5 mol\%), using pyrrolidine or tetra- $n$-butylammonium acetate (TBAA) as base, in NMP as solvent at $110^{\circ} \mathrm{C}$ and without any additional oxidant. In addition, the cationic bipyridine ligand $\mathbf{2 9 5}$ has been used combined to a very low loading of the palladium complex $\mathrm{PdCl}_{2}\left(\mathrm{NH}_{3}\right)_{2}(0.001-1 \mathrm{~mol} \%)$ and $\mathrm{CuI}(1 \mathrm{~mol} \%)$ to generate a catalytic system that allows the coupling of terminal alkynes in water as solvent at room temperature, working in the presence of TBAB and with or without iodine as oxidant in open air. An example of the use of this methodology is the coupling of acetylene 296 to furnish 1,3-diyne 297 (Scheme 112). ${ }^{370}$ In this case, the watersoluble catalyst system was separated from the organic products by extraction and the residual aqueous solution was active for reuse for several cycles without a significant decrease in activity.

\section{Scheme 112}

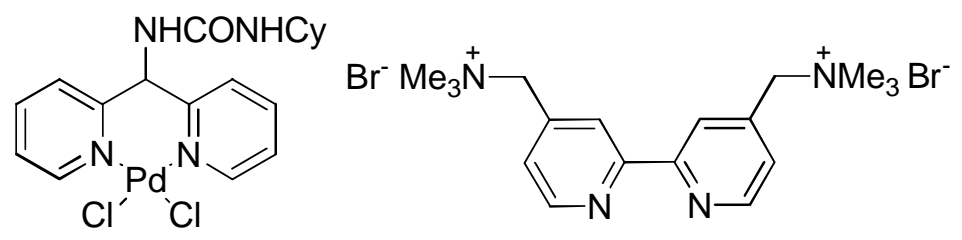

294

295

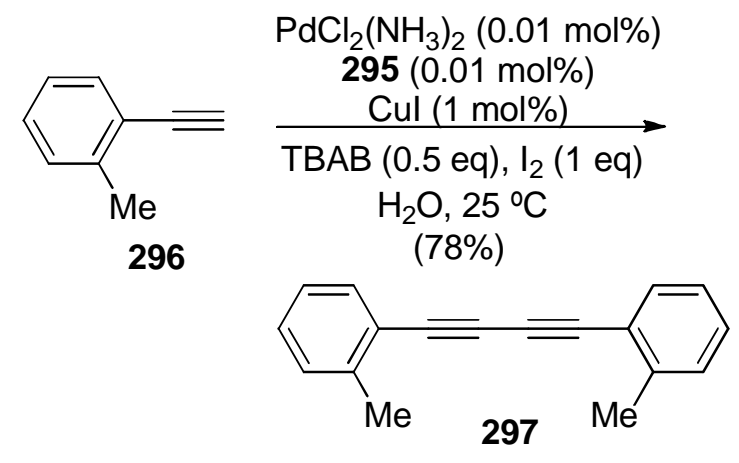

In the presence of dialkynylated bis-heterocycle 298 as ligand (2 mol\%), $\mathrm{PdCl}_{2}\left(\mathrm{PPh}_{3}\right)_{2}$ (2 mol\%) has shown to catalyze the copper-free homocoupling of aromatic and aliphatic terminal alkynes in the presence of triethylamine as base, in 
acetonitrile at $40{ }^{\circ} \mathrm{C}$ or room temperature in air, as in the case of the homocoupling of enyne 205 to diyne 299 (Scheme 113). ${ }^{371}$

\section{Scheme 113}

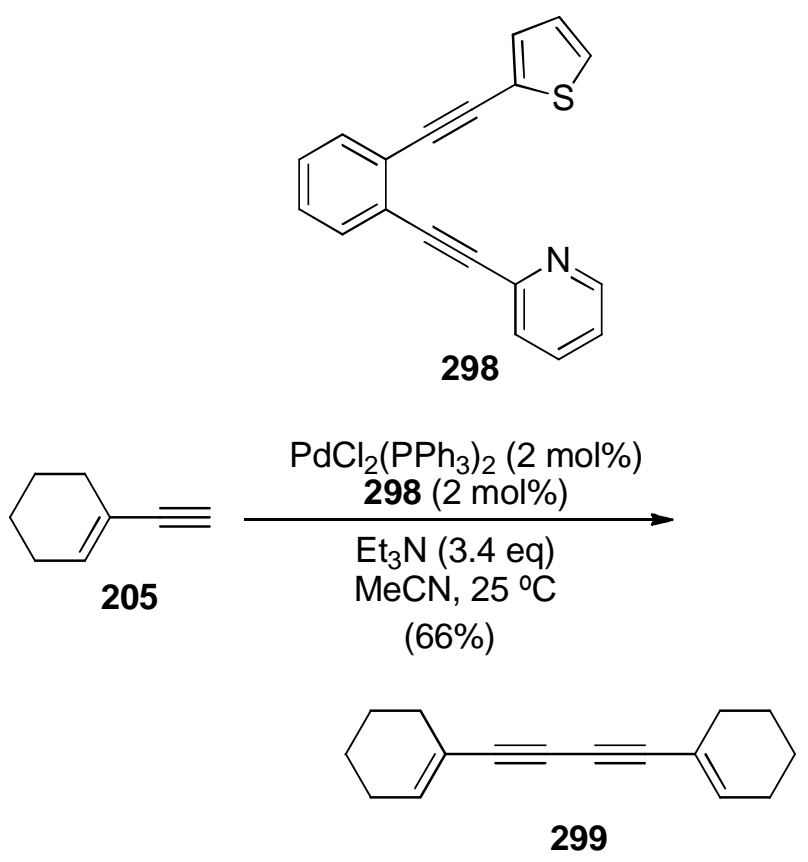

There are a few examples were NHC-palladium complexes have been used as catalysts in the homocoupling of terminal alkynes, as is the case of complexes $\mathbf{3 0 0}$ which have been used as catalysts $(0.3 \mathrm{~mol} \%)$ in the homocoupling of arylacetylenes, working in the presence of benzoquinone as oxidant in acetonitrile as solvent at $70{ }^{\circ} \mathrm{C}$, although the conversions were low to moderate. ${ }^{372}$ In addition, NHC-palladium complexes such as $\mathbf{3 0 1}$ has been used as catalyst $(0.5 \mathrm{~mol} \%)$ in the presence of $\mathrm{CuI}$ as co-catalyst (3 mol\%) and 2-(benzylamino)ethanol as base under molecular oxygen in DMF at room temperature to give homocoupled products from terminal acetylenes, as is the case of the coupling of alkynylated aniline $\mathbf{3 0 2}$ to give 1,3-diyne $\mathbf{3 0 3}$ (Scheme 114) ${ }^{373}$ Furthermore, the use of NHC macrocyclic palladium pincer complexes for this homocoupling reaction has also been reported. ${ }^{374}$ 


\section{Scheme 114}<smiles>[R]n1ccnc1C(=O)O[Pb]OC(C)=O</smiles>

$\mathrm{n}=2,3$

$\mathrm{R}=\mathrm{Bn}, 1-\mathrm{Naphthyl}$

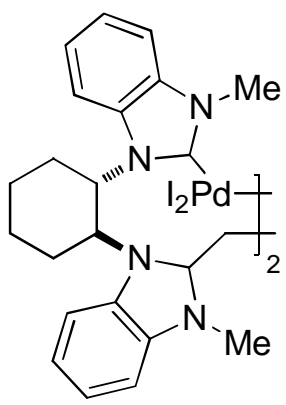

301

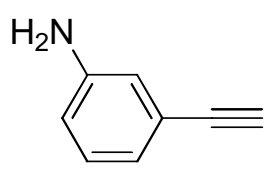

302

$$
\begin{aligned}
& \underset{\mathrm{BnNHCH} \mathrm{CH}_{2} \mathrm{OH}, \mathrm{O}_{2}}{\stackrel{301(0.5 \mathrm{~mol} \%), \mathrm{Cul}(3 \mathrm{~mol} \%)}{\longrightarrow}} \\
& \text { DMF, } 40^{\circ} \mathrm{C}
\end{aligned}
$$

$(82 \%)$

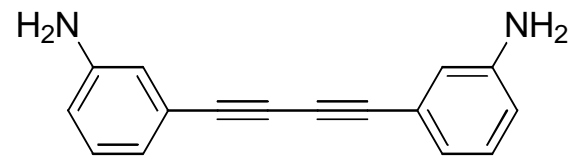

303

Palladacycles have also been employed as catalysts in the homocoupling of terminal alkynes in the absence of oxidants. Thus, there are examples where palladacycles from ferrocenylimines $(2.5 \mathrm{~mol} \%)$ combined to $\mathrm{CuI}(2.5 \mathrm{~mol} \%)$ catalyze the homocoupling of aromatic and aliphatic terminal alkynes leading to diynes. ${ }^{375}$ However, better results were achieved employing as catalyst the oxime-derived palladacycle 304, which at very low loadings (0.05-0.5 mol\%) and combined to $\mathrm{CuI}(5$ mol\%) was able to catalyze the homocoupling of aromatic and aliphatic terminal alkynes, as illustrated in Scheme 115 with the formation of diyne $\mathbf{3 0 5}$ from oct-1-yne, the reaction being carried out in the presence of pyrrolidine as base in NMP at 110 ${ }^{\circ} \mathrm{C} .{ }^{376}$ 
Scheme 115<smiles>ON(O)c1ccc(Cl)cc1Cl</smiles>

304

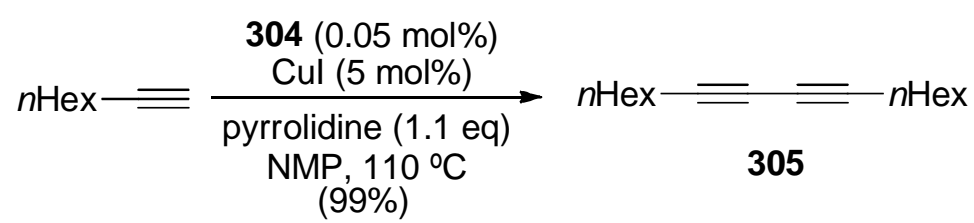

The use of supported palladium species for achieving this homocoupling reaction has also been explored. ${ }^{352 \mathrm{c}}$ Examples are the use of a polystyrene-PEG400- $\mathrm{PPh}_{2}$ as a supported phosphine ligand combined to $\mathrm{PdCl}_{2}(3 \mathrm{~mol} \%)$ and in the presence of $\mathrm{CuI}(3$ mol\%). The reaction was carried out in acetonitrile/water with sodium percarbonate as both an oxidant and a base at room temperature, and the catalyst was recovered by filtration and reused up to five times with a certain decrease in its activity. ${ }^{377}$ In addition, the palladium complex anchored to mesoporous silica 306 (1 mol\%) promotes the homocoupling of phenylacetylene. ${ }^{378}$ The reaction proceeds in the presence of 4 iodophenol which acts as oxidizer and triethylamine as base at $70{ }^{\circ} \mathrm{C}$, no reusing experiments being performed. Moreover, $\operatorname{Pd}(0)$ and $\operatorname{Pd}(\mathrm{II})$ nanoparticles have been supported on a 1,4-diazabicyclo[2.2.2] octane (DABCO)-functionalized mesoporous silica SBA-15 307 after heating $\operatorname{Pd}(\mathrm{OAc})_{2}$ and the support in refluxing acetone. The resulting anchored palladium species 307-Pd has been used as catalyst ( $1 \mathrm{~mol} \%$ ) in the homocoupling of aromatic and aliphatic terminal alkynes at room temperature. ${ }^{379}$ However, the presence of 1 equivalent of DABCO and $\mathrm{CuI}(1 \mathrm{~mol} \%)$ was necessary. The catalysts was recovered by centrifugation and reused up to four times keeping its activity. An example of the use of this methodology is the synthesis of diyne $\mathbf{3 0 8}$ from tert-butylacetylene (Scheme 116). 


\section{Scheme 116}

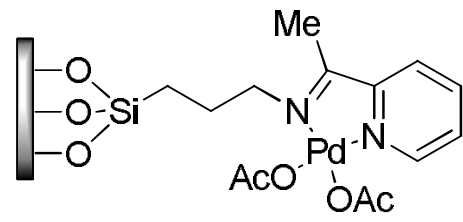

306

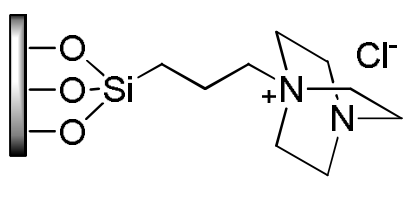

307

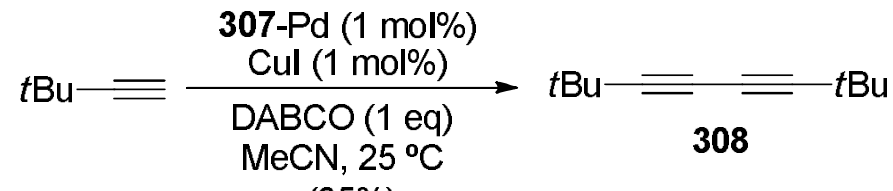

$(65 \%)$

Low loading of $1 \% \mathrm{Pd} / \mathrm{C}(0.01-0.03 \mathrm{~mol} \% \mathrm{Pd})$ combined to $\mathrm{CuI}(3 \mathrm{~mol} \%)$ have been employed as a catalytic mixture in the homocoupling of aromatic and aliphatic terminal alkynes leading to 1,3-diynes in good yields, using oxygen as oxidant in DMSO as solvent at room temperature, no attempts for recycling being made. ${ }^{380}$ An example of the application of this methodology is the homocoupling of propargyl alcohol 309 to furnish diyne 310 (Scheme 117).

\section{Scheme 117}

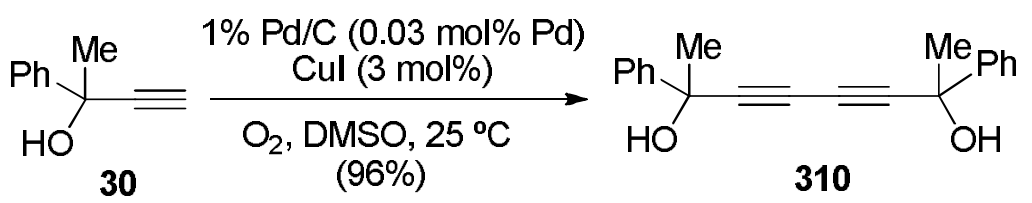

All the above mentioned procedures for the synthesis of 1,3-diynes are limited to the preparation of symmetrically substituted systems, as they are all dealing with the palladium-catalyzed homocoupling of terminal alkynes. However, there are also procedures which allow the formation of unsymmetrically substituted 1,3-diynes through palladium-catalysis, one of them being the direct coupling of terminal alkynes and 1-haloalkynes. This process was demonstrated as possible, using the $\mathrm{Pd} / \mathrm{Cu}$ Sonogashira reaction conditions, employing 1 iodoalkynes ${ }^{381}$ or 1-bromoalkynes ${ }^{382}$ as terminal alkyne counterparts. In addition, the catalytic combination of $\mathrm{Pd}(\mathrm{OAc})_{2} / \mathrm{TPPTS}$ $(1 / 2,5 \mathrm{~mol} \%)$ has been used for the heterocoupling of terminal alkynes and 1iodoalkynes under aqueous conditions, although certain amounts of the homocoupling product were observed. ${ }^{157}$ However, good results have been obtained using a 
combination of the phosphine ligand 311 and $\operatorname{Pd}_{2}(\mathrm{dba})_{3}$ to generate a catalyst (4 mol\%) employed in the coupling of terminal alkynes and 1-bromoalkynes, the process being cocatalyzed by $\mathrm{CuI}(2 \mathrm{~mol} \%)$ in the presence of triethylamine as base in DMF as solvent at room temperature. ${ }^{383}$ An example of this process is the cross-coupling of 2methylbut-3-yn-2-ol to (bromoethynyl)benzene (312) to give unsymmetrically substituted 1,3-diyne 313 (Scheme 118). This process has also been carried out using low loadings of $\mathrm{Pd}(\mathrm{OAc})_{2}(0.01 \mathrm{~mol} \%)$ as catalyst and $\mathrm{CuI}(0.2-2 \mathrm{~mol} \%)$ as cocatalyst, in the presence of $\mathrm{TBAB}$ and using diisopropylamine as base and solvent at $70{ }^{\circ} \mathrm{C}$, PdNPs being involved in the catalysis. ${ }^{384}$ In addition, this procedure has also been performed using as catalyst PdNPs ( $2 \mathrm{~mol} \%$ ) supported on the (DABCO)-functionalized mesoporous silica SBA-15 307. ${ }^{385}$ In this case, the reaction was achieved using CuI as cocatalyst (2 mol\%) triethylamine as base in DMF as solvent at room temperature, and the catalyst was recovered by filtration and reused up to three times, a certain loss of activity observed in the third run.

\section{Scheme 118}<smiles>CC(=O)/C=C/c1ccccc1Pc1ccccc1</smiles>
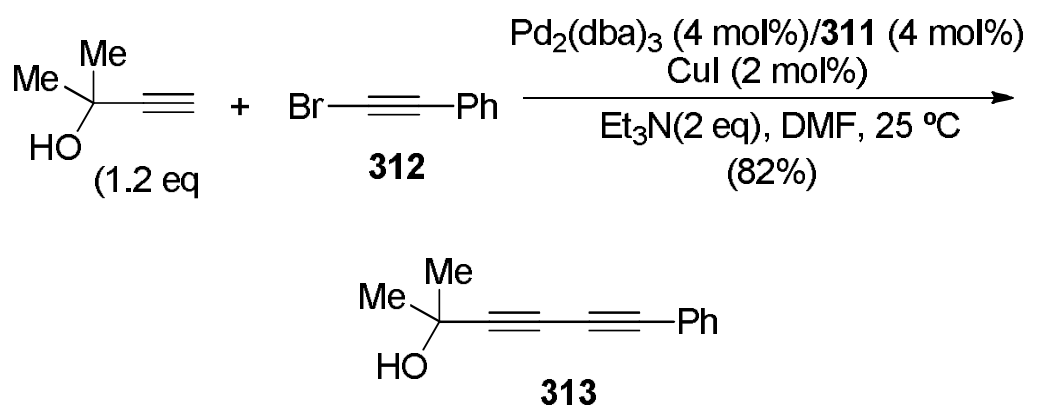

The preparation of unsymmetrical 1,3-diynes has also been carried out by the palladium-catalyzed coupling of terminal alkynes with $(E)$-1,2-diiodoalkenes followed by an in situ dehydroiodination. ${ }^{386}$ The process was performed using the combination of $\mathrm{Pd}(\mathrm{OAc})_{2}(1 \mathrm{~mol} \%)$ and $\mathrm{CuI}(5 \mathrm{~mol} \%)$ as catalyst, and a mixture of triethylamine and THF as basic solvent at room temperature, as shown in Scheme 119 with the coupling of phenylacetylene with diiodoacrylate 314 to give 1,3-diyne 315 . 
Scheme 119

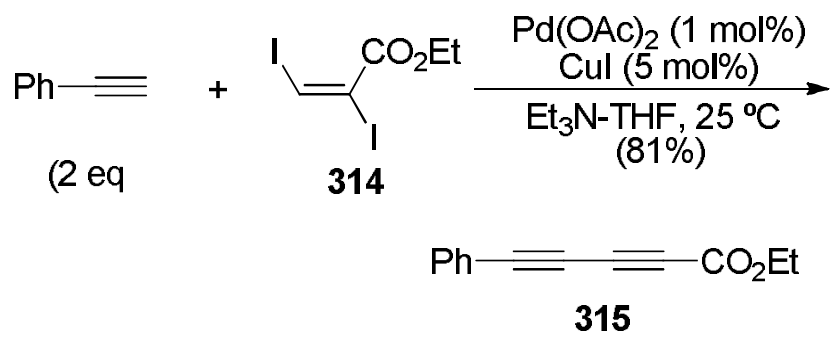

\subsection{Ynones}

Alkynylated ketones (ynones) are important structural motifs found in many biologically interesting compounds, ${ }^{387}$ and also are multipurpose intermediates in the synthesis of natural products ${ }^{388}$ and in the formation of several heterocycles. ${ }^{389}$ Suitable synthetic methods for the preparation of conjugated ynones utilize palladium catalysts for the coupling of terminal alkynes with an acid chloride (acyl Sonogashira reactions) $)^{226 \mathrm{~b}, \mathrm{c}}$ or with organic halides in the presence of carbon monoxide (carbonylative Sonogashira reactions). ${ }^{226 b, c, 390}$

The acyl Sonogashira reaction has been frequently performed by combining a terminal alkyne and acyl chloride under the typical palladium-copper cocatalyzed reaction conditions. ${ }^{226 \mathrm{~b}, \mathrm{c}}$ However, some difficulties are often encountered and related to unstability of the necessary acyl chlorides are prompting modifications in this old synthetic methodology. Thus, carboxylic acids from heterocyclic systems can be activated in situ with oxalyl chloride, a subsequent one-pot copper-cocatalyzed Sonogashira coupling with terminal alkynes under the usual conditions leading to ynones. ${ }^{391}$ An example of this methodology which avoids the isolation of unstable heterocyclic acyl chlorides is shown in Scheme 120, where pyrimidine-5-carboxylic acid (316) is transformed into its unstable acyl chloride and reacts in cross-coupled in situ with phenylacetylene to give ynone (317). 
Scheme 120<smiles>O=C(O)c1cncnc1</smiles>

316
1) $(\mathrm{COCl})_{2}(1 \mathrm{eq})$ dioxane, $50^{\circ} \mathrm{C}$

2) $\mathrm{Ph}=(1 \mathrm{eq})$ $\mathrm{PdCl}_{2}\left(\mathrm{PPh}_{3}\right)_{2}(2 \mathrm{~mol} \%)$ Cul (4 mol\%) $\mathrm{Et}_{3} \mathrm{~N}(3 \mathrm{eq}), \mathrm{rt}$ (58\%)<smiles>O=C(C#Cc1ccccc1)c1cncnc1</smiles>

317

The formation of undesirable diynes as byproducts is another of the known problems of using the typical copper cocatalyzed Sonogashira reaction conditions in the formation of ynones. Therefore, the use of copper-free procedures by using more reactive palladium species is receiving special interest. ${ }^{226 b, c}$ Thus, the common palladium complex $\mathrm{PdCl}_{2}\left(\mathrm{PPh}_{3}\right)_{2}(2 \mathrm{~mol} \%)$, in the presence of the former dialkynylated bis-heterocycle 298 as ligand ( $2 \mathrm{~mol} \%$ ), catalyzes the acyl Sonogashira reaction of aryloyl and alkyloyl chlorides and terminal alkynes to give the corresponding ynones, the reaction being perfomed in the presence of triethylamine as base, in toluene at 40 ${ }^{\circ} \mathrm{C} .{ }^{392}$ An example of this methodology is the coupling of pivaloyl chloride with oct-1yne to give ynone 318 (Scheme 121). In addition, the oxime-derived palladacycle 304 has been used as low-loading catalyst $(0.001 \mathrm{~mol} \%)$ for the copper-free acylation of terminal alkynes with carboxylic acid chlorides, in the presence of triethylamine as base in toluene at $110^{\circ} \mathrm{C} .{ }^{393}$ Furthermore, recent examples employing as catalysts other less common palladium complexes ${ }^{394}$ as well as recyclable supported palladium complexes $^{395}$ or nanoparticles ${ }^{396}$ able to perform this copper-free ynone formation reaction can also be found. ${ }^{397}$

\section{Scheme 121}

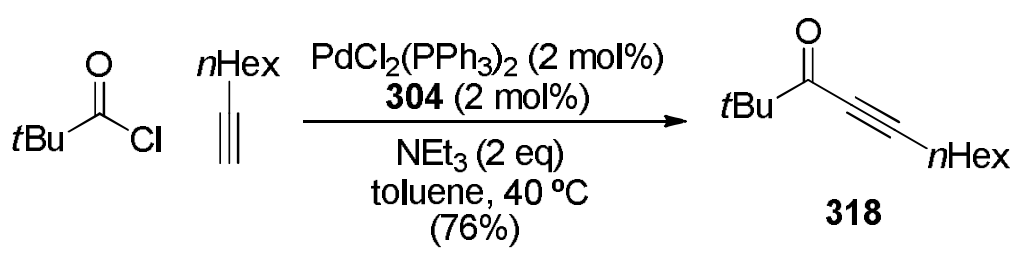

According to the sometimes limited stability of the respective acid chlorides and to a certain lack of functional tolerance of this acyl Sonogashira methodology, the carbonylative Sonogashira coupling of terminal alkynes and aryl halides (mostly 
iodides) in the presence of carbon monoxide represents the most straightforward way to prepare ynones. ${ }^{26 \mathrm{~b}, \mathrm{c}, 390 \mathrm{a}, \mathrm{b}}$ In addition, is a useful procedure for the generation of nonisolated ynone intermediates for the synthesis of heterocycles. ${ }^{390 \mathrm{~b}}$ such as 2-aryl phenyl$4 H$-chromen-4-ones by in situ cyclization of ynones from 2-iodophenols, ${ }^{398}$ or $1,2,3$ $(\mathrm{NH})$-triazoles by reaction of ynone intermediates with sodium azide. ${ }^{399}$

The first carbonylative Sonogashira reaction was reported more than thirty years ago using $\mathrm{PdCl}_{2} \mathrm{dppf}$ as catalyst $(5 \mathrm{~mol} \%) .{ }^{400}$ Aryl iodides, such as phenyl iodide, were coupled with terminal acetylenes, such as phenylacetylene, in triethylamine under $\mathrm{CO}$ at pressures up to 80 bar and a temperature of $120^{\circ} \mathrm{C}$ giving ynones such as $\mathbf{3 1 9}$ (Scheme 122). Since then, many palladium catalysts, unsupported and supported, as well as many reaction conditions have been reported attempting to achieve this transformation using more active palladium species, lower CO pressures, lower temperatures, environmentally-friendly solvents and so on. ${ }^{390 \mathrm{~b}}$ For instance, using recyclable PdNPs supported on polymers as catalyst $(0.5 \mathrm{~mol} \%)$ and water as solvent (CO pressure: 30 bar, $\left.130{ }^{\circ} \mathrm{C}\right),{ }^{401}$ or avoiding the use of $\mathrm{CO}$ using CO-releasing molecules such as silacarboxylic acids. ${ }^{402}$

\section{Scheme 122}

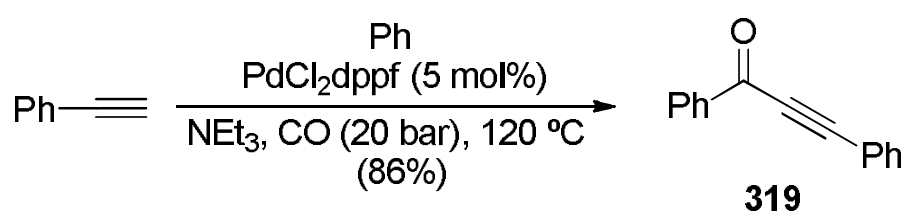

However, although there are examples of the use of vinyl triflates as alkyne counterpart in this process, ${ }^{403}$ almost all the examples of carbonylative Sonogashira reactions have been carried out using aryl iodides, which is somehow a shortcoming of the methodology. ${ }^{390 \mathrm{~b}}$ Therefore, recent research has been done in order to overcome this limitation, allowing the use other substrates. Thus, aryl bromides have been used in the carbonylative Sonogashira reaction of arylacetylenes, using as catalyst a combination of $[\mathrm{PdCl}(\text { cinnamyl })]_{2}(2 \mathrm{~mol} \%)$ and $n \mathrm{BuPAd}_{2}(\mathrm{Ad}=$ adamantyl $)(6 \mathrm{~mol} \%)$ in the presence of potassium hydroxide as base under an atmosphere of CO (10 bar) in DMF at $100{ }^{\circ} \mathrm{C}$, as in the case of the synthesis of ynone $\mathbf{3 2 0}$ from phenylacetylene and 4-bromoanisole (Scheme 123). ${ }^{404}$ In addition aryl triflates have also been used as coupling partners, 
using the former palladium source (1 mol\%) and Xantphos (80) as ligand (2 mol\%), triethylamine as base under $\mathrm{CO}(10 \mathrm{bar})$ in toluene as solvent at $110^{\circ} \mathrm{C} .{ }^{405}$

\section{Scheme 123}

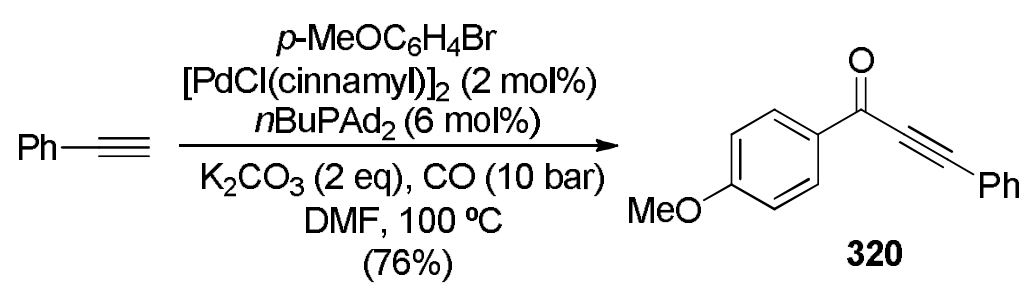

Aryl amines can also be used in this carbonylative reaction with alkynes, after an in situ formation of the corresponding arenediazonium salts with tert-butyl nitrite and a carbonylative coupling with terminal alkynes catalyzed by $\mathrm{Pd}(\mathrm{OAc})_{2}(2 \mathrm{~mol} \%)$-TFP (6 mol\% $)[$ TFP $=$ tri(2-furyl)phosphine $]$ under CO (10 bar) in THF/DMSO at $32{ }^{\circ} \mathrm{C}$, as shown in Scheme 124 in the formation of ynone $\mathbf{3 2 1}$ from ethynylcyclopentane and aniline. $^{406}$ In addition, benzyl chlorides have been employed in the carbonylative Sonogashira reaction of arylacetylenes, using as catalyst $\mathrm{PdCl}_{2}\left(\mathrm{PPh}_{3}\right)_{2}(2 \mathrm{~mol} \%)$ accompanied of $\mathrm{P}(\mathrm{OPh})_{3}(6 \mathrm{~mol} \%)$, in the presence of triethylamine under $\mathrm{CO}$ (10 bar) in toluene as solvent at $100{ }^{\circ} \mathrm{C}$, as in the case of the preparation of ynone $\mathbf{3 2 2}$ from benzyl chloride and phenylacetylene (Scheme 124). ${ }^{407}$ Moreover, there are recent examples of the synthesis of 3-alkylidenefuran-2-ones using a palladium-catalyzed multicomponent reaction between aryl bromides or triflates, terminal acetylenes and $\mathrm{CO}$, the process taking place through carbonylation of the ynone intermediate. ${ }^{408}$

\section{Scheme 124}
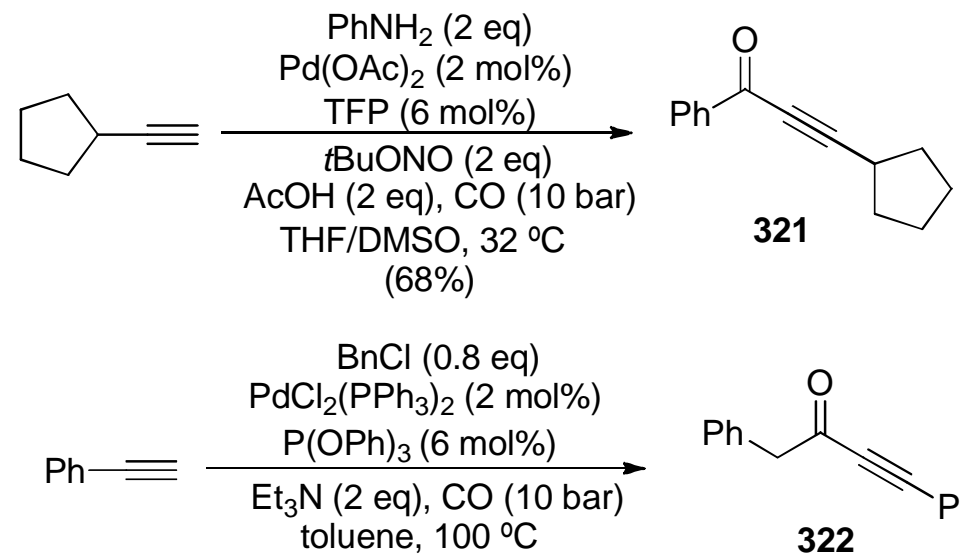

$(80 \%)$

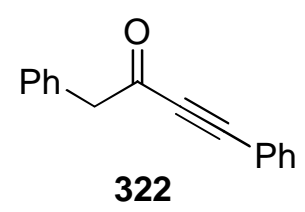


Examples of the use of recyclable supported catalysts for this reaction can also be found, although then the most reactive iodides must be used as coupling counterparts. Thus, the MCM-41-supported bidentate phosphine palladium(0) complex 105 has been used as catalyst $(0.05 \mathrm{~mol} \%)$ in the heterogeneous carbonylative Sonogashira coupling reaction of terminal alkynes with aryl iodides under CO (1 bar). ${ }^{409}$ This polymeric palladium catalyst was reused up to ten times without any decrease in activity.

Non-conjugated ynones, such as $\beta$-alkynyl ketones can be obtained by palladium-catalyzed conjugate addition of terminal alkynes to enones. Thus, reaction of a monosubstituted acetylene such as dec-1-yne with $\beta$-unsubstitured acyclic enones such as methyl vinyl ketone has allowed to obtain alkynylated ketone 323, in a process catalyzed by $\mathrm{Pd}(\mathrm{OAc})_{2}(5 \mathrm{~mol} \%)$ and $\mathrm{PMe}_{3}(20 \mathrm{~mol} \%)$ in water or acetone as solvent at $60{ }^{\circ} \mathrm{C}$ (Scheme 125). ${ }^{410} \beta$-Substituted acyclic and cyclic enones have also been employed more recently in this conjugate addition reaction, using as catalyst the combination $\mathrm{Pd}_{2}(\mathrm{dba})_{3}(5 \mathrm{~mol} \%) /\left(2,4-t \mathrm{BuC}_{6} \mathrm{H}_{3} \mathrm{O}\right)_{3} \mathrm{P}(10 \mathrm{~mol} \%)$, in dioxane at $90{ }^{\circ} \mathrm{C} .{ }^{411}$

\section{Scheme 125}

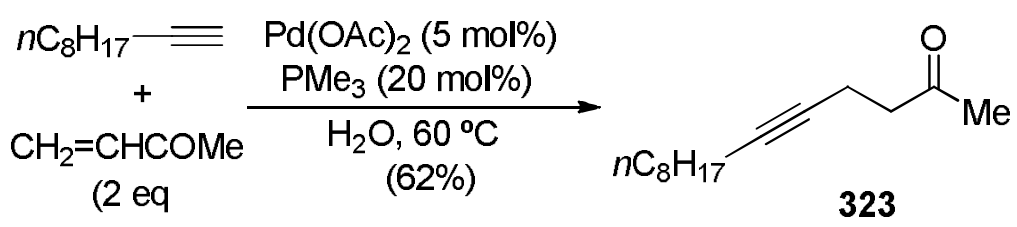

\subsection{Ynoates and Ynamides}

The transition metal-catalyzed oxidative carbonylation is a convenient way of introducing carboxyl-derived functionalities in hydrocarbons acting as nucleophiles. ${ }^{412}$ When the oxidative carbonylation is carried out on the terminal C-H of monosubstituted alkynes in the presence of alcohols or amides under palladium catalysis, substituted 2ynoates and 2-ynamides, respectively, are obtained.

The first oxidative carbonylation of terminal alkynes in the presence of an alcohol leading to 2-alkynoates was developed more than thirty years ago, ${ }^{413}$ the process being carried out using $\mathrm{PdCl}_{2}(5 \mathrm{~mol} \%)$ as catalyst and $\mathrm{CuCl}_{2}$ as reoxidant in the presence of sodium acetate as base under an atmospheric pressure of $\mathrm{CO}$ at room 
temperature. Lately, other more convenient procedures based on the use of oxygen as the final oxidant were developed, as in the case of the synthesis of methyl aryl- and alkyl-2-ynoates using of a multicatalytic system consisting of $\operatorname{Pd}(\mathrm{OAc})_{2}(5 \mathrm{~mol} \%)$ chlorohydroquinone-molybdovanadophosphate in the presence of methanesulfonic acid in methanol as solvent at room temperature and under a mixed atmosphere of $\mathrm{CO} / \mathrm{O}_{2}{ }^{414}$ A more simple procedure was developed, although with higher catalyst loading, based on the use of $\mathrm{PdCl}_{2}(10 \mathrm{~mol} \%)$ and $\mathrm{PPh}_{3}(20 \mathrm{~mol} \%)$ as catalyst, in the presence of sodium acetate as base and working under an atmospheric pressure of $\mathrm{CO} / \mathrm{O}_{2}$ in $\mathrm{DMF}$ as solvent at room temperature. ${ }^{415}$ Employing these reaction conditions, terminal alkynes such as phenylacetylene was converted into ynoates such as methyl phenylpropiolate (324) (Scheme 126). In addition, on the basis of the findings on this homogeneous catalytic system, a heterogeneous catalytic one using $10 \% \mathrm{Pd} / \mathrm{C}(0.05 \mathrm{~mol} \%)$ was also developed and applied to formation of methyl phenylpropiolate, although high pressures of $\mathrm{CO}(50 \mathrm{bar})$ and $\mathrm{O}_{2}(7.5 \mathrm{bar})$ were needed and no attempts of catalyst recovery were made. $^{415}$

\section{Scheme 126}

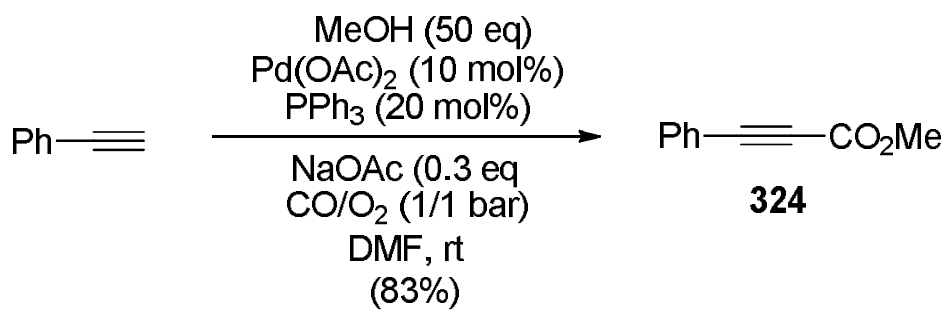

Non-conjugated ynoates, such as $\beta$-alkynylated esters, have been obtained by palladium-catalyzed conjugate addition of terminal alkynes to methyl or tert-butyl acrylate, following a similar procedure than the above mentioned for the preparation of alkynylated ketones, although using now a NHC ligand generated from 325. ${ }^{410 \mathrm{~b}}$ An example of this methodology is illustrated in Scheme 127, where phenylacetylene adds to methyl acrylate to give $\beta$-alkynylated ester $\mathbf{3 2 6}$. 
Scheme 127

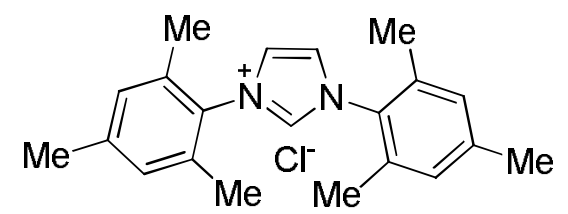

325

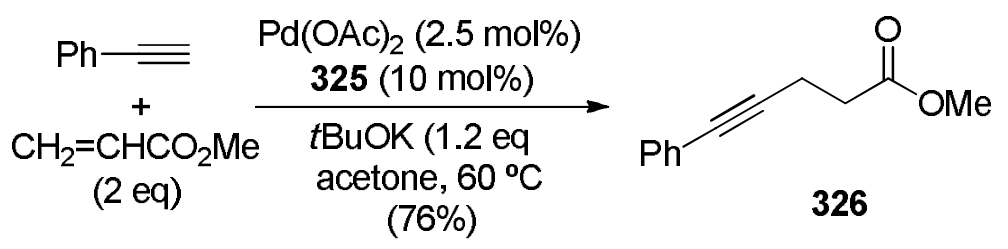

Although some conjugated ynamides have been prepared by Sonogashira-type palladium-catalyzed coupling of terminal alkynes with carbamoyl chlorides, ${ }^{416}$ a more direct synthetic procedure is the palladium-catalyzed oxidative carbonylation using amines. However, this process is not as easy as in the case of the preparation of ynoates, as a reaction between phenylacetylene and diethylamine under the above mentioned pioneering procedure for the preparation of ynoates using $\mathrm{PdCl}_{2} / \mathrm{CuCl}_{2} / \mathrm{AcONa}$, gave only $5 \%$ yield of the corresponding diethylamine of phenylpropiolic acid. ${ }^{413}$ Thus, the first successful procedure for this transformation was the conversion of alkyl- and arylacetylenes into 2-ynamides catalyzed by a mixture of $\mathrm{PdI}_{2}(0.2 \mathrm{~mol} \%)$ and $\mathrm{KI}(2$ mol\%), the process being carried out in the presence of secondary amines under CO/air in dioxane at $100{ }^{\circ} \mathrm{C} .{ }^{417}$ The reaction afforded better results with aryl acetylenes, as alkylacetylenes afforded small amounts of products from diaminocarbonylation of the triple bond, and the use of secondary amines was necessary, primary amines being unreactive or affording complex mixtures. This catalytic system has been used in other carbonylation reactions of functionalized terminal alkynes, the corresponding products leading to heterocyclic systems after cyclization. ${ }^{418}$ In addition, $10 \% \mathrm{Pd} / \mathrm{C}(8 \mathrm{~mol} \%)$ can be used as catalyst in a ligand-free oxidative aminocarbonylation of terminal alkynes, the reaction being carried out with secondary amines in the presence of tetra- $n$ butylammonium iodide (TBAI) under $\mathrm{CO} / \mathrm{O}_{2}$ in dioxane at $80{ }^{\circ} \mathrm{C}^{419}$ When using arylacetylenes the reaction afforded high yields of the corresponding ynamides, as exemplified in the preparation of ynamide $\mathbf{3 2 7}$ from phenylacetylene and piperidine (Scheme 128), the use of an alkyl acetylene such as hex-1-yne affording 55\% yield for the same reaction. The catalyst was recycled and reused up to four times without loss of 
activity, no significative palladium leaching being detected by inductively coupled plasma atomic emission spectroscopy (ICP-AES).

\section{Scheme 128}

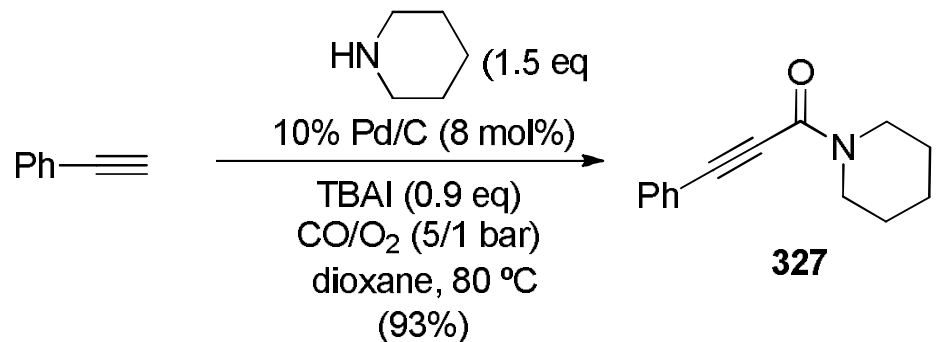

\section{Conclusions}

This review has intended to illustrate how the familiar alkynes, combined to the powerful catalytic properties of palladium species, can be converted into very versatile starting materials for the preparation of an enormous variety of compounds of interest. The development over the last few years of more reactive palladium catalysts, apart from the traditional phosphine-containing complexes, as well as new reaction conditions has broadened the reaction possibilities of alkynes, from the traditional addition reactions of heteronucleophiles, to many synthetically important carbon-carbon bond formation reactions. Particular attention has been devoted in the past ten years to the use of supported palladium catalysts suitable to being recovered and reused once the transformation of the alkyne has been achieved, something especially convenient when industrially useful processes are intended, although sometimes their reactivity was lower compared to homogeneous systems. Similarly, the use of palladium nanoparticles as catalysts is a topic making rapid progress in the last years and their use for the transformation of alkynes in interesting chemicals is no exception. In addition, the present environmental worries have also been shown with examples of the use of friendly solvents, such as water, for carrying out the synthesis of different chemicals from alkynes. However, in spite of all these developments, plenty of work is still ahead in order to achieve low loadings of catalytic systems, supported or not, applicable to the reaction of alkynes, functionalized or not, with synthetic counterparts bearing any functionality, under mild and environmentally friendly reaction conditions. There is no 
doubt that alkynes still will continue showing more and more synthetic possibilities in the near future.

\section{Acknowledgments}

The financial support from the Spanish Ministerio de Ciencia e Innovacion (projects CTQ2010-20387 and Consolider Ingenio 2010, CSD2007-00006), the Generalitat Valenciana (Prometeo/2009/039), FEDER and the University of Alicante is fully acknowledged.

\section{References}

(1) (a) Modern Acetylene Chemistry; Stang, P. J.; Diederich, F., Eds.; VCH: Weinheim, 1995. (b) Acetylene Chemistry; Diederich, F.; Stang, P. J.; Tykwinski, R. R., Eds.; Wiley-VCH: Weinheim, 2005.

(2) Saito, S.; Yamamoto, Y. Chem. Rev. 2000, 100, 2901.

(3) (a) Malatesta, L.; Santarella, G.; Vallarino, L.; Zingales, F. Angew. Chem. 1960, 72, 34. (b) Zingales, F. Ann. Chim. 1962, 52, 1174.

(4) (a) Maitlis, P. M. Acc. Chem. Res. 1976, 9, 93. (b) Maitlis, P. M. J. Organomet. Chem. 1980, 200, 161.

(5) Li, J.; Jiang, H.; Feng, A.; Jia, L. J. Org. Chem. 1999, 64, 5984.

(6) Li, J.; Jiang, H.; Chen, M. J. Org. Chem. 2001, 66, 3627.

(7) (a) Li, J.-H.; Xie, Y.-X. Chin. J. Chem. 2004, 22, 1421. (b) Li, J.-H.; Xie, Y.-X. Synth. Commun. 2004, 34, 1737.

(8) Cheng, J.-S.; Jiang, H.-F. Eur. J. Org. Chem. 2004, 643.

(9) Peña, D.; Pérez, D.; Guitián, E. Chem. Rec. 2007, 7, 326.

(10) Iglesias, B.; Peña, D.; Pérez, D.; Guitián, E.; Castedo, L. Synlett 2002, 486.

(11) Stacchiola, D.; Calaza, F.; Zheng, T.; Tysoe, W. T. J. Mol. Catal. A: Chem. 2005, 228,35 .

(12) Ormerod, R. M.; Lambert, R. M. J. Chem. Soc., Chem. Commun. 1990, 1421. 
(13) Rucker, T. G.; Logan, M. A.; Gentle, T. M.; Muetterties, E. L.; Somorjai, G. A. J. Phys. Chem. 1986, 90, 2703.

(14) Jhingan, A. K.; Maier, W. F. J. Org. Chem. 1987, 52, 1161.

(15) Worlikar, S. A.; Larock, R. C. Curr. Org. Chem. 2011, 15, 3214.

(16) (a) Peña, D.; Pérez, D.; Guitián, E.; Castedo, L. J. Am. Chem. Soc. 1999, 121, 5827. (b) Peña, D.; Pérez, D.; Guitián, E.; Castedo, L. J. Org. Chem. 2000, 65, 6944.

(17) Radhakrishnan, K. V.; Yoshikawa, E.; Yamamoto, Y. Tetrahedron Lett. 1999, $40,7533$.

(18) Liu, Z.; Larock, R. C. Angew. Chem., Int. Ed. 2007, 46, 2535.

(19) Cant, A. A.; Roberts, L.; Greaney, M. F. Chem. Commun. 2010, 46, 8671.

(20) Deng, Y.; Persson, A. K. A.; Bäckvall, J.-E. Chem.-Eur. J. 2012, 18, 11498.

(21) Wu, Y.-T.; Huang, K.-H.; Shin, C.-C.; Wu, T.-C. Chem.-Eur. J. 2008, 14, 6697.

(22) Wu, J.; Cui, X.; Mi, X.; Li, Y.; Wu, Y. Chem. Commun. 2010, 46, 6771.

(23) Wang, C.; Rakshit, S.; Glorius, F. J. Am. Chem. Soc. 2010, 132, 14006.

(24) Zhang, D.; Liu, Z.; Yum, E. K.; Larock, R. C. J. Org. Chem. 2007, 72, 251.

(25) Yang, M.; Zhang, X.; Lu, X. Org. Lett. 2007, 9, 5131.

(26) Larock, R. C.; Doty, M. J.; Cacchi, S. J. Org. Chem. 1993, 58, 4579.

(27) (a) Alonso, D. A.; Nájera, C.; Pacheco, M. C. Adv. Synth. Catal. 2002, 344, 172.

(b) Alacid, E.; Nájera, C. Arkivoc 2008, 50.

(28) Zhang, J.; Yang, F.; Wu, Y. Appl. Organomet. Chem. 2011, 25, 675.

(29) Rivera-Fuentes, P.; von, W. R. M.; Schweizer, W. B.; Gisselbrecht, J.-P.; Boudon, C.; Diederich, F. Org. Lett. 2012, 14, 4066.

(30) (a) Alonso, F.; Beletskaya, I. P.; Yus, M. Chem. Rev. 2004, 104, 3079. (b) Zeni, G.; Larock, R. C. Chem. Rev. 2006, 106, 4644. (c) Majumdar, K. C.; Chattopadhyay, B.; Maji, P. K.; Chattopadhyay, S. K.; Samanta, S. Heterocycles 2010, 81, 795. (d) Majumdar, K. C.; Samanta, S.; Sinha, B. Synthesis 2012, 44, 817.

(31) Crawley, M. L.; Goljer, I.; Jenkins, D. J.; Mehlmann, J. F.; Nogle, L.; Dooley, R.; Mahaney, P. E. Org. Lett. 2006, 8, 5837.

(32) (a) Cacchi, S.; Fabrizi, G. Chem. Rev. 2005, 105, 2873. (b) Humphrey, G. R.; Kuethe, J. T. Chem. Rev. 2006, 106, 2875. (c) Krüger, K.; Tillack, A.; Beller, M. Adv. Synth. Catal. 2008, 350, 2153. (d) Vicente, R. Org. Biomol. Chem. 2011, 9 , 
6469. (e) Cacchi, S.; Fabrizi, G. Chem. Rev. 2011, 111, PR215. (f) Platon, M.; Amardeil, R.; Djakovitch, L.; Hierso, J.-C. Chem. Soc. Rev. 2012, 41, 3929.

(33) (a) Larock, R. C.; Yum, E. K. J. Am. Chem. Soc. 1991, 113, 6689. (b) Larock, R. C.; Yum, E. K.; Refvik, M. D. J. Org. Chem. 1998, 63, 7652.

(34) (a) Batail, N.; Bendjeriou, A.; Lomberget, T.; Barret, R.; Dufaud, V.; Djakovitch, L. Adv. Synth. Catal. 2009, 351, 2055. (b) Batail, N.; Bendjeriou, A.; Djakovitch, L.; Dufaud, V. Appl. Catal., A 2010, 388, 179. (c) Batail, N.; Dufaud, V.; Djakovitch, L. Tetrahedron Lett. 2011, 52, 1916.

(35) Livecchi, M.; Calvet, G.; Schmidt, F. J. Org. Chem. 2012, 77, 5006.

(36) Shen, M.; Li, G.; Lu, B. Z.; Hossain, A.; Roschangar, F.; Farina, V.; Senanayake, C. H. Org. Lett. 2004, 6, 4129.

(37) Leogane, O.; Lebel, H. Angew. Chem., Int. Ed. 2008, 47, 350.

(38) Shi, Z.; Zhang, C.; Li, S.; Pan, D.; Ding, S.; Cui, Y.; Jiao, N. Angew. Chem., Int. Ed. 2009, 48, 4572 .

(39) Aggarwal, T.; Jha, R. R.; Tiwari, R. K.; Kumar, S.; Kotla, S. K. R.; Kumar, S.; Verma, A. K. Org. Lett. 2012, 14, 5184.

(40) Sreenivas, D. K.; Sandhyarani, J.; Nagarajan, R. Synthesis 2012, 1268.

(41) Zhu, C.; Yamane, M. Tetrahedron 2011, 67, 4933.

(42) Larock, R. C.; Doty, M. J.; Han, X. Tetrahedron Lett. 1998, 39, 5143.

(43) (a) Larock, R. C.; Yum, E. K.; Doty, M. J.; Sham, K. K. C. J. Org. Chem. 1995, 60, 3270. (b) Bishop, B. C.; Cottrell, I. F.; Hands, D. Synthesis 1997, 1315.

(44) Larock, R. C.; Doty, M. J.; Han, X. J. Org. Chem. 1999, 64, 8770.

(45) Zhong, H.; Yang, D.; Wang, S.; Huang, J. Chem. Commun. 2012, 48, 3236.

(46) Ding, S.; Shi, Z.; Jiao, N. Org. Lett. 2010, 12, 1540.

(47) Shi, Z.; Cui, Y.; Jiao, N. Org. Lett. 2010, 12, 2908.

(48) Wang, L.; Huang, J.; Peng, S.; Liu, H.; Jiang, X.; Wang, J. Angew. Chem. Int. Ed. 2013, 52, 1768.

(49) (a) Nevado, C.; Echavarren, A. M. Synthesis 2005, 167. (b) Vasil'ev, A. V. Russ. J. Org. Chem. 2009, 45, 1. (c) Kitamura, T. Eur. J. Org. Chem. 2009, 1111.

(50) Beller, M.; Seayad, J.; Tillack, A.; Jiao, H. Angew. Chem., Int. Ed. 2004, 43, 3368

(51) (a) Jia, C.; Piao, D.; Oyamada, J.; Lu, W.; Kitamura, T.; Fujiwara, Y. Science 2000, 287, 1992. (b) Jia, C.; Lu, W.; Oyamada, J.; Kitamura, T.; Matsuda, K.; Irie, M.; Fujiwara, Y. J. Am. Chem. Soc. 2000, 122, 7252. 
(52) Tunge, J. A.; Foresee, L. N. Organometallics 2005, 24, 6440.

(53) (a) Biffis, A.; Gazzola, L.; Gobbo, P.; Buscemi, G.; Tubaro, C.; Basato, M. Eur. J. Org. Chem. 2009, 3189. (b) Buscemi, G.; Biffis, A.; Tubaro, C.; Basato, M. Catal. Today 2009, 140, 84. (c) Biffis, A.; Gazzola, L.; Tubaro, C.; Basato, M. ChemSusChem 2010, 3, 834. (d) Gazzola, L.; Tubaro, C.; Biffis, A.; Basato, M. New J. Chem. 2010, 34, 482. (e) Gonell, S.; Poyatos, M.; Mata, J. A.; Peris, E. Organometallics 2011, 30, 5985.

(54) (a) Lu, W.; Jia, C.; Kitamura, T.; Fujiwara, Y. Org. Lett. 2000, 2, 2927. (b) Oyamada, J.; Lu, W.; Jia, C.; Kitamura, T.; Fujiwara, Y. Chem. Lett. 2002, 20.

(55) Tsukada, N.; Mitsuboshi, T.; Setoguchi, H.; Inoue, Y. J. Am. Chem. Soc. 2003, $125,12102$.

(56) Cacchi, S. Pure Appl. Chem. 1990, 62, 713.

(57) (a) Cacchi, S.; Fabrizi, G.; Marinelli, F.; Moro, L.; Pace, P. Tetrahedron 1996, 52, 10225. (b) Cacchi, S.; Fabrizi, G.; Moro, L.; Pace, P. Synlett 1997, 1367.

(58) Cacchi, S.; Fabrizi, G.; Goggiamani, A. J. Mol. Catal. A: Chem. 2004, 214, 57.

(59) Ahlquist, M.; Fabrizi, G.; Cacchi, S.; Norrby, P.-O. J. Am. Chem. Soc. 2006, $128,12785$.

(60) (a) Oh, C. H.; Jung, H. H.; Kim, K. S.; Kim, N. Angew. Chem., Int. Ed. 2003, 42, 805. (b) Oh, C. H.; Ryu, J. H. Bull. Korean Chem. Soc. 2003, 24, 1563. (c) Gupta, A. K.; Kim, K. S.; Oh, C. H. Synlett 2005, 457. (d) Arcadi, A.; Aschi, M.; Chiarini, M.; Ferrara, G.; Marinelli, F. Adv. Synth. Catal. 2010, 352, 493. (e) Xu, X.; Chen, J.; Gao, W.; Wu, H.; Ding, J.; Su, W. Tetrahedron 2010, 66, 2433.

(61) Zeng, H.; Hua, R. J. Org. Chem. 2008, 73, 558.

(62) Zhou, C.; Larock, R. C. J. Org. Chem. 2006, 71, 3184.

(63) Cacchi, S.; Fabrizi, G.; Goggiamani, A.; Persiani, D. Org. Lett. 2008, 10, 1597.

(64) (a) Kiss, G. Chem. Rev. 2001, 101, 3435-3456. (b) Brennführer, A.; Neumann, H.; Beller, M. ChemCatChem 2009, 1, 28.

(65) Doherty, S.; Knight, J. G.; Smyth, C. H., Recent Developments in Alkyne Carbonylation, in Modern Carbonylation Methods; Kollár, L., Ed.; Wiley-VCH: Weinheim, 2008.

(66) Tang, C.-M.; Zeng, Y.; Yang, X.-G.; Lei, Y.-C.; Wang, G.-Y. J. Mol. Catal. A: Chem. 2009, 314, 15.

(67) Magro, A. A. N.; Robb, L.-M.; Pogorzelec, P. J.; Slawin, A. M. Z.; Eastham, G. R.; Cole-Hamilton, D. J. Chem. Sci. 2010, 1, 723. 
(68) Williams, D. B. G.; Shaw, M. L.; Hughes, T. Organometallics 2011, 30, 4968.

(69) Drent, E.; Jager, W. W.; Keijsper, J. J.; Niele, F. G. M., A Clean Route to Methacrylates via Carbonylation of Alkynes, in Applied Homogeneous Catalalysis with Organometallic. Compdounds (2nd Ed.); Cornils, B.; Herrmann, W. A., Eds.; Wiley-VCH: Weinheim, 2002; Vol. 1, p 316.

(70) Tang, C.-M.; Li, X.-L.; Wang, G.-Y. Korean J. Chem. Ing. 2012, 29, 1700.

(71) Nagai, K. Appl. Catal., A 2001, 221, 367.

(72) Suleiman, R.; Tijani, J.; El, A. B. Appl. Organomet. Chem. 2010, 24, 38.

(73) Kato, K.; Motodate, S.; Mochida, T.; Kobayashi, T.; Akita, H. Angew. Chem. Int. Ed. 2009, 48, 3326.

(74) Kuniyasu, H.; Yoshizawa, T.; Kambe, N. Tetrahedron Lett. 2010, 51, 6818.

(75) Katafuchi, Y.; Fujihara, T.; Iwai, T.; Terao, J.; Tsuji, Y. Adv. Synth. Catal. 2011, $353,475$.

(76) Suleiman, R.; Ibdah, A.; El, A. B. J. Organomet. Chem. 2011, 696, 2355.

(77) Fujihara, T.; Katafuchi, Y.; Iwai, T.; Terao, J.; Tsuji, Y. J. Am. Chem. Soc. 2010, 132, 2094.

(78) Tsukada, N.; Takahashi, A.; Inoue, Y. Tetrahedron Lett. 2011, 52, 248.

(79) Hintermann, L.; Labonne, A. Synthesis 2007, 1121.

(80) Imi, K.; Imai, K.; Utimoto, K. Tetrahedron Lett. 1987, 28, 3127.

(81) Arcadi, A.; Cacchi, S.; Marinelli, F. Tetrahedron 1993, 49, 4955.

(82) Meier, I. K.; Marsella, J. A. J. Mol. Catal. 1993, 78, 31.

(83) Tauchman, J.; Carvalho, M. F. N. N.; Štěpnička, P. Collect. Czech. Chem. Commun. 2011, 76, 1277.

(84) Kadota, I.; Lutete, L. M.; Shibuya, A.; Yamamoto, Y. Tetrahedron Lett. 2001, 42,6207 .

(85) Hidai, M.; Mizobe, Y. ACS Symp. Ser. 1996, 653, 310.

(86) Murata, T.; Mizobe, Y.; Gao, H.; Ishii, Y.; Wakabayashi, T.; Nakano, F.; Tanase, T.; Yano, S.; Hidai, M.; Echizen, I.; Nanikawa, H.; Motomura, S. J. Am. Chem. Soc. 1994, 116, 3389.

(87) Masui, D.; Kochi, T.; Tang, Z.; Ishii, Y.; Mizobe, Y.; Hidai, M. J. Organomet. Chem. 2001, 620, 69.

(88) Camacho, D. H.; Saito, S.; Yamamoto, Y. Tetrahedron Lett. 2002, 43, 1085.

(89) (a) Pohlki, F.; Doye, S. Chem. Soc. Rev. 2003, 32, 104. (b) Severin, R.; Doye, S. Chem. Soc. Rev. 2007, 36, 1407. (c) Müller, T. E.; Hultzsch, K. C.; Yus, M.; 
Foubelo, F.; Tada, M. Chem. Rev. 2008, 108, 3795. (d) Adrio, L. A.; Hii, K. K. Curr. Org. Chem. 2011, 15, 3337.

(90) Yuan, D.; Tang, H.; Xiao, L.; Huynh, H. V. Dalton Trans. 2011, 40, 8788.

(91) Shaffer, A. R.; Schmidt, J. A. R. Organometallics 2008, 27, 1259.

(92) (a) Kadota, I.; Shibuya, A.; Lutete, L. M.; Yamamoto, Y. J. Org. Chem. 1999, 64, 4570. (b) Lutete, L. M.; Kadota, I.; Shibuya, A.; Yamamoto, Y. Heterocycles 2002, 58, 347.

(93) (a) Beletskaya, I. P.; Ananikov, V. P. Pure Appl. Chem. 2007, 79, 1041. (b) Beletskaya, I. P.; Ananikov, V. P. Eur. J. Org. Chem. 2007, 3431. (c) Beletskaya, I. P.; Ananikov, V. P. Chem. Rev. 2011, 111, 1596.

(94) Kuniyasu, H.; Ogawa, A.; Sato, K.; Ryu, I.; Kambe, N.; Sonoda, N. J. Am. Chem. Soc. 1992, 114, 5902.

(95) Mitamura, T.; Daitou, M.; Nomoto, A.; Ogawa, A. Bull. Chem. Soc. Jpn. 2011, $84,413$.

(96) Ananikov, V. P.; Orlov, N. V.; Beletskaya, I. P.; Khrustalev, V. N.; Antipin, M. Y.; Timofeeva, T. V. J. Am. Chem. Soc. 2007, 129, 7252.

(97) Ananikov, V. P.; Beletskaya, I. P. Organometallics 2012, 31, 1595.

(98) Gerber, R.; Frech, C. M. Chem.-Eur. J. 2012, 18, 8901.

(99) Kuniyasu, H.; Ogawa, A.; Sato, K.; Ryu, I.; Sonoda, N. Tetrahedron Lett. 1992, 33,5525 .

(100) Kamiya, I.; Nishinaka, E.; Ogawa, A. J. Org. Chem. 2005, 70, 696.

(101) Kuniyasu, H.; Ogawa, A.; Miyazaki, S.; Ryu, I.; Kambe, N.; Sonoda, N. J. Am. Chem. Soc. 1991, 113, 9796.

(102) Li, J.; Liu, J.; Cai, M. J. Chem. Res. 2009, 61

(103) Cai, M.; Wang, Y.; Hao, W. Green Chem. 2007, 9, 1180.

(104) Ozaki, T.; Nomoto, A.; Kamiya, I.; Kawakami, J.-i.; Ogawa, A. Bull. Chem. Soc. Jpn. 2011, 84, 155.

(105) Minami, Y.; Kuniyasu, H.; Sanagawa, A.; Kambe, N. Org. Lett. 2010, 12, 3744.

(106) Minami, Y.; Kuniyasu, H.; Kambe, N. Org. Lett. 2008, 10, 2469.

(107) (a) Beletskaya, I. P.; Kazankova, M. A. Russ. J. Org. Chem. 2002, 38, 1391. (b) Baillie, C.; Xiao, J. Curr. Org. Chem. 2003, 7, 477. (c) Tanaka, M. Top. Curr. Chem. 2004, 232, 25. (d) Delacroix, O.; Gaumont, A. C. Curr. Org. Chem. 2005, 9, 1851. (e) Coudray, L.; Montchamp, J.-L. Eur. J. Org. Chem. 2008, 3601. (f) Glueck, D. S. Top. Organomet. Chem. 2010, 31, 65. 
(108) Ananikov, V. P.; Makarov, A. V.; Beletskaya, I. P. Chem.-Eur. J. 2011, 17, 12623.

(109) (a) Kazankova, M. A.; Efimova, I. V.; Kochetkov, A. N.; Afanas'ev, V. V.; Beletskaya, I. P.; Dixneuf, P. H. Synlett 2001, 497. (b) Kazankova, M. A.; Efimova, I. V.; Kochetkov, A. N.; Afanas'ev, V. V.; Beletskaya, I. P. Russ. J. Org. Chem. 2002, 38, 1465.

(110) Arisawa, M.; Yamaguchi, M. J. Am. Chem. Soc. 2000, 122, 2387.

(111) Han, L.-B.; Choi, N.; Tanaka, M. Organometallics 1996, 15, 3259.

(112) Han, L.-B.; Hua, R.; Tanaka, M. Angew. Chem. Int. Ed. 1998, 37, 94.

(113) Duraud, A.; Toffano, M.; Fiaud, J.-C. Eur. J. Org. Chem. 2009, 4400.

(114) Dobashi, N.; Fuse, K.; Hoshino, T.; Kanada, J.; Kashiwabara, T.; Kobata, C.; Nune, S. K.; Tanaka, M. Tetrahedron Lett. 2007, 48, 4669.

(115) Kawaguchi, S.-i.; Nagata, S.; Nomoto, A.; Sonoda, M.; Ogawa, A. J. Org. Chem. 2008, 73, 7928.

(116) Nagata, S.; Kawaguchi, S.-i.; Matsumoto, M.; Kamiya, I.; Nomoto, A.; Sonoda, M.; Ogawa, A. Tetrahedron Lett. 2007, 48, 6637.

(117) Mizuta, T.; Miyaji, C.; Katayama, T.; Ushio, J.-i.; Kubo, K.; Miyoshi, K. Organometallics 2009, 28, 539.

(118) Han, L.-B.; Zhao, C.-Q.; Onozawa, S.-y.; Goto, M.; Tanaka, M. J. Am. Chem. Soc. 2002, 124, 3842.

(119) Nune, S. K.; Tanaka, M. Chem. Commun. 2007, 2858.

(120) Montchamp, J.-L. J. Organomet. Chem. 2005, 690, 2388.

(121) Deprele, S.; Montchamp, J.-L. J. Am. Chem. Soc. 2002, 124, 9386.

(122) Belabassi, Y.; Bravo-Altamirano, K.; Montchamp, J.-L. J. Organomet. Chem. 2011, 696, 106.

(123) Han, L.-B.; Tanaka, M. J. Am. Chem. Soc. 1996, 118, 1571.

(124) (a) Gulykina, N. S.; Dolgina, T. M.; Bondarenko, G. N.; Beletskaya, I. P. Russ. J. Org. Chem. 2003, 39, 797. (b) Ananikov, V. P.; Khemchyan, L. L.; Beletskaya, I. P. Synlett 2009, 2375. (c) Ananikov, V. P.; Khemchyan, L. L.; Beletskaya, I. P. Russ. J. Org. Chem. 2010, 46, 1269.

(125) Bravo-Altamirano, K.; Montchamp, J.-L. Tetrahedron Lett. 2007, 48, 5755.

(126) Dénès, F.; Pérez-Luna, A.; Chemla, F. Chem. Rev. 2010, 110, 2366.

(127) (a) Monteiro, N.; Balme, G.; Gore, J. Tetrahedron Lett. 1991, 32, 1645. (b) Monteiro, N.; Gore, J.; Balme, G. Tetrahedron 1992, 48, 10103. 
(128) Fujino, D.; Yorimitsu, H.; Osuka, A. Org. Lett. 2012, 14, 2914.

(129) Guo, L.-N.; Duan, X.-H.; Liang, Y.-M. Acc. Chem. Res. 2011, 44, 111.

(130) Guo, L.-N.; Duan, X.-H.; Bi, H.-P.; Liu, X.-Y.; Liang, Y.-M. J. Org. Chem. 2006, $71,3325$.

(131) Kadoya, N.; Murai, M.; Ishiguro, M.; Uenishi, J. i.; Uemura, M. Tetrahedron Lett. 2013, 54, 512.

(132) Utimoto, K. Pure Appl. Chem. 1983, 55, 1845.

(133) (a) Fukuda, Y.; Matsubara, S.; Utimoto, K. J. Org. Chem. 1991, 56, 5812. (b) Müller, T. E.; Berger, M.; Grosche, M.; Herdtweck, E.; Schmidtchen, F. P. Organometallics 2001, 20, 4384.

(134) Utimoto, K.; Miwa, H.; Nozaki, H. Tetrahedron Lett. 1981, 22, 4277.

(135) Luo, F. T.; Wang, R. T. Tetrahedron Lett. 1992, 33, 6835.

(136) Terrason, V.; Michaux, J.; Gaucher, A.; Wehbe, J.; Marque, S.; Prim, D.; Campagne, J.-M. Eur. J. Org. Chem. 2007, 5332.

(137) Tyrrell, E.; Whiteman, L.; Williams, N. Synthesis 2009, 829.

(138) (a) Iritani, K.; Matsubara, S.; Uchimoto, K. Tetrahedron Lett. 1988, 29, 1799. (b) Arcadi, A.; Cacchi, S.; Marinelli, F. Tetrahedron Lett. 1989, 30, 2581.

(139) Ambrogio, I.; Cacchi, S.; Fabrizi, G. Tetrahedron Lett. 2007, 48, 7721.

(140) Yao, B.; Wang, Q.; Zhu, J. Angew. Chem., Int. Ed. 2012, 51, 5170.

(141) (a) Arcadi, A.; Cacchi, S.; Marinelli, F. Tetrahedron Lett. 1992, 33, 3915. (b) Cacchi, S.; Fabrizi, G.; Marinelli, F.; Moro, L.; Pace, P. Synlett 1997, 1363. (c) Arcadi, A.; Cacchi, S.; Cassetta, A.; Fabrizi, G.; Parisi, L. M. Synlett 2001, 1605. (d) Cacchi, S.; Fabrizi, G.; Lamba, D.; Marinelli, F.; Parisi, L. M. Synthesis 2003, 728. (e) Abbiati, G.; Arcadi, A.; Beccalli, E.; Bianchi, G.; Marinelli, F.; Rossi, E. Tetrahedron 2006, 62, 3033. (f) Cacchi, S.; Fabrizi, G.; Goggiamani, A. Adv. Synth. Catal. 2006, 348, 1301. (g) Arcadi, A.; Chiarini, M.; Marinelli, F.; Picchini, S. Synthesis 2011, 4084.

(142) Arcadi, A.; Cacchi, S.; Fabrizi, G.; Marinelli, F. Synlett 2000, 394.

(143) Arcadi, A.; Cacchi, S.; Fabrizi, G.; Marinelli, F.; Parisi, L. M. J. Org. Chem. 2005, 70, 6213.

(144) Arcadi, A.; Cianci, R.; Ferrara, G.; Marinelli, F. Tetrahedron 2010, 66, 2378.

(145) (a) Cacchi, S.; Fabrizi, G.; Goggiamani, A.; Perboni, A.; Sferrazza, A.; Stabile, P. Org. Lett. 2010, 12, 3279. (b) Cacchi, S.; Fabrizi, G.; Goggiamani, A.; Sferrazza, A. Org. Biomol. Chem. 2011, 9, 1727. 
(146) Cacchi, S.; Fabrizi, G.; Pace, P. J. Org. Chem. 1998, 63, 1001.

(147) Arcadi, A.; Cacchi, S.; Fabrizi, G.; Goggiamani, A.; Iazzetti, A.; Marinelli, F. Org. Biomol. Chem. 2013, 11, 545.

(148) Xu, C.; Murugan, V. K.; Pullarkat, S. A. Org. Biomol. Chem. 2012, 10, 3875.

(149) Lu, B. Z.; Zhao, W.; Wei, H.-X.; Dufour, M.; Farina, V.; Senanayake, C. H. Org. Lett. 2006, 8, 3271.

(150) Mphahlele, M. J.; Lesenyeho, L. G.; Makelane, H. R. Tetrahedron 2010, 66, 6040.

(151) (a) Seiller, B.; Bruneau, C.; Dixneuf, P. H. Tetrahedron 1995, 51, 13089. (b) Gabriele, B.; Salerno, G. Chem. Commun. 1997, 1083. (c) Gabriele, B.; Salerno, G.; Lauria, E. J. Org. Chem. 1999, 64, 7687.

(152) Arcadi, A.; Cacchi, S.; Larock, R. C.; Marinelli, F. Tetrahedron Lett. 1993, 34, 2813.

(153) Huang, W.-Y.; Liu, J. H.-C.; Alayoglu, P.; Li, Y.-M.; Witham, C. A.; Tsung, C.K.; Toste, F. D.; Somorjai, G. A. J. Am. Chem. Soc. 2010, 132, 16771.

(154) Martínez, C.; Aurrecoechea, J. M.; Madich, Y.; Denis, J. G.; de Lera, A. R.; Álvarez, R. Eur. J. Org. Chem. 2012, 99.

(155) Arcadi, A.; Cacchi, S.; Rosario, M. D.; Fabrizi, G.; Marinelli, F. J. Org. Chem. 1996, 61, 9280 .

(156) (a) Arcadi, A.; Marinelli, F.; Cacchi, S. Synthesis 1986, 749. (b) Kundu, N. G.; Pal, M.; Mahanty, J. S.; Dasgupta, S. K. J. Chem. Soc., Chem. Commun. 1992, 41. (c) Kundu, N. G.; Pal, M.; Mahanty, J. S.; De, M. J. Chem. Soc., Perkin Trans. 1 1997, 2815.

(157) Amatore, C.; Blart, E.; Genêt, J. P.; Jutand, A.; Lemaire-Audoire, S.; Savignac, M. J. Org. Chem. 1995, 60, 6829.

(158) Palimkar, S. S.; More, V. S.; Srinivasan, K. V. Ultrason. Sonochem. 2008, 15, 853.

(159) Khan, M. W.; Kundu, N. G. Synlett 1999, 456.

(160) Liao, H.-Y.; Cheng, C.-H. J. Org. Chem. 1995, 60, 3711.

(161) Asao, N.; Nogami, T.; Takahashi, K.; Yamamoto, Y. J. Am. Chem. Soc. 2002, 124,764 .

(162) Chandra, A.; Singh, B.; Khanna, R. S.; Singh, R. M. J. Org. Chem. 2009, 74, 5664.

(163) Tang, R.-Y.; Li, J.-H. Chem.-Eur. J. 2010, 16, 4733. 
(164) Arcadi, A.; Burini, A.; Cacchi, S.; Delmastro, M.; Marinelli, F.; Pietroni, B. R. J. Org. Chem. 1992, 57, 976.

(165) Shiva, K. K.; Rambabu, D.; Prasad, B.; Mujahid, M.; Krishna, G. R.; Basaveswara, R. M. V.; Malla, R. C.; Vanaja, G. R.; Kalle, A. M.; Pal, M. Org. Biomol. Chem. 2012, 10, 4774.

(166) (a) Muzart, J. J. Mol. Catal. A: Chem. 2011, 338, 7-17. (b) Wu, W.; Jiang, H. Acc. Chem. Res. 2012, 45, 1736.

(167) (a) Chi, K.-W.; Yusubov, M. S.; Filimonov, V. D. Synth. Commun. 1994, 24, 2119. (b) Yusubov, M. S.; Krasnokutskaya, E. A.; Vasilyeva, V. P.; Filimonov, V. D.; Chi, K.-W. Bull. Korean Chem. Soc. 1995, 16, 86. (c) Yusubov, M. S.; Filimonov, V. D.; Vasilyeva, V. P.; Chi, K.-W. Synthesis 1995, 1234. (d) Yusubov, M. S.; Filimonov, V. D.; Chi, K.-W. Russ. Chem. Bull. 2001, 50, 649. (e) Yusubov, M. S.; Zholobova, G. A.; Vasilevsky, S. F.; Tretyakov, E. V.; Knight, D. W. Tetrahedron 2002, 58, 1607.

(168) Mousset, C.; Provot, O.; Hamze, A.; Bignon, J.; Brion, J.-D.; Alami, M. Tetrahedron 2008, 64, 4287.

(169) Gao, A.; Yang, F.; Li, J.; Wu, Y. Tetrahedron 2012, 68, 4950.

(170) Mori, S.; Takubo, M.; Yanase, T.; Maegawa, T.; Monguchi, Y.; Sajiki, H. Adv. Synth. Catal. 2010, 352, 1630.

(171) Sawama, Y.; Takubo, M.; Mori, S.; Monguchi, Y.; Sajiki, H. Eur. J. Org. Chem. 2011, 3361.

(172) Ren, W.; Xia, Y.; Ji, S.-J.; Zhang, Y.; Wan, X.; Zhao, J. Org. Lett. 2009, 11, 1841.

(173) Chandrasekhar, S.; Reddy, N. K.; Kumar, V. P. Tetrahedron Lett. 2010, 51, 3623.

(174) Wang, A.; Jiang, H. J. Am. Chem. Soc. 2008, 130, 5030.

(175) Wang, A.; Jiang, H.; Xu, Q. Synlett 2009, 929.

(176) Wang, L.; Li, J.; Lv, Y.; Zhao, G.; Gao, S. Synlett 2012, 23, 1074.

(177) Wen, Y.; Zhu, S.; Jiang, H.; Wang, A.; Chen, Z. Synlett 2011, 1023.

(178) (a) Molnár, A.; Sárkány, A.; Varga, M. J. Mol. Catal. A: Chem. 2001, 173, 185. (b) Kluwer, A. M.; Elsevier, C. J., Homogeneous Hydrogenation of Alkynes and Dienes, in The Handbook of Homogeneous Hydrogenation; de Vries, J. G.; Elsevier, C. J., Eds.; Wiley-VCH Weinheim, 2007; p 375. (c) Munslow, I. J., Alkyne Reductions, in Modern Reduction Methods; Andersson, P. G.; Munslow, 
I. J., Eds.; Wiley-VCH: Weinheim, 2008; p 363. (d) Arnold, H.; Döbert, F.; Gaube, J., Selective Hydrogenation of Hydrocarbons, in Handbook of Heterogeneous Catalysis; Ertl, G.; Knözinger, H.; Schüth, F.; Weitkamp, J., Eds.; Wiley-VCH Weinheim, 2008; Vol. 7, p 3266.

(179) (a) Borodzinski, A.; Bond, G. C. Catal. Rev. - Sci. Eng. 2006, 48, 91. (b) Borodzinski, A.; Bond, G. C. Catal. Rev. - Sci. Eng. 2008, 50, 379.

(180) (a) Osswald, J.; Giedigkeit, R.; Jentoft, R. E.; Armbrüster, M.; Girgsdies, F.; Kovnir, K.; Ressler, T.; Grin, Y.; Schlögl, R. J. Catal. 2008, 258, 210. (b) Armbrüster, M.; Kovnir, K.; Behrens, M.; Teschner, D.; Grin, Y.; Schlögl, R. J. Am. Chem. Soc. 2010, 132, 14745. (c) Ota, A.; Armbrüster, M.; Behrens, M.; Rosenthal, D.; Friedrich, M.; Kasatkin, I.; Girgsdies, F.; Zhang, W.; Wagner, R.; Schlögl, R. J. Phys. Chem. C 2011, 115, 1368.

(181) López, N.; Vargas-Fuentes, C. Chem. Commun. 2012, 48, 1379.

(182) Garcia, P. E.; Lynch, A. S.; Monaghan, A.; Jackson, S. D. Catal. Today 2011, $164,548$.

(183) (a) Teschner, D.; Borsodi, J.; Wootsch, A.; Révay, Z.; Hävecker, M.; KnopGericke, A.; Jackson, S. D.; Schlögl, R. Science 2008, 320, 86. (b) Teschner, D.; Révay, Z.; Borsodi, J.; Hävecker, M.; Knop-Gericke, A.; Schlögl, R.; Milroy, D.; Jackson, S. D.; Torres, D.; Sautet, P. Angew. Chem. Int. Ed. 2008, 47, 9274. (c) Teschner, D.; Borsodi, J.; Kis, Z.; Szentmiklósi, L.; Révay, Z.; KnopGericke, A.; Schlögl, R.; Torres, D.; Sautet, P. J. Phys. Chem. C 2010, 114, 2293. (d) García-Mota, M.; Bridier, B.; Pérez-Ramírez, J.; López, N. J. Catal. 2010, 273, 92. (e) Seriani, N.; Mittendorfer, F.; Kresse, G. J. Chem. Phys. 2010, 132, 024711/1. (f) Armbrüster, M.; Behrens, M.; Cinquini, F.; Föttinger, K.; Grin, Y.; Haghofer, A.; Klötzer, B.; Knop-Gericke, A.; Lorenz, H.; Ota, A.; Penner, S.; Prinz, J.; Rameshan, C.; Révay, Z.; Rosenthal, D.; Rupprechter, G.; Sautet, P.; Schlögl, R.; Shao, L.; Szentmiklósi, L.; Teschner, D.; Torres, D.; Wagner, R.; Widmer, R.; Wowsnick, G. ChemCatChem 2012, 4, 1048.

(184) Lindlar, H. Helv. Chim. Acta 1952, 35, 446.

(185) Stakheev, A. Y.; Mashkovskii, I. S.; Baeva, G. N.; Telegina, N. S. Russ. J. Gen. Chem. 2010, 80, 618.

(186) Tew, M. W.; Janousch, M.; Huthwelker, T.; van Bokhoven, J. A. J. Catal. 2011, 283,45 . 
(187) Lederhos, C. R.; Maccarrone, M. J.; Badano, J. M.; Torres, G.; Coloma-Pascual, F.; Yori, J. C.; Quiroga, M. E. Appl. Catal., A 2011, 396, 170.

(188) Tew, M. W.; Emerich, H.; van Bokhoven, J. A. J. Phys. Chem. C 2011, 115, 8457.

(189) Takahashi, Y.; Hashimoto, N.; Hara, T.; Shimazu, S.; Mitsudome, T.; Mizugaki, T.; Jitsukawa, K.; Kaneda, K. Chem. Lett. 2011, 40, 405.

(190) Shao, Z.; Li, C.; Chen, X.; Pang, M.; Wang, X.; Liang, C. ChemCatChem 2010, 2,1555 .

(191) Weerachawanasak, P.; Mekasuwandumrong, O.; Arai, M.; Fujita, S.-I.; Praserthdam, P.; Panpranot, J. J. Catal. 2009, 262, 199.

(192) Yabe, Y.; Yamada, T.; Nagata, S.; Sawama, Y.; Monguchi, Y.; Sajiki, H. Adv. Synth. Catal. 2012, 354, 1264.

(193) Witte, P. T.; Berben, P. H.; Boland, S.; Boymans, E. H.; Vogt, D.; Geus, J. W.; Donkervoort, J. G. Top. Catal. 2012, 55, 505.

(194) Zhao, Y.; Liu, Q.; Li, J.; Liu, Z.; Zhou, B. Synlett 2010, 1870.

(195) Chan, C. W. A.; Xie, Y.; Cailuo, N.; Yu, K. M. K.; Cookson, J.; Bishop, P.; Tsang, S. C. Chem. Commun. 2011, 47, 7971.

(196) Domínguez-Domínguez, S.; Berenguer-Murcia, A.; Pradhan, B. K.; LinaresSolano, A.; Cazorla-Amorós, D. J. Phys. Chem. C 2008, 112, 3827.

(197) de Loos, S. R. A.; van der Schaaf, J.; de Croon, M. H. J. M.; Nijhuis, T. A.; Schouten, J. C. Chem. Eng. J. 2011, 167, 671.

(198) Lee, Y.; Motoyama, Y.; Tsuji, K.; Yoon, S.-H.; Mochida, I.; Nagashima, H. ChemCatChem 2012, 4, 778.

(199) Turova, O. V.; Starodubtseva, E. V.; Vinogradov, M. G.; Sokolov, V. I.; Abramova, N. V.; Vul, A. Y.; Alexenskiy, A. E. Catal. Commun. 2011, 12, 577.

(200) Sulman, E. M.; Nikoshvili, L. Z.; Matveeva, V. G.; Tyamina, I. Y.; Sidorov, A. I.; Bykov, A. V.; Demidenko, G. N.; Stein, B. D.; Bronstein, L. M. Top. Catal. 2012, 55, 492.

(201) Gao, Y.; Chen, C.-A.; Gau, H.-M.; Bailey, J. A.; Akhadov, E.; Williams, D.; Wang, H.-L. Chem. Mater. 2008, 20, 2839.

(202) (a) Sajiki, H.; Mori, S.; Ohkubo, T.; Ikawa, T.; Kume, A.; Maegawa, T.; Monguchi, Y. Chem.-Eur. J. 2008, 14, 5109. (b) Mori, S.; Ohkubo, T.; Ikawa, T.; Kume, A.; Maegawa, T.; Monguchi, Y.; Sajiki, H. J. Mol. Catal. A: Chem. 2009, 307, 77. 
(203) (a) Drelinkiewicz, A.; Knapik, A.; Stanuch, W.; Sobczak, J.; Bukowska, A.; Bukowski, W. React. Funct. Polym. 2008, 68, 1652. (b) Drelinkiewicz, A.; Stanuch, W.; Knapik, A.; Ghanem, A.; Kosydar, R.; Bukowska, A.; Bukowski, W. J. Mol. Catal. A: Chem. 2009, 300, 8.

(204) Mizugaki, T.; Murata, M.; Fukubayashi, S.; Mitsudome, T.; Jitsukawa, K.; Kaneda, K. Chem. Commun. 2008, 241.

(205) Itoh, H.; Maeda, H.; Yamada, S.; Hori, Y. ChemCatChem 2012, 4, 1737.

(206) (a) López-Serrano, J.; Duckett, S. B.; Dunne, J. P.; Godard, C.; Whitwood, A. C. Dalton Trans. 2008, 4270. (b) López-Serrano, J.; Lledós, A.; Duckett, S. B. Organometallics 2008, 27, 43.

(207) Luo, F.; Pan, C.; Wang, W.; Ye, Z.; Cheng, J. Tetrahedron 2010, 66, 1399.

(208) Shen, R.; Chen, T.; Zhao, Y.; Qiu, R.; Zhou, Y.; Yin, S.; Wang, X.; Goto, M.; Han, L.-B. J. Am. Chem. Soc. 2011, 133, 17037.

(209) Jurčik, V.; Nolan, S. P.; Cazin, C. S. J. Chem.-Eur. J. 2009, 15, 2509.

(210) Hauwert, P.; Maestri, G.; Sprengers, J. W.; Catellani, M.; Elsevier, C. J. Angew. Chem. Int. Ed. 2008, 47, 3223.

(211) (a) Hauwert, P.; Boerleider, R.; Warsink, S.; Weigand, J. J.; Elsevier, C. J. J. Am. Chem. Soc. 2010, 132, 16900. (b) Warsink, S.; Bosman, S.; Weigand, J. J.; Elsevier, C. J. Appl. Organomet. Chem. 2011, 25, 276. (c) Hauwert, P.; Dunsford, J. J.; Tromp, D. S.; Weigand, J. J.; Lutz, M.; Cavell, K. J.; Elsevier, C. J. Organometallics 2013, 32, 131.

(212) Hartmann, C. E.; Jurčík, V.; Songis, O.; Cazin, C. S. J. Chem. Commun. 2013, $49,1005$.

(213) Li, J.; Hua, R.; Liu, T. J. Org. Chem. 2010, 75, 2966.

(214) Hori, J.; Murata, K.; Sugai, T.; Shinohara, H.; Noyori, R.; Arai, N.; Kurono, N.; Ohkuma, T. Adv. Synth. Catal. 2009, 351, 3143.

(215) Semagina, N.; Kiwi-Minsker, L. Catal. Lett. 2009, 127, 334.

(216) Crespo-Quesada, M.; Yarulin, A.; Jin, M.; Xia, Y.; Kiwi-Minsker, L. J. Am. Chem. Soc. 2011, 133, 12787.

(217) Lee, J. K.; Kim, D. W.; Cheong, M.; Lee, H.; Cho, B. W.; Kim, H. S.; Mukherjee, D. Bull. Korean Chem. Soc. 2010, 31, 2195.

(218) Venkatesan, R.; Prechtl, M. H. G.; Scholten, J. D.; Pezzi, R. P.; Machado, G.; Dupont, J. J. Mater. Chem. 2011, 21, 3030. 
(219) Mandity, I. M.; Martinek, T. A.; Darvas, F.; Fülöp, F. Tetrahedron Lett. 2009, 50,4372 .

(220) Yabe, Y.; Sawama, Y.; Monguchi, Y.; Sajiki, H. Chem.-Eur. J. 2012, 19, 484.

(221) Shirakawa, E.; Otsuka, H.; Hayashi, T. Chem. Commun. 2005, 5885.

(222) (a) Grimsdale, A. C.; Leok, C. K.; Martin, R. E.; Jokisz, P. G.; Holmes, A. B. Chem. Rev. 2009, 109, 897. (b) Cheng, Y.-J.; Yang, S.-H.; Hsu, C.-S. Chem. Rev. 2009, 109, 5868. (c) Silvestri, F.; Marrocchi, A. Int. J. Mol. Sci. 2010, 11, 1471.

(223) Jenny, N. M.; Mayor, M.; Eaton, T. R. Eur. J. Org. Chem. 2011, 4965.

(224) Kim, S. H.; Park, S. H.; Chang, S. Tetrahedron 2012, 68, 5162.

(225) (a) Javaid, R.; Kawanami, H.; Chatterjee, M.; Ishizaka, T.; Suzuki, A.; Suzuki, T. M. Chem. Eng. J. 2011, 167, 431. (b) Tan, L.-M.; Sem, Z. Y.; Chong, W.-Y.; Liu, X.; Hendra; Kwan, W. L.; Lee, C.-L. K. Org. Lett. 2013, 15, 65.

(226) (a) Doucet, H.; Hierso, J.-C. Angew. Chem. Int. Ed. 2007, 46, 834. (b) Chinchilla, R.; Nájera, C. Chem. Rev. 2007, 107, 874. (c) Chinchilla, R.; Nájera, C. Chem. Soc. Rev. 2011, 40, 5084.

(227) Evano, G.; Blanchard, N.; Toumi, M. Chem. Rev. 2008, 108, 3054.

(228) Cassar, L. J. Organomet. Chem. 1975, 93, 253.

(229) Dieck, H. A.; Heck, F. R. J. Organomet. Chem. 1975, 93, 259.

(230) (a) Sikk, L.; Tammiku-Taul, J.; Burk, P. Organometallics 2011, 30, 5656. (b) Chen, L.-P.; Chen, H.-P. Chin. J. Struct. Chem. 2011, 30, 1289. (c) Sikk, L.; Tammiku-Taul, J.; Burk, P.; Kotschy, A. J. Mol. Model. 2012, 18, 3025. (d) García-Melchor, M.; Pacheco, M. C.; Nájera, C.; Lledós, A.; Ujaque, G. ACS Catal. 2012, 2, 135.

(231) Bai, X.; Chen, X.; Barnes, C.; Dias, J. R.; Sandreczki, T. C. Tetrahedron 2013, 69, 1105.

(232) Wiener, J. J.; Wickboldt, A. T.; Nguyen, S.; Sun, S.; Rynberg, R.; Rizzolio, M.; Karlsson, L.; Edwards, J. P.; Grice, C. A. Bioorg. Med. Chem. Lett. 2013, 23, 1070.

(233) Lee, Y. O.; Pradhan, T.; No, K.; Kim, J. S. Tetrahedron 2012, 68, 1704.

(234) Yi, T.; Mo, M.; Fu, H.-Y.; Li, R.-X.; Chen, H.; Li, X.-J. Catal. Lett. 2012, 142, 594.

(235) Mai, W. P.; Yuan, J. W.; Li, Z. C.; Sun, G. C. Chin. Chem. Lett. 2012, 23, 185. 
(236) He, T.; Wu, L. L.; Fu, X. L.; Fu, H. Y.; Chen, H.; Li, R. X. Chin. Chem. Lett. 2011, 22, 1175.

(237) Zhang, J.; Dakovic, M.; Popović, Z.; Wu, H.; Liu, Y. Catal. Commun. 2012, 17, 160.

(238) Shu, W.; Buchwald, S. L. Chem. Sci. 2011, 2, 2321.

(239) Li, P.; Wang, L.; Zhang, L.; Wang, G.-W. Adv. Synth. Catal. 2012, 354, 1307.

(240) Huang, J.; Wang, M.; Zhang, S.; Hu, B.; Li, H. J. Phys. Chem. C 2011, 115, 22514.

(241) He, W.; Zhang, F.; Li, H. Chem. Sci. 2011, 2, 961.

(242) Zhang, S.; Liu, Q.; Shen, M.; Hu, B.; Chen, Q.; Li, H.; Amoureux, J.-P. Dalton Trans. 2012, 41, 4692.

(243) Sedelmeier, J.; Ley, S. V.; Lange, H.; Baxendale, I. R. Eur. J. Org. Chem. 2009, 4412.

(244) Mino, T.; Suzuki, S.; Hirai, K.; Sakamoto, M.; Fujita, T. Synlett 2011, 1277.

(245) He, Y.; Cai, C. J. Organomet. Chem. 2011, 696, 2689.

(246) Suzuka, T.; Kimura, K.; Nagamine, T. Polymers 2011, 3, 621.

(247) Bakherad, M.; Keivanloo, A.; Samangooei, S. Tetrahedron Lett. 2012, 53, 5773.

(248) Bahramian, B.; Bakherad, M.; Keivanloo, A.; Bakherad, Z.; Karrabi, B. Appl. Organomet. Chem. 2011, 25, 420.

(249) Phan, N. T. S.; Le, H. V. J. Mol. Catal. A: Chem. 2011, 334, 130.

(250) Wang, D.; Denux, D.; Ruiz, J.; Astruc, D. Adv. Synth. Catal. 2013, 355, 129.

(251) Modak, A.; Mondal, J.; Bhaumik, A. Green Chem. 2012, 14, 2840.

(252) Kim, J. Y.; Park, K.; Bae, S. Y.; Kim, G. C.; Lee, S.; Choi, H. C. J. Mater. Chem. 2011, 21, 5999.

(253) Yang, L.; Guan, P.; He, P.; Chen, Q.; Cao, C.; Peng, Y.; Shi, Z.; Pang, G.; Shi, Y. Dalton Trans. 2012, 41, 5020.

(254) Inomata, S.; Hiroki, H.; Terashima, T.; Ogata, K.; Fukuzawa, S.-i. Tetrahedron 2011, 67, 7263.

(255) Holm, S. C.; Rominger, F.; Straub, B. F. J. Organomet. Chem. 2012, 719, 54.

(256) Alonso, D. A.; Nájera, C. Chem. Soc. Rev. 2010, 39, 2891.

(257) Bai, S.-Z.; Xu, C.; Li, H.-M.; Wang, Z.-Q.; Fu, W.-J. Molecules 2012, 17, 5532.

(258) Marziale, A. N.; Schlueter, J.; Eppinger, J. Tetrahedron Lett. 2011, 52, 6355.

(259) Hajipour, A. R.; Rahimi, H.; Rafiee, F. Appl. Organomet. Chem. 2012, 26, 727. 
(260) (a) Blaszczyk, I.; Gniewek, A.; Trzeciak, A. M. J. Organomet. Chem. 2011, 696, 3601. (b) Blaszczyk, I.; Gniewek, A.; Trzeciak, A. M. J. Organomet. Chem. 2012, 710, 44.

(261) (a) Islam, M.; Mondal, P.; Roy, A. S.; Tuhina, K.; Mondal, S.; Hossain, D. Synth. Commun. 2011, 41, 2583. (b) Islam, S. M.; Salam, N.; Mondal, P.; Roy, A. S. J. Mol. Catal. A: Chem. 2013, 366, 321.

(262) (a) Bolliger, J. L.; Frech, C. M. Adv. Synth. Catal. 2009, 351, 891. (b) SanMartin, R.; Inés, B.; Moure, M. J.; Herrero, M. T.; Domínguez, E. Helv. Chim. Acta 2012, 95, 955.

(263) Urgaonkar, S.; Verkade, J. G. J. Org. Chem. 2004, 69, 5752.

(264) Iranpoor, N.; Firouzabadi, H.; Ahmadi, Y. Eur. J. Org. Chem. 2012, 305.

(265) Kuang, Y.-Y.; Chen, F.-E. Helv. Chim. Acta 2009, 92, 897.

(266) Carpita, A.; Ribecai, A. Tetrahedron Lett. 2009, 50, 204.

(267) Beaumont, S. K. J. Chem. Technol. Biotechnol. 2012, 87, 595.

(268) Jiang, J.-Z.; Cai, C. J. Colloid Interface Sci. 2007, 307, 300.

(269) (a) Xue, C.; Palaniappan, K.; Arumugam, G.; Hackney, S. A.; Liu, J.; Liu, H. Catal. Lett. 2007, 116, 94. (b) Sawoo, S.; Srimani, D.; Dutta, P.; Lahiri, R.; Sarkar, A. Tetrahedron 2009, 65, 4367. (c) Senra, J. D.; Malta, L. F. B.; da Costa, M. E. H. M.; Michel, R. C.; Aguiar, L. C. S.; Simas, A. B. C.; Antunes, O. A. C. Adv. Synth. Catal. 2009, 351, 2411.

(270) (a) Borah, B. J.; Saikia, K.; Saikia, P. P.; Barua, N. C.; Dutta, D. K. Catal. Today 2012, 198, 174. (b) Chu, Y.-T.; Chanda, K.; Lin, P.-H.; Huang, M. H. Langmuir 2012, 28, 11258.

(271) Ohtaka, A.; Teratani, T.; Fujii, R.; Ikeshita, K.; Kawashima, T.; Tatsumi, K.; Shimomura, O.; Nomura, R. J. Org. Chem. 2011, 76, 4052.

(272) Shao, L.; Ji, W.; Dong, P.; Zeng, M.; Qi, C.; Zhang, X.-M. Appl. Catal., A 2012, 413-414, 267.

(273) Magdesieva, T. V.; Nikitin, O. M.; Zolotukhin, E. V.; Zinovieva, V. A.; Vorotyntsev, M. A. Mendeleev Commun. 2012, 22, 305.

(274) Firouzabadi, H.; Iranpoor, N.; Kazemi, F.; Gholinejad, M. J. Mol. Catal. A: Chem. 2012, 357, 154.

(275) Monguchi, Y.; Sakai, K.; Endo, K.; Fujita, Y.; Niimura, M.; Yoshimura, M.; Mizusaki, T.; Sawama, Y.; Sajiki, H. ChemCatChem 2012, 4, 546. 
(276) Rumi, L.; Scheuermann, G. M.; Muelhaupt, R.; Bannwarth, W. Helv. Chim. Acta 2011, 94, 966 .

(277) Moussa, S.; Siamaki, A. R.; Gupton, B. F.; El-Shall, M. S. ACS Catal. 2012, 2, 145.

(278) Banerjee, S.; Khatri, H.; Balasanthiran, V.; Koodali, R. T.; Sereda, G. Tetrahedron 2011, 67, 5717.

(279) Borkowski, T.; Subik, P.; Trzeciak, A. M.; Wolowiec, S. Molecules 2011, 16, 427.

(280) Kollhofer, A.; Pullmann, T.; Plenio, H. Angew. Chem., Int. Ed. 2003, 42, 1056.

(281) Huang, H.; Liu, H.; Jiang, H.; Chen, K. J. Org. Chem. 2008, 73, 6037.

(282) Gelman, D.; Buchwald, S. L. Angew. Chem. Int. Ed. 2003, 42, 5993.

(283) Yi, C.; Hua, R. J. Org. Chem. 2006, 71, 2535.

(284) Pu, X.; Li, H.; Colacot, T. J. J. Org. Chem. 2013, 78, 568.

(285) Lee, D.-H.; Kwon, Y.-J.; Jin, M.-J. Adv. Synth. Catal. 2011, 353, 3090.

(286) Cargill, M. R.; Sandford, G.; Kilickiran, P.; Nelles, G. Tetrahedron 2013, 69, 512.

(287) (a) R'Kyek, O.; Halland, N.; Lindenschmidt, A.; Alonso, J.; Lindemann, P.; Urmann, M.; Nazaré, M. Chem.-Eur. J. 2010, 16, 9986. (b) Choy, P. Y.; Chow, W. K.; So, C. M.; Lau, C. P.; Kwong, F. Y. Chem.-Eur. J. 2010, 16, 9982.

(288) Shirbin, S. J.; Boughton, B. A.; Zammit, S. C.; Zanatta, S. D.; Marcuccio, S. M.; Hutton, C. A.; Williams, S. J. Tetrahedron Lett. 2010, 51, 2971.

(289) Cívicos, J. F.; Alonso, D. A.; Nájera, C. Adv. Synth. Catal. 2013, 355, 203.

(290) Fabrizi, G.; Goggiamani, A.; Sferrazza, A.; Cacchi, S. Angew. Chem. Int. Ed. 2010, 49, 4067.

(291) Wu, X.-F.; Neumann, H.; Beller, M. Chem. Commun. 2011, 47, 7959.

(292) (a) Schroeter, S.; Stock, C.; Bach, T. Tetrahedron 2005, 61, 2245. (b) Schnurch, M.; Flasik, R.; Khan, A. F.; Spina, M.; Mihovilovic, M. D.; Stanetty, P. Eur. J. Org. Chem. 2006, 3283.

(293) Souffrin, A.; Croix, C.; Viaud-Massuard, M.-C. Eur. J. Org. Chem. 2012, 2499.

(294) Yu, Z.; Ptaszek, M. Org. Lett. 2012, 14, 3708.

(295) Worlikar, S. A.; Neuenswander, B.; Lushington, G. H.; Larock, R. C. J. Comb. Chem. 2009, 11, 875.

(296) Layek, M.; Gajare, V.; Kalita, D.; Islam, A.; Mukkanti, K.; Pal, M. Tetrahedron 2009, 65, 4814. 
(297) Pal, M. Synlett 2009, 2896.

(298) El, A. A.; Bassoude, I.; Koubachi, J.; Berteina-Raboin, S.; Mouaddib, A.; Guillaumet, G. Tetrahedron 2011, 67, 7128.

(299) El, A. A.; Koubachi, J.; El, K. S.; Berteina-Raboin, S.; Mouaddib, A.; Guillaumet, G. Tetrahedron Lett. 2008, 49, 2472.

(300) Arbačiauskienè, E.; Martynaitis, V.; Krikštolaitytè, S.; Holzer, W.; Šačkus, A. Arkivoc 2011, 1.

(301) Zhu, R.; Wang, M.; Xia, Y.; Qu, F.; Neyts, J.; Peng, L. Bioorg. Med. Chem. Lett. 2008, 18, 3321.

(302) Sajith, A. M.; Muralidharan, A. Tetrahedron Lett. 2012, 53, 5206.

(303) Sagitullina, G. P.; Vorontsova, M. A.; Garkushenko, A. K.; Poendaev, N. V.; Sagitullin, R. S. Russ. J. Org. Chem. 2010, 46, 1830.

(304) Okamoto, N.; Sakurai, K.; Ishikura, M.; Takeda, K.; Yanada, R. Tetrahedron Lett. 2009, 50, 4167.

(305) Peixoto, D.; Begouin, A.; Queiroz, M.-J. R. P. Tetrahedron 2012, 68, 7082.

(306) Lin, B.-N.; Huang, S.-H.; Wu, W.-Y.; Mou, C.-Y.; Tsai, F.-Y. Molecules 2010, $15,9157$.

(307) Ehlers, P.; Neubauer, A.; Lochbrunner, S.; Villinger, A.; Langer, P. Org. Lett. 2011, 13, 1618.

(308) Fleckenstein, C. A.; Plenio, H. Green Chem. 2008, 10, 563.

(309) Córdoba, M.; Izquierdo, M. L.; Alvarez-Builla, J. Tetrahedron Lett. 2011, 52, 1738.

(310) Reddy, E. A.; Barange, D. K.; Islam, A.; Mukkanti, K.; Pal, M. Tetrahedron 2008, 64, 7143.

(311) (a) Mphahlele, M. J. Tetrahedron 2010, 66, 8261. (b) Almeida, A. I. S.; Silva, A. M. S.; Cavaleiro, J. A. S. Synlett 2011, 2955.

(312) Schneider, C.; Goyard, D.; Gueyrard, D.; Joseph, B.; Goekjian, P. G. Eur. J. Org. Chem. 2010, 6665.

(313) Prabakaran, K.; Nawaz, K. F.; Jin, J. S. Tetrahedron Lett. 2011, 52, 2566.

(314) Ali, H.; van, L. J. E. Tetrahedron Lett. 2012, 53, 4824.

(315) Claerhout, S.; Sharma, S.; Skold, C.; Cavaluzzo, C.; Sandstrom, A.; Larhed, M.; Thirumal, M.; Parmar, V. S.; Van, d. E. E. V. Tetrahedron 2012, 68, 3019. 
(316) Ibrahim, M. A.; Blaise, E.; Lozach, O.; Szalata, C.; Schmitt, M.; El-Etrawy, A.A. S.; Elagawany, M.; El-Feky, S. A.; Abdel-Samii, Z. K.; Meijer, L.; Bourguignon, J.-J.; Bihel, F. Synthesis 2012, 3216.

(317) Cho, J. H.; Prickett, C. D.; Shaughnessy, K. H. Eur. J. Org. Chem. 2010, 3678.

(318) Paul, S.; Nandi, B.; Pattanayak, S.; Sinha, S. Tetrahedron Lett. 2012, 53, 4179.

(319) Manarin, F.; Roehrs, J. A.; Brandao, R.; Nogueira, C. W.; Zeni, G. Synthesis 2009, 4001.

(320) Boukouvalas, J.; Côté, S.; Ndzi, B. Tetrahedron Lett. 2007, 48, 105.

(321) Torborg, C.; Huang, J.; Schulz, T.; Schäffner, B.; Zapf, A.; Spannenberg, A.; Börner, A.; Beller, M. Chem.-Eur. J. 2009, 15, 1329.

(322) Alves, D.; dos Reis, J. S.; Luchese, C.; Nogueira, C. W.; Zeni, G. Eur. J. Org. Chem. 2008, 377.

(323) Rosario, A. R.; Schumacher, R. F.; Gay, B. M.; Menezes, P. H.; Zeni, G. Eur. J. Org. Chem. 2010, 5601.

(324) Luo, Y.; Wu, J. Tetrahedron 2009, 65, 6810.

(325) Lechel, T.; Dash, J.; Brüdgam, I.; Reißig, H.-U. Eur. J. Org. Chem. 2008, 3647.

(326) Shi, C.; Aldrich, C. C. Org. Lett. 2010, 12, 2286.

(327) Yang, L.; Zhao, L.; Li, C.-J. Chem. Commun. 2010, 46, 4184.

(328) Kim, S. H.; Yoon, J.; Chang, S. Org. Lett. 2011, 13, 1474.

(329) Shibahara, F.; Dohke, Y.; Murai, T. J. Org. Chem. 2012, 77, 5381.

(330) Jie, X.; Shang, Y.; Hu, P.; Su, W. Angew. Chem., Int. Ed. 2013, 52, 3630.

(331) Praveen, C.; Kiruthiga, P.; Perumal, P. T. Synlett 2009, 1990.

(332) Sunagatullina, A. S.; Shakhmaev, R. N.; Zorin, V. V. Russ. J. Gen. Chem. 2012, $82,1313$.

(333) Gu, X.-X.; Xie, M.-H.; Zhao, X.-Y.; Sun, Y.; Zhang, W.; Xie, F.-D.; Wang, S.W. Chin. J. Chem. 2008, 26, 1625.

(334) Nazario, C. E. D.; Santana, A. S.; Kawasoko, C. Y.; Carollo, C. A.; Hurtado, G. R.; Viana, L. H.; Barbosa, S. L.; Guerrero, P. G., Jr.; Marques, F. A.; Dabdoub, V. B.; Dabdoub, M. J.; Baroni, A. C. M. Tetrahedron Lett. 2011, 52, 4177.

(335) Huang, M.; Feng, Y.; Wu, Y. Tetrahedron 2012, 68, 376.

(336) Mi, X.; Huang, M.; Feng, Y.; Wu, Y. Synlett 2012, 23, 1257.

(337) Zhu, G.; Chen, D.; Wang, Y.; Zheng, R. Chem. Commun. 2012, 48, 5796.

(338) Provot, O.; Giraud, A.; Peyrat, J.-F.; Alami, M.; Brion, J.-D. Tetrahedron Letters 2005, 46, 8547. 
(339) Gredicak, M.; Jeric, I. Synlett 2009, 1063.

(340) Visnevska, J.; Belyakov, S.; Abele, E. Lett. Org. Chem. 2012, 9, 250.

(341) Sun, Q.; Jiang, C.; Xu, H.; Zhang, Z.; Liu, L.; Wang, C. Steroids 2010, 75, 936.

(342) Wen, Y.; Wang, A.; Jiang, H.; Zhu, S.; Huang, L. Tetrahedron Lett. 2011, 52, 5736.

(343) (a) Trost, B. M.; Chan, C.; Ruhter, G. J. Am. Chem. Soc. 1987, 109, 3486. (b) Trost, B. M.; Sorum, M. T.; Chan, C.; Ruehter, G. J. Am. Chem. Soc. 1997, 119, 698.

(344) Yang, C.; Nolan, S. P. J. Org. Chem. 2002, 67, 591.

(345) Rubina, M.; Gevorgyan, V. J. Am. Chem. Soc. 2001, 123, 11107.

(346) Jahier, C.; Zatolochnaya, O. V.; Zvyagintsev, N. V.; Ananikov, V. P.; Gevorgyan, V. Org. Lett. 2012, 14, 2846.

(347) Shao, Y.-L.; Zhang, X.-H.; Han, J.-S.; Zhong, P. Org. Lett. 2012, 14, 5242.

(348) Hadi, V.; Yoo, K. S.; Jeong, M.; Jung, K. W. Tetrahedron Lett. 2009, 50, 2370.

(349) Shun, A. L. K. S.; Tykwinski, R. R. Angew. Chem. Int. Ed. 2006, 45, 1034.

(350) Crowley, J. D.; Goldup, S. M.; Lee, A.-L.; Leigh, D. A.; McBurney, R. T. Chem. Soc. Rev. 2009, 38, 1530.

(351) (a) Polyynes: Synthesis, Properties and Applications; Cataldo, F., Ed.; CRC Press/Taylor and Francis: Boca Raton, FL, 2005. (b) Gholami, M.; Tykwinski, R. R. Chem. Rev. 2006, 106, 4997. (c) Liu, J.; Lam, J. W. Y.; Tang, B. Z. Chem. Rev. 2009, 109, 5799.

(352) (a) Siemsen, P.; Livingston, R. C.; Diederich, F. Angew. Chem. Int. Ed. 2000, 39, 2632. (b) Stefani, H. A.; Guarezemini, A. S.; Cella, R. Tetrahedron 2010, 66, 7871. (c) Alonso, F.; Yus, M. ACS Catal. 2012, 2, 1441.

(353) Glaser, C. Ber. Dtsh. Chem. Ges. 1869, 2, 422.

(354) Sonogashira, K.; Tohda, Y.; Hagihara, N. Tetrahedron Lett. 1975, 4467.

(355) Rossi, R.; Carpita, A.; Bigelli, C. Tetrahedron Lett. 1985, 26, 523.

(356) Kundu, N. G.; Pal, M.; Chowdhury, C. J. Chem. Res. (S) 1993, 432.

(357) Liu, Q.; Burton, D. J. Tetrahedron Lett. 1997, 38, 4371.

(358) Lei, A.; Srivastava, M.; Zhang, X. J. Org. Chem. 2002, 67, 1969.

(359) Li, J.-H.; Liang, Y.; Xie, Y.-X. J. Org. Chem. 2005, 70, 4393.

(360) Li, J.-H.; Liang, Y.; Zhang, X.-D. Tetrahedron 2005, 61, 1903.

(361) Chen, C.; Ai, Z.; Lin, J.; Hong, X.; Xi, C. Synlett 2006, 2454.

(362) Yan, J.; Wu, J.; Jin, H. J. Organomet. Chem. 2007, 692, 3636. 
(363) Yan, J.; Lin, F.; Yang, Z. Synthesis 2007, 1301.

(364) Feng, X.; Zhao, Z.; Yang, F.; Jin, T.; Ma, Y.; Bao, M. J. Organomet. Chem. 2011, 696, 1479.

(365) Fairlamb, I. J. S.; Baeuerlein, P. S.; Marrison, L. R.; Dickinson, J. M. Chem. Commun. 2003, 632.

(366) Roy, R.; Das, S. K.; Hernández-Mateo, F.; Santoyo-González, F.; Gan, Z. Synthesis 2001, 1049.

(367) Dibowski, H.; Schmidtchen, F. P. Tetrahedron 1995, 51, 2325.

(368) Vlassa, M.; Ciocan-Tarta, I.; Margineanu, F.; Oprean, I. Tetrahedron 1996, 52, 1337.

(369) Gil-Moltó, J.; Nájera, C. Eur. J. Org. Chem. 2005, 4073.

(370) Chen, S.-N.; Wu, W.-Y.; Tsai, F.-Y. Green Chem. 2009, 11, 269.

(371) Atobe, S.; Sonoda, M.; Suzuki, Y.; Yamamoto, T.; Masuno, H.; Shinohara, H.; Ogawa, A. Res. Chem. Intermed. 2013, 39, 359.

(372) Hsiao, T.-H.; Wu, T.-L.; Chatterjee, S.; Chiu, C.-Y.; Lee, H.-M.; Bettucci, L.; Bianchini, C.; Oberhauser, W. J. Organomet. Chem. 2009, 694, 4014.

(373) Shi, M.; Qian, H.-x. Appl. Organomet. Chem. 2006, 20, 771.

(374) Watarai, N.; Kawasaki, H.; Azumaya, I.; Yamasaki, R.; Saito, S. Heterocycles 2009, 79, 531.

(375) Yang, F.; Cui, X.; Li, Y.-n.; Zhang, J.; Ren, G.-r.; Wu, Y. Tetrahedron 2007, 63, 1963.

(376) Alonso, D. A.; Nájera, C.; Pacheco, M. C. Adv. Synth. Catal. 2003, 345, 1146.

(377) Zhou, L.; Zhan, H.-Y.; Liu, H.-L.; Jiang, H.-F. Chin. J. Chem. 2007, 25, 1413.

(378) Bandini, M.; Luque, R.; Budarin, V.; Macquarrie, D. J. Tetrahedron 2005, 61, 9860

(379) Li, H.; Yang, M.; Pu, Q. Microporous Mesoporous Mater. 2012, 148, 166.

(380) Kurita, T.; Abe, M.; Maegawa, T.; Monguchi, Y.; Sajiki, H. Synlett 2007, 2521.

(381) Wityak, J.; Chan, J. B. Synth. Commun. 1991, 21, 977.

(382) Alami, M.; Ferri, F. Tetrahedron Lett. 1996, 37, 2763.

(383) Shi, W.; Luo, Y.; Luo, X.; Chao, L.; Zhang, H.; Wang, J.; Lei, A. J. Am. Chem. Soc. 2008, 130, 14713.

(384) Weng, Y.; Cheng, B.; He, C.; Lei, A. Angew. Chem. Int. Ed. 2012, $51,9547$.

(385) Li, H.; Wang, L.; Yang, M.; Qi, Y. Catal. Commun. 2012, 17, 179.

(386) Liang, Y.; Tao, L.-M.; Zhang, Y.-H.; Li, J.-H. Synthesis 2008, 3988. 
(387) Quesnelle, C. A.; Gill, P.; Dodier, M.; St, L. D.; Serrano-Wu, M.; Marinier, A.; Martel, A.; Mazzucco, C. E.; Stickle, T. M.; Barrett, J. F.; Vyas, D. M.; Balasubramanian, B. N. Bioorg. Med. Chem. Lett. 2003, 13, 519.

(388) (a) Karpov, A. S.; Merkul, E.; Rominger, F.; Müller, T. J. J. Angew. Chem. Int. Ed. 2005, 44, 6951. (b) Forsyth, C. J.; Xu, J.; Nguyen, S. T.; Samdal, I. A.; Briggs, L. R.; Rundberget, T.; Sandvik, M.; Miles, C. O. J. Am. Chem. Soc. 2006, 128, 15114. (c) Tietze, L. F.; Singidi, R. R.; Gericke, K. M.; Boeckemeier, H.; Laatsch, H. Eur. J. Org. Chem. 2007, 5875.

(389) (a) Willy, B.; Müller, T. J. J. Arkivoc 2008, 195. (b) Willy, B.; Müller, T. J. J. Curr. Org. Chem. 2009, 13, 1777. (c) Müller, T. J. J. Top. Heterocycl. Chem. 2010, 25, 25.

(390) (a) Brennführer, A.; Neumann, H.; Beller, M. Angew. Chem. Int. Ed. 2009, 48, 4114. (b) Wu, X.-F.; Neumann, H.; Beller, M. Chem. Soc. Rev. 2011, 40, 4986. (c) Wu, X.-F.; Neumann, H.; Beller, M. ChemSusChem 2013, 6, 229.

(391) Boersch, C.; Merkul, E.; Müller, T. J. J. Angew. Chem. Int. Ed. 2011, 50, 10448.

(392) Atobe, S.; Masuno, H.; Sonoda, M.; Suzuki, Y.; Shinohara, H.; Shibata, S.; Ogawa, A. Tetrahedron Lett. 2012, 53, 1764.

(393) Alonso, D. A.; Nájera, C.; Pacheco, M. C. J. Org. Chem. 2004, 69, 1615.

(394) Bakherad, M.; Amin, A. H.; Keivanloo, A.; Bahramian, B.; Raessi, M. Chin. Chem. Lett. 2010, 21, 656.

(395) (a) Bakherad, M.; Keivanloo, A.; Bahramian, B.; Rajaie, M. Tetrahedron Lett. 2010, 51, 33. (b) Bakherad, M.; Keivanloo, A.; Bahramian, B.; Kalantar, Z.; Ashrafi, F. N. Lett. Org. Chem. 2011, 8, 364.

(396) (a) Santra, S.; Dhara, K.; Ranjan, P.; Bera, P.; Dash, J.; Mandal, S. K. Green Chem. 2011, 13, 3238. (b) Santra, S.; Ranjan, P.; Bera, P.; Ghosh, P.; Mandal, S. K. $R S C A d v .2012,2,7523$.

(397) Bakherad, M.; Keivanloo, A.; Bahramian, B.; Jajarmi, S. Synlett 2011, 311.

(398) Xue, L.; Shi, L.; Han, Y.; Xia, C.; Huynh, H. V.; Li, F. Dalton Trans. 2011, 40, 7632.

(399) Li, N.; Wang, D.; Li, J.; Shi, W.; Li, C.; Chen, B. Tetrahedron Lett. 2011, 52, 980.

(400) Kobayashi, T.; Tanaka, M. J. Chem. Soc., Chem. Commun. 1981, 333.

(401) Wang, Y.; Liu, J.; Xia, C. Tetrahedron Lett. 2011, 52, 1587. 
(402) Friis, S. D.; Taaning, R. H.; Lindhardt, A. T.; Skrydstrup, T. J. Am. Chem. Soc. 2011, 133, 18114.

(403) Ciattini, P. G.; Morera, E.; Ortar, G. Tetrahedron Lett. 1991, 32, 6449.

(404) Wu, X.-F.; Neumann, H.; Beller, M. Chem.-Eur. J. 2010, 16, 12104.

(405) Wu, X.-F.; Sundararaju, B.; Neumann, H.; Dixneuf, P. H.; Beller, M. Chem.Eur. J. 2011, 17, 106.

(406) Wu, X.-F.; Neumann, H.; Beller, M. Angew. Chem. Int. Ed. 2011, 50, 11142.

(407) Wu, X.-F.; Neumann, H.; Beller, M. Org. Biomol. Chem. 2011, 9, 8003.

(408) Wu, X.-F.; Sundararaju, B.; Anbarasan, P.; Neumann, H.; Dixneuf, P. H.; Beller, M. Chem.-Eur. J. 2011, 17, 8014.

(409) Hao, W.; Sha, J.; Sheng, S.; Cai, M. J. Mol. Catal. A: Chem. 2009, 298, 94.

(410) (a) Chen, L.; Li, C.-J. Chem. Commun. 2004, 2362-2364. (b) Zhou, L.; Chen, L.; Skouta, R.; Jiang, H.-f.; Li, C.-J. Org. Biomol. Chem. 2008, 6, 2969.

(411) Villariño, L.; García-Fandiño, R.; López, F.; Mascareñas, J. L. Org. Lett. 2012, 14, 2996.

(412) Liu, Q.; Zhang, H.; Lei, A. Angew. Chem. Int. Ed. 2011, 50, 10788.

(413) Tsuji, J.; Takahashi, M.; Takahashi, T. Tetrahedron Lett. 1980, 21, 849.

(414) Sakurai, Y.; Sakaguchi, S.; Ishii, Y. Tetrahedron Lett. 1999, 40, 1701.

(415) Izawa, Y.; Shimizu, I.; Yamamoto, A. Bull. Chem. Soc. Jpn. 2004, 77, 2033.

(416) Tohda, Y.; Sonogashira, K.; Hagihara, N. Synthesis 1977, 777.

(417) Gabriele, B.; Salerno, G.; Veltri, L.; Costa, M. J. Organomet. Chem. 2001, 622, 84.

(418) Grigg, R.; Mutton, S. P. Tetrahedron 2010, 66, 5515.

(419) Gadge, S. T.; Khedkar, M. V.; Lanke, S. R.; Bhanage, B. M. Adv. Synth. Catal. 2012, 354, 2049. 